\title{
Oral hygiene care for critically ill patients to prevent ventilator-associated pneumonia
}

DOI:

10.1002/14651858.CD008367.pub4

Document Version

Final published version

Link to publication record in Manchester Research Explorer

\section{Citation for published version (APA):}

Zhao, T., Wu, X., Zhang, Q., Li, C., Worthington, H. V., \& Hua, F. (2020). Oral hygiene care for critically ill patients to prevent ventilator-associated pneumonia. The Cochrane Library.

https://doi.org/10.1002/14651858.CD008367.pub4

\section{Published in:}

The Cochrane Library

\section{Citing this paper}

Please note that where the full-text provided on Manchester Research Explorer is the Author Accepted Manuscript or Proof version this may differ from the final Published version. If citing, it is advised that you check and use the publisher's definitive version.

\section{General rights}

Copyright and moral rights for the publications made accessible in the Research Explorer are retained by the authors and/or other copyright owners and it is a condition of accessing publications that users recognise and abide by the legal requirements associated with these rights.

\section{Takedown policy}

If you believe that this document breaches copyright please refer to the University of Manchester's Takedown Procedures [http://man.ac.uk/04Y6Bo] or contact uml.scholarlycommunications@manchester.ac.uk providing relevant details, so we can investigate your claim.

\section{OPEN ACCESS}


Cochrane Database of Systematic Reviews

\section{Oral hygiene care for critically ill patients to prevent ventilator- associated pneumonia (Review)}

Zhao T, Wu X, Zhang Q, Li C, Worthington HV, Hua F

Zhao T, Wu X, Zhang Q, Li C, Worthington HV, Hua F.

Oral hygiene care for critically ill patients to prevent ventilator-associated pneumonia.

Cochrane Database of Systematic Reviews 2020, Issue 12. Art. No.: CD008367.

DOI: 10.1002/14651858.CD008367.pub4.

www.cochranelibrary.com 
TABLE OF CONTENTS

HEADER

ABSTRACT

PLAIN LANGUAGE SUMMARY

SUMMARY OF FINDINGS

BACKGROUND

OBJECTIVES

METHODS

Figure 1.

Figure 2.

RESULTS

Figure 3.

DISCUSSION

AUTHORS' CONCLUSIONS

ACKNOWLEDGEMENTS

REFERENCES

CHARACTERISTICS OF STUDIES

DATA AND ANALYSES

Analysis 1.1. Comparison 1: Chlorhexidine versus placebo/usual care, Outcome 1: Incidence of VAP

Analysis 1.2. Comparison 1: Chlorhexidine versus placebo/usual care, Outcome 2: Mortality

Analysis 1.3. Comparison 1: Chlorhexidine versus placebo/usual care, Outcome 3: Duration of ventilation (days) ....................

Analysis 1.4. Comparison 1: Chlorhexidine versus placebo/usual care, Outcome 4: Duration of ICU stay (days) .......................

Analysis 1.5. Comparison 1: Chlorhexidine versus placebo/usual care, Outcome 5: Duration of systemic antibiotic therapy (days)

Analysis 1.6. Comparison 1: Chlorhexidine versus placebo/usual care, Outcome 6: Number of participants treated with systemic antibiotics

Analysis 1.7. Comparison 1: Chlorhexidine versus placebo/usual care, Outcome 7: Plaque index

Analysis 1.8. Comparison 1: Chlorhexidine versus placebo/usual care, Outcome 8: Adverse effects

Analysis 2.1. Comparison 2: Chlorhexidine versus other oral care agents, Outcome 1: Incidence of VAP

Analysis 2.2. Comparison 2: Chlorhexidine versus other oral care agents, Outcome 2: Mortality

Analysis 2.3. Comparison 2: Chlorhexidine versus other oral care agents, Outcome 3: Number of participants treated with systemic antibiotics

Analysis 3.1. Comparison 3: Toothbrushing versus no toothbrushing, Outcome 1: Incidence of VAP

Analysis 3.2. Comparison 3: Toothbrushing versus no toothbrushing, Outcome 2: Mortality

Analysis 3.3. Comparison 3: Toothbrushing versus no toothbrushing, Outcome 3: Duration of ventilation (days) ....................

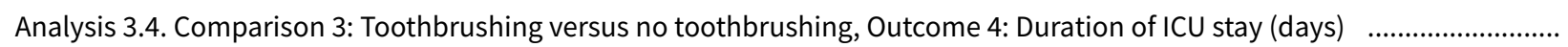

Analysis 3.5. Comparison 3: Toothbrushing versus no toothbrushing, Outcome 5: Plaque score

Analysis 4.1. Comparison 4: Powered toothbrush versus manual toothbrush, Outcome 1: Incidence of VAP ............................

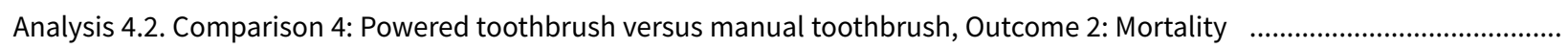

Analysis 4.3. Comparison 4: Powered toothbrush versus manual toothbrush, Outcome 3: Duration of ventilation (days) .........

Analysis 4.4. Comparison 4: Powered toothbrush versus manual toothbrush, Outcome 4: Duration of ICU stay (days) .............

Analysis 5.1. Comparison 5: Other oral care agents, Outcome 1: Incidence of VAP

Analysis 5.2. Comparison 5: Other oral care agents, Outcome 2: Mortality

Analysis 5.3. Comparison 5: Other oral care agents, Outcome 3: Duration of ventilation (days)

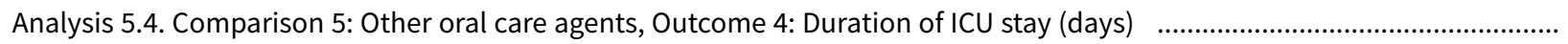

Analysis 5.5. Comparison 5: Other oral care agents, Outcome 5: Number of participants treated with systemic antibiotics .......

Analysis 5.6. Comparison 5: Other oral care agents, Outcome 6: Adverse effects 
[Intervention Review]

\section{Oral hygiene care for critically ill patients to prevent ventilator- associated pneumonia}

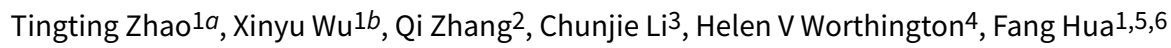

1Hubei-MOST KLOS \& KLOBM, School and Hospital of Stomatology, Wuhan University, Wuhan, China. 2Department of Oral Implantology, The Affiliated Stomatology Hospital, Zhejiang University School of Medicine, Key Laboratory of Oral Biomedical Research of Zhejiang Province, Hangzhou, China. ${ }^{3}$ State Key Laboratory of Oral Diseases, National Clinical Research Center for Oral Diseases, Department of Head and Neck Oncology, West China Hospital of Stomatology, Sichuan University, Chengdu, China. ${ }^{4}$ Cochrane Oral Health, Division of Dentistry, School of Medical Sciences, Faculty of Biology, Medicine and Health, The University of Manchester, Manchester, UK. ${ }^{5}$ Division of Dentistry, School of Medical Sciences, Faculty of Biology, Medicine and Health, The University of Manchester, Manchester, UK. ${ }^{6}$ Centre for Evidence-Based Stomatology, School and Hospital of Stomatology, Wuhan University, Wuhan, China

aThese authors contributed equally to this work.. $b$ These authors contributed equally to this work.

Contact address: Fang Hua, huafang@whu.edu.cn.

Editorial group: Cochrane Oral Health Group.

Publication status and date: New search for studies and content updated (conclusions changed), published in Issue 12, 2020.

Citation: Zhao T, Wu X, Zhang Q, Li C, Worthington HV, Hua F. Oral hygiene care for critically ill patients to prevent ventilator-associated pneumonia. Cochrane Database of Systematic Reviews 2020, Issue 12. Art. No.: CD008367. DOI: 10.1002/14651858.CD008367.pub4.

Copyright ( 2020 The Cochrane Collaboration. Published by John Wiley \& Sons, Ltd.

\section{A B S T R A C T}

\section{Background}

Ventilator-associated pneumonia (VAP) is defined as pneumonia developing in people who have received mechanical ventilation for at least 48 hours. VAP is a potentially serious complication in these patients who are already critically ill. Oral hygiene care (OHC), using either a mouthrinse, gel, swab, toothbrush, or combination, together with suction of secretions, may reduce the risk of VAP in these patients.

\section{Objectives}

To assess the effects of oral hygiene care $(\mathrm{OHC})$ on incidence of ventilator-associated pneumonia in critically ill patients receiving mechanical ventilation in hospital intensive care units (ICUs).

\section{Search methods}

Cochrane Oral Health's Information Specialist searched the following databases: Cochrane Oral Health's Trials Register (to 25 February 2020), the Cochrane Central Register of Controlled Trials (CENTRAL) (the Cochrane Library, 2020, Issue 1), MEDLINE Ovid (1946 to 25 February 2020), Embase Ovid (1980 to 25 February 2020), LILACS BIREME Virtual Health Library (1982 to 25 February 2020) and CINAHL EBSCO (1937 to 25 February 2020). We also searched the VIP Database (January 2012 to 8 March 2020). The US National Institutes of Health Trials Registry (ClinicalTrials.gov) and the World Health Organization International Clinical Trials Registry Platform were searched for ongoing trials. No restrictions were placed on the language or date of publication when searching the electronic databases.

\section{Selection criteria}

We included randomised controlled trials (RCTs) evaluating the effects of OHC (mouthrinse, gel, swab, toothbrush or combination) in critically ill patients receiving mechanical ventilation for at least 48 hours.

\section{Data collection and analysis}

At least two review authors independently assessed search results, extracted data and assessed risk of bias in included studies. We contacted study authors for additional information. We reported risk ratio (RR) for dichotomous outcomes and mean difference (MD) for continuous outcomes, using the random-effects model of meta-analysis when data from four or more trials were combined. 


\section{Main results}

We included 40 RCTs (5675 participants), which were conducted in various countries including China, USA, Brazil and Iran. We categorised these RCTs into five main comparisons: chlorhexidine (CHX) mouthrinse or gel versus placebo/usual care; $\mathrm{CHX}$ mouthrinse versus other oral care agents; toothbrushing ( \pm antiseptics) versus no toothbrushing ( \pm antiseptics); powered versus manual toothbrushing; and comparisons of other oral care agents used in $\mathrm{OHC}$ (other oral care agents versus placebo/usual care, or head-to-head comparisons between other oral care agents). We assessed the overall risk of bias as high in 31 trials and low in two, with the rest being unclear.

Moderate-certainty evidence from 13 RCTs (1206 participants, 92\% adults) shows that CHX mouthrinse or gel, as part of OHC, probably reduces the incidence of VAP compared to placebo or usual care from $26 \%$ to about $18 \%(\mathrm{RR} 0.67,95 \%$ confidence intervals $(\mathrm{Cl}) 0.47$ to $\left.0.97 ; \mathrm{P}=0.03 ; \mathrm{I}^{2}=66 \%\right)$. This is equivalent to a number needed to treat for an additional beneficial outcome (NNTB) of 12 (95\% $\mathrm{Cl} 7$ to 128), i.e. providing $\mathrm{OHC}$ including $\mathrm{CHX}$ for 12 ventilated patients in intensive care would prevent one patient developing VAP. There was no evidence of a difference between interventions for the outcomes of mortality (RR 1.03, 95\% Cl 0.80 to $1.33 ; \mathrm{P}=0.86, \mathrm{I}^{2}=0 \% ; 9 \mathrm{RCTs}$, 944 participants; moderate-certainty evidence), duration of mechanical ventilation (MD -1.10 days, $95 \% \mathrm{Cl}-3.20$ to 1.00 days; $\mathrm{P}=0.30, \mathrm{I}=$ 74\%; 4 RCTs, 594 participants; very low-certainty evidence) or duration of intensive care unit (ICU) stay (MD - 0.89 days, $95 \%$ Cl -3.59 to 1.82 days; $\mathrm{P}=0.52, \mathrm{I}^{2}=69 \% ; 5 \mathrm{RCTs}, 627$ participants; low-certainty evidence). Most studies did not mention adverse effects. One study reported adverse effects, which were mild, with similar frequency in $\mathrm{CHX}$ and control groups and one study reported there were no adverse effects.

Toothbrushing ( \pm antiseptics) may reduce the incidence of VAP (RR $0.61,95 \% \mathrm{Cl} 0.41$ to $0.91 ; \mathrm{P}=0.01,12=40 \% ; 5 \mathrm{RCTs}, 910$ participants; lowcertainty evidence) compared to $\mathrm{OHC}$ without toothbrushing ( \pm antiseptics). There is also some evidence that toothbrushing may reduce the duration of ICU stay (MD -1.89 days, $95 \% \mathrm{Cl}-3.52$ to -0.27 days; $\mathrm{P}=0.02,12=0 \% ; 3 \mathrm{RCTs}, 749$ participants), but this is very low certainty. Low-certainty evidence did not show a reduction in mortality (RR $0.84,95 \% \mathrm{Cl} 0.67$ to $1.05 ; \mathrm{P}=0.12, \mathrm{I}=0 \%$; 5 RCTs, 910 participants) or duration of mechanical ventilation (MD $-0.43,95 \% \mathrm{Cl}-1.17$ to $0.30 ; \mathrm{P}=0.25, \mathrm{I} 2=46 \% ; 4 \mathrm{RCTs}, 810$ participants).

\section{Authors' conclusions}

Chlorhexidine mouthwash or gel, as part of OHC, probably reduces the incidence of developing ventilator-associated pneumonia (VAP) in critically ill patients from $26 \%$ to about $18 \%$, when compared to placebo or usual care. We did not find a difference in mortality, duration of mechanical ventilation or duration of stay in the intensive care unit, although the evidence was low certainty. OHC including both antiseptics and toothbrushing may be more effective than $\mathrm{OHC}$ with antiseptics alone to reduce the incidence of VAP and the length of ICU stay, but, again, the evidence is low certainty. There is insufficient evidence to determine whether any of the interventions evaluated in the studies are associated with adverse effects.

\section{PLAIN LANGUAGE SUMMARY}

\section{Oral hygiene care for critically ill patients to prevent ventilator-associated pneumonia}

\section{Why is this question important?}

Ventilator-associated pneumonia (VAP) is a lung infection. It develops in patients who are on artificial breathing machines (ventilators) in hospitals for more than 48 hours. Often, these patients are very ill - they may have had a heart attack or stroke, a serious accident, or major surgery. They may be unable to breathe on their own because they are unconscious or sedated while they receive treatment.

Ventilators supply patients with oxygen through a tube placed in the mouth or nose, or through a hole in the front of the neck. If germs enter through the tube and get into the patient's lungs, this can lead to VAP. VAP is a potentially very serious complication in patients who are already very ill. It can cause worsening health and increases patients' risk of dying.

Keeping a patient's mouth clean and free of disease (oral hygiene) could help to prevent VAP. Oral hygiene care includes:

- mouthwash;

- antiseptic (a substance that destroys harmful micro-organisms in the mouth) gel for the gums and teeth;

- a soft foam sponge (swab) or toothbrush, to clean the mouth and teeth; and

- tools (e.g. a suction tube) to suck away excess fluid, toothpaste or other debris from the mouth.

These can be used alone, or in combination.

To find out if oral hygiene care does prevent VAP, and whether some types of oral hygiene care are better than others, we reviewed the evidence from research studies.

\section{How did we identify and evaluate the evidence?}


First, we searched for randomised controlled studies. These are clinical studies where people are randomly put into one of two or more treatment groups, to compare the effects of different treatments. We then compared the results, and summarised the evidence from all the studies. Finally, we rated our confidence in the evidence, based on factors such as study size and methods, and the consistency of findings across studies.

\section{What did we find?}

We found 40 studies that involved a total of 5675 people. All the people in the studies received treatment in hospital intensive care units. They required assistance from healthcare staff for their oral hygiene care. Most studies involved adults only, though one study focussed on children and another on newborn babies. The studies took place in a range of countries, including China (10 studies), Brazil (6 studies), the USA ( 6 studies) and Iran (5 studies).

Studies compared a range of oral health care (such as mouthwashes, gels or toothbrushes) against either:

- a placebo (dummy) treatment;

- usual care; or

- another oral health care treatment.

Here we report the findings for two comparisons:

1) Chlorhexidine ( $\mathrm{CHX}$, an antiseptic) in the form of mouthwash or gel, against placebo or usual care (13 studies); and

2) Toothbrushing against no tooth brushing, with or without an antiseptic (8 studies).

CHX against placebo or usual care

The evidence suggests that, compared to placebo or usual care, $\mathrm{CHX}$ :

- probably prevents VAP from developing in very ill patients (13 studies);

- probably has little or no effect on the risk of dying (9 studies);

- may make little to no difference to patients' length of stay in the intensive care unit (5 studies).

We do not know if $\mathrm{CHX}$ affects the length of time patients spend on a ventilator, or if it leads to adverse (unwanted) effects. This is because we have too little confidence in the evidence, because studies either:

- reported imprecise or inconsistent results;

- were conducted in ways likely to introduce error into the results; or

- reported too little information.

Toothbrushing against no toothbrushing, with or without an antiseptic

The evidence suggests that, compared to no toothbrushing, toothbrushing may:

- prevent VAP from developing in very ill patients (5 studies);

- have little or no effect on the risk of dying (5 studies);

- make little to no difference to how long people spend on ventilators (4 studies).

We do not know if toothbrushing affects patients' length of stay in the intensive care unit, or if it leads to adverse effects. This is because we have too little confidence in the evidence, because studies either:

- reported imprecise or inconsistent results; or

- were conducted in ways likely to introduce error into the results.

\section{What does this mean?}

Oral hygiene with $\mathrm{CHX}$ probably prevents VAP from developing in very ill patients treated in intensive care units. It probably has little or no effect on patients' risk of dying, or length of stay in the intensive care unit. 
Toothbrushing may prevent VAP from developing in very ill patients treated in intensive care units. It may have little or no effect on patients' risk of dying, or how long patients spend on a ventilator.

We do not know if $\mathrm{CHX}$ or toothbrushing lead to adverse effects, because there is insufficient robust evidence about this.

\section{How-up-to date is this review?}

The evidence in this Cochrane Review is current to February 2020. 
UMMARY OF FINDINGS

Summary of findings 1. Chlorhexidine (mouthrinse or gel) versus placebo/usual care for critically ill patients to prevent ventilator-associated pneumonia

Chlorhexidine (mouthrinse or gel) versus placebo/usual care for critically ill patients to prevent ventilator-associated pneumonia (VAP)

Population: critically ill adults and children receiving mechanical ventilation

Setting: intensive care units (ICU)

Intervention: chlorhexidine (mouthrinse or gel)

Comparison: placebo or usual care

\begin{tabular}{|c|c|c|c|c|c|c|}
\hline \multirow[t]{3}{*}{ Outcomes } & \multicolumn{2}{|l|}{ Illustrative comparative risks $(95 \% \mathrm{Cl})$} & \multirow{3}{*}{$\begin{array}{l}\text { Relative } \\
\text { effect } \\
(95 \% \mathrm{CI})\end{array}$} & \multirow{3}{*}{$\begin{array}{l}\text { Num- } \\
\text { ber of } \\
\text { partici- } \\
\text { pants } \\
\text { (stud- } \\
\text { ies) }\end{array}$} & \multirow{3}{*}{$\begin{array}{l}\text { Certain- } \\
\text { ty of } \\
\text { the evi- } \\
\text { dence } \\
\text { (GRADE) }\end{array}$} & \multirow[t]{3}{*}{ Comments } \\
\hline & Assumed risk & Corresponding risk & & & & \\
\hline & Control (placebo or usual care) & $\begin{array}{l}\text { Chlorhexidine (mouthrinse } \\
\text { or gel) }\end{array}$ & & & & \\
\hline $\begin{array}{l}\text { Incidence of VAP } \\
\text { Follow-up: mean } \\
1 \text { month }\end{array}$ & 261 per $1000^{1}$ & $\begin{array}{l}\mathbf{1 7 5} \text { per } \mathbf{1 0 0 0} \\
\text { (123 to } 253)\end{array}$ & $\begin{array}{l}\text { RR } 0.67 \\
(0.47 \text { to } \\
0.97)\end{array}$ & $\begin{array}{l}1206 \\
\text { (13 stud- } \\
\text { ies) }\end{array}$ & $\begin{array}{l}\oplus \oplus \oplus \ominus \\
\text { moder- } \\
\text { ate }^{2}\end{array}$ & $\begin{array}{l}\text { This equates to an NNTB of } 12 \\
\text { ( } 95 \% \mathrm{Cl} 7 \text { to } 128) \text {; probably re- } \\
\text { duces the incidence of VAP }\end{array}$ \\
\hline $\begin{array}{l}\text { Mortality } \\
\text { Follow-up: mean } \\
1 \text { month }\end{array}$ & 190 per $1000^{1}$ & $\begin{array}{l}\mathbf{2 4 7} \text { per } \mathbf{1 0 0 0} \\
\text { (192 to } 319)\end{array}$ & $\begin{array}{l}\text { RR } 1.03 \\
(0.80 \text { to } \\
1.33)\end{array}$ & $\begin{array}{l}944 \\
\text { (9 stud- } \\
\text { ies) }\end{array}$ & $\begin{array}{l}\oplus \oplus \oplus \ominus \\
\text { moder- } \\
\text { ate }^{3}\end{array}$ & $\begin{array}{l}\text { The evidence does not show a } \\
\text { difference in mortality }\end{array}$ \\
\hline $\begin{array}{l}\text { Duration of ven- } \\
\text { tilation } \\
\text { Days of ventila- } \\
\text { tion required } \\
\text { Follow-up: mean } \\
1 \text { month }\end{array}$ & $\begin{array}{l}\text { The mean duration of ventilation in the control } \\
\text { groups ranged from } 7 \text { to } 12 \text { days }\end{array}$ & $\begin{array}{l}\text { The mean duration of ven- } \\
\text { tilation in the intervention } \\
\text { groups was } \\
\mathbf{1 . 1 0} \text { days fewer } \\
\text { ( } 3.20 \text { fewer to } 1.00 \text { more) }\end{array}$ & & $\begin{array}{l}594 \\
\text { (4 stud- } \\
\text { ies) }\end{array}$ & $\begin{array}{l}\oplus \odot \ominus \ominus \\
\text { very } \\
\text { low4 }\end{array}$ & $\begin{array}{l}\text { The evidence does not show a } \\
\text { difference in duration of ven- } \\
\text { tilation }\end{array}$ \\
\hline $\begin{array}{l}\text { Duration of ICU } \\
\text { stay } \\
\text { Follow-up: mean } \\
1 \text { month }\end{array}$ & $\begin{array}{l}\text { The mean duration of ICU stay in the control } \\
\text { groups ranged from } 10 \text { to } 15 \text { days }\end{array}$ & $\begin{array}{l}\text { The mean duration of ICU stay } \\
\text { in the intervention groups } \\
\text { was } \\
\mathbf{0 . 8 9} \text { days fewer } \\
\text { (3.59 fewer to } 1.82 \text { more) }\end{array}$ & & $\begin{array}{l}627 \\
\text { (5 stud- } \\
\text { ies) }\end{array}$ & $\begin{array}{l}\oplus \oplus \odot \ominus \\
\text { low } 5\end{array}$ & $\begin{array}{l}\text { The evidence does not show } \\
\text { a difference in duration of ICU } \\
\text { stay }\end{array}$ \\
\hline Adverse effects & $\begin{array}{l}\text { Most of the studies did not provide informa- } \\
\text { tion on adverse events. Information on ad- } \\
\text { verse events were identified from } 2 \text { studies. }\end{array}$ & & & & $\begin{array}{l}\oplus \ominus \ominus \ominus \\
\text { very low } \\
6\end{array}$ & $\begin{array}{l}\text { There was a lack of evidence } \\
\text { about adverse effects }\end{array}$ \\
\hline
\end{tabular}


*The basis for the assumed risk (e.g. the median control group risk across studies) is provided in footnotes. The corresponding risk (and its $95 \%$ confidence interval) is based on the assumed risk in the comparison group and the relative effect of the intervention (and its $95 \% \mathrm{Cl}$ )

Cl: confidence interval; NNTB: number needed to treat for an additional beneficial outcome; RR: risk ratio

GRADE Working Group grades of evidence

High certainty: we are very confident that the true effect lies close to that of the estimate of the effect.

Moderate certainty: we are moderately confident in the effect estimate; the true effect is likely to be close to the estimate of the effect, but there is a possibility that it is substantially different.

Low certainty: our confidence in the effect estimate is limited; the true effect may be substantially different from the estimate of the effect.

Very low certainty: we have very little confidence in the effect estimate; the true effect is likely to be substantially different from the estimate of effect.

${ }^{1}$ Assumed risk was based on the median event rate in the control groups of the included studies.

2Downgraded one level due to substantial heterogeneity $(12=66 \%)$.

3Downgraded one level due to imprecision.

4Downgraded three levels due to serious imprecision, substantial heterogeneity $(12=74 \%)$, and serious risk of bias: two studies at high risk of bias.

5 Downgraded two levels due to serious imprecision and substantial heterogeneity $(12=69 \%)$.

${ }^{6}$ Downgraded three levels due to very serious imprecision and serious inconsistency: only two studies reported on this outcome, and they did not report data adequately enough to enable us to evaluate the risk of adverse events.

\section{Summary of findings 2 . Toothbrushing ( \pm antiseptics) versus no toothbrushing ( \pm antiseptics) for critically ill patients to prevent ventilator-} associated pneumonia

Toothbrushing ( \pm antiseptics) versus no toothbrushing ( \pm antiseptics) for critically ill patients to prevent ventilator-associated pneumonia (VAP)

Population: critically ill adults receiving mechanical ventilation

Setting: intensive care units (ICUs)

Intervention: toothbrushing ( \pm antiseptics)

Comparison: no toothbrushing ( \pm antiseptics)

\begin{tabular}{|c|c|c|c|c|c|c|}
\hline \multirow[t]{2}{*}{ Outcomes } & \multicolumn{2}{|c|}{ Illustrative comparative risks* $(95 \% \mathrm{Cl})$} & \multirow{2}{*}{$\begin{array}{l}\text { Relative } \\
\text { effect } \\
(95 \% \mathrm{CI})\end{array}$} & \multirow{2}{*}{$\begin{array}{l}\text { Num- } \\
\text { ber of } \\
\text { partici- } \\
\text { pants } \\
\text { (stud- } \\
\text { ies) }\end{array}$} & \multirow{2}{*}{$\begin{array}{l}\text { Certain- } \\
\text { ty of } \\
\text { the evi- } \\
\text { dence } \\
\text { (GRADE) }\end{array}$} & \multirow[t]{2}{*}{ Comments } \\
\hline & Assumed risk & Corresponding risk & & & & \\
\hline Incidence of VAP & 259 per 10001 & $\begin{array}{l}\mathbf{1 7 9} \text { per } \mathbf{1 0 0 0} \\
\text { (106 to } 236)\end{array}$ & RR 0.61 & 910 & $\begin{array}{l}\oplus \oplus \ominus \ominus \\
\text { low } 3\end{array}$ & $\begin{array}{l}\text { There may be a reduction in } \\
\text { the incidence of VAP }\end{array}$ \\
\hline
\end{tabular}




\begin{tabular}{|c|c|c|c|c|c|c|c|}
\hline \multirow{2}{*}{\multicolumn{2}{|c|}{ 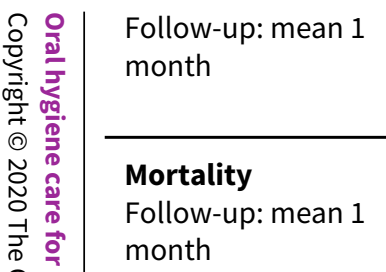 }} & \multirow[b]{2}{*}{250 per $1000^{1}$} & \multirow[b]{2}{*}{$\begin{array}{l}210 \text { per } 1000 \\
\text { (168 to } 263)\end{array}$} & \multirow{2}{*}{$\begin{array}{l}(0.41 \text { to } \\
0.91) \\
\text { RR } 0.84 \\
(0.67 \text { to } \\
1.05)\end{array}$} & \multicolumn{2}{|l|}{$\begin{array}{l}(5 \text { stud- } \\
\text { ies })^{2}\end{array}$} & \multirow[b]{2}{*}{$\begin{array}{l}\text { The evidence does not show a } \\
\text { difference in mortality }\end{array}$} \\
\hline & & & & & $\begin{array}{l}910 \\
(5 \text { stud- } \\
\text { ies })^{2}\end{array}$ & $\begin{array}{l}\oplus \oplus \oplus \ominus \\
\text { low } 4\end{array}$ & \\
\hline 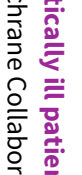 & $\begin{array}{l}\text { Duration of venti- } \\
\text { lation } \\
\text { Follow-up: mean } 1 \\
\text { month }\end{array}$ & $\begin{array}{l}\text { The mean duration of ventilation in the } \\
\text { control groups ranged from } 10 \text { to } 11 \\
\text { days }\end{array}$ & $\begin{array}{l}\text { The mean duration of ventilation in } \\
\text { the intervention groups was } \\
0.43 \text { days fewer } \\
\text { (1.17 fewer to } 0.30 \text { more) }\end{array}$ & & $\begin{array}{l}810 \\
\text { (4 stud- } \\
\text { ies) }\end{array}$ & $\begin{array}{l}\oplus \oplus \odot \odot \\
\text { low } 5\end{array}$ & $\begin{array}{l}\text { The evidence does not show a } \\
\text { difference in duration of ven- } \\
\text { tilation }\end{array}$ \\
\hline 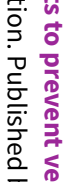 & $\begin{array}{l}\text { Duration of ICU } \\
\text { stay } \\
\text { Follow-up: mean } 1 \\
\text { month }\end{array}$ & $\begin{array}{l}\text { The mean duration of ICU stay in the } \\
\text { control groups ranged from } 13 \text { to } 16 \\
\text { days }\end{array}$ & $\begin{array}{l}\text { The mean duration of ICU stay in } \\
\text { the intervention groups was } \\
1.89 \text { days fewer } \\
\text { ( } 3.52 \text { fewer to } 0.27 \text { fewer) }\end{array}$ & & $\begin{array}{l}749 \\
\text { (3 stud- } \\
\text { ies) }\end{array}$ & $\begin{array}{l}\oplus \ominus \Theta \Theta \\
\text { very low } \\
6\end{array}$ & $\begin{array}{l}\text { There may be a reduction in } \\
\text { the duration of ICU stay }\end{array}$ \\
\hline 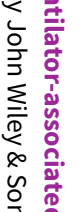 & Adverse effects & $\begin{array}{l}\text { Most of the studies did not provide infor- } \\
\text { mation on adverse events. Information } \\
\text { on adverse events was identified from } \\
\text { two studies, which stated that there } \\
\text { were none. }\end{array}$ & & & & $\begin{array}{l}\oplus \odot \odot \ominus \\
\text { very low } \\
7\end{array}$ & $\begin{array}{l}\text { There is a lack of evidence } \\
\text { about adverse effects. }\end{array}$ \\
\hline 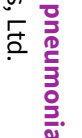 & \multicolumn{7}{|c|}{$\begin{array}{l}\text { *The basis for the assumed risk (e.g. the median control group risk across studies) is provided in footnotes. The corresponding risk (and its } 95 \% \text { confidence interval) is } \\
\text { based on the assumed risk in the comparison group and the relative effect of the intervention (and its } 95 \% \mathrm{Cl} \text { ) } \\
\text { Cl: confidence interval; RR: risk ratio }\end{array}$} \\
\hline
\end{tabular}

GRADE Working Group grades of evidence

High certainty: we are very confident that the true effect lies close to that of the estimate of the effect.

Moderate certainty: we are moderately confident in the effect estimate; the true effect is likely to be close to the estimate of the effect, but there is a possibility that it is substantially different.

Low certainty: our confidence in the effect estimate is limited; the true effect may be substantially different from the estimate of the effect.

Very low certainty: we have very little confidence in the effect estimate; the true effect is likely to be substantially different from the estimate of effect.

${ }^{1}$ Assumed risk was based on the outcomes in the control groups of the included studies.

2Four studies compared toothbrushing + chlorhexidine with chlorhexidine alone, one study compared toothbrushing with no toothbrushing (no chlorhexidine in either group), another study compared toothbrushing + povidone iodine with povidone iodine alone.

${ }^{3}$ Downgraded two levels due to very serious risk of bias: five studies at high risk of bias.

${ }^{4}$ Downgraded two levels due to very serious risk of bias: five studies at high risk of bias.

${ }^{5}$ Downgraded two levels due to very serious risk of bias: four studies at high risk of bias.

${ }^{6}$ Downgraded three levels due to serious imprecision and very serious risk of bias: three studies at high risk of bias.

${ }^{7}$ Downgraded three levels due to very serious imprecision and serious inconsistency: only two studies reported on this outcome, with data that did not enable us to evaluate 


\section{B A C K G R O U N D}

\section{Description of the condition}

Patients in intensive care units (ICUs) in hospital frequently require mechanical ventilation because their ability to breathe unassisted is impaired due to trauma, or as a result of a medical condition or recent surgery. These critically ill patients are also dependent on hospital staff to meet their needs for nutrition and hygiene, including oral hygiene.

Overall, the research suggests that oral health deteriorates following admission to a critical care unit (Sachdev 2013; Terezakis 2011). Endotracheal intubation and critical illness reduce oral immunity, may be associated with mechanical injury of the mouth or respiratory tract, increase the likelihood of dry mouth, and the presence of the endotracheal tube may also make access for oral care more difficult (Alhazzani 2013; Labeau 2011). Dental plaque accumulates rapidly in the mouths of critically ill patients and as the amount of plaque increases, colonisation by microbial pathogens is likely (Fourrier 1998; Sands 2016; Scannapieco 1992). Plaque colonisation may be exacerbated in the absence of adequate oral hygiene care and by the drying of the oral cavity due to prolonged mouth opening, which reduces the buffering and cleansing effects of saliva. In addition, the patient's normal defence mechanisms for resisting infection may be impaired (Alhazzani 2013; Terpenning 2005). Dental plaque is a complex biofilm which, once formed, is relatively resistant to chemical control, requiring mechanical disruption (such as toothbrushing) for maximum impact (Marsh 2010).

One of the complications that may develop in ventilated patients is ventilator-associated pneumonia (VAP). VAP is generally defined as a pneumonia developing in a patient who has received mechanical ventilation for at least 48 hours (ATS Guideline 2005). It is thought that the endotracheal tube, which delivers the necessary oxygen to the patient, may also act as a conduit for pathogenic bacteria, which multiply in the oral cavity and move down the tube into the lungs. Micro-aspiration of pharyngeal secretions may also occur around an imperfect seal of the cuff of the endotracheal tube in a ventilated patient. Several studies have shown that micro-aspiration contributes to the development of nosocomial pneumonia (Azoulay 2006; Mojon 2002; Scannapieco 1992).

VAP is a relatively common nosocomial infection in critically ill patients, with pooled incidence from $23.8 \%$ to $36.0 \%$ in recent systematic reviews (Ding 2017; Li 2020), with some indications that incidence is decreasing as understanding of the risk factors and preventative measures improves. Another systematic review estimated the attributable mortality of VAP to be $13 \%$ (Melsen 2013). Cohort studies have found that duration of ICU stay is increased in patients who develop VAP, but it is unclear whether this is cause or effect (Apostolopoulou 2003; Cook 1998).

Antibiotics, administered either intraorally as topical pastes or systemically, have been used to prevent VAP, and these interventions are evaluated in other Cochrane systematic reviews (D'Amico 2009; Arthur 2016). As the overuse of systemic antibiotics may be associated with the development of multidrug-resistant pathogens, there is merit in using other approaches to prevent infections such as VAP.

\section{Description of the intervention}

This systematic review evaluates various types of oral hygiene care as a means of reducing the incidence of VAP in critically ill patients receiving mechanical ventilation for at least 48 hours. Oral hygiene care is promoted in clinical guidelines as a means of reducing the incidence of VAP, but the evidence base is limited (Khasanah 2019; Tablan 2004).

Oral hygiene care includes the use of mouthrinse, gel, swab or toothbrushing (either manual or powered) etc. to remove plaque and debris from the oral cavity. Oral hygiene care also involves suction to remove excess fluid, toothpaste, and debris, and may be followed by the application of an antiseptic gel. Antiseptics are broadly defined to include saline, chlorhexidine, povidone iodine, cetylpyridium, and possibly others (but exclude antibiotics).

\section{How the intervention might work}

Patients on mechanical ventilation often have a very dry mouth due to prolonged mouth opening, which may be exacerbated by the side effects of medications used in their treatment. In healthy individuals, saliva functions to maintain oral health through its lubricating, antibacterial, and buffering properties (Labeau 2011), but patients on ventilators lack sufficient saliva for this to occur, and the usual stimuli (e.g. food intake) for saliva production are absent.

Routine oral hygiene care is designed to remove plaque and debris, as well as replacing some of the functions of saliva, moistening and rinsing the mouth. Toothbrushing, with either a manual or powered toothbrush, removes plaque from teeth and gums and disrupts the biofilm within which plaque bacteria multiply (Whittaker 1996; Zanatta 2011). It is hypothesised that using an antiseptic, such as chlorhexidine gluconate or povidone iodine, as either a rinse or a gel, may further reduce the bacterial load or delay a subsequent increase in bacterial load.

However, it is important, that during oral hygiene care for critically ill patients in ICUs, the plaque and debris are removed from the oral cavity with care by trained healthcare professionals, in order to avoid aspiration of contaminated fluids into the respiratory tract. Raising the head of the bed, and careful use of appropriately-maintained closed suction systems, together with an appropriately-fitted cuff around the endotracheal tube are other important aspects of care of critically ill patients that are not part of this systematic review.

\section{Why it is important to do this review}

Cochrane Oral Health undertook an extensive prioritisation exercise in 2014 to identify a core portfolio of titles that were the most clinically important reviews to produce and keep up-todate on the Cochrane Library (Worthington 2015). The periodontal expert panel identified the topic of this review as a priority at that time and this was confirmed in our recent priority setting update (Cochrane Oral Health Priority Setting Exercise).

Other Cochrane Reviews have evaluated the use of topical antibiotic pastes applied to the oral cavity to prevent VAP (selective oral decontamination (D'Amico 2009), probiotics (Bo 2014), and systemic antibiotics (Arthur 2016)). Other published reviews have evaluated aspects of oral hygiene care, such as toothbrushing (Alhazzani 2013) or use of chlorhexidine (Pineda 2006), and broader reviews have noted the lack of available evidence (Berry 2007; Shi 
2004). Some previous clinical guidelines recommended the use of oral hygiene care, but also suggested a lack of available evidence as a basis for specifying the essential components of such care (Muscedere 2008; Tablan 2004).

In terms of oral hygiene care including chlorhexidine, despite the accumulating evidence supporting its effectiveness in VAP prevention, its use for patients requiring mechanical ventilation remains a conflicting topic (Martin-Loeches 2018) due to potential adverse effects such as hypersensitivity (Pemberton 2012), oral mucosa lesions (Plantinga 2016), reduced bacterial susceptibility (La Combe 2018) and increased risk of mortality (Price 2014).

The goal of this Cochrane Review was to evaluate all oral hygiene care interventions (excluding the use of antibiotics) used in ICU for patients on ventilators for at least 48 hours, to determine the effects of oral hygiene care on the development of VAP. We planned to summarise all the available research in order to facilitate the provision of evidence-based care for these vulnerable patients.

\section{O B JECT IVES}

To assess the efficacy and safety of oral hygiene care in the prevention of VAP among critically ill patients receiving mechanical ventilation for at least 48 hours in hospital intensive care units (ICUs).

\section{METHODS}

\section{Criteria for considering studies for this review \\ Types of studies}

Randomised controlled trials (RCTs) of oral hygiene care interventions. We did not consider quasi-randomised studies for inclusion.

\section{Types of participants}

Critically ill patients in hospital settings receiving mechanical ventilation for a minimum of 48 hours, without ventilatorassociated pneumonia or respiratory infection at baseline. We included trials where only some of the participants were receiving mechanical ventilation if the outcome of ventilator-associated pneumonia was reported and data were available for those who had been treated with mechanical ventilation for a minimum of 48 hours and then developed nosocomial pneumonia.

We included trials where participants were undergoing a surgical procedure that involved mechanical ventilation (e.g. cardiac surgery) only if the oral hygiene care was given during the period of mechanical ventilation that had a minimum duration of 48 hours. We excluded trials where patients received a single preoperative dose of antibacterial rinse or gargle, and received mechanical ventilation only for the duration of the surgery, with no further mechanical ventilation and oral hygiene care during the postoperative period.

\section{Types of interventions}

- Intervention group: received oral hygiene care procedures such as healthcare professional assisted toothbrushing, oral and pharyngeal cavity rinse, decontamination of oropharyngeal cavities with antiseptics;
- Control group: received no treatment, placebo, 'usual care', or a different specific oral hygiene care procedure.

We excluded trials where the intervention being evaluated was a type of suction system or variation of method, timing, or place where mechanical ventilation was introduced (e.g. emergency room or ICU).

We excluded trials of selective decontamination using topical antibiotics administered to the oral cavity or oropharynx, because these interventions are covered in another Cochrane Review (D'Amico 2009). We also excluded trials of probiotics administered to prevent respiratory infections, as these are covered in a separate review (Hao 2015).

\section{Types of outcome measures}

We included studies that aimed to assess at least one of our primary outcomes, as we consider these essential for trials about the prevention of VAP.

\section{Primary outcomes}

1. Incidence of VAP (defined as pneumonia developing in a patient who has received mechanical ventilation for at least 48 hours)

2. Mortality (either all-cause ICU mortality if these data were available, or all-cause 30-day mortality)

\section{Secondary outcomes}

1. Duration of mechanical ventilation

2. Duration of ICU stay

3. Systemic antibiotic use

4. Oral health indices such as gingival index, plaque index, bleeding index, periodontal index, etc.

5. Adverse effects of the interventions

6. Caregivers' preferences for oral hygiene care

7. Economic data

\section{Search methods for identification of studies}

\section{Electronic searches}

Cochrane Oral Health's Information Specialist conducted systematic searches in the following databases for randomised controlled trials and controlled clinical trials without language or publication status restrictions:

- Cochrane Oral Health's Trials Register (searched 25 February 2020) (Appendix 1);

- Cochrane Central Register of Controlled Trials (CENTRAL; 2020, Issue 1) in the Cochrane Library (searched 25 February 2020) (Appendix 2);

- MEDLINE Ovid (1946 to 25 February 2020) (Appendix 3);

- Embase Ovid (1980 to 25 February 2020) (Appendix 4);

- CINAHL EBSCO (Cumulative Index to Nursing and Allied Health Literature; 1937 to 25 February 2020) (Appendix 5);

- LILACS BIREME Virtual Health Library (Latin American and Caribbean Health Science Information database; from 1982 to 25 February 2020) (Appendix 6);

We also searched:

- VIP Database (January 2012 to 8 March 2020) (Appendix 7). 
For previous versions of this review, we searched the Chinese Biomedical Literature Database, the China National Knowledge Infrastructure and the Wan Fang Database from inception to 14 January 2013 (see Appendix 8 for details). However, for this update, we did not search these databases as we found that they were adequately covered by searches of the VIP Database.

Subject strategies were modelled on the search strategy designed for MEDLINE Ovid. The Embase subject search was combined with a subject strategy adaptation of the highly sensitive search strategy designed by Cochrane for identifying randomised controlled trials and controlled clinical trials, as described in the Cochrane Handbook for Systematic Reviews of Interventions, Technical Supplement to Chapter 4 (Lefebvre 2019).

\section{Searching other resources}

The following trials registries were searched for ongoing studies:

- US National Institutes of Health Ongoing Trials Register ClinicalTrials.gov (clinicaltrials.gov; searched 25 February 2020) (see Appendix 9);

- World Health Organization International Clinical Trials Registry Platform (apps.who.int/trialsearch; searched 25 February 2020) (see Appendix 10).

We manually checked all the references lists of the included studies and relevant systematic reviews to identify any additional studies.

We contacted the first or corresponding authors of the included studies, other experts in the field, and manufacturers of oral hygiene products to request unpublished relevant information.

We checked that none of the included studies in this review were retracted due to error or fraud.

We did not perform a separate search for adverse effects of interventions used; we considered adverse effects described in included studies only.

\section{Data collection and analysis}

\section{Selection of studies}

At least two of six review authors independently examined each title and abstract of articles obtained from the searches. The search was designed to be sensitive and include controlled clinical trials; these were filtered out early in the selection process if they were not randomised. We resolved disagreements by discussion among all authors. We linked multiple reports from a study, and designated the report with the most complete follow-up data as the primary source of data.

We obtained copies of potentially relevant reports and examined them in detail to determine whether the study fulfilled the eligibility criteria. We resolved any queries by discussion. We attempted to contact study authors to obtain additional information as necessary. We excluded studies when the only information available was from the abstract and this was insufficient to enable full assessment of risk of bias.

\section{Data extraction and management}

At least two of six review authors independently extracted data from each included study onto structured data extraction forms that we had designed in advance. We resolved any disagreements by discussion. We extracted the following items:

- General characteristics of the study: authors, year of publication, country where the study was performed, funding, language of publication, study duration, citation, contact details for the authors and identifier.

- Specific trial characteristics: we collected basic study design characteristics: sequence generation, allocation sequence concealment, blinding, incomplete outcome data and selective outcome reporting, etc., and presented them in the table of 'Characteristics of included studies. We included verbatim quotes on the first three issues from original reports.

- Participants: total number, setting, age, sex, country, ethnicity, sociodemographic details (e.g. education level), diagnostic criteria for VAP and the presence of comorbid conditions.

- Interventions: we collected details of all experimental and control interventions, such as dosages for drugs used and routes of delivery, format for oral hygiene care, timing and duration of the oral care procedures. We also collected information on any co-interventions administered.

- Outcomes: we collected the incidence of VAP or other respiratory diseases and mortality (directly and indirectly attributable), duration of mechanical ventilation, duration of ICU stay, systemic antibiotic use, oral health indices, and adverse outcomes resulting from the interventions, etc. We specified all outcome variables in terms of definition, timing, units and scales.

- Other results: we also collected summary statistics, sample size, key conclusions, comments and any explanations provided for unexpected findings by the study authors. We contacted the lead authors of included studies if there were issues to be clarified.

\section{Assessment of risk of bias in included studies}

At least two of six review authors assessed the risk of bias of each included study, using the Cochrane domain-based, two-part tool as described in Chapter 8 of the Cochrane Handbook for Systematic Reviews of Interventions (Higgins 2011). We contacted study authors for clarification or missing information where necessary. We resolved any disagreements concerning risk of bias by discussion. We completed a 'Risk of bias' table for each included study. For each domain of risk of bias, we described what was reported to have happened in the study in order to provide a rationale for the second part, which involved assigning a judgement of 'low risk' of bias, 'high risk' of bias, or 'unclear risk' of bias.

For each included study, we assessed the following seven domains of risk of bias.

- Random sequence generation (selection bias): use of simple randomisation (e.g. random-number table, computergenerated randomisation, central randomisation by a specialised unit), restricted randomisation (e.g. random permuted blocks), stratified randomisation and minimisation were assessed as low risk of bias. Other forms of simple randomisation such as repeated coin-tossing, throwing dice or dealing cards were also considered as low risk of bias (Schulz 2002). Where a study report used the phrase 'randomised' or 'random allocation' but with no further information, we assessed it as unclear for this domain. 
- Allocation concealment (selection bias): use of centralised/ remote allocation, pharmacy-controlled randomisation and sequentially-numbered, sealed, opaque envelopes were assessed as low risk of bias. If a study report did not mention allocation concealment, we assessed it as unclear for this domain.

- Blinding of participants and personnel (performance bias): participants in included studies were in intensive care and on mechanical ventilation and were therefore unlikely to be aware of the treatment group to which they were assigned. We therefore assessed caregiver and outcome assessor blinding. Where no placebo was used, caregivers would be aware of the assigned intervention and this would introduce a risk of performance bias. If a study was described as double-blind and a placebo was used, we assumed that caregivers were blinded to the allocated treatment. If blinding was not mentioned and no placebo was used, we assumed that no blinding of caregivers occurred and we assessed this domain as being at high risk of bias.

- Blinding of outcome assessment (detection bias): if outcome assessor blinding was not mentioned in the trial report, we assessed this domain as being at unclear risk of bias.
- Incomplete outcome data (attrition bias): where we judged the overall rate of attrition to be high, we assessed the risk of attrition bias as high. If numbers of participants and/or reasons for exclusion were significantly different in each arm of the study, we assessed the risk of attrition bias as high. If numbers of participants randomised or evaluated in each arm of the study were not reported, we assessed this domain as unclear.

- Selective reporting (reporting bias): if the study did not report outcomes stated in the Methods section, or reported outcomes without estimates of variance, we assessed the study as being at high risk of reporting bias.

- Other bias: any other potential source of bias that might feasibly alter the magnitude of the effect estimate, e.g. baseline imbalance between study arms in important prognostic factors (e.g. clinical pulmonary infection scores (CPIS), antibiotic exposure), early stopping of the trial, or co-interventions or differences in other treatment between study arms. We described any other potential sources of bias and assessed their risk of bias.

We summarised the overall risks of bias as follows.

\begin{tabular}{llll}
\hline Risk of bias & Interpretation & In outcome & In included studies \\
\hline Low risk of bias & $\begin{array}{l}\text { Plausible bias unlikely to seriously } \\
\text { alter the results }\end{array}$ & $\begin{array}{l}\text { Low risk of bias for all key } \\
\text { domains }\end{array}$ & $\begin{array}{l}\text { Most information is from studies at low risk of } \\
\text { bias }\end{array}$ \\
\hline $\begin{array}{l}\text { Unclear risk of } \\
\text { bias }\end{array}$ & $\begin{array}{l}\text { Plausible bias that raises some } \\
\text { doubt about the results }\end{array}$ & $\begin{array}{l}\text { Unclear risk of bias for } \\
\text { one or more key domains }\end{array}$ & $\begin{array}{l}\text { Most information is from studies at low or un- } \\
\text { clear risk of bias }\end{array}$ \\
\hline High risk of bias & $\begin{array}{l}\text { Plausible bias that seriously weak- } \\
\text { ens confidence in the results }\end{array}$ & $\begin{array}{l}\text { High risk of bias for one } \\
\text { or more key domains }\end{array}$ & $\begin{array}{l}\text { The proportion of information from studies at } \\
\text { high risk of bias is sufficient to affect the inter- } \\
\text { pretation of results }\end{array}$ \\
\hline
\end{tabular}

We present the risk of bias graphically by: (a) proportion of studies with each judgement (low, high, or 'unclear risk of bias) for each domain, and (b) cross-tabulation of judgements by study and by domain (Figure 1; Figure 2).

Figure 1. Risk of bias graph: review authors' judgements about each risk of bias item presented as percentages across all included studies

Random sequence generation (selection bias)

Allocation concealment (selection bias)

Blinding of participants and personnel (performance bias): All outcomes Blinding of outcome assessment (detection bias): All outcomes Incomplete outcome data (attrition bias): All outcomes Selective reporting (reporting bias)

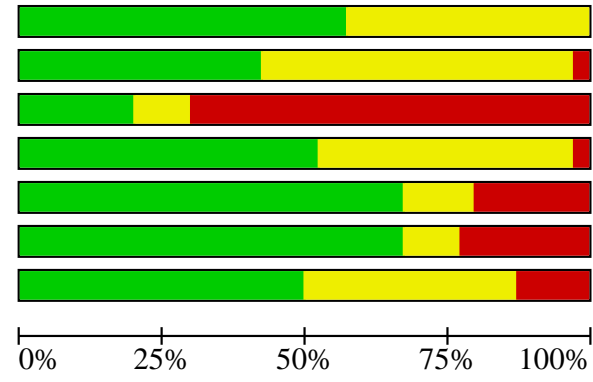


Figure 2. Risk of bias summary graph: review authors' judgements about each risk of bias item for each included study

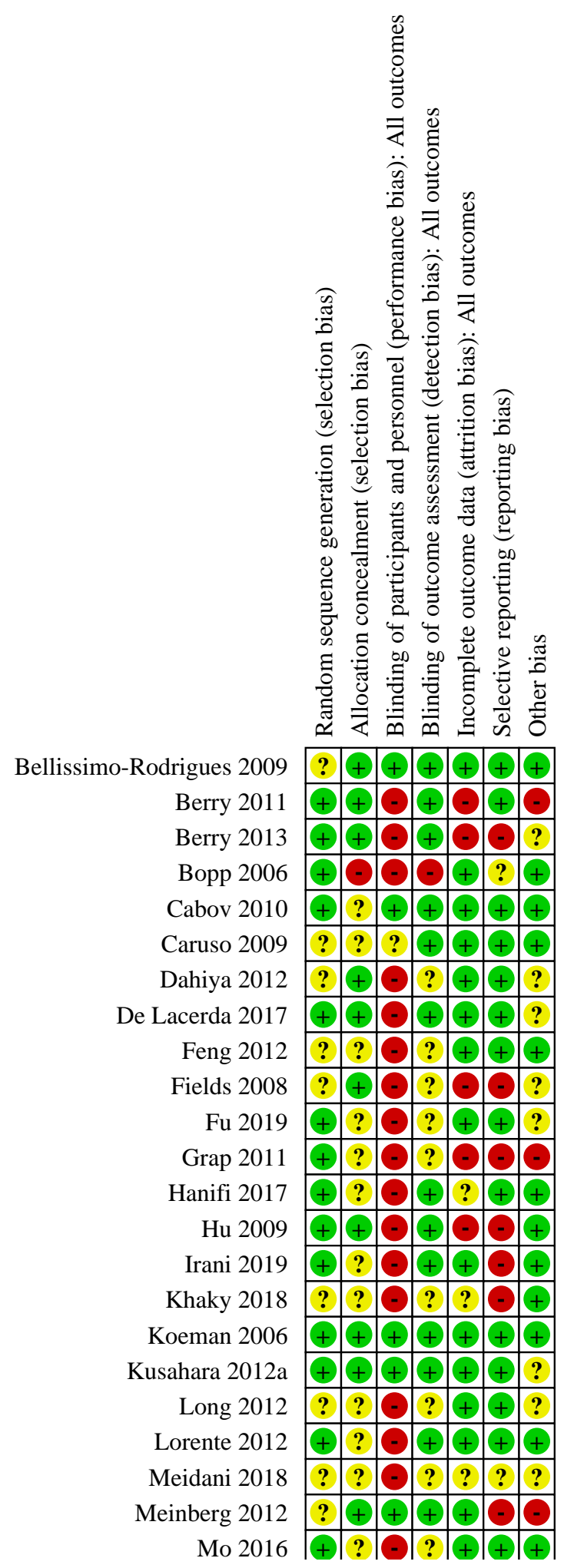


Figure 2. (Continued)

\begin{tabular}{|c|c|c|c|c|c|c|c|}
\hline Meinh & ? & + & + & & & & \\
\hline o 20 & + & $?$ & - & $?$ & + & + & \\
\hline Nobahar 2016 & + & $?$ & $?$ & $?$ & + & & \\
\hline Ozc & $?$ & $?$ & + & + & + & + & \\
\hline Panchab & $?$ & $?$ & 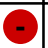 & + & $?$ & + & \\
\hline 2009 & + & + & C & + & + & + & \\
\hline Prenderg & + & + & 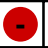 & + & & + & \\
\hline ca B & $?$ & + & 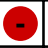 & $?$ & & & \\
\hline 9 & + & + & + & + & & $?$ & \\
\hline 6 & + & + & C & $?$ & + & + & \\
\hline 20 & + & + & + & + & + & + & \\
\hline Stefan & + & + & 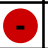 & $?$ & + & + & \\
\hline 20 & $?$ & $?$ & & $?$ & + & + & : \\
\hline Tantip & + & $?$ & ת & + & $?$ & $?$ & ? \\
\hline 2017 & $?$ & $?$ & $?$ & $?$ & + & + & \pm \\
\hline Xu 2007 & $?$ & $?$ & & $?$ & + & + & + \\
\hline Xu 2008 & $?$ & $?$ & & $?$ & + & + & \pm \\
\hline Yao 2011 & + & $?$ & E & + & + & + & \\
\hline hao 2012 & $?$ & $?$ & $?$ & $?$ & + & + & \\
\hline
\end{tabular}

\section{Measures of treatment effect}

For dichotomous outcomes, we computed the effect measure as the risk ratio (RR) together with the $95 \%$ confidence interval $(\mathrm{Cl})$. For continuous outcomes, we used the mean difference (MD) with 95\% $\mathrm{Cl}$ to estimate the summary effect. If different scales were used, we calculated the standardised mean difference (SMD).

\section{Unit of analysis issues}

The unit of analysis was the participant. The indices of plaque and gingivitis were measured as mean values for the participants. Episodes of care were also related back to individual participants.

\section{Dealing with missing data}

We contacted the lead author of studies requesting that they supply any missing data. We planned to obtain missing standard deviations using the methods outlined in the Cochrane Handbook for Systematic Reviews of Interventions (Higgins 2011).

\section{Assessment of heterogeneity}

To detect heterogeneity among studies in a meta-analysis, we applied a $\mathrm{Chi}^{2}$ test with a 0.10 level of significance as the cut-off value. We quantified the impact of statistical heterogeneity using the $1^{2}$ statistic. To interpret the results, we used the thresholds of $I^{2}$ recommended by the Cochrane Handbook for Systematic Reviews of Interventions (Higgins 2011):

- $0 \%$ to $40 \%$ : might not be important;

- $30 \%$ to $60 \%$ : may represent moderate heterogeneity;

- $50 \%$ to $90 \%$ : may represent substantial heterogeneity;

- $75 \%$ to $100 \%$ : considerable heterogeneity.
If considerable heterogeneity existed, we investigated it using subgroup analyses.

\section{Assessment of reporting biases}

Only a proportion of research projects conducted are ultimately published in an indexed journal and become easily identifiable for inclusion in systematic reviews. Reporting biases arise when the reporting of research findings is influenced by the nature and direction of the findings of the research. We investigated and attempted to minimise potential reporting biases in this review, including publication bias, time lag bias, multiple (duplicate) publication bias, and language bias.

We planned to construct funnel plots where there were more than 10 studies in an outcome. We planned to investigate any asymmetry in the funnel plot (indicating possible publication bias) by undertaking statistical analysis using the methods introduced by Egger 1997 (continuous outcome) and Rücker 2008 (dichotomous outcome) (such analysis would have been done in Stata).

\section{Data synthesis}

We undertook meta-analyses for similar comparisons and the same outcomes across studies. We used random-effects models providing there were four or more trials in any one meta-analysis.

\section{Subgroup analysis and investigation of heterogeneity}

We proposed several subgroup analyses a priori. We decided to undertake a subgroup analysis according to whether participants' teeth were cleaned by toothbrushing or not, as we hypothesised that antiseptics would be less effective if toothbrushing was not used to disrupt dental plaque biofilm. We also planned to perform 
subgroup analyses by grouping studies according to concentration of the intervention.

\section{Sensitivity analysis}

To determine whether the intervention effects of oral hygiene care were robust, we planned to perform sensitivity analyses to assess the effect on the estimates of effect of studies with questionable diagnostic criteria for VAP, by excluding studies with high risk of bias, or by changing our assumptions about missing data.

If the results had not changed substantially in sensitivity analyses, we would have regarded our conclusions as stable with a higher degree of certainty. If sensitivity analyses had identified particular factors that greatly influenced the conclusions of the review, we would have explored the plausible causes of the uncertainties and interpreted the results with more caution.

\section{Summary of findings and assessment of the certainty of the evidence}

Consistent with the last version of this review, we prepared 'Summary of findings' tables for two main comparisons: chlorhexidine versus placebo/usual care, and toothbrushing versus no toothbrushing, using the GRADE system for evaluating certainty of the evidence from systematic reviews (Guyatt 2008; Higgins 2011) and the software GRADEpro (GRADEpro 2020). We included the following outcomes in the 'Summary of findings' tables: incidence of VAP, mortality, duration of ventilation, duration of ICU stay, and adverse effects. We assessed the certainty of the body of evidence with reference to the overall risk of bias of the included studies, the directness of the evidence, the consistency of the results, the precision of the estimates, and the risk of publication bias. We classified the certainty of the body of evidence into four categories: high, moderate, low and very low.

\section{RESULTS}

\section{Description of studies}

\section{Results of the search}

For this review update, we identified 385 records from electronic databases and other resources after removal of duplicates. At least two review authors screened all records against the review inclusion criteria. We discarded 350 records as not relevant, and identified 10 additional records of studies awaiting classification (see Characteristics of studies awaiting classification) and two ongoing trials (see Characteristics of ongoing studies). We requested full-text copies of the remaining 23 references. At least two review authors assessed these papers to determine their eligibility: we excluded 10 studies for reasons described in Characteristics of excluded studies; four studies await classification until we have further information (see Characteristics of studies awaiting classification); and we deemed nine studies eligible for inclusion. In the previous version of the review, there were 38 included studies, but we excluded seven of these from this update (Chen 2008; DeRiso 1996; Fourrier 2000; Fourrier 2005; Jacomo 2011; Munro 2009; Sebastian 2012) (see below and Characteristics of excluded studies tables for details). Therefore, the total number of studies in this update is 40 . The study selection process is depicted in Figure 3. 


\section{Figure 3. Study flow diagram}

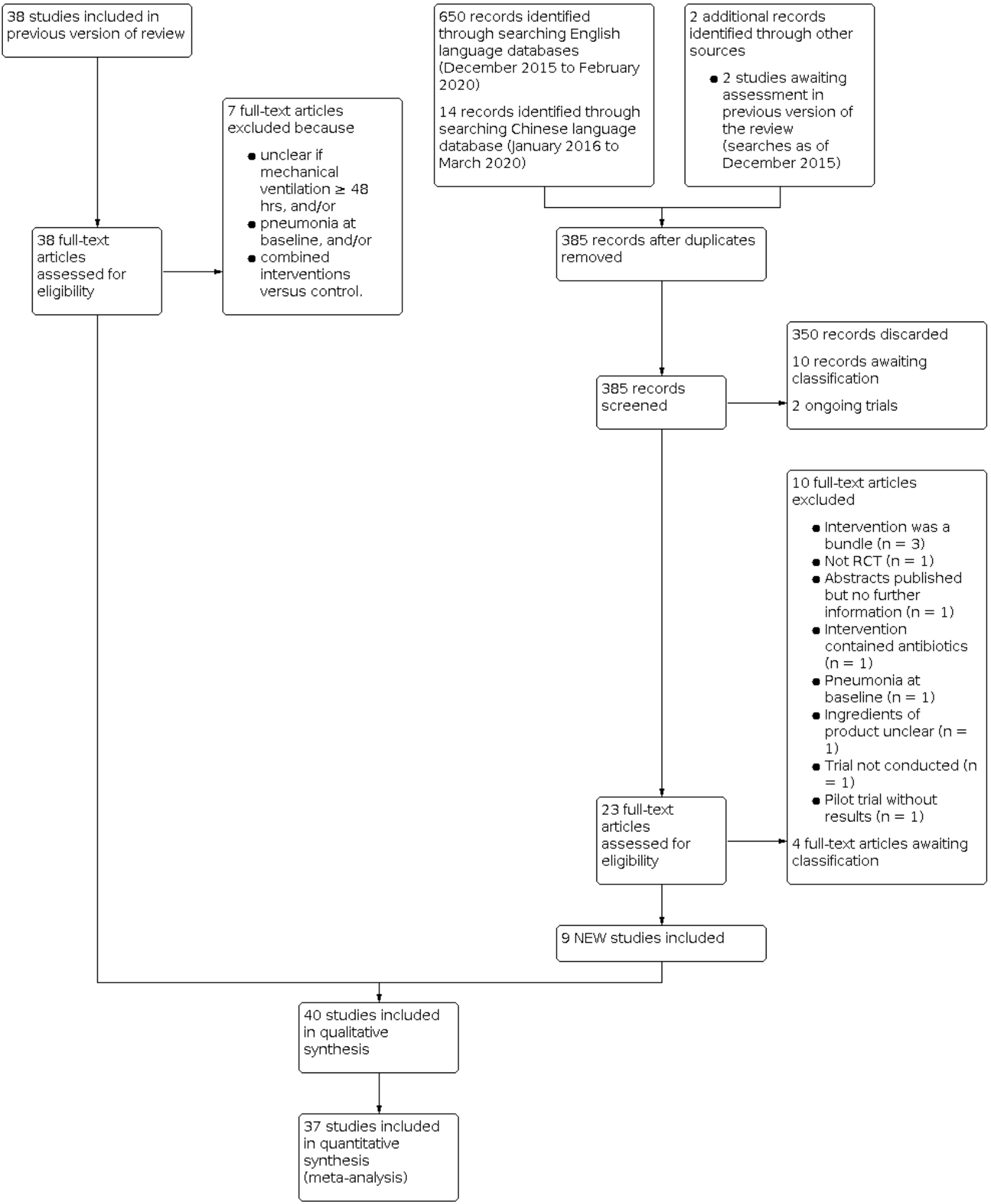

\section{Included studies}

We included 40 RCTs in this review.

\section{Setting}

Ten of the included studies were conducted in China (Feng 2012; Fu 2019; Hu 2009; Long 2012; Mo 2016; Tang 2013; Xu 2007; Xu 2008; Yao 2011; Zhao 2012), six in the USA (Bopp 2006; Fields 2008; Grap 
2011; Prendergast 2012; Scannapieco 2009; Stefanescu 2013), six in Brazil (Bellissimo-Rodrigues 2009; Caruso 2009; De Lacerda 2017; Kusahara 2012a; Meinberg 2012; Tuon 2017), five in Iran (Hanifi 2017; Irani 2019; Khaky 2018; Meidani 2018; Nobahar 2016), three in Spain (Lorente 2012; Pobo 2009; Roca Biosca 2011), two in France (Seguin 2006; Seguin 2014), two in India (Dahiya 2012; Panchabhai 2009), two in Australia (Berry 2011; Berry 2013), and one each in Croatia (Cabov 2010), Thailand (Tantipong 2008), Turkey (Ozcaka 2012), and the Netherlands (Koeman 2006).

All studies took place in ICUs in hospitals. Most of the studies were two-arm parallel-group RCTs, but seven studies had three arms (Berry 2011; Berry 2013; Fu 2019; Meidani 2018; Scannapieco 2009; Seguin 2006; Xu 2007).

\section{Participants}

There were 5675 participants randomly allocated to treatment in 39 RCTs, and the other trial (Fields 2008) did not state how many participants were included. The criteria for inclusion in these studies generally specified no prior intubation, no clinicallyapparent pneumonia at baseline, and an expected requirement for mechanical ventilation for a minimum of 48 hours. Participants were critically ill and required assistance from nursing staff for their oral hygiene care. In two of the included studies, participants were children (Kusahara 2012a; Stefanescu 2013); one of which enrolled only neonates (Stefanescu 2013). In the remaining studies, only adults participated.

In seven studies, participants were either medical or surgical patients (Berry 2013; De Lacerda 2017; Koeman 2006; Meinberg 2012; Mo 2016; Nobahar 2016; Panchabhai 2009); in another seven studies, participants were described as trauma patients (Grap 2011; Hanifi 2017; Irani 2019; Prendergast 2012; Scannapieco 2009; Seguin 2006; Seguin 2014); four studies recruited surgical patients only (Fu 2019; Kusahara 2012a; Yao 2011; Zhao 2012); six studies recruited medical patients only (Cabov 2010; Fields 2008; Ozcaka 2012; Stefanescu 2013; Tang 2013; Tantipong 2008); and in the remaining studies, it was not clearly stated whether participants were medical, surgical, or trauma cases.

Nine of the included studies specifically excluded edentulous participants (De Lacerda 2017; Fields 2008; Grap 2011; Lorente 2012; Ozcaka 2012; Pobo 2009; Prendergast 2012; Roca Biosca 2011; Tuon 2017), and the remaining studies did not report whether or not participants were dentate.

\section{Classification of the interventions}

We classified the interventions into three broad groups.

- Chlorhexidine

* Chlorhexidine solution (applied as mouthrinse, spray or on a swab)

* Chlorhexidine gel

- Toothbrushing

* Powered

* Manual
- Other agents

* Povidone iodine

* Saline

* Bicarbonate

* Triclosan

* Furacilin

* Listerine

* Biotene OralBalance

* Hydrogen peroxide

* Potassium permanganate

* Ozonated water

* Nanosil

* Miswak

These interventions were used either singly or in combinations. We evaluated the following comparisons.

1. Chlorhexidine versus placebo/usual care, with or without toothbrushing (13 studies: Bellissimo-Rodrigues 2009; Berry 2011; Cabov 2010; Fu 2019; Grap 2011; Koeman 2006; Kusahara 2012a; Meidani 2018; Meinberg 2012; Ozcaka 2012; Scannapieco 2009; Tantipong 2008; Tuon 2017)

2. Chlorhexidine versus other oral care agents ( 7 studies), including potassium permanganate (Meidani 2018; Panchabhai 2009), ozonated water (Hanifi 2017), miswak (Irani 2019), Nanosil (Khaky 2018), hydrogen peroxide (Bopp 2006; Dahiya 2012).

3. Toothbrushing versus no toothbrushing (in addition to usual care) (8 studies: Bopp 2006; De Lacerda 2017; Fields 2008; Lorente 2012; Long 2012; Pobo 2009; Roca Biosca 2011; Yao 2011)

4. Powered toothbrushing versus manual toothbrushing (one study: Prendergast 2012)

5. Other oral care agents (17 studies), including saline (Caruso 2009; Hu 2009; Mo 2016; Seguin 2006; Tang 2013; Xu 2007; Xu 2008), bicarbonate (Berry 2011; Berry 2013), povidone iodine (Feng 2012; Seguin 2006; Seguin 2014), triclosan (Zhao 2012), furacilin (Feng 2012), Listerine (Berry 2013), Biotene OralBalance (Stefanescu 2013), hydrogen peroxide (Nobahar 2016), potassium permanganate (Meidani 2018)

There was some variation between the studies in the number of episodes of $\mathrm{OHC}$ per day, with most of the studies delivering two to four episodes of $\mathrm{OHC}$ daily. Seventeen studies delivered two episodes of OHC a day (Berry 2011; Bopp 2006; Dahiya 2012; De Lacerda 2017; Fields 2008; Fu 2019; Hu 2009; Irani 2019; Kusahara 2012a; Nobahar 2016; Panchabhai 2009; Prendergast 2012; Scannapieco 2009; Tuon 2017; Xu 2007; Xu 2008; Yao 2011); eight studies had three episodes a day (Bellissimo-Rodrigues 2009; Cabov 2010; Hanifi 2017; Khaky 2018; Long 2012; Lorente 2012; Meidani 2018; Pobo 2009), and seven studies had four episodes a day (Feng 2012; Koeman 2006; Meinberg 2012; Mo 2016; Ozcaka 2012; Tantipong 2008; Zhao 2012). One study delivered OHC every two hours (Berry 2013), another only once (Grap 2011), and, in the remaining three studies, it was unclear (Caruso 2009; Roca Biosca 2011; Tang 2013).

In some of the included studies, the control intervention described as 'placebo' may have had some antibacterial activity, but this was considered by the trialists to be negligible compared to the active intervention. Such control interventions included saline (Feng 2012; Fu 2019; Hu 2009; Ozcaka 2012; Seguin 2006; Tantipong 
2008; Tuon 2017), potassium permanganate (Panchabhai 2009), half-strength hydrogen peroxide (Bopp 2006), placebo gel (Koeman 2006; Kusahara 2012a; Meinberg 2012), base solution (Scannapieco 2009) or water (Berry 2011; Berry 2013). In two trials, the nature of the placebo was not specified (Bellissimo-Rodrigues 2009; Meidani 2018).

In eight studies, the control group received usual/standard care (Caruso 2009; Fields 2008; Hu 2009; Grap 2011; Pobo 2009; Roca Biosca 2011; Seguin 2006; Yao 2011) (for specific details see Characteristics of included studies), and in nine studies, there was a head-to-head comparison between two potentially active interventions (Berry 2013; Dahiya 2012; Feng 2012; Hanifi 2017; Irani 2019; Khaky 2018; Meidani 2018; Panchabhai 2009; Prendergast 2012).

\section{Measures of primary outcomes}

\section{Incidence of VAP}

The primary outcome of our review is ventilator-associated pneumonia (VAP), defined as pneumonia developing in a person who has been on mechanical ventilation for at least 48 hours. VAP was fully reported by 38 of the included studies (BellissimoRodrigues 2009; Berry 2011; Berry 2013; Bopp 2006; Cabov 2010; Caruso 2009; Dahiya 2012; De Lacerda 2017; Feng 2012; Fu 2019; Grap 2011; Hanifi 2017; Hu 2009; Irani 2019; Khaky 2018; Koeman 2006; Kusahara 2012a; Long 2012; Lorente 2012; Meidani 2018; Meinberg 2012; Mo 2016; Nobahar 2016; Ozcaka 2012; Panchabhai 2009; Pobo 2009; Prendergast 2012; Scannapieco 2009; Seguin 2006; Seguin 2014; Stefanescu 2013; Tang 2013; Tantipong 2008; Tuon 2017; Xu 2007; Xu 2008; Yao 2011; Zhao 2012). One study only reported that there was no difference in VAP between the two arms of the study (Roca Biosca 2011). One study reported that the VAP rate dropped to zero in the intervention group but the control group event rate was not reported (Fields 2008).

Diagnostic criteria for the outcome of ventilator-associated pneumonia were specified in 37 studies. Seventeen studies used Pugin's criteria (Cook 1998; Pugin 1991), which form the basis of the CPIS score, based on the presence of an infiltrate on chest radiograph, plus two or more of the following: temperature greater than $38.5^{\circ} \mathrm{C}$ or less than $35^{\circ} \mathrm{C}$, white blood cell count greater than $11,000 / \mathrm{mm}^{3}$ or less than $4000 / \mathrm{mm}^{3}$, mucopurulent or purulent bronchial secretions, or more than $20 \%$ increase in fraction of inspired oxygen required to maintain saturation above 92\% (Berry 2011; Berry 2013; Cabov 2010; Caruso 2009; Grap 2011; Hanifi 2017; Koeman 2006; Kusahara 2012a; Meinberg 2012; Pobo 2009; Scannapieco 2009; Seguin 2006; Seguin 2014; Tantipong 2008; Yao 2011). Three studies used the modified clinical pulmonary infection score (MCPIS) (Irani 2019; Khaky 2018; Nobahar 2016). In Ozcaka 2012, no specific criteria were reported, but communication with the author confirmed that participants with new pulmonary infiltrates or opacities on the chest X-ray were prediagnosed with VAP; lower tracheal mini-bronchoalveolar lavage (mini-BAL) samples were taken and then participants were diagnosed according to CPIS criteria. Those who had a score of six or more and the presence of $10^{4}$ or more colony-forming units $/ \mathrm{mL}$ of a target potential respiratory bacterial pathogen (PRP) in miniBAL were diagnosed with VAP.

A further six studies used the CDC criteria as described in Horan 2008 (Bellissimo-Rodrigues 2009; Dahiya 2012; Fields 2008; Meidani
2018; Panchabhai 2009; Tuon 2017). Stefanescu 2013 used CDC criteria for diagnosis of neonatal VAP.

Five studies used the criteria of the Chinese Society of Respiratory Diseases: presence of new infiltrates on chest radiographs developed after 48 hours of mechanical ventilation with any two of the following items: (a) temperature greater than $38^{\circ} \mathrm{C}$, (b) change in characteristics of bronchial secretions from mucoid to mucopurulent or purulent, (c) white cell count greater than 10,000/ $\mathrm{mm}^{3}$, (d) positive culture of tracheal aspirate or positive culture of bronchoalveolar lavage fluid or both, or (e) arterial oxygen tension/ inspiratory fraction of oxygen $\mathrm{PaO}_{2} / \mathrm{FiO}_{2}$ decreased over $30 \%$ within the period of ventilation (Feng 2012; Mo 2016; Tang 2013; Xu 2007; Xu 2008).

De Lacerda 2017 used the American Thoracic Society criteria (ATS Guideline 2005) for diagnosis. Hu 2009 reported the outcome of VAP based on clinical examination plus three criteria: chest radiograph, white cell count and culture of the aspirate from lower respiratory tract (but no precise parameters were specified). In Lorente 2012, the diagnosis of VAP was made by an expert panel blinded to the allocated intervention, but the diagnostic criteria were not specified. Prendergast 2012 had a single diagnostic criterion of a new or worsening pulmonary infiltrate on chest radiograph. Two studies used positive culture from the lower respiratory tract as criteria for diagnosis of VAP (Long 2012; Zhao 2012).

The remaining three studies with the outcome of VAP did not report their diagnostic criteria (Bopp 2006; Fu 2019; Roca Biosca 2011).

Among the above-mentioned studies that provided data on incidence of VAP, 28 reported their follow-up length/time point of measurement for this outcome. In 10 of these studies, the length of follow-up was between three to nine days (Berry 2011; Berry 2013; Dahiya 2012; Grap 2011; Hanifi 2017; Irani 2019; Khaky 2018; Nobahar 2016; Prendergast 2012; Yao 2011), while in another 10 studies, the length of follow-up was between 10 to 30 days (Caruso 2009; De Lacerda 2017; Hu 2009; Ozcaka 2012; Pobo 2009; Scannapieco 2009; Seguin 2014; Tang 2013; Xu 2008; Zhao 2012). In the remaining five studies, the reported end of follow-up was discharge from the ICU (Bellissimo-Rodrigues 2009; Cabov 2010; Kusahara 2012a; Panchabhai 2009; Stefanescu 2013).

\section{Mortality}

Twenty-two studies reported the outcome of mortality, either as ICU mortality or 30-day mortality (Bellissimo-Rodrigues 2009; Cabov 2010; Caruso 2009; De Lacerda 2017; Fu 2019; Kusahara 2012a; Long 2012; Lorente 2012; Meidani 2018; Meinberg 2012; Mo 2016; Ozcaka 2012; Panchabhai 2009; Pobo 2009; Prendergast 2012; Scannapieco 2009; Seguin 2006; Seguin 2014; Stefanescu 2013; Tang 2013; Tantipong 2008; Yao 2011). Where ICU mortality was reported, we used these data; where ICU mortality was not reported, we used 30-day mortality.

\section{Measures of secondary outcomes}

\section{Duration of ventilation}

Seventeen studies reported this outcome (Bellissimo-Rodrigues 2009; Caruso 2009; De Lacerda 2017; Fu 2019; Hu 2009; Koeman 2006; Long 2012; Lorente 2012; Meidani 2018; Ozcaka 2012; Pobo 2009; Prendergast 2012; Scannapieco 2009; Seguin 2006; Tang 2013; Xu 2008; Zhao 2012). Berry 2013 and Meinberg 2012 reported the 
median duration of ventilation or the range for each group or both, but we could not combine these data in a meta-analysis. Unless explicitly reported otherwise, we have assumed that all studies used similar methods to calculate these data including participants who died. Stefanescu 2013 reported only a P value for the difference between groups in duration of ventilation.

\section{Duration of ICU stay}

Sixteen studies reported this outcome (Bellissimo-Rodrigues 2009; Bopp 2006; Caruso 2009; De Lacerda 2017; Fu 2019; Koeman 2006; Kusahara 2012a; Lorente 2012; Meidani 2018; Ozcaka 2012; Panchabhai 2009; Pobo 2009; Prendergast 2012; Seguin 2006; Seguin 2014; Zhao 2012). Berry 2013 and Meinberg 2012 reported the median ICU stay and the range for each group, but we could not combine these data in a meta-analysis. Unless explicitly reported otherwise, we have assumed that all studies used similar methods to calculate these data including participants who died.

\section{Systemic antibiotic therapy}

Five studies reported some measure of systemic antibiotic use. Irani 2019, Seguin 2014 and Tuon 2017 reported the number of participants who were treated with antibiotics. Scannapieco 2009 reported the mean number of days of systemic antibiotic use in the intervention and control groups. Berry 2013 reported only a P value for the difference between groups in antibiotic administration.

\section{Oral health indices}

Plaque indices were mentioned as outcomes in five studies (Fu 2019; Ozcaka 2012; Roca Biosca 2011; Scannapieco 2009; Yao 2011). Complete data for plaque indices were reported in two studies (Fu 2019; Ozcaka 2012), and were supplied by the corresponding author of one study (Yao 2011). Scannapieco 2009 reported this outcome in graphs only, and Roca Biosca 2011 did not report any estimate of variance, so we could not use these data in this review.

\section{Adverse effects}

Most studies did not mention adverse effects in their reports. Two studies reported the adverse effects of the interventions (Seguin 2014; Tantipong 2008); four studies reported that there were no adverse effects (Berry 2011; Berry 2013; De Lacerda 2017; Ozcaka 2012); and one study (Stefanescu 2013) reported no significant difference between groups with respect to adverse events in buccal mucosa.

\section{Excluded studies}

In this update, we excluded 17 studies for the reasons summarised below. Seven studies that we included in the previous version of the review are excluded from this version (Chen 2008; DeRiso 1996; Fourrier 2000; Fourrier 2005; Jacomo 2011; Munro 2009; Sebastian 2012).

- Guo 2017 and Sebastian 2012 were excluded because the participants had pneumonia at baseline.

- In Fourrier 2005, it was unclear if some of the participants had pneumonia at baseline and if all those who developed VAP had been on mechanical ventilation for at least 48 hours.

- DeRiso 1996 and Fourrier 2000 were excluded because it was unclear if all those who developed VAP had been on mechanical ventilation for at least 48 hours.
- In Jacomo 2011, it was unclear how many participants were on mechanical ventilation for at least 48 hours.

- Nasiriani 2016 was excluded because the authors replaced 22 dropouts with new participants (selection method unknown) and thereby compromised the randomisation.

- Four studies were excluded because the intervention of interest was a bundle that included not only OHC (Atashi 2018; Chen 2008; Dale 2019; Haghighi 2017).

- Tsai 2017 was reported as abstract only and our attempts to find a full publication or obtain sufficient data to enable inclusion in this review were unsuccessful.

- Wang 2016 was excluded because the CHX solution used for interventions contained antibiotics.

- Tian 2017 was excluded because authors did not report either the ingredients or product name of the 'biological enzyme disinfectant' used, therefore we could not judge whether it contained antibiotics. The authors' contact information was also not provided.

- One study was excluded because it was a pilot trial and patient outcomes were not collected (NCT01657396).

- Da Collina 2017 was excluded because the trial was not performed.

For further information, see the Characteristics of excluded studies table, which also provides information on studies excluded in the last version of this review.

\section{Risk of bias in included studies}

\section{Overall risk of bias}

Overall, we rated just two of the included studies (5\%) as having low risk of bias for all domains (Koeman 2006; Seguin 2014), and nine studies (23\%) were at unclear risk of bias for at least one domain. Over two-thirds of the included studies (29 studies, $73 \%$ ) were at high risk of bias in at least one domain (see Figure 1; Figure 2).

\section{Allocation}

\section{Sequence generation}

Twenty-three of the included studies clearly described a random method of sequence generation and we assessed them as at low risk of bias for this domain. The remaining 17 studies stated that allocation was random but provided no further details and we therefore assessed them as having unclear risk of bias for this domain (Bellissimo-Rodrigues 2009; Caruso 2009; Dahiya 2012; Feng 2012; Fields 2008; Khaky 2018; Long 2012; Meidani 2018; Meinberg 2012; Ozcaka 2012; Panchabhai 2009; Roca Biosca 2011; Tang 2013; Tuon 2017; Xu 2007; Xu 2008; Zhao 2012).

\section{Allocation concealment}

Allocation concealment was clearly described in 20 of the included studies and we assessed them as at low risk of bias for this domain. In 22 studies, allocation concealment was not described in sufficient detail to determine risk of bias and we rated these studies as having unclear risk of bias (Cabov 2010; Caruso 2009; Feng 2012; Fu 2019; Grap 2011; Hanifi 2017; Irani 2019; Khaky 2018; Long 2012; Lorente 2012; Meidani 2018; Mo 2016; Nobahar 2016; Ozcaka 2012; Panchabhai 2009; Tang 2013; Tantipong 2008; Tuon 2017; Xu 2007; Xu 2008; Yao 2011; Zhao 2012). We assessed Bopp 2006 as having high risk of bias because the allocation was not concealed from the researchers. 
The risk of selection bias based on combined assessment of these two domains was high in one study (Bopp 2006), unclear in 24 studies (Dahiya 2012; Cabov 2010; Caruso 2009; Feng 2012; Fields 2008; Fu 2019; Grap 2011; Hanifi 2017; Khaky 2018; Long 2012; Lorente 2012; Meidani 2018; Mo 2016; Nobahar 2016; Irani 2019; Panchabhai 2009; Roca Biosca 2011; Tang 2013; Tantipong 2008; Tuon 2017; Xu 2007; Xu 2008; Yao 2011; Zhao 2012), and low in the remaining 15 studies.

\section{Blinding}

Eight studies were described as double-blind and we assessed them as having low risk of performance bias (Bellissimo-Rodrigues 2009; Cabov 2010; Koeman 2006; Kusahara 2012a; Meinberg 2012; Ozcaka 2012; Scannapieco 2009; Seguin 2014). There was insufficient information to determine whether blinding occurred in four studies (Caruso 2009; Nobahar 2016; Tuon 2017; Zhao 2012). In the remaining 28 studies, blinding of the participants and their caregivers to the allocated treatment was not possible because the active and control treatments were so different, and no placebos were used. We assessed these studies as having high risk of performance bias.

Blinding of outcome assessment was possible in all of the included studies and was described in 21 studies (Bellissimo-Rodrigues 2009; Berry 2011; Berry 2013; Cabov 2010; Caruso 2009; Dahiya 2012; De Lacerda 2017; Hanifi 2017; Hu 2009; Irani 2019; Kusahara 2012a; Lorente 2012; Meinberg 2012; Ozcaka 2012; Panchabhai 2009; Pobo 2009; Prendergast 2012; Scannapieco 2009; Seguin 2014; Tantipong 2008; Yao 2011), which we assessed as being at low risk of detection bias. One of the included studies reported no blinding of outcome assessment and we assessed it as having high risk of detection bias (Bopp 2006). In the remaining 18 studies, there was insufficient information provided and we rated the risk of detection bias as unclear.

\section{Incomplete outcome data}

In the studies included in this review, loss of participants during the course of the study is to be expected, as these critically ill people leave the intensive care unit either because they recover and no longer require mechanical ventilation, or because they die from their illness. In 27 of the included studies, either all the randomised participants were included in the outcome, or the number of losses/ withdrawals and the reasons given were similar in both arms of the study, and we assessed these studies as at low risk of attrition bias (Bellissimo-Rodrigues 2009; Bopp 2006; Cabov 2010; Caruso 2009; Dahiya 2012; De Lacerda 2017; Feng 2012; Fu 2019; Irani 2019; Koeman 2006; Kusahara 2012a; Long 2012; Lorente 2012; Meinberg 2012; Mo 2016; Nobahar 2016; Ozcaka 2012; Pobo 2009; Seguin 2006; Seguin 2014, Stefanescu 2013; Tang 2013; Tuon 2017; Xu 2007; Xu 2008; Yao 2011; Zhao 2012).

We rated eight of the included studies as having high risk of attrition bias, because the numbers and reasons for withdrawal/exclusion were different in each arm of the study, or because the number of participants withdrawn or excluded from the outcomes evaluation was high and insufficient information was provided (Berry 2011; Berry 2013; Fields 2008; Grap 2011; Hu 2009; Prendergast 2012; Roca Biosca 2011; Scannapieco 2009). In the remaining five studies, there was insufficient information available to determine the risk of attrition bias.

\section{Selective reporting}

Twenty-seven of the included studies reported the outcomes specified in their Methods section in full, or this information was supplied by trial authors, and we assessed these studies as being at low risk of reporting bias (Bellissimo-Rodrigues 2009; Berry 2011; Cabov 2010; Caruso 2009; Dahiya 2012; De Lacerda 2017; Feng 2012; Fu 2019; Hanifi 2017; Koeman 2006; Kusahara 2012a; Long 2012; Lorente 2012; Mo 2016; Ozcaka 2012; Panchabhai 2009; Pobo 2009; Prendergast 2012; Seguin 2006; Seguin 2014; Stefanescu 2013; Tang 2013; Tuon 2017; Xu 2007; Xu 2008; Yao 2011; Zhao 2012).

Six studies did not report all the outcomes specified in their Methods sections (Grap 2011; Irani 2019; Khaky 2018; Meinberg 2012; Nobahar 2016; Roca Biosca 2011); two studies reported outcomes as percentages only, with unclear denominators for each arm (Berry 2013; Hu 2009); and one study did not report the number of participants evaluated (Fields 2008). We rated these nine trials as at high risk of reporting bias.

We assessed the remaining four trials as being at unclear risk of reporting bias, because there was insufficient information reported to make a clear judgement (Bopp 2006; Meidani 2018; Scannapieco 2009; Tantipong 2008).

\section{Other potential sources of bias}

We rated five studies as at high risk of other bias. Three studies were stopped early (Berry 2011; Meinberg 2012; Pobo 2009 ). Berry 2011 was stopped due to withdrawal of one of the investigational products by a regulatory authority. Pobo 2009 was stopped after $37 \%$ of the planned 400 participants had been recruited because there appeared to be no difference between the study arms in the outcome of VAP. Meinberg 2012 was stopped due to "futility"; however, we were unsure whether this was the main problem. Grap 2011 did not report baseline data for each randomised treatment group but the trial report noted that there was a "statistically significant difference in gender and CPIS score between groups at baseline", and we considered that this difference was likely to have biased the results. In Scannapieco 2009, the imputations used for the missing data were unclear and the pre-study exposure to systemic antibiotics was greater in the control group, so we assessed this study as having high risk of other bias.

In 15 studies, we rated the risk of other bias as unclear (Berry 2013; Dahiya 2012; De Lacerda 2017; Fields 2008; Fu 2019; Kusahara 2012a; Long 2012; Meidani 2018; Panchabhai 2009; Roca Biosca 2011; Stefanescu 2013; Tang 2013; Tantipong 2008; Yao 2011; Zhao 2012). The reasons for this are as follows.

- In Berry 2013, ineligible participants were included in the ITT analysis, but reasons for ineligibility in each group were not given;

- In Dahiya 2012; Fields 2008; Meidani 2018 and Roca Biosca 2011, the study reports contained insufficient information for us to be confident that study methodology was robust;

- In Stefanescu 2013, more infants in the control group received a complete course of antenatal steroids compared to infants in the Biotene OralBalance group ( $P=0.045)$. A complete course of antenatal steroids improves antenatal lung maturity and function and may reduce the risk of VAP (Roberts 2017). This imbalance is likely to lead to an underestimate of the benefit of the active treatment; 
- In Kusahara 2012a, there was a statistically significant difference in the age of the children in each arm of the study and we were unclear whether this was associated with potential bias;

- Panchabhai 2009 reported baseline characteristics only for those participants completing the study;

- In Tang 2013, a detailed description about the intervention methods and frequency of oral care in each group was not reported;

- Tantipong 2008 included participants treated in different units of the hospital where care and co-interventions were likely to have been different;

- In Yao 2011, there was no information as to how the edentulous participants in each arm were treated;

- Long 2012 and Zhao 2012 reported the criteria for VAP diagnosis as being positive culture of lower respiratory tract secretions, with no other criteria, and it was unclear if this would have introduced a bias in these unblinded studies;

- Fu 2019 did not report the criteria used for VAP diagnosis, and it was unclear if this would have introduced a bias;

- In De Lacerda 2017, there was an imbalance between two groups in the method of $\mathrm{CHX}$ application (CHX gel vs. $\mathrm{CHX}$ solution).

We assessed the remaining 20 studies as having low risk of other bias.

\section{Effects of interventions}

See: Summary of findings 1 Chlorhexidine (mouthrinse or gel) versus placebo/usual care for critically ill patients to prevent ventilator-associated pneumonia; Summary of findings 2 Toothbrushing ( \pm antiseptics) versus no toothbrushing ( \pm antiseptics) for critically ill patients to prevent ventilatorassociated pneumonia

\section{Comparison 1: Chlorhexidine versus placebo/usual care (with or without toothbrushing)}

Chlorhexidine antiseptic was evaluated in 13 studies included in this review.

Concentration of the chlorhexidine used was $2 \%$ in four studies (Koeman 2006; Meinberg 2012; Tantipong 2008; Tuon 2017), 0.2\% in three studies (Berry 2011; Cabov 2010; Meidani 2018), and 0.12\% in the remaining studies.

We assessed seven of the 13 studies as having high risk of bias (Berry 2011; Fu 2019; Grap 2011; Meidani 2018; Meinberg 2012; Scannapieco 2009; Tantipong 2008), one study as at low risk of bias (Koeman 2006;), and the remaining five studies as at unclear risk of bias.

We subgrouped these studies according to whether chlorhexidine was administered as a liquid mouthrinse or a gel, and whether chlorhexidine was used in conjunction with toothbrushing or not.

\section{Incidence of VAP}

Overall, the meta-analysis of 13 studies using any form of chlorhexidine (seven studies at high risk of bias, five at unclear risk of bias and one at low risk of bias) showed that $\mathrm{CHX}$ probably reduced the incidence of VAP (risk ratio (RR) $0.67,95 \%$ confidence interval $(\mathrm{Cl}) 0.47$ to $0.97, \mathrm{P}=0.05, \mathrm{I}^{2}=72 \% ; 1206$ participants; moderate-certainty evidence) (Analysis 1.1). This equates to a number needed to treat for an additional beneficial outcome (NNTB) of 12 (95\% Cl 7 to 128$)$.

Six studies (429 participants) compared chlorhexidine solution $(2 \%, 0.12 \%$ or $0.2 \%)$ with either placebo (Bellissimo-Rodrigues 2009; Fu 2019; Meidani 2018; Ozcaka 2012; Tuon 2017) or 'usual care' (Grap 2011) without toothbrushing. Four of these studies reported the use of a swab, either to clean the mouth prior to chlorhexidine application or to ensure that the chlorhexidine solution was applied to all oral surfaces. Tuon 2017 applied CHX through mouth-rinsing. In the other study (Meidani 2018), the mode of application was unclear. The meta-analysis showed a reduction in VAP in the chlorhexidine group ( $\mathrm{RR} 0.57,95 \% \mathrm{Cl} 0.33$ to $1.00, \mathrm{P}=$ $0.05, \mathrm{I}^{2}=72 \%$ ) (Analysis 1.1, subgroup 1.1.1).

A further two studies (297 participants) compared chlorhexidine gel $(0.2 \%$ or $2 \%)$ versus placebo, with no toothbrushing in either group (one of the studies administered $0.2 \%$ chlorhexidine gel three times daily following rinsing of the mouth and aspiration of rinse (Cabov 2010), and the other study used a gel with higher chlorhexidine concentration (2\%) and applied the gel using a swab (Koeman 2006)). Meta-analysis showed a reduction in the risk of VAP for $\mathrm{CHX}$ gel (RR $0.53,95 \% \mathrm{Cl} 0.29$ to $0.97, \mathrm{P}=0.04, \mathrm{I}^{2}=0 \%$ ) (Analysis 1.1 , subgroup 1.1.2).

Three studies (332 participants) compared chlorhexidine solution $(2 \%, 0.12 \%$ or $0.2 \%)$ with placebo (with toothbrushing in both groups). The meta-analysis showed no evidence of a difference in VAP between the groups (RR $0.74,95 \% \mathrm{Cl} 0.29$ to $1.89, \mathrm{P}=0.53, \mathrm{I}^{2}=$ 53\%) (Analysis 1.1, subgroup 1.1.3).

Two further studies (Kusahara 2012a; Meinberg 2012, including 52 adults and 96 children), at high and unclear risk of bias, compared chlorhexidine gel ( $2 \%$ and $0.12 \%$ ) with placebo (with toothbrushing in both groups) and found no difference in the incidence of VAP (RR $1.22,95 \% \mathrm{Cl} 0.83$ to $1.79, \mathrm{P}=0.32, \mathrm{I}=0 \%$ ) (Analysis 1.1 , subgroup 1.1.4).

\section{Mortality}

The outcome of mortality was reported in nine studies (944 participants), and overall the meta-analysis showed that there may not be a difference between chlorhexidine and placebo/usual care (RR $1.02,95 \% \mathrm{Cl} 0.84$ to $1.23, \mathrm{P}=0.86, \mathrm{I}^{2}=0 \%$; moderate-certainty evidence) (Analysis 1.2). There was no evidence of a difference in mortality between $(\mathrm{P}=0.99,12=0 \%)$ or within the subgroups (chlorhexidine mouthrinse/gel with or without toothbrushing) (Analysis 1.2).

\section{Duration of ventilation}

From the four studies (594 participants) that reported data in a way that could be combined in meta-analysis, we did not find evidence of a difference in the duration of ventilation (days) between groups receiving chlorhexidine compared to those receiving placebo/usual care (mean difference (MD) -1.10 days, $95 \% \mathrm{Cl}-3.20$ to 1.00 days, $\mathrm{P}$ $=0.30,1^{2}=74 \%$; very low-certainty evidence) (Analysis 1.3).

There was some evidence of a reduction in duration of ventilation in Analysis 1.3, subgroup 1.3.1 (MD -2.63 days, $95 \% \mathrm{Cl}-3.35$ to -1.90 days, $P<0.00001, \mathrm{I}^{2}=0 \%$ ), and insufficient evidence (based on a single study) to determine whether or not there was a difference in Analysis 1.3, subgroup 1.3.2 or Analysis 1.3, subgroup 1.3.3. 
A further study (Meinberg 2012), comparing chlorhexidine gel and placebo, also found no difference in duration of ventilation (Additional Table 1).

\section{Duration of ICU stay}

There was no evidence of a difference between those receiving chlorhexidine compared to placebo/usual care in the outcome of duration of ICU stay (days) (MD -0.89 days, $95 \% \mathrm{Cl}-3.59$ to 1.82 days, $\mathrm{P}=0.69, \mathrm{I}^{2}=79 \%, 5 \mathrm{RCTs}, 627$ participants; low-certainty evidence). There was some evidence of a reduction in duration of ICU stay in Analysis 1.4, subgroup 1.4.1 (MD -2.92 days, $95 \% \mathrm{Cl}-4.18$ to -1.66 days, $\mathrm{P}<0.00001, \mathrm{I}^{2}=18 \%$, three RCTs, 274 participants), no evidence of a difference in Analysis 1.4, subgroup 1.4.2 (MD 1.32 days, $95 \% \mathrm{Cl}-2.43$ to 5.07 days, $\mathrm{P}=0.49$, one $\mathrm{RCT}, 257$ participants), and insufficient evidence (based on a single study with very low precision) to determine whether or not there was a difference in Analysis 1.4, subgroup 1.4.3.

Another study (Meinberg 2012) compared chlorhexidine gel with placebo and also found no difference in duration of ICU stay (Additional Table 1).

\section{Use of systemic antibiotics}

One trial (146 participants) reported this outcome, but there was insufficient evidence to determine whether or not there was a difference in duration of systemic antibiotic therapy between the chlorhexidine and control groups (MD 0.65 days, $95 \% \mathrm{Cl}-0.58$ to $1.88, \mathrm{P}=0.30$ ) (Analysis 1.5)

Tuon 2017 compared chlorhexidine solution and placebo and found no evidence of a difference in the number of participants treated with systemic antibiotics (Analysis 1.6).

\section{Oral health indices: plaque index}

Two of the studies in this group reported numerical data for the outcome of plaque index (Fu 2019; Ozcaka 2012); one study used a four-point ordinal scale as the plaque index and found significant reduction in the $\mathrm{CHX}$ group (Fu 2019), while the other study measured the proportion of participants presented with dental plaque and found no significant difference between groups (Ozcaka 2012) (Analysis 1.7). A further study (Scannapieco 2009) found no difference in plaque indices between the chlorhexidine and control groups (Additional Table 1 ).

\section{Adverse effects}

Two studies in this group reported on adverse effects. Tantipong 2008 found mild reversible irritation of the oral mucosa in $10 \%$ of the chlorhexidine participants compared to $1 \%$ of the control group participants (Analysis 1.8). Berry 2011 stated that there were no adverse events in either group (Additional Table 1).

Adverse effects were not mentioned in the other studies in this group.

\section{Other outcomes}

The outcomes of caregivers' preferences and cost were not reported.

\section{Heterogeneity}

The substantial statistical heterogeneity found for the outcome of VAP incidence is likely to be due to clinical differences between these studies, attributable to variability in the frequency, application method, volume, and concentration of chlorhexidine solution (Analysis 1.1).

In subgroup 1.1.1, all of the six studies used a placebo control and the volume of chlorhexidine $(2 \%, 0.12 \%$ or $0.2 \%)$ used varied between 10 and $15 \mathrm{~mL}$ administered either two, three, or four times daily. One study used a single application by swab of a very small volume of chlorhexidine within 12 hours after intubation (Grap 2011). All the studies involved adult participants.

\section{Sensitivity analyses and subgroup analyses}

For the primary outcomes, we conducted a sensitivity analysis excluding studies at high risk of bias. The estimate remained similar for both VAP incidence (RR $0.78,95 \% \mathrm{Cl} 0.56$ to $1.10, \mathrm{P}=0.16, \mathrm{I}^{2}=$ 26\%; 603 participants) compared with 0.70 , and mortality (RR 1.04, $95 \% \mathrm{Cl} 0.81$ to $1.33, \mathrm{P}=0.77, \mathrm{I}^{2}=0 \%$; 330 participants) compared with 1.06 (analyses not shown).

In addition, we also performed subgroup analyses by grouping the included studies according to chlorhexidine concentration $(0.12 \%$ vs $0.2 \%$ vs $2 \%$ ). Results of these subgroup analyses suggest no evidence of a difference between subgroups in either incidence of $\operatorname{VAP}(P=0.64)$ or mortality $(P=0.91)$ (analyses not shown).

\section{Comparison 2: Chlorhexidine versus other oral care agents}

Seven studies were included in this comparison (Bopp 2006; Dahiya 2012; Hanifi 2017; Irani 2019; Khaky 2018; Meidani 2018; Panchabhai 2009). All of the studies were at high risk of bias. Bopp 2006 was a very small pilot study $(n=5)$ and the data from this study are recorded in Additional Table 1.

Concentration of the chlorhexidine used was $0.2 \%$ in five studies (Dahiya 2012; Hanifi 2017; Irani 2019; Meidani 2018; Panchabhai 2009), and $0.12 \%$ in two studies (Bopp 2006; Khaky 2018). Six of these seven studies reported numerical data, and we subgrouped them according to the oral care agents used in control groups, including potassium permanganate (Meidani 2018; Panchabhai 2009), ozonated water (Hanifi 2017), Nanosil (Khaky 2018), hydrogen peroxide (Dahiya 2012), and miswak (Irani 2019).

\section{Incidence of VAP}

Meidani 2018 and Panchabhai 2009 compared chlorhexidine with potassium permanganate, and found no evidence of a difference in incidence of VAP (RR $0.87,95 \% \mathrm{Cl} 0.50$ to $1.52, \mathrm{P}=0.63, \mathrm{I}=0 \%$ ) (Analysis 2.1, subgroup 2.1.1).

A single study (Hanifi 2017) compared chlorhexidine with ozonated water, and found some evidence for a benefit for ozonated water (Analysis 2.1, subgroup 2.1.2). The results of this study have not been replicated, so should be interpreted with caution.

A single study (Khaky 2018) compared chlorhexidine with Nanosil, and found some evidence for a benefit for Nanosil (Analysis 2.1, subgroup 2.1.3). The results of this study have not been replicated, so should be interpreted with caution. 
A single study (Dahiya 2012) compared chlorhexidine with hydrogen peroxide, and found no evidence of a difference in incidence of VAP (Analysis 2.1, subgroup 2.1.4).

A further study (Irani 2019) compared chlorhexidine with miswak, and found no evidence of a difference in incidence of VAP (Analysis 2.1, subgroup 2.1.5).

The pilot study by Bopp 2006 reported a reduction in VAP associated with chlorhexidine but the evidence was insufficient (Additional Table 1).

\section{Mortality}

Meidani 2018 and Panchabhai 2009 compared chlorhexidine with potassium permanganate, and found no evidence of a difference in mortality ( $R R 1.11,95 \% \mathrm{Cl} 0.89$ to $1.38, \mathrm{P}=0.34, \mathrm{I}=37 \%$ ) (Analysis 2.2, subgroup 2.2.1)

A single study (Khaky 2018) compared chlorhexidine with Nanosil, and found no evidence of a difference in mortality (Analysis 2.2, subgroup 2.2.2).

\section{Use of systemic antibiotics}

A single study (Irani 2019) compared chlorhexidine with miswak, and found no evidence of a difference in the number of participants treated with systemic antibiotics (Analysis 2.3).

\section{Other outcomes}

The duration of mechanical ventilation, duration of ICU stay, oral health indices, adverse effects, caregivers' preferences and cost were not reported.

\section{Comparison 3: Toothbrushing versus no toothbrushing (with or without antiseptics)}

The eight studies included in this comparison (Bopp 2006; De Lacerda 2017; Fields 2008; Long 2012; Lorente 2012; Pobo 2009; Roca Biosca 2011; Yao 2011) had toothbrushing as part of the intervention versus no toothbrushing in the control group. The studies were all at high risk of bias. Two studies used powered toothbrushes (Pobo 2009; Roca Biosca 2011), and six used manual toothbrushes. Bopp 2006 was a very small pilot study $(n=5)$ and the data from this study are recorded in Additional Table 1. Fields 2008 reported no numerical data at all. Roca Biosca 2011 did not report data for each arm of the study and we were not able to obtain these data from the authors. Available data from this study are recorded in Additional Table 1.

\section{Incidence of VAP}

There is some low-certainty evidence that toothbrushing may be beneficial in reducing the incidence of VAP in the combined metaanalysis of five studies (RR $0.61,95 \% \mathrm{Cl} 0.41$ to $0.91, \mathrm{P}=0.01, \mathrm{I}^{2}=$ 40\%, 910 participants, low-certainty evidence) (Analysis 3.1).

One small study (Yao 2011; 53 participants) at high risk of bias, compared usual care plus the addition of twice daily toothbrushing with a powered toothbrush, to usual care alone, and found a reduction in VAP. The usual-care intervention comprised the participant's bed being elevated $30^{\circ}$ to $45^{\circ}$, hypopharyngeal suctioning, lips moistened with 'toothette' swab and water, then further hypopharyngeal suctioning. A second study with 147 participants, also assessed at high risk of bias (Pobo 2009), compared powered toothbrushing plus usual care including chlorhexidine, with usual care alone, and found no difference in the outcome of VAP. The combined estimate from these studies showed no difference in the incidence of VAP (RR $0.49,95 \% \mathrm{Cl}$ 0.16 to $1.53, P=0.22, I^{2}=75 \%$ ) (Analysis 3.1, subgroup 3.1.1), with the heterogeneity probably due to the additional exposure to chlorhexidine in both groups of only one of the studies.

In De Lacerda 2017 and Lorente 2012 (649 participants), where the intervention group received toothbrushing with a manual toothbrush as well as chlorhexidine compared to chlorhexidine alone in the control group, there was no evidence of a difference in the incidence of VAP between the intervention and control groups (RR $0.74,95 \% \mathrm{Cl} 0.50$ to $1.09, \mathrm{P}=0.13, \mathrm{I}^{2}=0 \%$ ) (Analysis 3.1 , subgroup 3.1.2).

A further study (Long 2012; 61 participants) compared toothbrushing plus povidone iodine with povidone iodine alone, and found some evidence for a benefit for toothbrushing (Analysis 3.1, subgroup 3.1.4). The results of this study have not been replicated, so should be interpreted with caution.

Bopp 2006 was a very small pilot study $(n=5)$ of toothbrushing versus none, and the data are reported in Additional Table 1. There were no numerical outcome data in the study by Fields 2008 the report makes the statement that "the VAP rate dropped to zero within a week of beginning the every 8 hours toothbrushing regimen in the intervention group." This rate of zero incidence of VAP was reportedly sustained for six months. Roca Biosca 2011 recruited 117 participants and reported a summary estimate for the outcome of VAP, with no difference between powered toothbrushing and no toothbrushing (Additional Table 1).

\section{Mortality}

Five studies (910 participants) evaluated the effect of toothbrushing, as an addition to oral care, on the outcome of mortality (De Lacerda 2017; Long 2012; Lorente 2012; Pobo 2009; Yao 2011). The comparisons were different in each trial and did not provide evidence of a difference in mortality with or without toothbrushing (RR $0.86,95 \% \mathrm{Cl} 0.70$ to $1.05, \mathrm{P}=0.14, \mathrm{I}^{2}=0 \%$; lowcertainty evidence) (Analysis 3.2).

In Pobo 2009 and Yao 2011 (200 participants), where the intervention group received toothbrushing with a powered toothbrush as well as usual care compared to usual care alone in the control group, there was no evidence of a difference in mortality (RR 1.31, 95\% Cl 0.17 to 9.91, $\mathrm{P}=0.79, \mathrm{I}^{2}=55 \%$ ) (Analysis 3.2, subgroup 3.2.1).

Two studies (De Lacerda 2017; Lorente 2012) with 649 participants) compared toothbrushing combined with chlorhexidine and chlorhexidine alone, and found no evidence of a difference in mortality (RR $0.87,95 \% \mathrm{Cl} 0.68$ to $1.12, \mathrm{P}=0.28, \mathrm{I} 2=0 \%$ ) (Analysis 3.2, subgroup 3.2.2).

Another single study (Long 2012; 61 participants) compared toothbrushing combined with povidone iodine and povidone iodine alone, also reported no evidence of a difference in mortality (Analysis 3.2, subgroup 3.2.4). 


\section{Duration of ventilation}

Meta-analysis of three trials of chlorhexidine (De Lacerda 2017; Lorente 2012; Pobo 2009; 749 participants) reported the outcome of mean duration of mechanical ventilation, and showed a significant reduction associated with toothbrushing (MD -1.46 days, $95 \% \mathrm{Cl}$ -2.69 to -0.23 days, $P=0.02,12=0 \%$; fixed-effect model) (Analysis 3.3 , subgroup 3.3.1). However, a further trial of povidone iodine failed to show a benefit for toothbrushing for this outcome (Long 2012). The data from Bopp 2006 are reported in Additional Table 1.

\section{Duration of ICU stay}

Meta-analysis of three trials of chlorhexidine (De Lacerda 2017; Lorente 2012; Pobo 2009; 749 participants) reported the outcome of mean duration of ICU stay and found that there may be a reduction associated with toothbrushing (MD -1.89 days, $95 \% \mathrm{Cl}-3.52$ to -0.27 days, $P=0.02, \mathrm{I}^{2}=0 \%$; fixed-effect model; very low-certainty evidence) (Analysis 3.4). The data from Bopp 2006 are reported in Additional Table 1.

\section{Use of systemic antibiotics}

This outcome was not reported by any of the studies in this group.

\section{Oral health indices: plaque score}

One study (Yao 2011) also reported the outcome of plaque score in each group after seven to eight days. The study showed evidence of reduced plaque in the toothbrushing group (Analysis 3.5).

Roca Biosca 2011 reported plaque scores, without any estimates of variance. The trial report stated that there was no difference between the groups (Additional Table 1).

\section{Adverse effects}

Pobo 2009 and De Lacerda 2017 reported that there were no adverse effects reported in either arm of the study and none of the other studies in this comparison mentioned adverse effects (Additional Table 1).

\section{Other outcomes}

The outcomes of caregivers' preferences and cost were not reported.

\section{Comparison 4: Powered toothbrushing versus manual toothbrushing}

One small study of 78 participants (Prendergast 2012), assessed at high risk of bias, compared the use of a powered toothbrush as a component of 'comprehensive oral care' with a control group receiving manual toothbrushing and standard oral care.

In this study, there was no difference between the intervention and control groups for the outcomes of incidence of VAP, mortality or mean duration of ventilation or ICU stay (Analysis 4.1; Analysis 4.2; Analysis 4.3; Analysis 4.4). There were no adverse effects mentioned in this study. The outcomes of oral health indices, systemic antibiotic therapy, caregivers' preferences for oral hygiene care or cost were not reported in the study.

\section{Comparison 5: Other oral care agents}

Fifteen studies were included in this comparison, with a total of 3062 participants randomised to treatments (Berry 2011; Berry
2013; Caruso 2009; Feng 2012; Hu 2009; Meidani 2018; Mo 2016; Nobahar 2016; Seguin 2006; Seguin 2014; Stefanescu 2013; Tang 2013; Xu 2007; Xu 2008; Zhao 2012). Twelve of these studies were at high risk of bias, two studies were at unclear risk of bias (Caruso 2009; Zhao 2012) and Seguin 2014 was at low risk of bias. The studies evaluated the effects of other oral care agents with a potential antiseptic effect on the outcomes of VAP, mortality, duration of ventilation, duration of ICU stay, number of participants treated with systemic antibiotics and adverse effects.

\section{Incidence of VAP}

Three studies (356 participants) compared povidone iodine rinse with a saline rinse or placebo (Feng 2012; Seguin 2006; Seguin 2014). They showed evidence of a reduction in VAP in the povidone iodine group ( $R R 0.69,95 \% \mathrm{Cl} 0.50$ to $0.95, P=0.02, \mathrm{I}^{2}=74 \%$, fixedeffect model) (Analysis 5.1, subgroup 5.1.1).

Seguin 2006 (67 participants) also compared povidone iodine rinse with usual care (suction alone with no rinse) and found a reduction in VAP in the povidone iodine group (Analysis 5.1, subgroup 5.1.2). The result of this study has not been replicated, so should be interpreted with caution.

Four studies (488 participants) (Mo 2016; Tang 2013; Xu 2007; Xu 2008), all at high risk of bias, which compared a saline rinse with a saline-soaked swab, found that saline rinse may reduce the incidence of VAP (RR $0.47,95 \% \mathrm{Cl} 0.37$ to $0.62, \mathrm{P}<0.001, \mathrm{I}^{2}=84 \%$, fixed-effect model) (Analysis 5.1, subgroup 5.1.3).

Two studies (Caruso 2009; Seguin 2006; 324 participants), both at high risk of bias, compared a saline rinse with usual care (no rinse) and found a reduction in VAP (RR $0.60,95 \% \mathrm{Cl} 0.39$ to $0.91, \mathrm{P}=0.02$, $\mathrm{I}^{2}=64 \%$, fixed-effect model) (Analysis 5.1, subgroup 5.1.4). While this result should be interpreted cautiously due to the high risk of bias, there appeared to be some evidence that the use of a saline rinse was associated with reduction of VAP.

Hu 2009 and Xu 2007, both at high risk of bias, compared both saline rinse plus swab in 153 participants, with a saline-soaked swab alone (usual care) and found that the combined rinse plus swab may reduce the incidence of VAP ( $R R 0.41,95 \% \mathrm{Cl} 0.23$ to $0.72, \mathrm{P}=0.002$, $1^{2}=0 \%$, fixed-effect model) (Analysis 5.1, subgroup 5.1.5).

Two studies (Berry 2011; Berry 2013; 347 participants), both at high risk of bias, compared bicarbonate rinse plus toothbrushing with a water rinse plus toothbrushing and found no evidence of a difference in the incidence of VAP (RR 1.57, 95\% Cl 0.62 to 3.99, $\mathrm{P}=$ $0.34,1^{2}=43 \%$, fixed-effect model) (Analysis 5.1, subgroup 5.1.6).

A single study compared triclosan rinse with saline rinse and found no difference in the outcome of VAP over the duration of the study (Zhao 2012) (Analysis 5.1, subgroup 5.1.7). The results of this study have not been replicated, so should be interpreted with caution.

A single three-arm study compared povidone iodine, furacilin and usual care (Feng 2012). It found both antiseptics combined with toothbrushing were more effective than usual care (Analysis 5.1, subgroup 5.1.1 and Analysis 5.1, subgroup 5.1.9) with insufficient evidence of a difference between the two antiseptic solutions (Analysis 5.1, subgroup 5.1.8). 
A single study (Berry 2013), comparing Listerine with water, and Listerine with bicarbonate, found no evidence of a difference in VAP incidence (Analysis 5.1, subgroups 5.1.10 and 5.1.11).

A single study (Stefanescu 2013; 41 participants) compared Biotene OralBalance with control and found no difference in incidence of VAP (Analysis 5.1, Subgroup 5.1.12).

A single study (Nobahar 2016) compared hydrogen peroxide with normal saline, and found a reduction in VAP (Analysis 5.1, subgroup 5.1.13). The result of this study has not been replicated, so should be interpreted with caution.

Another single study (Meidani 2018) compared potassium permanganate with placebo, and found no evidence of a difference in VAP incidence (Analysis 5.1, subgroup 5.1.14).

\section{Mortality}

Eight studies reported mortality in the following comparisons (Analysis 5.2).

- Povidone iodine versus saline/placebo: two studies $(217$ participants) (RR $1.00,95 \% \mathrm{Cl} 0.66$ to $1.50, \mathrm{P}=0.98, \mathrm{I}^{2}=65 \%$; fixed-effect model); no evidence to suggest a difference in mortality.

- Povidone iodine versus usual care: a single study $(67$ participants) reported no difference.

- Saline rinse versus saline swab: two studies (270 participants) (RR 0.29, 95\% Cl 0.12 to $0.69 ; \mathrm{P}=0.005, \mathrm{I}^{2}=0 \%$; fixed-effect model), suggesting a significant reduction in mortality for saline rinse.

- Saline rinse plus swab versus saline swab (usual care): a single study (47 participants) reported no difference.

- Saline rinse versus usual care: two studies (324 participants) (RR $1.10,95 \% \mathrm{Cl} 0.87$ to $1.39, \mathrm{P}=0.43, \mathrm{I}^{2}=2 \%$; fixed-effect model); no evidence to suggest a difference in mortality.

- Biotene OralBalance versus control: a single study (41 participants) reported no difference.

- Potassium permanganate versus placebo: a single study (100 participants) reported no difference.

\section{Duration of ventilation}

Six studies reported duration of ventilation (days) in the following comparisons (Analysis 5.3).

- Povidone iodine versus saline/placebo: a single study $(67$ participants) reported no difference.

- Povidone iodine versus usual care: a single study $(67$ participants) reported no difference.

- Saline rinse versus usual care: two studies (324 participants) (MD -0.40 days, $95 \% \mathrm{Cl}-2.55$ to 1.75 days, $\mathrm{P}=0.72, \mathrm{I} 2=0 \%$ ); no evidence to suggest a difference in duration of ventilation.

- Saline rinse plus swab versus saline swab (usual care): a single study (47 participants) reported a statistically significant effect in favour of shorter duration for the saline rinse plus swab.

- Saline rinse versus saline swab: two studies (176 participants) (MD -6.83 days, $95 \% \mathrm{Cl}-8.94$ to -4.72 days; $\mathrm{P}<0.00001, \mathrm{I}^{2}=65 \%$ ) suggested saline rinse led to shorter duration of ventilation.
- Triclosan rinse versus saline: a single study (324 participants) reported that triclosan led to shorter duration of ventilation than saline.

Berry 2013, comparing Listerine with water, and Listerine with bicarbonate, found no difference among groups in median ventilation hours. Another study (Stefanescu 2013), comparing Biotene OralBalance and control, also found no difference between groups in duration of ventilation. (Additional Table 1).

\section{Duration of ICU stay}

Four studies reported duration of ICU stay (days) in the following comparisons (Analysis 5.4).

- Povidone iodine versus saline/placebo: two studies (217 participants) (MD -0.35 days, $95 \% \mathrm{Cl}-3.90$ to 3.21 days, $\mathrm{P}=0.85$, $1^{2}=0 \%$; fixed-effect model); no evidence to suggest a difference.

- Povidone iodine versus usual care: a single study $(67$ participants) reported no difference.

- Saline rinse versus usual care: two studies (324 participants) (MD -1.17 days, $95 \% \mathrm{Cl}-3.95$ to 1.60 days, $\mathrm{P}=0.41, \mathrm{I}^{2}=32 \%$; fixedeffect model); no evidence to suggest a difference in duration of ICU stay.

- Triclosan rinse versus saline: a single study (324 participants) reported that triclosan led to shorter stay in ICU than saline.

Another study (Berry 2013), comparing Listerine with water, and Listerine with bicarbonate, found no difference among groups in median ICU length of stay (Additional Table 1).

\section{Use of systemic antibiotics}

Seguin 2014, comparing povidone iodine and placebo, showed no evidence of a difference in the number of participants treated with systemic antibiotics (Analysis 5.5). Berry 2013, comparing Listerine with water, and Listerine with bicarbonate, found no difference among groups in antibiotic administration. See Additional Table 1.

\section{Adverse effects}

Seguin 2014 found no evidence of a difference in the occurrence of acute respiratory distress syndrome, agitation and/ or hypertension, epistaxis, oxygen desaturation and aspiration (Analysis 5.6). Berry 2013 found no adverse events associated with interventions. Stefanescu 2013, comparing Biotene OralBalance and control, found no significant difference between groups with respect to adverse events in buccal mucosa. See Additional Table 1.

\section{DISCUSSION}

\section{Summary of main results}

In this updated review, we included 40 randomised controlled trials evaluating interventions in the oral hygiene care of critically ill patients receiving mechanical ventilation for at least 48 hours in intensive care units. We classified these trials into five broad groups, based on the intervention, control and co-interventions used.

- Chlorhexidine (CHX) antiseptic versus placebo/usual care (with or without toothbrushing)

There is moderate-certainty evidence from 13 RCTs that the use of chlorhexidine (either as a mouthrinse or a gel) probably reduces 
the incidence of ventilator-associated pneumonia (VAP) from $26 \%$ to about $18 \%$ (see Summary of findings 1 ). However, there may be no difference in mortality (moderate-certainty evidence), duration of mechanical ventilation (very low-certainty evidence) or duration of ICU stay (low-certainty evidence). There is insufficient evidence to determine the effect of chlorhexidine on the other secondary outcomes of this review.

\section{- $\mathrm{CHX}$ antiseptic versus other oral care agents}

Six RCTs compared CHX with other oral care agents, two of which suggested no evidence of a difference between chlorhexidine and potassium permanganate in incidence of VAP or mortality. Due to variation in comparisons and outcomes among trials, there is insufficient evidence concerning the effects of $\mathrm{CHX}$ and other oral care agents.

- Toothbrushing versus no toothbrushing (with or without antiseptics)

Based on six RCTs (low-certainty evidence), toothbrushing may be beneficial in reducing the incidence of VAP. Also, very low-certainty evidence from 3 RCTs shows that toothbrushing might reduce the duration of ICU stay. No evidence of a difference was found between toothbrushing or no toothbrushing for the outcomes of mortality (low-certainty evidence) or duration of ventilation (low-certainty evidence) (see Summary of findings 2).

- Oral care with powered toothbrush versus oral care with manual toothbrush

From the single study in this comparison, there is insufficient evidence to determine the effects of powered versus manual toothbrushing on the outcomes of VAP, mortality, duration of mechanical ventilation or duration of ICU stay.

\section{- Oral care with other solutions}

The studies in this comparison, most of which were at high overall risk of bias, made different comparisons. For the reduction of VAP, there is some weak evidence that povidone iodine rinse is more effective than saline/placebo, use of saline rinse is more effective than saline swab, use of both a saline swab and a saline rinse may be more effective than a saline swab alone, and use of saline rinse may be more effective than usual care. There is no evidence of a difference between bicarbonate rinse and a water rinse.

For the outcome of mortality, we found no evidence of a difference between povidone iodine rinse and saline/placebo or between saline rinse and usual care. We found some very weak evidence of a difference between saline rinse and saline swab.

For the duration of ventilation, we found no evidence of a difference between saline rinse and usual care, and some weak evidence that saline rinse leads to shorter duration of ventilation compared to saline swab. For the duration of ICU stay, we found no evidence of a difference between povidone iodine and saline/placebo or between saline rinse and usual care.

\section{Overall completeness and applicability of evidence}

In this review, we have included studies that compared active oral hygiene care interventions with either placebo or usual care. We recognise that the use of a placebo is a better control comparison in research studies because it enables the masking of caregivers to whether group participants are in the active or control group, thus eliminating some possible performance bias. However, we chose to include pragmatic studies where 'usual care' was the control comparator, despite recognising that in many instances 'usual care' was not specified and may have varied between participants and between individual caregivers. Where there was no blinding, we assessed studies as being at high risk of performance and detection bias.

There are some other variables that may have influenced the outcomes in the included studies. These include the number of episodes of $\mathrm{OHC}$ a day, the 'dose' of the antiseptic, and whether participants were dentate or edentulous. Most of the studies stated that they delivered between two and four episodes of $\mathrm{OHC}$ per day. Nine studies specified that edentulous people were excluded, one study focussed on newborns, but most of the included studies did not report whether or not participants were dentate. We investigated whether there was a dose-response effect and could find no evidence for this.

We also recognise that participation in a research study is likely to have a positive effect on the performance of 'usual care', improving both the quality of care and compliance with routine practice - a Hawthorne effect (McCarney 2007). The combination of a 'usualcare' control group, the absence of caregiver blinding in most cases, and the Hawthorne effect of being part of a study may have reduced the observed difference in effect between the active and control interventions in these studies. None of the studies included in this review reported compliance with oral hygiene care protocols.

Another area of variability between the studies (and possibly also between studies and usual practice) is the diagnosis of VAP, which is at least partly subjective and may be based on variable diagnostic criteria. Most of the included studies stated the criteria used to diagnose VAP, of which the two most common were the original or modified version of the clinical pulmonary infection score (CPIS) based on Pugin's criteria (Cook 1998; Pugin 1991) and Centers for Disease Control (CDC) criteria as described in Horan 2008. Five studies conducted in China used Chinese Society of Respiratory Diseases (CSRD) criteria for diagnosis of VAP (Feng 2012; Mo 2016; Tang 2013; Xu 2007; Xu 2008).

Currently there is no clearly accepted gold standard for the diagnosis of VAP, and when different criteria are applied to the same cohort of patients, the estimated VAP prevalence could vary widely (Klompas 2007). In light of the limited sensitivity and specificity of the traditional VAP diagnosis, the US Centers for Disease Control (CDC) has developed a new surveillance criterion, ventilatorassociated event (VAE), to incorporate all complications (including VAP) leading to the worsening of gas exchange in mechanicallyventilated patients. However, the advent of a more objective and definitive diagnosis of VAP may depend on further development of biomarker technologies, which may not occur in the near future (Waters 2015).

This review has not found evidence that oral hygiene care including both toothbrushing and chlorhexidine is different from oral hygiene care with chlorhexidine alone in reducing VAP. Only one of the trials of toothbrushing that reported the outcome of VAP also reported plaque levels as an indicator of the effectiveness of the toothbrushing carried out in this trial (Yao 2011). This small trial (53 participants), which we assessed as being at high risk of bias, did 
not use chlorhexidine in either group, and found a reduction in both plaque and VAP in the powered toothbrushing group compared to the non-toothbrushing group. Three other trials of toothbrushing in our meta-analysis (De Lacerda 2017 (manual), Lorente 2012 (manual), Pobo 2009 (powered toothbrush)), with a combined total of 796 participants, included exposure to chlorhexidine in both intervention and control groups. Meta-analysis of these four trials with high risk of bias showed no evidence of a difference in the outcome of VAP (analyses not shown). A further study (Roca Biosca 2011), included in this review and also at high risk of bias, could not be included in the meta-analysis, but also found no difference between oral care with chlorhexidine and toothbrushing and oral care with chlorhexidine alone. All six of these studies described the toothbrushing intervention in detail, and noted that nurses delivering the intervention received specific training. While the presence of ventilator tubes in the mouths of trial participants makes effective toothbrushing difficult, it seems likely that, despite this, the toothbrushing intervention was carried out thoroughly within these trials.

Earlier cohort studies noted that patients in ICU who developed VAP were likely to have increased length of stay in the ICU (Apostolopoulou 2003; Cook 1998). However, our Cochrane Review has not evaluated duration of ICU stay in patients who develop VAP. The studies in our review reported mean length of ICU stay and the standard deviation for each arm of the study. We have combined these in meta-analyses based on an assumption that the duration of ICU stay in each arm of each trial follows an approximately normal distribution. In fact, the distribution of duration of stay in ICU is likely to be skewed, and the means are likely to be a poor indicator of the effect of oral hygiene care on duration of ICU stay.

Our review did not consider the cost-effectiveness of the interventions, but may explore this in the next update of the review.

The increasing incidence of bacteria that are resistant to current antibiotics is of concern worldwide, and one of the reasons for bacterial resistance is the overuse of systemic antibiotics (Gyssens 2011). Oral hygiene care, using antiseptics such as chlorhexidine to reduce the risk of VAP, could potentially also result in a reduced requirement for these patients to be treated with systemic antibiotics. Because only three of the 40 studies included in this review provided data about the use of systemic antibiotics in study participants, we do not have sufficient information to determine whether there was any effect on systemic antibiotic use.

It is interesting that only one of the studies that evaluated chlorhexidine reported adverse reactions to chlorhexidine (mild reversible irritation of the oral mucosa) (Tantipong 2008). Hypersensitivity is a rare but potentially severe side effect of chlorhexidine (Pemberton 2012). In over 2000 participants included in these studies, there was no report of hypersensitivity to chlorhexidine. However, it is notable that in six of the included studies (De Lacerda 2017; Khaky 2018; Kusahara 2012a; Meidani 2018; Ozcaka 2012; Scannapieco 2009), a prior history of hypersensitivity to chlorhexidine was an exclusion criterion during participant recruitment. In view of reports in the UK of two cases of serious adverse events associated with irrigation of dry socket with chlorhexidine mouthrinse, it is recommended that all members of the dental team prescribing chlorhexidine products are aware of the potential for both minor and serious adverse effects (Pemberton 2012).

\section{Quality of the evidence}

For the first main comparison of interest in this review (comparison between chlorhexidine and placebo/usual care), although only one of the trials was assessed at low risk of bias (Koeman 2006) for all domains, we did not consider that the impact of bias reduced our confidence in the outcome of VAP incidence and mortality, because sensitivity analysis according to risk of bias did not alter the size or direction of the effect. However, due to substantial heterogeneity and serious imprecision, we considered the certainty of the evidence for VAP incidence and mortality to be moderate. We downgraded the certainty of evidence for duration of ICU stay and duration of ventilation to low and very low, mainly because of serious imprecision, substantial heterogeneity and high risk of bias. Most studies did not provide information on adverse events, and the scant information we could obtain from two studies prompted us to downgrade the certainty of evidence to very low (see Summary of findings 1).

For the second main comparison of interest (comparison between toothbrushing and no toothbrushing), all of the included trials were at high risk of bias. Therefore, we considered the certainty of evidence for incidence of VAP, mortality, duration of ventilation and duration of ICU stay to be low or very low, mainly due to the existence of very serious risk of bias, substantial heterogeneity and/ or serious imprecision. Also, as only two studies provided limited information on adverse events, we downgraded the certainty of evidence for adverse effects to very low (see Summary of findings 2).

\section{Potential biases in the review process}

In order to reduce the risk of publication bias, we conducted a broad search for both published and unpublished studies, with no restrictions on language. We searched the reference lists of included studies and contacted many of the study authors in order to obtain information that was not included in the published reports. We also searched the reference lists of other published reviews of oral hygiene care for critically ill patients. However, our search strategy did not include the term 'mortality'. It is possible that studies looked at $\mathrm{OHC}$ and all-cause mortality without mentioning 'VAP' or 'pneumonia', and these may not have been identified by our searches. To our knowledge, we have not missed any studies, but we will therefore consider adding mortality-related terms to our search strategy in the next update of this review, to ensure that all potentially eligible studies can be identified and assessed.

For this review we also chose very broad inclusion criteria, which has resulted in a clinically heterogeneous group of studies including adults, children and neonates, and a range of indications for ICU care, including medical conditions, surgery and trauma where patients were ventilated for over 48 hours. In some of the included studies, the precise details of what was involved in the oral hygiene care intervention were poorly described, making it difficult to determine the similarity between studies in oral hygiene care practices. There was also potential variation in the methods used for intubation and for the calculation of duration outcomes (e.g. duration of mechanical ventilation, duration of ICU stay) (Contentin 2014), both of which were not always clearly specified.

One other potential bias in this review is the variation in and the subjective nature of criteria/methods used for VAP diagnosis 
(Klompas 2007). Also, we have made a number of changes to the methods of this review since the publication of the protocol (see Differences between protocol and review). Some of these changes were clarifications, and some were undertaken to take account of other Cochrane Reviews published or in preparation, to avoid unnecessary duplication of effort. We acknowledge that post hoc changes to the review methods may introduce a risk of bias into this review.

\section{Agreements and disagreements with other studies or reviews}

A previous meta-analysis by Pineda 2006 found that the use of chlorhexidine for oral decontamination did not reduce the incidence of nosocomial pneumonia. However, their meta-analysis included only four studies and the outcome was nosocomial pneumonia rather than VAP. Another systematic review by Labeau 2011 included 14 studies of either chlorhexidine or povidone iodine antiseptics and found that the use of antiseptics as part of oral hygiene care reduced the incidence of VAP by approximately onethird. Our review confirmed these findings.

One systematic review looked at the effects of selective digestive/ oropharyngeal decontamination and topical oropharyngeal chlorhexidine on the prevention of death in general intensive care (Price 2014), and claimed that CHX may be associated with increased mortality (odds ratio (OR) $1.25,95 \% \mathrm{Cl} 1.05$ to 1.50 ). Reasons for the discrepancy between this finding and ours mainly include differences in the review scope (e.g. whether focussed on adults, general intensive care only) and review methodology (e.g. requiring that participants were ventilated for at least 48 hours, inclusion of studies for which only abstracts were available). In a recent cluster-randomised trial, Wittekamp and colleagues studied the effects of decontamination strategies on ventilated patients in ICUs with moderate to high levels of antibiotic resistance, and found no significant difference in 28-day mortality between $\mathrm{CHX}$ mouthrinse and standard care (Wittekamp 2018). However, the primary focus of this trial was bloodstream infections caused by multidrug-resistant gram-negative bacteria, and its design and methodology did not meet our eligibility criteria. More trials are needed of the association between CHX usage and ICU mortality, to provide more insight into this issue.

Another two systematic reviews have looked at the effects of chlorhexidine with different concentrations. One claimed that the use of higher concentration chlorhexidine was associated with higher mortality (Klompas 2014), and the other stated that chlorhexidine with the concentration of $0.12 \%$ had the best effect in reducing VAP incidence (Zhang 2013). However, these findings were all based on trivial differences in point estimates, with wide confidence intervals for each estimate and statistically non-significant differences between concentrations. The results of our sensitivity analyses do not support the dose-response relationships that they proposed, and confirm that differences between concentrations were statistically non-significant.

Although this review found evidence that the use of chlorhexidine as part of oral care reduces the incidence of VAP, there was no evidence of a reduction in mortality. This is in contrast to a review by Price 2014 which claimed that $\mathrm{CHX}$ is possibly associated with increased mortality. There has been some debate in the literature about the attributable mortality of VAP. In 2017, the panel of ERS/ESICM/ESCMID/ALAT guidelines noticed an unclear balance between potential reduction in VAP incidence and potential increase in mortality, and therefore decided not to issue a recommendation on the use of chlorhexidine in oral decontamination until more safety data become available (Torres 2017).

\section{AUTHORS' CONCLUSIONS}

\section{Implications for practice}

Effective oral hygiene care is important for ventilated patients in intensive care to reduce ventilator-associated pneumonia. The definition of oral hygiene care varied among the studies included in this review, but common elements included cleaning of the teeth and gums with a swab or gauze, toothbrushing, and rinsing the mouth. Compared with placebo/usual care, chlorhexidine mouthwash or gel, as part of $\mathrm{OHC}$, probably reduces the incidence of developing ventilator-associated pneumonia in critically ill patients from $26 \%$ to about $18 \%$. However, there is no evidence of a benefit for mortality or duration of mechanical ventilation or ICU stay. Low-certainty evidence suggests that $\mathrm{OHC}$ including both antiseptics and toothbrushing may be more effective than $\mathrm{OHC}$ with antiseptics alone for reducing VAP incidence and length of ICU stay, but there was no evidence for a reduction in mortality or duration of mechanical ventilation. There is insufficient evidence to determine whether any of the interventions evaluated in the studies are associated with adverse effects.

\section{Implications for research}

Although the included studies provided some evidence for the benefits of oral hygiene care for critically ill patients to prevent ventilator-associated pneumonia, incomplete reporting of studies is a major limitation. More consistent use of the CONSORT statement for reporting of randomised controlled trials (CONSORT 2012) would increase the value of research.

1. Detailed reporting of methods, such as generation of allocation sequence, allocation concealment, and numbers and reasons for withdrawals and exclusions.

2. Use of a placebo where possible to enable blinding.

3. Full reporting of methods used to diagnose ventilatorassociated pneumonia.

4. Reporting of adverse effects of interventions.

Further trials of oral hygiene care (including use of manual or powered toothbrushes, or swabs) should use well-defined outcomes including both measures of effectiveness of plaque removal and prevention of ventilator-associated pneumonia. They should also state explicitly whether those patients who have died during the study were included in the calculation of duration outcomes (e.g. duration of ICU stay, duration of mechanical ventilation), and describe in detail the type and frequency of all interventions given to participants (especially 'usual care').

Future studies may also consider adopting the new definitions and diagnostic criteria (ventilator-associated event, VAE) developed by the US CDC (Waters 2015), which is likely to overcome the limitations of traditional VAP diagnosis and facilitate high-quality synthesis of research findings. 


\section{A C K N OWLEDGEMENTS}

For the 2020 update, we would like to thank Philip Riley, Ana Jeroncic, Anne-Marie Glenny, Laura MacDonald and Janet Lear at Cochrane Oral Health, as well as Jennifer Hilgart, Richard Price, Julián Balanta-Melo and SK Sidhu for their helpful commentsm and Anne Lethaby for copy editing.

We would also like to thank Anne Littlewood, Information Specialist of Cochrane Oral Health $(\mathrm{COH})$, for refining search strategies and providing searching results from the databases of COH's Trials Register, CENTRAL, MEDLINE, Embase, LILACS, CINAHL, ClinicalTrials.gov and the WHO International Clinical Trials Registry Platform. For help with the translations of foreign papers, our thanks go to Sepideh Banava (Persian), Kim Kun Hyung (Korean), Luisa Fernandez-Mauleffinch (Portuguese) and Roca Biosca (Spanish).

We would like to acknowledge the contributions of Zongdao Shi, Ping Wang, Yan Wu, E Chen, Linda $\mathrm{Ng}$ and Ian Needleman as authors of the original review published in 2013 (Shi 2013), and the contributions of Susan Furness and Huixu Xie as authors of the 2016 update (Hua 2016). 


\section{R E F E R E N C E S}

\section{References to studies included in this review}

Bellissimo-Rodrigues 2009 \{published data only\}

Bellissimo-Rodrigues F, Bellissimo-Rodrigues WT, Viana JM, Teixeira GC, Nicolini E, Auxiliadora-Martins M, et al. Effectiveness of oral rinse with chlorhexidine in preventing nosocomial respiratory tract infections among intensive care unit patients. Infection Control \& Hospital Epidemiology 2009;30(10):952-8.

Berry 2011 \{published data only\}

Berry AM, Davidson PM, Masters J, Rolls K, Ollerton R. Effects of three approaches to standardized oral hygiene to reduce bacterial colonization and ventilator associated pneumonia in mechanically ventilated patients: a randomised control trial. International Journal of Nursing Studies 2011;48(6):681-8.

\section{Berry 2013 \{published data only\}}

Berry A M. A comparison of Listerine and sodium bicarbonate oral cleansing solutions on dental plaque colonisation and incidence of ventilator associated pneumonia in mechanically ventilated patients: a randomised control trial. Intensive \& Critical Care Nursing 2013;29(5):275-81.

\section{Bopp 2006 \{published data only\}}

Bopp M, Darby M, Loftin KC, Broscious S. Effects of daily oral care with $0.12 \%$ chlorhexidine gluconate and a standard oral care protocol on the development of nosocomial pneumonia in intubated patients: a pilot study. Journal of Dental Hygiene 2006;80(3):9.

\section{Cabov 2010 \{published and unpublished data\}}

Cabov T, Macan D, Husedzinovic I, Skrlin-Subic J, Bosnjak D, Sestan-Crnek S, et al. The impact of oral health and $0.2 \%$ chlorhexidine oral gel on the prevalence of nosocomial infections in surgical intensive-care patients: a randomized placebo-controlled study. Wiener Klinische Wochenschrift 2010;122(13-14):397-404.

\section{Caruso 2009 \{published data only\}}

Caruso P, Denari S, Ruiz SAL, Demarzo SE, Deheinzelin D. Saline instillation before tracheal suctioning decreases the incidence of ventilator-associated pneumonia. Critical Care Medicine 2009:37(1):32-8

\section{Dahiya 2012 \{published data only\}}

Dahiya U. Decontamination with chlorhexidine gluconate reduces the incidence of ventilator associated pneumonia. Nursing Journal of India 2012;103:89-91.

\section{De Lacerda 2017 \{published data only\}}

De Lacerda Vidal CF, Vidal AK de L, Monteiro JG de M, Cavalcanti A, Henriques AP de C, Olveira M, et al. Impact of oral hygiene involving toothbrushing versus chlorhexidine in the prevention of ventilator-associated pneumonia: a randomized study. BMC Infectious Diseases 2017;17:112 [Erratum appears in BMC Infect Dis. 2017 Feb 27;17 (1):173; PMID: 28241748].
Feng 2012 \{published data only\}

Feng S, Sun X, Chen Y. Application of different mouthwashes in oral nursing for patients with orotracheal intubation. China Medicine and Pharmacy 2012;8(2):100-1.

Fields 2008 \{published data only\}

Fields LB. Oral care intervention to reduce incidence of ventilator-associated pneumonia in the neurologic intensive care unit. Journal of Neuroscience Nursing 2008;40(5):291-8.

Fu 2019 \{published data only\}

Fu T, Zhong Q, Zheng C. Bacteriostasis effect of oral administration of chlorhexidine on patients with mechanical ventilation and prevention and treatment of ventilator - associated pneumonia. Chinese Nursing Research 2019;33(3):431-4.

\section{Grap 2011 \{published data only\}}

Grap MJ, Munro CL, Hamilton VA, Elswick RK Jr, Sessler CN, Ward KR. Early, single chlorhexidine application reduces ventilator-associated pneumonia in trauma patients. Heart \& Lung 2011;40(5):e115-22.

\section{Hanifi 2017 \{published data only\}}

Hanifi N, Masoumi M, Jamshidi MR, Faghihzadeh S. The effect of ozonated water and chlorhexidine gluconate on prevention of ventilator-associated pneumonia: a double-blind, randomized, clinical trial. Iranian Red Crescent Medical Journal 2017;19(10):e60576.

\section{Hu 2009 \{published data only\}}

Hu X, Chen X. Application of improved oral nursing method to orotracheal intubation. Chinese Journal of Misdiagnostics 2009;9(17):4058-9.

\section{Irani 2019 \{published data only\}}

Irani H, Sargazi G, Dahmardeh AR, Mofrad ZP. The effect of oral care with miswak versus chlorhexidine on the incidence of ventilator-associated pneumonia: a clinical trial study. MedicalSurgical Nursing Journal 2019;8(4):e100387.

\section{Khaky 2018 \{published data only\}}

Khaky B, Yazdannik A, Mahjobipoor H. Evaluating the efficacy of nanosil mouthwash on the preventing pulmonary infection in intensive care unit: a randomized clinical trial. Medicinski Arhiv 2018;72:206-9.

\section{Koeman 2006 \{published data only\} \\ * Koeman M, Van der Ven AJ, Hak E, Joore HC, Kaasjager K, De Smet AG, et al. Oral decontamination with chlorhexidine reduces the incidence of ventilator-associated pneumonia. American Journal of Respiratory \& Critical Care Medicine 2006;173(12):1348-55}

Koeman M, Van der Ven AJ, Hak E, Joore JC, Kaasjager HA, De Smet AM, et al. Less ventilator-associated pneumonia after oral decontamination with chlorhexidine; a randomised trial. Nederlands Tijdschrift voor Geneeskunde 2008;152(13):752-9. 
Kusahara 2012a \{published data only\}

* Kusahara DM, Peterlini MA, Pedreira ML. Oral care with $0.12 \%$ chlorhexidine for the prevention of ventilator-associated pneumonia in critically ill children: randomised, controlled and double blind trial. International Journal of Nursing Studies 2012;49(11):1354-63.

Kusahara DM, Peterlini MAS, Pedreira MLG. Randomized, controlled and double blinded trial of oral decontamination with $0.12 \%$ chlorhexidine for the prevention of ventilatorassociated pneumonia in children. Pediatric Critical Care Medicine 2011;12(3, Suppl 1):A16.

Pedreira MLG, Kusahara DM, De Carvalho WB, Nunez SC, Peterlini MAS. Oral care interventions and oropharyngeal colonization in children receiving mechanical ventilation. American Journal of Critical Care 2009;18(4):319-29.

Long 2012 \{published data only\}

Long Y, Mou G, Zuo Y, Iv F, Feng Q, Du J. Effect of modified oral nursing method on the patients with orotracheal intubation. Journal of Nurses Training 2012;27(24):2290-3.

\section{Lorente 2012 \{published data only\}}

Lorente L, Lecuona M, Jimenez A, Palmero S, Pastor E, Lafuente $\mathrm{N}$, et al. Ventilator-associated pneumonia with or without toothbrushing: a randomized controlled trial. European Journal of Clinical Microbiology and Infectious Diseases 2012;31(10):2621-9.

\section{Meidani 2018 \{published data only\}}

Meidani M, Khorvash F, Abbasi S, Cheshmavar M, Tavakoli H. Oropharyngeal irrigation to prevent ventilator-associatedpneumonia: comparing potassium permangenate with chlorhexidine. International Journal of Preventive Medicine 2018;9(1):93.

\section{Meinberg 2012 \{published data only\}}

Meinberg MC, Cheade M de F, Miranda AL, Fachini MM, Lobo SM. The use of $2 \%$ chlorhexidine gel and toothbrushing for oral hygiene of patients receiving mechanical ventilation: effects on ventilator-associated pneumonia [Uso de clorexidina $2 \%$ gel e escovacao mecanica na higiene bucal de pacientes sob ventilacao mecanica: efeitos na pneumonia associada a ventilador]. Revista Brasileira de Terapia Intensiva 2012;24(4):369-74. [PMID: 23917935]

\section{Mo 2016 \{published data only\}}

Mo ZD, Li XL, Ke JY, Wu JP, Chen XW. Analysis of risk factors in ventilator-associated pneumonia and preventive effect of oral care. Chinese Journal of Nosocomiology 2016;26(3):698-9, 705.

\section{Nobahar 2016 \{published data only\}}

Nobahar M, Razavi Mohammad R, Malek F, Ghorbani R. Effects of hydrogen peroxide mouthwash on preventing ventilator-associated pneumonia in patients admitted to the intensive care unit. Brazilian Journal of Infectious Diseases 2016;20:444-50. [1413-8670]

\section{Ozcaka 2012 \{published data only\}}

Ozcaka O, Basoglu OK, Buduneli N, Tasbakan MS, Bacakoglu F, Kinane DF. Chlorhexidine decreases the risk of ventilatorassociated pneumonia in intensive care unit patients: a randomized clinical trial. Journal of Periodontal Research 2012;47(5):584-92.

Panchabhai 2009 \{published data only\}

Panchabhai TS, Dangayach NS, Krishnan A, Kothari VM, Karnad DR. Oropharyngeal cleansing with $0.2 \%$ chlorhexidine for prevention of nosocomial pneumonia in critically ill patients: an open-label randomized trial with $0.01 \%$ potassium permanganate as control. Chest 2009;135(5):1150-6.

Pobo 2009 \{published data only\}

Pobo A, Lisboa T, Rodriguez A, Sole R, Magret M, Trefler S, et al. A randomized trial of dental brushing for preventing ventilatorassociated pneumonia. Chest 2009;136(2):433-9.

Prendergast 2012 \{published data only\}

Prendergast V, Hagell P, Hallberg IR. Electric versus manual tooth brushing among neuroscience ICU patients: is it safe? Neurocritical Care 2011;14(2):281-6.

* Prendergast V, Hallberg IR, Jakobsson U, Renvert S, Moran A, Gonzalez O. Comparison of oropharyngeal and respiratory nosocomial bacteria between two methods of oral care: a randomized controlled trial. Journal of Neuroscience and Neurosurgical Nursing 2012;1(1):10-8.

Prendergast V, Jakobsson U, Renvert S, Hallberg IR. Effects of a standard versus comprehensive oral care protocol among intubated neuroscience ICU patients: results of a randomized controlled trial. Journal of Neuroscience Nursing 2012;44(3):134-46.

Prendergast V. Safety and efficacy of oral care for intubated neuroscience intensive care patients. In: Doctoral Dissertation Series 2012-3. Lund, Sweden: Lund University, 2012:1-86.

\section{Roca Biosca 2011 \{published data only\}}

Roca Biosca A, Anguera Saperas L, García Grau N, Rubio Rico L, Velasco Guillén MC. Prevention of mechanical ventilatorassociated pneumonia: a comparison of two different oral hygiene methods. Enfermería Intensiva 2011;22(3):104-11.

\section{Scannapieco 2009 \{published data only\}}

Scannapieco FA, Yu J, Raghavendran K, Vacanti A, Owens SI, Wood K, et al. A randomized trial of chlorhexidine gluconate on oral bacterial pathogens in mechanically ventilated patients. Critical Care 2009;13(4):R117.

\section{Seguin 2006 \{published data only\}}

Seguin P, Tanguy M, Laviolle B, Tirel O, Malledant Y. Effect of oropharyngeal decontamination by povidone-iodine on ventilator-associated pneumonia in patients with head trauma. Critical Care Medicine 2006;34(5):1514-9.

\section{Seguin 2014 \{published data only\}}

Seguin P, Laviolle B, Dahyot-Fizelier C, Dumont R, Veber B, Gergaud $S$, et al. Effect of oropharyngeal povidone-iodine preventive oral care on ventilator-associated pneumonia in 
severely brain-injured or cerebral hemorrhage patients: a multicenter, randomized controlled trial. Critical Care Medicine 2014;42:1-8.

\section{Stefanescu 2013 \{published data only\}}

Stefanescu BM, Hétu C, Slaughter JC, O'Shea TM, Shetty AK. A pilot study of Biotene OralBalance gel for oral care in mechanically ventilated preterm neonates. Contemporary Clinical Trials 2013;35(2):33-9.

Tang 2013 \{published data only\}

Tang J, Chen SL, Deng JL. Efficacy of mouth cavity irrigation in prevention of ventilator-associated pneumonia. Chinese Journal of Nosocomiology 2013;23(17):4119-21.

\section{Tantipong 2008 \{published data only\}}

Silvestri L, Van Saene HK, Milanese M, Zei E, Blazic M. Prevention of ventilator-associated pneumonia by use of oral chlorhexidine. Infection Control \& Hospital Epidemiology 2009;30(1):101-3.

* Tantipong H, Morkchareonpong C, Jaiyindee S, Thamlikitkul V. Randomized controlled trial and meta-analysis of oral decontamination with $2 \%$ chlorhexidine solution for the prevention of ventilator-associated pneumonia. Infection Control \& Hospital Epidemiology 2008;29(2):131-6.

Tuon 2017 \{published data only\}

Tuon FF, Gavrilko O, Almeida S, Sumi ER, Alberto T, Rocha JL, et al. Prospective, randomised, controlled study evaluating early modification of oral microbiota following admission to the intensive care unit and oral hygiene with chlorhexidine. Journal of Global Antimicrobial Resistance 2017;8:159-63.

\section{Xu 2007 \{published data only\}}

Xu J, Feng B, He L, Shen H, Chen XY. Influence of different oral nursing methods on ventilator-associated pneumonia and oral infection in the patients undergoing mechanical ventilation. Journal of Nursing Science 2007;7(22):56-7.

\section{Xu 2008 \{published data only\}}

$\mathrm{Xu} \mathrm{HL}$. Application of improved oral nursing method to the prevention of ventilator-associated pneumonia. Journal of Qilu Nursing 2008;14(19):15-6.

\section{Yao 2011 \{published data only\}}

Yao L, Chang C, Wang C, Chen C. Effect of an oral care protocol in preventing ventilator associated pneumonia in ICU patients. Critical Care 2008;12(Suppl 2):Abs No P48.

* Yao LY, Chang CK, Maa SH, Wang C, Chen CC. Brushing teeth with purified water to reduce ventilator-associated pneumonia. Journal of Nursing Research 2011;19(4):289-97.

\section{Zhao 2012 \{published data only\}}

Zhao Y. Research on application of Yikou gargle in prevention of ventilation associated pneumonia. Chinese Journal of Nosocomiology 2012;23(22):5232-3.

\section{References to studies excluded from this review}

Abusibeih 2010 \{published data only\}

Abusibeih A, Lev A. Randomized control trial comparing oral care methods and VAP. Intensive Care Medicine 2010;36:S329.

Anon 2012 \{published data only\}

Anon. EB57 Development of an oral care-based programme for prevention of ventilator-associated pneumonia. Critical Care Nurse 2012;32(2):e34.

\section{Atashi 2018 \{published data only\}}

Atashi V, Yousefi H, Mahjobipoor H, Bekhradi R, Yazdannik A. Effect of oral care program on prevention of ventilatorassociated pneumonia in intensive care unit patients: a randomized controlled trial. Iranian Journal of Nursing and Midwifery Research 2018;23(6):486-90.

Baradari 2012 \{published data only\}

Baradari AG, Khezri HD, Arabi S. Comparison of antibacterial effects of oral rinses chlorhexidine and herbal mouth wash in patients admitted to intensive care unit. Bratislavske Lekarske Listy 2012;113(9):556-60.

\section{Bellissimo-Rodrigues 2014 \{published data only\}}

Bellissimo-Rodrigues WT, Menegueti MG, Gaspar GG, Nicolini EA, Auxiliadora-Martins M, Basile-Filho A, et al. Effectiveness of a dental care intervention in the prevention of lower respiratory tract nosocomial infections among intensive care patients: a randomized clinical trial. Infection Control and Hospital Epidemiology 2014;35(11):1342-8.

\section{Bordenave 2011 \{published data only\}}

Bordenave C. Evaluation of the effectiveness of a protocol of intensification of mouth care (teeth brushing and chlorhexidine $0.12 \%$ ) on the colonisation of tracheal aspirations in intubated and ventilated patients in intensive care. Recherche en Soins Infirmiers 2011;2011(106):92-8.

\section{Buckley 2013 \{published data only\}}

Buckley MS, Dzierba AL, Smithburger PL, McAllen KJ, Jordan CJ, Kane-Gill SL. Chlorhexidine for the prevention of ventilator associated pneumonia in critically ill adults. Journal of Infection Prevention 2013;14:162-9.

\section{Chao 2009 \{published data only\}}

Chao YC, Chen Y, Wang KK, Lee R, Tsai H. Removal of oral secretion prior to position change can reduce the incidence of ventilator-associated pneumonia for adult ICU patients: a clinical controlled trial study. Journal of Clinical Nursing 2009;18(1):22-8.

\section{Chen 2008 \{published data only\}}

Chen QL, Ye XF, Jiang YZ, Yan MQ. Application of new oral care method to orotracheal intubation. Fujian Medical Journal 2008;30(5):155-7.

\section{Da Collina 2017 \{published data only\}}

Da Collina GA, Tempestini-Horliana ACR, Da Silva DFT, Longo PL, Makabe MLF, Pavani C. Oral hygiene in intensive care unit patients with photodynamic therapy: study protocol for 
randomised controlled trial. Trials [electronic resource] 2017;18:385.

\section{Dale 2019 \{published data only\}}

Dale CM, Rose L, Carbone S, Smith OM, Burry L, Fan E, et al. Protocol for a multi-centered, stepped wedge, cluster randomized controlled trial of the de-adoption of oral chlorhexidine prophylaxis and implementation of an oral care bundle for mechanically ventilated critically ill patients: the CHORAL study. Trials 2019;20(1):603.

\section{Darnell 2015 \{published data only\}}

Darnell J. EB44 TMI: Reducing ventilator-associated pneumonia in the surgical intensive care unit. Critical Care Nurse 2015;35:e20.

\section{DeRiso 1996 \{published data only\}}

DeRiso AJ 2nd, Ladowski JS, Dillon TA, Justice JW, Peterson AC. Chlorhexidine gluconate $0.12 \%$ oral rinse reduces the incidence of total nosocomial respiratory infection and nonprophylactic systemic antibiotic use in patients undergoing heart surgery. Chest 1996;109(6):1556-61.

\section{Epstein 1994 \{published data only\}}

Epstein J, Ransier A, Lunn R, Spinelli J. Enhancing the effect of oral hygiene with the use of a foam brush with chlorhexidine. Oral Surgery, Oral Medicine, Oral Pathology 1994;77(3):242-7.

\section{Fan 2012 \{published data only\}}

Fan T. The effect of a modified oral nursing care method on prevention of ventilator associated pneumonia. Nursing Practice and Research 2012;9(12):99-100.

\section{Fan 2015 \{published data only\}}

Fan YL, Chang QF, Zhang L. Research of oropharyngeal cleaning methods for ventilator associated pneumonia. Chinese Journal of Nosocomiology 2015;25(12):2777-9.

\section{Ferozali 2007 \{published data only\}}

Ferozali F, Johnson G, Cavagnaro A. Health benefits and reductions in bacteria from enhanced oral care. Special Care in Dentistry 2007;27(5):168-76.

\section{Fourrier 2000 \{published data only\}}

Fourrier F, Cau-Pottier E, Boutigny H, Roussel-Delvallez M, Jourdain M, Chopin C. Effects of dental plaque antiseptic decontamination on bacterial colonization and nosocomial infections in critically ill patients. Intensive Care Medicine 2000;26(9):1239-47.

\section{Fourrier 2005 \{published data only\}}

Fourrier F, Dubois D, Pronnier P, Herbecq P, Leroy O, Desmettre $T$, et al. Effect of gingival and dental plaque antiseptic decontamination on nosocomial infections acquired in the intensive care unit: a double-blind placebo-controlled multicenter study. Critical Care Medicine 2005;33(8):1728-35.

\section{Genuit 2001 \{published data only\}}

Genuit T, Bochicchio G, Napolitano LM, McCarter RJ, Roghman MC. Prophylactic chlorhexidine oral rinse decreases ventilator-associated pneumonia in surgical ICU patients. Surgical Infections 2001;2(1):5-18.

Grap 2004 \{published data only\}

Grap MJ, Munro CL, Elswick RK Jr, Sessler CN, Ward KR. Duration of action of a single, early oral application of chlorhexidine on oral microbial flora in mechanically ventilated patients: a pilot study. Heart \& Lung 2004;33(2):83-91.

\section{Gu 2013 \{published data only\}}

Gu WJ, Liu JC. Toothbrushing for critically ill mechanically ventilated patients: a duplicated trial included? Critical Care Medicine 2013;41(7):e137-8.

Guo 2007 \{published data only\}

Guo MJ. Study on the new oral nursing for the patient of acute lung brain-storm through tracheal. Chinese Journal of Mordern Nursing 2007;13(26):2537-8.

\section{Guo 2017 \{published data only\}}

Guo S, Xie L, Chen K, Ke C, Dai D, Zhang X, et al. The effects of oral care using hydrogen peroxide combined with sodium bicarbonate on neonatal ventilator associated pneumonia. Chinese Journal of Nursing 2017;52(6):645-8.

\section{Haghighi 2017 \{published data only\}}

Haghighi A, Shafipour V, Bagheri-Nesami M, Gholipour Baradari A, Yazdani Charati J. The impact of oral care on oral health status and prevention of ventilator-associated pneumonia in critically ill patients. Australian Critical Care 2017;30:69-73.

\section{Houston 2002 \{published data only\}}

Houston S, Hougland P, Anderson JJ, LaRocco M, Kennedy V, Gentry LO. Effectiveness of $0.12 \%$ chlorhexidine gluconate oral rinse in reducing prevalence of nosocomial pneumonia in patients undergoing heart surgery. American Journal of Critical Care 2002;11(6):567-70.

\section{Jacomo 2011 \{published data only\}}

Jacomo AD, Carmona F, Matsuno AK, Manso PH, Carlotti AP. Effect of oral hygiene with $0.12 \%$ chlorhexidine gluconate on the incidence of nosocomial pneumonia in children undergoing cardiac surgery. Infection Control \& Hospital Epidemiology 2011;32(6):591-6.

\section{Jafari 2007 \{published data only\}}

Jafari S, Ranjbar H, Kamrani F, Alavi-Majd H, Yaghmaei F. Effects of chlorhexidine and normal saline on dental plaque formation in ICU patients: a comparative study. Journal of Nurse Midwifery 2007;17(56):36-43.

\section{Kusahara 2012b \{published data only\}}

Kusahara DM, Friedlander LT, Peterlini MAS, Pedreira MLG. Oral care and oropharyngeal and tracheal colonization by Gram-negative pathogens in children. Nursing in Critical Care 2012;17:115-22. 
Labeau 2013 \{published data only\}

Labeau SO, Blot SI. Oral care for mechanically ventilated patients involving toothbrushing. Critical Care Medicine 2013;41(7):e136-7.

\section{Lai 1997 \{published data only\}}

Lai M, Huang $\mathrm{H}$. Toothpaste mouth care for critically ill patients. Journal of Nursing Science 1997;12(2):106-7.

\section{Li 2011 \{published data only\}}

Li W, Ma X, Peng Y, Cao J, Loo WTY, Hao L, et al. Application of a nano-antimicrobial film to prevent ventilator-associated pneumonia: a pilot study. African Journal of Biotechnology 2011;10(10):1926-31.

\section{Li 2012 \{published data only\}}

Li S, Zhang H, Zhang B. Application of different oral nursing methods to prevent ventilation associated pneumonia. Practical Clinical Medicine 2012;13(5):92-3.

\section{Liang 2007 \{published data only\}}

Liang YL, Lu LQ, Liang JT. Oral cavity nursing study in endotracheal intubation with the Baihu decoction. Journal of Nurses Training 2007;1(22):79-80.

\section{Liao 2015 \{published data only\}}

Liao YM, Tsai JR, Chou FH. The effectiveness of an oral health care program for preventing ventilator-associated pneumonia. Nursing in Critical Care 2015;20(2):89-97.

\section{Liwu 1990 \{published data only\}}

Liwu A. Oral hygiene in intubated patients. Australian Journal of Advanced Nursing 1990;7(2):4-7.

\section{MacNaughton 2004 \{published data only\}}

MacNaughton PD, Bailey J, Donlin N, Branfield P, Williams A, Rowswell $\mathrm{H}$. A randomised controlled trial assessing the efficacy of oral chlorhexidine in ventilated patients (029). Intensive Care Medicine 2004;30(Suppl):S12.

\section{Maury 2015 \{published data only\}}

Maury E, London J, Offenstadt G. Community-acquired pneumonia. New England Journal of Medicine 2015;372(3):292.

\section{McCartt 2010 \{published data only\}}

McCartt PAM. Effect of Chlorhexidine Oral Spray versus Mechanical Toothbrushing and Chlorhexindine Rinse in Decreasing Ventilator Associated Pneumonia in Critically III Adults [PhD thesis]. Gainesville, Florida, USA: University of Florida, 2010.

\section{McCoy 2012 \{published data only\}}

McCoy T, Fields W, Kent N. Evaluation of emergency department evidence-based practices to prevent the incidence of ventilatoracquired pneumonia. Journal of Nursing Care Quality 2012;27(1):83-8.

\section{Munro 2009 \{published data only\}}

Munro C, Grap M, Sessler C, McClish D. Effect of oral care interventions on dental plaque in mechanically ventilated ICU adults. American Journal of Critical Care 2007;16(3):309.
* Munro CL, Grap MJ, Jones DJ, McClish DK, Sessler CN. Chlorhexidine, toothbrushing, and preventing ventilatorassociated pneumonia in critically ill adults. American Journal of Critical Care 2009;18(5):428-37.

\section{Munro 2015 \{published data only\}}

Munro CL, Grap MJ, Sessler CN, Elswick RK Jr, Mangar D, Karlnoski-Everall R, et al. Preintubation application of oral chlorhexidine does not provide additional benefit in prevention of early-onset ventilator-associated pneumonia. Chest 2015;147(2):328-34

\section{Nasiriani 2016 \{published data only\}}

Nasiriani K, Torki F, Jarahzadeh MH, Rashidi Maybodi F. The effect of brushing with a soft toothbrush and distilled water on the incidence of ventilator-associated pneumonia in the intensive care unit. Tanaffos 2016;15:101-7. [1735-0344: (Print) // 1735-0344 (Linking)]

\section{NCT01657396 \{unpublished data only\}}

NCT01657396. Implementation and evaluaion of revised protocols for oral hygiene for mechanically ventilated patients [Implementation and evaluation of revised protocols for oral hygiene for mechanically ventilated patients in Alberta Health Services Calgary Region - a pilot project.]. www.clinicaltrials.gov/ct2/show/NCT01657396? term $=01657396 \& d r a w=1 \&$ rank $=1$ (first received 6 August 2012).

\section{Needleman 2011 \{published data only\}}

Needleman IG, Hirsch NP, Leemans M, Moles DR, Wilson M, Ready DR, et al. Randomized controlled trial of toothbrushing to reduce ventilator-associated pneumonia pathogens and dental plaque in a critical care unit. Journal of Clinical Periodontology 2011;38(3):246-52.

\section{Ogata 2004 \{published data only\}}

Ogata J, Minami K, Miyamoto H, Horishita T, Ogawa M, Sata T, et al. Gargling with povidone-iodine reduces the transport of bacteria during oral intubation. Canadian Journal of Anaesthesia 2004;51(9):932-6.

Pawlak 2005 \{published data only\}

Pawlak D, Semar R, Cantos K. Improving frequency of oral care in the medical intensive care unit. American Journal of Infection Control 2005;33(5):E147.

\section{Pelucchi 2013 \{published data only\}}

Pelucchi G, Ciucur M, Giacovelli M, Lucchini A, Luongo M. Ora hygiene [L'igiene del cavo orale]. SCENARIO: Official Italian Journal of ANIARTI 2013;30:23-34.

Pivkina 2014 \{published data only\}

Pivkina AI, Gusarov VG, Zhivotneva IV, Bodunova GE. Oral care in ventilated patients - can we improve it? Intensive Care Medicine 2014;40:S28

\section{Sands 2015 \{published data only\}}

Sands KM, Twigg JA, Wise MP. Oral hygiene with chlorhexidine in critically ill patients. JAMA Internal Medicine 2015;175(2):316. 
Santos 2008 \{published data only\}

Santos PS, Mello WR, Wakim RCS, Paschoal MG. Use of oral rinse with enzymatic system in patients totally dependent in the intensive care unit [Uso de solução bucal com sistema enzimático em pacientes totalmente dependentes de cuidados em unidade de terapia intensiva]. Revista Brasileira de Terapia Intensiva 2008;20(2):154-9.

\section{Sebastian 2012 \{published data only\}}

Sebastian MR, Lodha R, Kapil A, Kabra SK. Oral mucosal decontamination with chlorhexidine for the prevention of ventilator-associated pneumonia in children - a randomized, controlled trial. Pediatric Critical Care Medicine 2012;13(5):e305-10.

\section{Segers 2006 \{published data only\}}

Segers P, Speekenbrink RG, Ubbink DT, Van Ogtrop ML, De Mol BA. Prevention of nosocomial infection in cardiac surgery by decontamination of the nasopharynx and oropharynx with chlorhexidine gluconate: a randomized controlled trial. JAMA 2006;296(20):2460-6.

\section{Seo 2011 \{published data only\}}

Seo HK, Choi EH, Kim JH. The effect of oral hygiene for ventilator-associated pneumonia (VAP) incidence. Journal of Korean Critical Care Nursing 2011;4(2):1.

\section{Swartz 2015 \{published data only\}}

Swartz AW. Community-acquired pneumonia. New England Journal of Medicine 2015;372(3):293.

\section{Tattevin 2015 \{published data only\}}

Tattevin P, Levy HG, Gould IM. Community-acquired pneumonia. New England Journal of Medicine 2015;372(3):293.

\section{Tian 2017 \{published data only\}}

Tian L, Zhu R, Peng Z, Zhao X, Yu Z, Gu Y, et al. Impact of oral care with biological enzyme disinfectants on ventilatorasociated pneumonia in mechanical ventilation patients. Chinese Journal of Nosocomiology 2017;27(1):101-4, 108.

\section{Tsai 2017 \{published data only\}}

Tsai HL, Cheng CJ, Yu CY, Lin HC, Chen CH, Lee LC, et al. The effectiveness of the use of chlorhexidine oral rinse to prevent respiratory-related pneumonia infection. International Journal of Antimicrobial Agents 2017;50:S239.

\section{Ueda 2004 \{published data only\}}

Ueda K, Yamada Y, Toyosato A, Nomura S, Saitho E. Effects of functional training of dysphagia to prevent pneumonia for patients on tube feeding. Gerodontology 2004;21(2):108-11.

\section{Wang 2006 \{published data only\}}

Wang MM. The improvement of oral care in ICU intubated patients. Journal of Mudanjiang Medical College 2006;27(5):80-1.

\section{Wang 2012 \{published data only\}}

Wang YX, He LY, Gao MR, Wang ZW, Li XY. Application of oral nursing care bundle to prevent VAP for critically surgically ill patients. Chinese Archives of General Surgery 2012;6(5):448-50.
Wang 2016 \{published data only\}

Wang N, Lu B, Yang W, Xu D. ICU patients in clinical studies of oral care solution to reduce lung infection. Chinese Journal of Nosocomiology 2016;26(14):3342-4.

\section{Yin 2004 \{published data only\}}

Yin XR, Liao Y. The improvement of the oral care for patients with orotracheal intubation. West China Medical Journal 2004;19(3):482.

Yun 2011 \{published data only\}

Yun HY, Lee ES, Kim JY, Kim HS, Kim KA, Kim ES, et al. Effect of tooth-brushing on oral health and ventilator-associated pneumonia of critically ill patients. Journal of Korean Critical Care Nursing 2011;4(2):1.

\section{Zouka 2010 \{published data only\}}

Zouka M, Soultati I, Hari H, Pourzitaki C, Paroutsidou G, Thomaidou E, et al. Oral dental hygiene and ventilatorassociated pneumonia prevention in an ICU setting: comparison between two methods (preliminary data of a randomised prospective study). Intensive Care Medicine 2010;36:S103.

\section{References to studies awaiting assessment}

Chacko 2017 \{published data only\}

Chacko R, Rajan A, Lionel P, Thilagavathi M, Yadav B, Premkumar J. Oral decontamination techniques and ventilatorassociated pneumonia. British Journal of Nursing 2017;26:594-9.

\section{Hashemi 2018 \{published data only\}}

Hashemi ST, Alikiaii B, Ali Fallah-Medvari M, Karimi F, FallahMedvari A. Comparison of effects of chlorhexidine mouthwash versus stop-snoring mouthwash in prevention of ventilatorassociated pneumonia. Journal of Isfahan Medical School 2018;36:227-32.

\section{Hashemi 2019 \{published data only\}}

Hashemi ST, Alikiaii B, Fallah Medvari MA, Karimi F, Fallah Medvari A. Comparison of effects of chlorhexidine mouthwash with herbal cinnamol mouthwash on prevention of ventilator associated pneumonia. Medical Journal of Tabriz University of Medical Sciences and Health Services 2020;41(6):91-7.

IRCT20110427006318N12 \{published data only\}

IRCT20110427006318N12. Effect of propolis mouthwash on incidence of pneumonia in hospitalized patient in critical care unit [Effect of propolis mouthwash on incidence of ventilator-associated pneumonia in hospitalized patient in critical care unit]. www.who.int/trialsearch/Trial2.aspx? TrialID=IRCT20110427006318N12 (first received 2 April 2019).

\section{IRCT2013050813278N1 \{published data only\}}

IRCT2013050813278N1. The effect of oral care on pulmonary infection in intensive care unit [Comparison of two methods of oral care on oral health and the prevention of ventilatorassociated pneumonia in mechanically ventilated patients in intensive care unit]. www.who.int/trialsearch/Trial2.aspx? TrialID=IRCT2013050813278N1 (first received 25 May 2013). 
IRCT201512115363N8 \{published data only\}

IRCT201512115363N8. Effect of damask rose extract in the prevention of ventilator-associated pneumonia [Clinical trial to compare the effect of damask rose extract and chlorhexidine in prevention of ventilator-associated pneumonia in critically ill patients]. www.who.int/trialsearch/Trial2.aspx? TrialID=IRCT201512115363N8 (first received 4 December 2016).

\section{IRCT2016052828134N1 \{published data only\}}

IRCT2016052828134N1. Effects of botanical mouthwash of aloe vera on ventilator associated pneumonia of patients having endotracheal tube hospitalized in the intensive care unit. www.who.int/trialsearch/Trial2.aspx? TrialID=IRCT2016052828134N1 (first received 21 June 2016).

\section{IRCT2017022032676N1 \{published data only\}}

IRCT2017022032676N1. Comparing the effect of persica and chlorhexidine on the prevention of ventilator associated pneumonia in patient admitted in ICU [Effect of persica and chlorhexidine on the prevention of ventilator associated pneumonia]. www.who.int/trialsearch/Trial2.aspx? TrialID=IRCT2017022032676N1 (first received 22 April 2017).

\section{IRCT2017050727819N4 \{published data only\}}

IRCT2017050727819N4. The effects of mouthwash on prevention of pneumonia [The comparison of the effects of orthodentol and chlorhexidine mouthwash on prevention of ventilator associated pneumonia in mechanically ventilated patients]. www.who.int/trialsearch/Trial2.aspx? TrialID=IRCT2017050727819N4 (first received 26 June 2017).

\section{IRCT20171225038053N1 \{published data only\}}

IRCT20171225038053N1. Effect of two methods mouth wash (chlorhexidine and chlorhexidine combined with hydrogen peroxide solution) on frequency of oral plaques and ventilatorassociated pneumonia in patients undergoing mechanical ventilation [Comparison of the effect of two methods mouth wash (chlorhexidine and chlorhexidine combined with hydrogen peroxide solution) on frequency of oral plaques and ventilator-associated pneumonia in patients undergoing mechanical ventilation in the intensive care unit of Imam Khomeini Educational Center, Urmia, 2017-18]. www.who.int/ trialsearch/Trial2.aspx?TrialID=IRCT20171225038053N1 (first received 9 September 2018).

\section{IRCT20180520039739N2 \{published data only\}}

IRCT20180520039739N2. Evaluation of effect of chlorhexidine on prevention of ventilator associated pneumonia [Comparison of the effect of Chlorhexidine mouthwash with Dine mouthwash on prevention of ventilator-associated pneumonia in pediatric intensive care unit]. www.who.int/trialsearch/Trial2.aspx? TrialID=IRCT20180520039739N2 (first received 26 November 2018).

\section{IRCT20191012045066N1 \{published data only\}}

IRCT20191012045066N1. The effects of oral care program on oropharyngeal complications and the occurrence of ventilator associated pneumonia [Evaluation and comparison of the effects of three oral care programs on oropharyngeal complications and the occurrence of ventilator associated pneumonia in patients undergoing mechanical ventilation]. www.who.int/trialsearch/Trial2.aspx? TrialID=IRCT20191012045066N1 (first received 7 November 2019).

\section{Jamshidi 2016 \{published data only\}}

Jamshidi MR, Qatreh Samany F, Goli Farhood G, Qodrati S, Falakaflaki B. Evaluating the effect of chlorhexidine and tooth brushing in preventing the ventilator associated pneumonia. Journal of Zanjan University of Medical Sciences and Health Services 2016;24(105):9-17.

\section{Mehrabadi 2015 \{published data only\}}

Gholami Mehrabadi M, Khosravi SH, Rezaie K, Malekianzadeh B, Ghorbanpour M, Moslemi A, et al. The effect of Echinacea mouthwash on ventilator associated pneumonia in patients in intensive care units. Medical-Surgical Nursing Journal 2015;4(3):13-20.

\section{References to ongoing studies}

RBR-7p6568 \{published data only\}

RBR-7p6568. Oral hygiene in critically ill patients [Oral hygiene in critically ill patients - a randomized controlled trial]. www.who.int/trialsearch/Trial2.aspx?TrialID=RBR-7p6568 (first received 8 October 2019).

\section{TCTR20190530003 \{published data only\}}

TCTR20190530003. Efficacy of moraceae with chlorhexidine mouthwash on microbial flora of critically ill intubated patients [Efficacy of moraceae with chlorhexidine mouthwash on microbial flora of critically ill intubated patients: a randomized controlled pilot study]. www.who.int/trialsearch/Trial2.aspx? TrialID=TCTR20190530003 (first received 29 May 2019).

\section{Additional references}

\section{Alhazzani 2013}

Alhazzani W, Smith O, Muscedere J, Medd J, Cook D. Toothbrushing for critically ill mechanically ventilated patients: a systematic review and meta-analysis of randomized trials evaluating ventilator-associated pneumonia. Critical Care Medicine 2013;41(2):646-55.

\section{Apostolopoulou 2003}

Apostolopoulou E, Bakakos P, Katostaras T, Gregorakos L. Incidence and risk factors for ventilator-associated pneumonia in 4 multidisciplinary intensive care units in Athens. Respiratory Care 2003;48(7):681-8.

\section{Arthur 2016}

Arthur LE, Kizor RS, Selim AG, Van Driel ML, Seoane L. Antibiotics for ventilator-associated pneumonia. Cochrane Database of Systematic Reviews 2016, Issue 10. Art. No: CD004267. [DOI: 10.1002/14651858.CD004267.pub4]

\section{ATS Guideline 2005}

American Thoracic Society, Infectious Diseases Society of America. Guidelines for the management of adults with hospital-acquired, ventilator-associated, and healthcare- 
associated pneumonia. American Journal of Respiratory and Critical Care Medicine 2005;171(4):388-416.

\section{Azoulay 2006}

Azoulay E, Timsit JF, Tafflet M, De Lassence A, Darmon M, Zahar JR, et al. Candida colonization of the respiratory tract and subsequent pseudomonas ventilator-associated pneumonia. Chest 2006;129(1):110-7.

\section{Berry 2007}

Berry AM, Davidson PM, Masters J, Rolls K. Systematic literature review of oral hygiene practices for intensive care patients receiving mechanical ventilation. American Journal of Critical Care 2007;16(6):552-62.

\section{Bo 2014}

Bo L, Li J, Tao T, Bai Y, Ye X, Hotchkiss RS, et al. Probiotics for preventing ventilator-associated pneumonia. Cochrane Database of Systematic Reviews 2014, Issue 10. Art. No: CD009066. [DOI: 10.1002/14651858.CD009066.pub2]

\section{CONSORT 2012}

Altman DG, Moher D, Schultz KF. Improving the reporting of randomised trials: the CONSORT statement and beyond. Statistics in Medicine 2012;31(25):2985-97.

\section{Contentin 2014}

Contentin L, Ehrmann S, Giraudeau B. Heterogeneity in the definition of mechanical ventilation duration and ventilator-free days. American Journal of Respiratory and Critical Care Medicine 2014;189(8):998-1002.

\section{Cook 1998}

Cook DJ, Walter SD, Cook RJ, Griffith LE, Guyatt GH, Leasa D, et al. Incidence of and risk factors for ventilator-associated pneumonia in critically ill patients. Annals of Internal Medicine 1998;29(6):433-46.

\section{D'Amico 2009}

D'Amico R, Pifferi S, Torri V, Brazzi L, Parmelli E, Liberati A. Antibiotic prophylaxis to reduce respiratory tract infections and mortality in adults receiving intensive care. Cochrane Database of Systematic Reviews 2009, Issue 4. Art. No: CD000022. [DOI: 10.1002/14651858.CD000022.pub3]

\section{Ding 2017}

Ding C, Zhang Y, Yang Z, Wang J, Jin A, Wang W, et al. Incidence, temporal trend and factors associated with ventilatorassociated pneumonia in mainland China: a systematic review and meta-analysis. BMC Infectious Diseases 2017;17(1):468.

\section{Fourrier 1998}

Fourrier F, Duvivier B, Boutigny H, Roussel-Delvallez M, Chopin C. Colonization of dental plaque: a source of nosocomial infections in intensive care unit patients. Critical Care Medicine 1998;26(2):301-8.

\section{GRADEpro 2020 [Computer program]}

McMaster University GRADEpro GDT: GRADEpro Guideline Development Tool. Grade Working Group. McMaster University, 2020.

\section{Guyatt 2008}

Guyatt GH, Oxman AD, Vist GE, Kunz R, Falck-Ytter Y, AlonsoCoello $P$, et al. GRADE: an emerging consensus on rating quality of evidence and strength of recommendations. $B M J$ 2008;336(7650):924-6.

\section{Gyssens 2011}

Gyssens IC. Antibiotic policy. International Journal of Antimicrobial Agents 2011;38 Suppl:11-20. [PMID: 22018989]

\section{Hao 2015}

Hao Q, Dong BR, Wu T. Probiotics for preventing acute upper respiratory tract infections. Cochrane Database of Systematic Reviews 2015, Issue 2. Art. No: CD006895. [DOI: 10.1002/14651858.CD006895.pub3]

\section{Higgins 2011}

Higgins JPT, Green S, editor(s). Cochrane Handbook for Systematic Reviews of Interventions version 5.1.0 (updated March 2011). The Cochrane Collaboration, 2011. Available from training.cochrane.org/handbook/archive/v5.1/.

\section{Horan 2008}

Horan TC, Andrus M, Dudeck MA. CDC/NHSN surveillance definition of health care-associated infection and criteria for specific types of infections in the acute care setting. American Journal of Infection Control 2008;36(5):309-32.

\section{Khasanah 2019}

Khasanah IH, Sae-Sia W, Damkliang J. The effectiveness of oral care guideline implementation on oral health status in critically ill patients. SAGE Open Nursing 2019;5:1-9.

\section{Klompas 2007}

Klompas M. Does this patient have ventilator-associated pneumonia? JAMA 2007;297(14):1583-93.

\section{Klompas 2014}

Klompas M, Speck K, Howell MD, Greene LR, Berenholtz SM. Reappraisal of routine oral care with chlorhexidine gluconate for patients receiving mechanical ventilation: systematic review and meta-analysis. JAMA Internal Medicine 2014;174(5):751-61. [DOI: 10.1001/jamainternmed.2014.359.]

\section{Labeau 2011}

Labeau SO, Van de Vyver K, Brusselaers N, Vogelaers D, Blot SI. Prevention of ventilator-associated pneumonia with oral antiseptics: a systematic review and meta-analysis. Lancet Infectious Diseases 2011;11(11):845-54.

\section{La Combe 2018}

La Combe B, Bleibtreu A, Messika J, Fernandes R, Clermont O, Branger $C$, et al. Decreased susceptibility to chlorhexidine affects a quarter of Escherichia coli isolates responsible for pneumonia in ICU patients. Intensive Care Medicine 2018;44(4):531-3.

\section{Lefebvre 2019}

Lefebvre C, Glanville J, Briscoe S, Littlewood A, Marshall C, Metzendorf M-I, et al. Technical Supplement to Chapter 4: Searching for and selecting studies. In: Higgins JPT, 
Thomas J, Chandler J, Cumpston MS, Li T, Page MJ, Welch VA (eds). Cochrane Handbook for Systematic Reviews of Interventions, Version 6. Cochrane, 2019. Available from: www.training.cochrane.org/handbook.

\section{Li 2020}

Li Y, Liu C, Xiao W, Song T, Wang S. Incidence, risk factors, and outcomes of ventilator-associated pneumonia in traumatic brain injury: a meta-analysis. Neurocritical Care 2020;32(1):272-85.

\section{Marsh 2010}

Marsh PD. Microbiology of dental plaque biofilms and their role in oral health and caries. Dental Clinics of North America 2010;54(3):441-54.

\section{Martin-Loeches 2018}

Martin-Loeches I, Rodriguez AH, Torres A. New guidelines for hospital-acquired pneumonia/ventilator-associated pneumonia: USA vs. Europe. Current Opinion in Critical Care 2018;24(5):347-52.

\section{McCarney 2007}

McCarney R, Warner J, Iliffe S, Van Haselen R, Griffin M, Fisher P. The Hawthorne Effect: a randomised, controlled trial. BMC Medical Research Methodology 2007;7:30.

\section{Melsen 2013}

Melsen WG, Rovers MM, Groenwold RH, Bergmans DC, Camus C, Bauer TT, et al. Attributable mortality of ventilator-associated pneumonia: a meta-analysis of individual patient data from randomised prevention studies. Lancet Infectious Diseases 2013;13(8):665-71.

\section{Mojon 2002}

Mojon P. Oral health and respiratory infection. Journal of the Canadian Dental Association 2002;68(6):340-6.

\section{Muscedere 2008}

Muscedere J, Dodek P, Keenan S, Fowler R, Cook D, Heyland D. Comprehensive evidence-based clinical practice guidelines for ventilator-associated pneumonia: prevention. Journal of Critical Care 2008;23(1):126-37.

\section{Pemberton 2012}

Pemberton MN, Gibson J. Chlorhexidine and hypersensitivity reactions in dentistry. British Dental Journal 2012;213(11):547-50.

\section{Pineda 2006}

Pineda LA, Saliba RG, El Solh AA. Effect of oral decontamination with chlorhexidine on the incidence of nosocomial pneumonia: a meta-analysis. Critical Care 2006;10(1):R35.

\section{Plantinga 2016}

Plantinga NL, Wittekamp BHJ, Leleu K, Depuydt P, Van den Abeele AM, Brun-Buisson C, et al. Oral mucosal adverse events with chlorhexidine $2 \%$ mouthwash in ICU. Intensive Care Medicine 2016;42(4):620-1.

\section{Price 2014}

Price R, MacLennan G, Glen J, SuDDICU Collaboration. Selective digestive or oropharyngeal decontamination and topical oropharyngeal chlorhexidine for prevention of death in general intensive care: systematic review and network meta-analysis. BMJ 2014;348:g2197.

\section{Pugin 1991}

Pugin J, Auckenthaler R, Mili N, Janssens JP, Lew PD, Suter PM. Diagnosis of ventilator-associated pneumonia by bacteriologic analysis of bronchoscopic and nonbronchoscopic 'blind' bronchoalveolar lavage fluid. American Review of Respiratory Disease 1991;143(5 Pt 1):1121-9.

\section{Roberts 2017}

Roberts D, Brown J, Medley N, Dalziel SR. Antenatal corticosteroids for accelerating fetal lung maturation for women at risk of preterm birth. Cochrane Database of Systematic Reviews 2017, Issue 3. Art. No: CD004454. [DOI: 10.1002/14651858.CD004454.pub3]

\section{Sachdev 2013}

Sachdev M, Ready D, Brealey D, Ryu J, Bercades G, Nagle J, et al. Changes in dental plaque following hospitalisation in a critical care unit: an observational study. Critical Care 2013;17(5):R189.

\section{Sands 2016}

Sands KM, Twigg JA, Lewis MAO, Wise MP, Marchesi JR, Smith A, et al. Microbial profiling of dental plaque from mechanically ventilated patients. Journal of Medical Microbiology 2016;65(2):147-59.

\section{Scannapieco 1992}

Scannapieco FA, Stewart EM, Mylotte JM. Colonization of dental plaque by respiratory pathogens in medical intensive care patients. Critical Care Medicine 1992;20(6):740-5.

\section{Schulz 2002}

Schulz KF, Grimes DA. Generation of allocation sequences in randomised trials: chance, not choice. Lancet 2002;359(9305):515-9.

\section{Shi 2004}

Shi ZD, Yu JR, Luo R, He Y, Liu XC, Chen E. Effect of oral nursing care: a systematic review. Chinese Journal of Evidence Based Medicine 2004;4(12):837-46, 858.

\section{Silness 1964}

Silness J, Loe H. Periodontal disease in pregnancy. Correlation between oral hygiene and periodontal condition. Acta odontologica Scandinavica 1964;22:121-35.

\section{Tablan 2004}

Tablan OC, Anderson L, Besser R, Bridges C, Hajjeh R. Guidelines for preventing healthcare-associated pneumonia: recommendations of CDC and the Healthcare Infection Control Practices Advisory Committee. Morbidity \& Mortality Weekly Report. Recommendations \& Reports 2004;55 (RR-3):1-36. 


\section{Terezakis 2011}

Terezakis E, Needleman I, Kumar N, Moles D, Agudo E. The impact of hospitalization on oral health: a systematic review. Journal of Clinical Periodontology 2011;38(7):628-36.

\section{Terpenning 2005}

Terpenning M. Geriatric oral health and pneumonia risk. Clinical Infectious Diseases 2005;40(12):1807-10.

\section{Torres 2017}

Torres A, Niederman MS, Chastre J, Ewig S, FernandezVandellos P, Hanberger $\mathrm{H}$, et al. International ERS/ESICM/ ESCMID/ALAT guidelines for the management of hospitalacquired pneumonia and ventilator-associated pneumonia: Guidelines for the management of hospital-acquired pneumonia (HAP)/ventilator-associated pneumonia (VAP) of the European Respiratory Society (ERS), European Society of Intensive Care Medicine (ESICM), European Society of Clinical Microbiology and Infectious Diseases (ESCMID) and Asociación Latinoamericana del Tórax (ALAT). European Respiratory Journal 2017;50(3):1700582.

\section{Waters 2015}

Waters B, Muscedere J. A 2015 update on ventilator-associated pneumonia: new insights on its prevention, diagnosis, and treatment. Current Infectious Disease Reports 2015;17(8):1-9.

\section{Whittaker 1996}

Whittaker CJ, Klier CM, Kolenbrander PE. Mechanisms of adhesion by oral bacteria. Annual Review of Microbiology 1996;50:513-52.

\section{Wittekamp 2018}

Wittekamp BH, Plantinga NL, Cooper BS, Lopez-Contreras J, Coll P, Mancebo J, et al. Decontamination strategies and bloodstream infections with antibiotic-resistant microorganisms in ventilated patients: a randomized clinical trial. JAMA 2018;320(20):2087-98.

\section{Worthington 2015}

Worthington $\mathrm{H}$, Clarkson J, Weldon J. Priority oral health research identification for clinical decision-making. Evidencebased Dentistry 2015;16(3):69-71.

\section{Zanatta 2011}

Zanatta FB, Bergoli AD, Werle SB, Antoniazzi RP. Biofilm removal and gingival abrasion with medium and soft toothbrushes. Oral Health and Preventive Dentistry 2011;9(2):177-83.

\section{Zhang 2013}

Zhang TT, Tang SS, Fu LJ. The effectiveness of different concentrations of chlorhexidine for prevention of ventilatorassociated pneumonia: a meta-analysis. Journal of Clinical Nursing 2014;23(11-12):1461-75.

\section{References to other published versions of this review Hua 2016 \\ Hua F, Xie H, Worthington HV, Furness S, Zhang Q, Li C. Oral hygiene care for critically ill patients to prevent ventilator-associated pneumonia. Cochrane Database of Systematic Reviews 2016, Issue 10. Art. No: CD008367. [DOI: 10.1002/14651858.CD008367.pub3]}

\section{Shi 2010}

Shi Z, Xie H, Wang P, Wu Y, Chen E, Ng L, et al. Oral hygiene care for critically ill patients to prevent ventilator associated pneumonia. Cochrane Database of Systematic Reviews 2010, Issue 2. Art. No: CD008367. [DOI: 10.1002/14651858.CD008367]

\section{Shi 2013}

Shi Z, Xie H, Wang P, Zhang Q, Wu Y, Chen E, et al. Oral hygiene care for critically ill patients to prevent ventilator-associated pneumonia. Cochrane Database of Systematic Reviews 2013, Issue 8. Art. No: CD008367. [DOI: 10.1002/14651858.CD008367.pub2]

* Indicates the major publication for the study

\title{
CHARACTERISTICS OF STUDIES
}

Characteristics of included studies [ordered by study ID]

Bellissimo-Rodrigues 2009

\section{Study characteristics}

Methods

\author{
Study design: RCT, 2 parallel groups \\ Location: Sao Paulo, Brazil \\ Number of centres: 1 \\ Study period: March 2006 to February 2008 \\ Funding source: not stated
}

Participants

Setting: ICU in tertiary care hospital 
Bellissimo-Rodrigues 2009 (Continued)

Inclusion criteria: all patients admitted to ICU with expected stay $>48$ hours Not all participants received mechanical ventilation.

Exclusion criteria: previous chlorhexidine sensitivity, pregnancy, formal indication for chlorhexidine use, prescription of another oral topical medication

Number randomised: 200 (only 133 on ventilators)

Number evaluated: 194

Baseline characteristics:

- Intervention group age: median 62.5 (17 - 89) M/F: 47/51; APACHE II Score: median 17 (5 - 35)

- Control group age: median 54.0 (15 - 85) M/F: 51/45; APACHE II Score: median 19 (5 - 41)

\section{Interventions Comparison: $\mathbf{0 . 1 2} \%$ chlorhexidine solution versus placebo}

Experimental group ( $n=64$ on vent): $0.12 \%$ chlorhexidine solution applied orally 3 times daily. Oral hygiene was conducted by nurses specially trained in the protocol. 3 times daily after mechanical cleaning of the mouth by a nurse, $15 \mathrm{~mL}$ of study solution was applied and attempts made to distribute solution over all oral surfaces.

Control group ( $n=69$ on vent): same protocol conducted with placebo solution, which was identical in colour, consistency, smell and taste

1. Respiratory tract infections (VAP for those on ventilators)
2. Respiratory tract infection-free survival time
3. Time from ICU admission to first RTI
4. Duration of mechanical ventilation
5. Length of ICU stay
6. Total mortality
7. Mortality due to RTI
8. Antibiotic use
9. Microbiological culture of endotracheal secretions
10. Adverse effects

Notes

Sample size calculation: "to have sufficient power to detect a $69 \%$ difference in incidence of VAP with $\alpha$ $=5 \%$ and $\beta=20 \%$ it was estimated that 96 patients per group were required".

Only $133 / 194$ of patients evaluated received mechanical ventilation.

Email sent 3 September 2012. Reply received

The Cochrane calculator was used to calculate the SD value for duration of mechanical ventilation, but the SD obtained seemed inappropriate and was therefore not used in data synthesis.

\section{Risk of bias}

\begin{tabular}{lll}
\hline Bias & Authors' judgement & Support for judgement \\
\hline $\begin{array}{ll}\text { Random sequence genera- } \\
\text { tion (selection bias) }\end{array}$ & Unclear risk & "randomised" \\
& & Method of sequence generation not described \\
\hline
\end{tabular}


Bellissimo-Rodrigues 2009 (Continued)

$\begin{array}{ll}\begin{array}{l}\text { Allocation concealment } \\ \text { (selection bias) }\end{array} & \begin{array}{l}\text { "only the pharmacist knew which code numbers corresponded to which type } \\ \text { of solution". }\end{array}\end{array}$

Blinding of participants Low risk Double-blind

and personnel (perfor-

mance bias)

All outcomes

Blinding of outcome as-
sessment (detection bias)

\title{
All outcomes
}

Incomplete outcome data Low risk

(attrition bias)

$6 / 200$ participants were excluded from the analysis. 1 control participant

All outcomes needed to receive chlorhexidine treatment, and a further 3 in the control group and 2 in the experimental group were excluded due to protocol violation. Unlikely to have introduced a bias

Selective reporting (re- Low risk All planned outcomes reported
porting bias)

Other bias Low risk No other sources of bias identified

Berry 2011

\section{Study characteristics}

Methods

\author{
Study design: feasibility study - single-blind parallel-group RCT with 3 groups \\ Location: Australia \\ Number of centres: 1 \\ Study period: not stated \\ Funding source: hospital
}

Participants

Setting: 20-bed adult intensive care unit in a university hospital

Inclusion criteria: all intubated patients admitted to the unit were considered for inclusion in the study provided they met the following criteria: able to be randomised within 12 hours of intubation, aged over 15 years and next-of-kin able to give informed consent.

Exclusion criteria: patients were ineligible for study participation if they: required specific oral hygiene procedures in relation to maxillofacial trauma or dental trauma/surgery; had been in the ICU previously during the current period of hospitalisation; received irradiation or chemotherapy on admission to the ICU or in the preceding 6 weeks; or suffered an autoimmune disease. Informed consent was obtained for all participants and agreement to participate could be withdrawn at any time.

Number randomised: $225(71,76,78$ in groups 1, 2, 3)

Number evaluated: 109 (33, 33, 43 in groups 1, 2, 3)

Group 1 (chlorhexidine 0.2\% aqueous) group: age: 58.2 \pm 19.4; M/F: 35/36; APACHE II Score: $22.8 \pm 7.8$

Group 2 (sodium bicarbonate mouthwash rinsed 2-hourly): age: 60.4 \pm 17.5; M/F: 42/24; APACHE II

Score: $22.0 \pm 7.5$

Group 3 (sterile water rinsed 2-hourly): age: 59.1 \pm 18.1; M/F: 44/34; APACHE II Score: $21.6 \pm 7.8$ 
Berry 2011 (Continued)

Interventions

\section{Comparison: Chlorhexidine $\mathbf{0 . 2} \%$ versus sodium bicarbonate versus water}

Group 1: Twice daily irrigation with chlorhexidine $0.2 \%$ aqueous oral rinse with 2-hourly irrigation with sterile water

Group 2: Sodium bicarbonate mouthwash rinsed 2-hourly

Group 3: Sterile water rinsed 2-hourly (used as the control in this review)

"All treatment options included a comprehensive cleaning of the mouth using a soft, pediatric toothbrush 3 times a day".

Outcomes
$\begin{aligned} & \text { 1. Microbial colonisation of dental plaque (or gums in edentulous participants) } \\ & \text { 2. Incidence of VAP } \\ & \text { 3. Adverse events }\end{aligned}$

Notes Sample size calculation: Feasibility study to inform sample size calculation for main study

\section{Risk of bias}

\begin{tabular}{|c|c|c|}
\hline Bias & Authors' judgement & Support for judgement \\
\hline $\begin{array}{l}\text { Random sequence genera- } \\
\text { tion (selection bias) }\end{array}$ & Low risk & $\begin{array}{l}\text { "...randomisation into one of three groups according to a balanced randomisa- } \\
\text { tion table prepared by biostatistician" }\end{array}$ \\
\hline $\begin{array}{l}\text { Allocation concealment } \\
\text { (selection bias) }\end{array}$ & Low risk & $\begin{array}{l}\text { Study packs were identical in outward appearance and allocation remained } \\
\text { blinded until study pack opened by attending nurse. }\end{array}$ \\
\hline $\begin{array}{l}\text { Blinding of participants } \\
\text { and personnel (perfor- } \\
\text { mance bias) } \\
\text { All outcomes }\end{array}$ & High risk & $\begin{array}{l}\text { Participants: blinding not possible, but non-blinding of caregivers may have } \\
\text { introduced a risk of bias. }\end{array}$ \\
\hline $\begin{array}{l}\text { Blinding of outcome as- } \\
\text { sessment (detection bias) } \\
\text { All outcomes }\end{array}$ & Low risk & $\begin{array}{l}\text { Microbiologist and radiologists who assessed outcomes were blinded to allo- } \\
\text { cated treatment. }\end{array}$ \\
\hline $\begin{array}{l}\text { Incomplete outcome data } \\
\text { (attrition bias) } \\
\text { All outcomes }\end{array}$ & High risk & $\begin{array}{l}\text { 102/225 participants evaluated. High rate of attrition and reasons varied in } \\
\text { each group. Death rate higher in group B, breach of inclusion criteria more like- } \\
\text { ly in groups B \& C }\end{array}$ \\
\hline $\begin{array}{l}\text { Selective reporting (re- } \\
\text { porting bias) }\end{array}$ & Low risk & Planned outcomes reported \\
\hline Other bias & High risk & Study stopped early due to withdrawal of investigational product by regulator. \\
\hline
\end{tabular}

Berry 2013

\section{Study characteristics}

\begin{tabular}{ll}
\hline Methods & Study design: 3-arm parallel-group RCT \\
& Location: Australia
\end{tabular}


Berry 2013 (Continued)

\author{
Number of centres: 1 \\ Study period: not stated \\ Funding source: Pfizer provided product only
}

Setting: ICU in a 1000-bed tertiary referral teaching hospital
Inclusion criteria: admitted to ICU, able to be randomised within 12 hours of intubation; aged over 15
years; next-of-kin able to give informed consent
Exclusion criteria: required specific oral hygiene procedures following facio-maxillary or dental trau-
ma/surgery; had received irradiation or chemotherapy on admission to the ICU or in the preceding 6
weeks; diagnosed with autoimmune disease; had previous ICU admission during current period of hos-
pitalisation
Number randomised: 398 (group A: 138; group B: 133; group C: 127$)$
Number evaluated: 398 (group A: 138; group B: 133; group C: 127); however, 11\% of these participants
were ineligible
Baseline characteristics:
- Group A: Age: 58.82 (16.7); M/F: 84/54; APACHE II Score: 20.86 (7.7)
- Group B: Age: 54.93 (19.5); M/F: 79/54; APACHE II Score: 21.38 (8.0)
- Group C: Age: 59.96 (18.0); M/F: 73/54; APACHE II Score: 21.21 (8.0)

Interventions

Comparison: Sterile water versus sodium bicarbonate versus Listerine

Group A: Control - sterile water mouth rinses, $20 \mathrm{~mL}$ every 2 hours.

Group B: Sodium bicarbonate mouth wash ( $6.5 \mathrm{~g} / \mathrm{L}$ sterile water), $20 \mathrm{~mL}$ every 2 hours

Group C: Listerine mouth wash, $20 \mathrm{~mL}$ instilled twice a day and sterile water every 2 hours for remaining time

All 3 groups received mechanical cleaning of the oral cavity with a small, soft-bristled toothbrush and general-purpose toothbrush 3 times a day. Curved-tip dental syringes were used to instil mouth rinses. During the study period, VAP preventive measures including head of the bed elevation, stress ulcer prophylaxis and endotracheal cuff occlusive pressure between 22 and $30 \mathrm{~cm} \mathrm{H}_{2} \mathrm{O}$ were maintained.

\begin{tabular}{|c|c|}
\hline \multirow[t]{4}{*}{ Outcomes } & 1. Incidence of VAP \\
\hline & 2. Dental plaque colonisation \\
\hline & 3. Systemic antibiotic administration (unclear if systemic) \\
\hline & 4. Adverse effects \\
\hline
\end{tabular}

Notes

Sample size calculation: reported for inhibition of microbial growth on dental plaque, not VAP

Emailed study investigator 10 April 2016 for publication details or full unpublished study data

\title{
Risk of bias
}

\begin{tabular}{lll}
\hline Bias & Authors' judgement & Support for judgement \\
\hline $\begin{array}{l}\text { Random sequence genera- } \\
\text { tion (selection bias) }\end{array}$ & Low risk & "Randomisation numbers were computer generated". \\
\hline
\end{tabular}


Berry 2013 (Continued)

Allocation concealment Low risk "Nurses were blinded to the study option until the study packs were opened".
(selection bias)

\begin{tabular}{lll}
\hline $\begin{array}{l}\text { Blinding of participants } \\
\text { and personnel (perfor- } \\
\text { mance bias) } \\
\text { All outcomes }\end{array}$ & High risk & Nurses were not blinded. \\
\hline $\begin{array}{l}\text { Blinding of outcome as- } \\
\text { sessment (detection bias) } \\
\text { All outcomes }\end{array}$ & Low risk & "Microbiologists...and...radiologists also blinded to the treatment code" \\
\hline $\begin{array}{l}\text { Incomplete outcome data } \\
\text { (attrition bias) } \\
\text { All outcomes }\end{array}$ & High risk & $\begin{array}{l}\text { 245 randomised participants (62\%) were no longer in the study on the 4th day; } \\
\text { Intention-to-treat analysis was used but unsure how and whether appropriate. }\end{array}$ \\
\hline $\begin{array}{l}\text { Selective reporting (re- } \\
\text { porting bias) }\end{array}$ & High risk & $\begin{array}{l}\text { VAP data were only presented as percentages; } 24 \text { participants died within } 4 \\
\text { days but unclear how many died after that; exact data for systemic antibiotic } \\
\text { administration was not reported. }\end{array}$ \\
\hline $\begin{array}{l}\text { Other bias } \\
\text { Ineligible patients were included in the ITT but reasons for ineligibility in each } \\
\text { group were not given. }\end{array}$
\end{tabular}

\section{Bopp 2006}

\section{Study characteristics}

$\begin{array}{ll}\text { Methods } & \text { Study design: pilot study, 2-arm RCT } \\ \text { Location: USA } \\ \text { Number of centres: } 1 \\ \text { Study period: February } 2002 \text { to August } 2002 \\ \text { Funding source: grant from American Dental Hygienists' Association's Institute for Oral Health } \\ \text { Setting: critical care unit } \\ \text { Inclusion criteria: orally and nasally intubated patients entering critical care unit } \\ \text { Exclusion criteria: taking metronidazole, history of allergy to chlorhexidine, sensitive to alcohol, risk for } \\ \text { endocarditis, history of other serious illness (specified), those with pneumonia } \\ \text { Number randomised: } 5 \\ \text { Number evaluated: } 5 \\ \text { Baseline characteristics: } \\ \text { - Intervention group: age: } 40 \text {, range } 28 \text { - 52; M/F: } 0 / 2 \\ \text { - Control group: age: } 73.7 \text {, range } 62 \text { - } 81 ; \mathrm{M} / \mathrm{F}: 2 / 1\end{array}$

Interventions

Comparison: $\mathbf{0 . 1 2} \%$ chlorhexidine + suction toothbrush versus suction swab + hydrogen peroxide

Experimental group $(n=2)$ : twice daily oral hygiene care with $0.12 \%$ chlorhexidine gluconate during intubation period plus oral cleaning with PlaqVac suction toothbrush 
Bopp 2006 (Continued)

Control group $(n=3)$ : standard oral care 6 times daily using a suctioning soft foam swab and halfstrength hydrogen peroxide, plus oral lubricant

\begin{tabular}{|c|c|}
\hline Outcomes & Microbial colonisation VAP, mortality \\
\hline \multirow[t]{2}{*}{ Notes } & $\begin{array}{l}\text { Sample size calculation: this was a pilot study. Data were not used in meta-analysis on advice of statis- } \\
\text { tician. }\end{array}$ \\
\hline & Email sent to contact author 14 November 2012, reply received 19 November 2012 \\
\hline
\end{tabular}

\section{Risk of bias}

\begin{tabular}{|c|c|c|}
\hline Bias & Authors' judgement & Support for judgement \\
\hline $\begin{array}{l}\text { Random sequence genera- } \\
\text { tion (selection bias) }\end{array}$ & Low risk & $\begin{array}{l}\text { "...randomly assigned to either control or experimental treatment by the flip of } \\
\text { a coin" }\end{array}$ \\
\hline $\begin{array}{l}\text { Allocation concealment } \\
\text { (selection bias) }\end{array}$ & High risk & Coin toss was undertaken by researcher. No allocation concealment \\
\hline $\begin{array}{l}\text { Blinding of participants } \\
\text { and personnel (perfor- } \\
\text { mance bias) } \\
\text { All outcomes }\end{array}$ & High risk & Blinding not possible. Reply from contact author "they were not blinded" \\
\hline $\begin{array}{l}\text { Blinding of outcome as- } \\
\text { sessment (detection bias) } \\
\text { All outcomes }\end{array}$ & High risk & Reply from contact author "they were not blinded" \\
\hline $\begin{array}{l}\text { Incomplete outcome data } \\
\text { (attrition bias) } \\
\text { All outcomes }\end{array}$ & Low risk & All randomised participants included in outcome evaluation \\
\hline $\begin{array}{l}\text { Selective reporting (re- } \\
\text { porting bias) }\end{array}$ & Unclear risk & $\begin{array}{l}\text { VAP planned and reported in this pilot study. Microbial culture data not report- } \\
\text { ed per person, and mortality was also reported }\end{array}$ \\
\hline Other bias & Low risk & No other sources of bias detected \\
\hline
\end{tabular}

\section{Cabov 2010}

\section{Study characteristics}

\begin{tabular}{ll}
\hline Methods & Study design: 2 parallel-arm RCT \\
Location: Croatia \\
Number of centres: 1 \\
Study period: March 2008 to December 2008 \\
Funding source: supported by Croatian Ministry of Science Education and Sports Grant number \\
065-1080057-0429 \\
Setting: surgical ICU in university hospital \\
Inclusion criteria: aged > 18 years, medical condition suggesting hospitalisation in ICU > 3 days, eventu- \\
al requirement for mechanical ventilation by oropharyngeal or nasotracheal ventilation
\end{tabular}


Exclusion criteria: number randomised: 60.40 of the 60 participants (17 and 23 in each group) were on mechanical ventilation

Number evaluated: 60

Baseline characteristics:

- Intervention group: age: $57 \pm 16 ;$ M/F: 19/11

- Control group: age: $52 \pm 19 ;$ M/F: 20/10

\section{Interventions Comparison: Chlorhexidine gel versus placebo}

Experimental group $(n=17): 3$ times daily, following standard oral care comprising rinsing mouth with bicarbonate isotonic serum, followed by gentle oropharyngeal sterile aspiration; participants received application of $0.2 \%$ chlorhexidine gel applied by nurses to dental gingival and oral surfaces using a sterile gloved finger

Control group $(n=23)$ : standard oral care, 3 times daily as above followed by administration of placebo gel

In both groups, gel was left in place and oral cavity was not rinsed

Outcomes Simplified acute physiological score (SAPS), dental status, dental plaque, plaque culture, nosocomial infections, mortality

Notes Sample size calculation: not reported

\section{Risk of bias}

\begin{tabular}{lll}
\hline Bias & Authors' judgement & Support for judgement \\
\hline $\begin{array}{l}\text { Random sequence genera- } \\
\text { tion (selection bias) }\end{array}$ & Low risk & $\begin{array}{l}\text { "...randomized into two groups using a computer-generated balanced ran- } \\
\text { domization table" }\end{array}$ \\
\hline $\begin{array}{l}\text { Allocation concealment } \\
\text { (selection bias) }\end{array}$ & Unclear risk & $\begin{array}{l}\text { Unclear who conducted the allocation and whether it was concealed from the } \\
\text { investigators }\end{array}$ \\
\hline $\begin{array}{l}\text { Blinding of participants } \\
\text { and personnel (perfor- } \\
\text { mance bias) }\end{array}$ & Low risk & Double-blind \\
All outcomes & & \\
\hline
\end{tabular}

\begin{tabular}{ll}
\hline Blinding of outcome as- & Low risk \\
sessment (detection bias) & \\
All outcomes & \\
\hline
\end{tabular}

\begin{tabular}{lll}
\hline $\begin{array}{l}\text { Incomplete outcome data } \\
\text { (attrition bias) } \\
\text { All outcomes }\end{array}$ & Low risk & All randomised participants included in outcome evaluations \\
\hline $\begin{array}{l}\text { Selective reporting (re- } \\
\text { porting bias) }\end{array}$ & Low risk & All planned outcomes reported \\
\hline Other bias & Low risk & No other sources of bias identified \\
\hline
\end{tabular}




\section{Caruso 2009}

\section{Study characteristics}

\begin{tabular}{ll}
\hline Methods & Study design: 2 -arm RCT \\
Location: Brazil \\
Number of centres: 1 \\
Study period: August 2001 to December 2004 \\
Funding source: Not stated \\
Setting: closed medical surgical ICU unit in oncologic hospital \\
Inclusion criteria: patients aged $>18$ years expected to need mechanical ventilation for $>72$ hours \\
through orotracheal or tracheotomy tube \\
Exclusion criteria: previous mechanical ventilation within past month, mechanical ventilation for $>6$ \\
hours prior to study enrolment, contraindication to bronchoscopy and expected to die or stop treat- \\
ment within 48 hours \\
Number randomised: 262 \\
Number evaluated: 262 \\
Baseline characteristics: \\
- Intervention group: age: $65 \pm 14$ years; M/F: $66 / 64$ \\
- Control group: age: $63 \pm 6$ years; M/F: $70 / 62$ \\
\hline
\end{tabular}

$\begin{array}{ll}\text { Interventions } & \text { Comparison: Saline rinse versus usua } \\ \text { Experimental group }(n=130) \text { : instillation } \\ \text { was conducted by respiratory therapist } \\ \text { Control group }(n=132) \text { : tracheal suction } \\ \text { Aspirations were carried out when } 1 \text { of } \\ \text { cheal tube, discomfort or participant asy } \\ \text { sures, or decreased tidal volume during }\end{array}$

Notes Sample size calculation: estimated that 130 participants per group required to give $80 \%$ power with $\alpha=$ $5 \%$ to detect a decrease in VAP from $30 \%$ to $15 \%$.

\section{Risk of bias}

\begin{tabular}{lll}
\hline Bias & Authors' judgement & Support for judgement \\
\hline $\begin{array}{l}\text { Random sequence genera- } \\
\text { tion (selection bias) }\end{array}$ & Unclear risk & "randomised" \\
\hline
\end{tabular}


Caruso 2009 (Continued)

No details of method of sequence generation provided in report

\begin{tabular}{|c|c|c|}
\hline $\begin{array}{l}\text { Allocation concealment } \\
\text { (selection bias) }\end{array}$ & Unclear risk & Not described \\
\hline $\begin{array}{l}\text { Blinding of outcome as- } \\
\text { sessment (detection bias) } \\
\text { All outcomes }\end{array}$ & Low risk & $\begin{array}{l}\text { Outcome assessment conducted by physicians and nurses blinded to allocat- } \\
\text { ed treatment }\end{array}$ \\
\hline $\begin{array}{l}\text { Incomplete outcome data } \\
\text { (attrition bias) } \\
\text { All outcomes }\end{array}$ & Low risk & All randomised participants included in outcome evaluation \\
\hline $\begin{array}{l}\text { Selective reporting (re- } \\
\text { porting bias) }\end{array}$ & Low risk & All planned outcomes reported in full \\
\hline Other bias & Low risk & No other sources of bias identified \\
\hline
\end{tabular}

Dahiya 2012

\section{Study characteristics}

\begin{tabular}{ll}
\hline Methods & Study design: RCT \\
Location: New Delhi, India \\
Number of centres: 1 \\
Study period: not reported \\
Funding source: not reported \\
Setting: ICU of All India Institute of Medical Sciences \\
Inclusion criteria: adult patients $>18$ years) admitted to ICU on mechanical ventilation for < 24 hours \\
Exclusion criteria: not reported \\
Number randomised: $70\left(\mathrm{CHX}: 35 ; \mathrm{H}_{2} \mathrm{O}_{2}: 35\right)$ \\
Number evaluated: 70 (CHX: $\left.35 ; \mathrm{H}_{2} \mathrm{O}_{2}: 35\right)$ \\
Baseline characteristics: not reported; only stated that the demographic characteristics including age \\
and sex were comparable between two groups $(\mathrm{P}>0.05)$
\end{tabular}

Oral decontamination was done for the groups twice daily at 8:00 a.m. and 7.00 p.m. for three consecutive days by the investigator.

CHX: oral decontamination with $0.2 \%$ chlorhexidine gluconate solution $(15 \mathrm{~mL})$ twice daily at 8 a.m. and 7 p.m. for three consecutive days 
Dahiya 2012 (Continued)

$\mathrm{H}_{2} \mathrm{O}_{2}$ : oral decontamination using $\mathrm{H}_{2} \mathrm{O}_{2}$ with normal saline in a ratio of $1: 8(16 \mathrm{~mL})$ twice daily at 8 a.m. and 7 p.m. for three consecutive days

\begin{tabular}{ll}
\hline Outcomes & $\begin{array}{l}\text { 1. Incidence of VAP } \\
\text { 2. Oropharyngeal colonisation }\end{array}$ \\
\hline Notes & Sample size calculation: not reported \\
& $\begin{array}{l}\text { Other information of note: study investigator replied to email } 18 \text { March } 2020 \text { and stated that 1) all in- } \\
\text { cluded patients received MV for over } 48 \text { hours, 2) the CDC standard was used for diagnosis, and 3) VAP } \\
\text { diagnosis was made at } 48 \text { and } 72 \text { hours. }\end{array}$ \\
\hline
\end{tabular}

\section{Risk of bias}

\begin{tabular}{|c|c|c|}
\hline Bias & Authors' judgement & Support for judgement \\
\hline $\begin{array}{l}\text { Random sequence genera- } \\
\text { tion (selection bias) }\end{array}$ & Unclear risk & Not described \\
\hline $\begin{array}{l}\text { Allocation concealment } \\
\text { (selection bias) }\end{array}$ & Low risk & "random assignment was done by using numbered sealed envelope method". \\
\hline $\begin{array}{l}\text { Blinding of participants } \\
\text { and personnel (perfor- } \\
\text { mance bias) } \\
\text { All outcomes }\end{array}$ & High risk & $\begin{array}{l}\text { Blinding not described and not possible. Difference between intervention and } \\
\text { control means caregivers would be aware of who was in each group. }\end{array}$ \\
\hline $\begin{array}{l}\text { Blinding of outcome as- } \\
\text { sessment (detection bias) } \\
\text { All outcomes }\end{array}$ & Unclear risk & Not described \\
\hline $\begin{array}{l}\text { Incomplete outcome data } \\
\text { (attrition bias) } \\
\text { All outcomes }\end{array}$ & Low risk & No dropouts \\
\hline $\begin{array}{l}\text { Selective reporting (re- } \\
\text { porting bias) }\end{array}$ & Low risk & Planned outcomes reported \\
\hline Other bias & Unclear risk & $\begin{array}{l}\text { Insufficient information in the trial report to produce confidence in the } \\
\text { methodology of this trial }\end{array}$ \\
\hline
\end{tabular}

\section{De Lacerda 2017}

\section{Study characteristics}

\begin{tabular}{ll}
\hline Methods & Study design: two-arm parallel-group RCT \\
& Location: Brazil \\
& Number of centres: 4 \\
& Study period: July 2013 to January 2014 \\
& Funding source: Research Fund Program of Academic Strengthening of University of Pernambuco, and \\
participating hospitals' resources
\end{tabular}


De Lacerda 2017 (Continued)

Inclusion criteria: age equal or greater than 18 years, expected to remain on mechanical ventilation for

$>48 \mathrm{~h}$, without evidence of pulmonary infection at admission

Exclusion criteria: individuals without teeth, suspicion of pneumonia at the time of intubation, preg-

nancy, tracheostomy and chlorhexidine allergy

Number randomised: 213 (gp A: 105; gp B: 108)

Number evaluated: 213 (gp A: 105; gp B: 108)

Baseline characteristics:

-Gp A: (age: $59.4 \pm$ 14.5; M/F: 51/54; APACHE II Score: $21.9 \pm 7.5$ )

-Gp B: (age: $63.2 \pm 14.5$; M/F: 54/54; APACHE II Score: $22.2 \pm 7.7$ )

\section{Interventions Comparison: Toothbrushing + CHX gel versus CHX solution only}

Gp A (toothbrushing + CHX gel): individuals undergoing oral hygiene every $12 \mathrm{~h}$ through aspiration of oropharyngeal secretion. Immediately after, toothbrushing was carried out on all tooth surfaces, tongue and mucosal surface of the mouth through the use of toothbrushes with small and soft bristles, and dental gel based on $0.12 \% \mathrm{CHX}$ gluconate. After these steps, they proceeded with rinsing and suction through a catheter coupled to own toothbrush for the purpose of aspiration.

$\mathrm{Gp} \mathrm{B} \mathrm{(CHX} \mathrm{solution} \mathrm{only):} \mathrm{individuals} \mathrm{undergoing} \mathrm{oral} \mathrm{hygiene} \mathrm{every} 12 \mathrm{~h}$, through aspiration of oropharyngeal secretion, immediately applying $15 \mathrm{~mL}$ of $0.12 \% \mathrm{CHX}$ gluconate oral solution using a swab on all tooth surfaces, tongue and mucosal surface of the mouth

All participants underwent the standard protocol for VAP prevention, which included maintaining a semirecumbent body position, with head elevation of $\geq 30^{\circ}$, gastrointestinal bleeding prophylaxis, deep venous thrombosis prophylaxis and daily interruption of sedation with assessing the possibility of extubation.

\begin{tabular}{|c|c|}
\hline \multirow[t]{4}{*}{ Outcomes } & 1. Incidence of VAP \\
\hline & 2. Duration of mechanical ventilation \\
\hline & 3. Duration of ICU stay \\
\hline & 4. Mortality rate in ICU \\
\hline
\end{tabular}

Notes

Sample size calculation: reported for VAP incidence

Other information of note: none

\section{Risk of bias}

\begin{tabular}{lll}
\hline Bias & Authors' judgement & Support for judgement \\
\hline $\begin{array}{l}\text { Random sequence genera- } \\
\text { tion (selection bias) }\end{array}$ & Low risk & $\begin{array}{l}\text { "Patients were randomized...by means of opaque sealed envelopes containing } \\
\text { the results from a computer generated random list." }\end{array}$ \\
\hline $\begin{array}{l}\text { Allocation concealment } \\
\text { (selection bias) }\end{array}$ & Low risk & $\begin{array}{l}\text { "Patients were randomized by means of opaque sealed envelopes containing } \\
\text { the results from a computer generated random list". }\end{array}$ \\
\hline $\begin{array}{l}\text { Blinding of participants } \\
\begin{array}{l}\text { and personnel (perfor- } \\
\text { mance bias) }\end{array}\end{array}$ & High risk & $\begin{array}{l}\text { Researchers and physicians were blinded but nurses responsible for oral hy- } \\
\text { giene care were not blinded. }\end{array}$ \\
\hline $\begin{array}{l}\text { Blinding of outcome as- } \\
\text { sessment (detection bias) }\end{array}$ & Low risk & $\begin{array}{l}\text { "Researchers and physicians did not know to which of both groups the individ- } \\
\text { uals belonged, providing information to blind". }\end{array}$ \\
\hline
\end{tabular}


De Lacerda 2017 (Continued)

All outcomes

Incomplete outcome data Low risk All randomised participants included in outcome evaluation
(attrition bias)

(attrition bias)

All outcomes

\begin{tabular}{lll}
\hline $\begin{array}{l}\text { Selective reporting (re- } \\
\text { porting bias) }\end{array}$ & Low risk & Planned outcomes reported \\
\hline Other bias & Unclear risk & $\begin{array}{l}\text { The method of } \mathrm{CHX} \text { application was imbalanced between two groups (CHX gel } \\
\text { vs. CHX solution). }\end{array}$ \\
\hline
\end{tabular}

Feng 2012

\section{Study characteristics}

\begin{tabular}{l} 
Methods \\
Location: China \\
Number of centres: 1 ICU in a city hospital \\
Study period: February 2009 to January 2011 \\
Funding source: not stated \\
Inclusion criteria: entry ICU, with orotracheal intubation and ventilation \\
Exclusion criteria: pulmonary infection, stomatitis or oral tumours before intubation, accompanied by \\
ulcer of the digestive tract, malignant tumours of the body, taking steroids $>3$ days, diabetes \\
Number randomised: 204 \\
Number evaluated: 204 \\
Intervention group: $0.05 \%$ povidone iodine: $\mathrm{n}=71 ;$ mean age: $43.7 \pm 8.1$ years \\
Intervention group: $1 / 5000$ furacilin: $\mathrm{n}=65 ;$ mean age: $38.5 \pm 11.6$ years \\
Control group: saline $\mathrm{n}=68$; mean age: $40.3 \pm 8.5$ years \\
Baseline characteristics: not specified \\
\hline
\end{tabular}

Interventions

\section{Comparison: Povidone iodine + toothbrushing versus furacilin versus saline + toothbrushing}

Group A $(n=71)$ : toothbrushing along the slits between the teeth with $0.05 \%$ povidone iodine by nurses, then the oropharyngeal cavity was rinsed with $50 \mathrm{~mL}$ of the solution and it was suctioned out completely. This procedure was repeated 4 times a day.

Group B ( $n=65)$ : toothbrushing along the slits between the teeth with $1 / 5000$ furacilin by nurses

Control group $(n=68)$ : toothbrushing along the slits between the teeth with $0.9 \%$ saline by nurses, then the oropharyngeal cavity was rinsed with $50 \mathrm{~mL}$ of the saline and it was suctioned out completely. This procedure was repeated 4 times a day.

\begin{tabular}{ll}
\hline Outcomes & $\begin{array}{l}\text { 4 outcome variables were reported: } \\
\text { 1. Incidence of VAP }\end{array}$ \\
2. Rates of oral ulcer or herpes, or both
\end{tabular}


Feng 2012 (Continued)

3. Oral cleanliness - no odour, no foreign bodies and visually clean surfaces of tube and equipment

4. Throat swab culture

Notes Diagnosis of VAP was according to Chinese Society of Respiratory Diseases criteria

\section{Risk of bias}

\begin{tabular}{|c|c|c|}
\hline Bias & Authors' judgement & Support for judgement \\
\hline $\begin{array}{l}\text { Random sequence genera- } \\
\text { tion (selection bias) }\end{array}$ & Unclear risk & $\begin{array}{l}\text { "Patients were divided into three groups according to randomisation princi- } \\
\text { ple". }\end{array}$ \\
\hline $\begin{array}{l}\text { Allocation concealment } \\
\text { (selection bias) }\end{array}$ & Unclear risk & Not specified \\
\hline $\begin{array}{l}\text { Blinding of participants } \\
\text { and personnel (perfor- } \\
\text { mance bias) } \\
\text { All outcomes }\end{array}$ & High risk & $\begin{array}{l}\text { Blinding not described and not possible for the caregivers who would be } \\
\text { aware of who was in each group }\end{array}$ \\
\hline $\begin{array}{l}\text { Blinding of outcome as- } \\
\text { sessment (detection bias) } \\
\text { All outcomes }\end{array}$ & Unclear risk & Not specified \\
\hline $\begin{array}{l}\text { Incomplete outcome data } \\
\text { (attrition bias) } \\
\text { All outcomes }\end{array}$ & Low risk & All randomised participants included in the outcome evaluation \\
\hline $\begin{array}{l}\text { Selective reporting (re- } \\
\text { porting bias) }\end{array}$ & Low risk & The results were fully reported. \\
\hline Other bias & Low risk & No other sources of bias identified \\
\hline
\end{tabular}

\section{Fields 2008}

\section{Study characteristics}

\begin{tabular}{ll}
\hline Methods & Study design: parallel-group RCT \\
Location: Akron Ohio, USA \\
Number of centres: 1 \\
Study period: October 2005 to March 2006 \\
Funding source: internal hospital funding \\
Setting: 24-bed stroke, neurological and medical ICU \\
Inclusion criteria: any mechanically-ventilated patient on the stroke/medical ICU intubated in the hos- \\
pital for < 24 hours, no previous diagnosis of pneumonia \\
Exclusion criteria: patients with prior tracheotomies, younger than 18 years, AIDS secondary to im- \\
munocompromised systems, edentulous patients \\
Number randomised: not stated \\
Number evaluated: not stated
\end{tabular}


Fields 2008 (Continued)

Baseline characteristics: not reported

\section{Interventions Comparison: Toothbrushing 8-hourly versus usual care}

Experimental group: Nurse brushed patient's teeth, tongue and hard palate for $>1$ minute, then used toothette swab to swab patient's teeth, tongue and hard palate for $>1$ minute, then apply moisturiser to lips. Mouth and pharynx were suctioned as needed using catheter which was replaced every 24 hours. Oral assessment every 12 hours. Oral care kit \#2 provided for each participant, with worksheet \#2

Control group: Usual care (unspecified) which could include up to 2 toothbrushings daily and toothette mouthcare as needed. Nurses used oral care kit \#1 and worksheet \#1

\begin{tabular}{ll}
\hline Outcomes & 1. Incidence of VAP \\
\hline Notes & $\begin{array}{l}\text { Sample size calculation: "Desired sample size was } 200 \text { ventilator dependent patients or } 2000 \text { ventilator } \\
\text { days". } \\
\text { Email sent to authors } 3 \text { September } 2012 \text { requesting numbers of patients treated. No reply received. Tri- } \\
\text { al included in text as narrative only }\end{array}$
\end{tabular}

\section{Risk of bias}

\begin{tabular}{lll}
\hline Bias & Authors' judgement & Support for judgement \\
\hline $\begin{array}{l}\text { Random sequence genera- } \\
\text { tion (selection bias) }\end{array}$ & Unclear risk & $\begin{array}{l}\text { "..a plastic bin labelled 1-350, containing sealed envelopes which each had ei- } \\
\text { ther worksheet \#1 or \#2, plus information about the trial to give to families". } \\
\text { No mention of whether envelopes were sequentially numbered. Method of se- } \\
\text { quence generation not described }\end{array}$ \\
\hline $\begin{array}{l}\text { Allocation concealment } \\
\text { (selection bias) }\end{array}$ & Low risk & Allocation contained in sealed envelopes \\
\hline $\begin{array}{l}\text { Blinding of participants } \\
\text { and personnel (perfor- } \\
\text { mance bias) }\end{array}$ & High risk & Not possible; both nurses and participants would have known allocated treat- \\
All outcomes & ment.
\end{tabular}

\begin{tabular}{|c|c|c|}
\hline $\begin{array}{l}\text { Blinding of outcome as- } \\
\text { sessment (detection bias) }\end{array}$ & Unclear risk & $\begin{array}{l}\text { Outcome of VAP assessed by infection control nurse. Unclear whether this per- } \\
\text { son was blinded to allocated treatment }\end{array}$ \\
\hline
\end{tabular}

All outcomes

\begin{tabular}{|c|c|c|}
\hline $\begin{array}{l}\text { Incomplete outcome data } \\
\text { (attrition bias) }\end{array}$ & High risk & $\begin{array}{l}\text { The study neither reported the number of participants randomised nor the } \\
\text { number analysed. }\end{array}$ \\
\hline
\end{tabular}

\begin{tabular}{lll}
\hline $\begin{array}{l}\text { Selective reporting (re- } \\
\text { porting bias) }\end{array}$ & High risk & $\begin{array}{l}\text { No numerical data were reported in this paper. VAP incidence was not report- } \\
\text { ed by treatment group or with any measure of variance. }\end{array}$ \\
\hline Other bias & Unclear risk & $\begin{array}{l}\text { Insufficient information in the trial report to produce confidence in the } \\
\text { methodology of this trial }\end{array}$ \\
\hline
\end{tabular}

Fu 2019

\section{Study characteristics}

Methods Study design: 3-arm parallel-group RCT


Fu 2019 (Continued)

\author{
Location: China \\ Number of centres: 1 \\ Study period: May 2015 to May 2017 \\ Funding source: not reported
}

\title{
Participants
}

Setting: tertiary hospital

Inclusion criteria: age between 18 and 75, male or female, complete medical record, mechanical ventilation of $>48 \mathrm{~h}$

Exclusion criteria: severe burns of the respiratory tract, patients who need oral surgery, extubation within $48 \mathrm{~h}$, already had pneumonia, patients who may die within $48 \mathrm{~h}$, severe coagulation disorders, incomplete medical record

Number randomised: 120 (gp A: 40; gp B: 40; gp C: 40)

Number evaluated: 120 (gp A: 40; gp B: 40; gp C: 40)

Baseline characteristics:

-Gp A: age: 49.96 (9.02); M/F: 21/19; APACHE II Score: 22.96 (2.88)

-Gp B: age: 50.30 (8.67); M/F: 20/20 ; APACHE II Score: 22.67 (3.05)

-Gp C: age: 50.12 (8.49); M/F: 22/18; APACHE II Score: 23.15 (2.49)

\section{Comparison: $0.2 \% \mathrm{CHX}$ solution versus $0.12 \% \mathrm{CHX}$ solution versus usual care}

$\mathrm{Gp} \mathrm{A}(0.2 \% \mathrm{CHX}$ solution): cleaning of tongue, teeth and gum with swab soaked in $0.2 \% \mathrm{CHX}$, twice a day, for 30 days consecutively

$\mathrm{Gp} \mathrm{B}(0.12 \% \mathrm{CHX}$ solution): cleaning of tongue, teeth and gum with swab soaked in $0.12 \% \mathrm{CHX}$, twice a day, for 30 days consecutively

Gp C (usual care): cleaning of tongue, teeth and gum with swab soaked in normal saline, twice a day, for 7 days consecutively

All groups also received cleaning of mucus and secretions.

\begin{tabular}{|c|c|}
\hline \multirow[t]{7}{*}{ Outcomes } & 1. Incidence of VAP \\
\hline & 2. Duration of mechanical ventilation \\
\hline & 3. Duration of ICU stay \\
\hline & 4. Duration of hospital stay \\
\hline & 5. Mortality \\
\hline & 6. Plaque index \\
\hline & 7. Microbial colonisation \\
\hline
\end{tabular}

Notes Sample size calculation: not reported

Other information of note: none

\section{Risk of bias}




\section{Fu 2019 (Continued)}

\begin{tabular}{ll} 
Random sequence genera- $\quad$ Low risk & $\begin{array}{l}120 \text { patients receiving mechanical ventilation were randomly allocated to } 3 \\
\text { tion (selection bias) }\end{array}$ \\
\hline
\end{tabular}
tion (selection bias)

Allocation concealment $\quad$ Unclear risk Not described
(selection bias)

Blinding of participants High risk and personnel (performance bias)

All outcomes
Blinding not described and not possible. Difference between intervention and control means caregivers would be aware of who was in each group.

\begin{tabular}{|c|c|c|}
\hline $\begin{array}{l}\text { Blinding of outcome as- } \\
\text { sessment (detection bias) } \\
\text { All outcomes }\end{array}$ & Unclear risk & Not described \\
\hline $\begin{array}{l}\text { Incomplete outcome data } \\
\text { (attrition bias) } \\
\text { All outcomes }\end{array}$ & Low risk & No dropouts \\
\hline $\begin{array}{l}\text { Selective reporting (re- } \\
\text { porting bias) }\end{array}$ & Low risk & Planned outcomes reported \\
\hline Other bias & Unclear risk & $\begin{array}{l}\text { 1. Criteria for VAP diagnosis were not reported. } \\
\text { 2.The time point for plaque index measurement was not reported. }\end{array}$ \\
\hline
\end{tabular}

Grap 2011

\section{Study characteristics}

\begin{tabular}{|c|c|}
\hline \multirow[t]{5}{*}{ Methods } & Study design: RCT \\
\hline & Location: Virginia, USA \\
\hline & Number of centres: 2 units in same hospital, level 1 trauma centre \\
\hline & Study period: not stated \\
\hline & Funding source: Triservice Nursing research programme grant TSNRP MDA-905-03-TS02 \\
\hline \multirow[t]{8}{*}{ Participants } & Setting: surgical trauma ICU \& neuroscience ICU \\
\hline & $\begin{array}{l}\text { Inclusion criteria: patients intubated within } 12 \text { hours of admission to trauma centre (intubation may } \\
\text { have occurred in emergency department, in the field or in pre-hospital setting) }\end{array}$ \\
\hline & $\begin{array}{l}\text { Exclusion criteria: previous endotracheal tube placed in } 48 \text { hours prior to admission, clinical diagnosis } \\
\text { of pneumonia on admission, burn injuries, edentulous persons }\end{array}$ \\
\hline & $\begin{array}{l}\text { Number randomised: 152, } 7 \text { lost, enrolled sample } 145 \text { (71/74) (only } 75 \text { were still intubated after } 48 \\
\text { hours) }\end{array}$ \\
\hline & Number evaluated: at 48 or 72 hours $=60(36 / 24)($ for VAP) $39(21 / 18)$ \\
\hline & Baseline characteristics: not reported for each randomised group \\
\hline & Those with 48/72 hour data: \\
\hline & - Experimental group: $\mathrm{n}=36, \mathrm{M} / \mathrm{F} 27 / 9$, APACHE $\| \mathrm{I} 70.69 \pm 30.14$ \\
\hline
\end{tabular}


Grap 2011 (Continued)

- Control group: $\mathrm{n}=24, \mathrm{M} / \mathrm{F}$ 11/13, APACHE II $60.46 \pm 23.45$

\section{Interventions Comparison: chlorhexidine applied by swab versus usual care}

Experimental group: $1 \times 5 \mathrm{~mL}$ dose of chlorhexidine $0.12 \%$ applied to all areas of the oral cavity by swab within 12 hours after intubation. All participants received the usual oral comfort care (details not reported).

Control group: usual oral comfort care

\begin{tabular}{ll}
\hline Outcomes & 1. Incidence of VAP \\
2. CPIS score & 3. APACHE III \\
4. TRISS & 5. Oral health (DMFT) \\
\hline Notes & Sample size calculation: not reported (but pilot study published in 2004) \\
& Email sent and reply received to clarify the data
\end{tabular}

\section{Risk of bias}

\begin{tabular}{|c|c|c|}
\hline Bias & Authors' judgement & Support for judgement \\
\hline $\begin{array}{l}\text { Random sequence genera- } \\
\text { tion (selection bias) }\end{array}$ & Low risk & $\begin{array}{l}\text { "The subjects were randomised to a treatment group or control group using a } \\
\text { block randomisation scheme". }\end{array}$ \\
\hline $\begin{array}{l}\text { Allocation concealment } \\
\text { (selection bias) }\end{array}$ & Unclear risk & Not described \\
\hline $\begin{array}{l}\text { Blinding of participants } \\
\text { and personnel (perfor- } \\
\text { mance bias) } \\
\text { All outcomes }\end{array}$ & High risk & Not possible because no placebo used \\
\hline $\begin{array}{l}\text { Blinding of outcome as- } \\
\text { sessment (detection bias) } \\
\text { All outcomes }\end{array}$ & Unclear risk & Not mentioned \\
\hline $\begin{array}{l}\text { Incomplete outcome data } \\
\text { (attrition bias) } \\
\text { All outcomes }\end{array}$ & High risk & $\begin{array}{l}\text { Huge attrition, and reasons for losses not described for each group. Conclu- } \\
\text { sions based on 39/152 (26\%) of those originally randomised to treatment or } \\
\text { control }\end{array}$ \\
\hline $\begin{array}{l}\text { Selective reporting (re- } \\
\text { porting bias) }\end{array}$ & High risk & $\begin{array}{l}\text { Primary outcome planned was development of VAP but inclusion criteria used } \\
\text { in this study meant that fewer than half those randomised were at risk of de- } \\
\text { veloping VAP. }\end{array}$ \\
\hline Other bias & High risk & $\begin{array}{l}\text { Study report noted statistically significant difference in gender and CPIS score } \\
\text { between groups at baseline. No baseline characteristics data reported for each } \\
\text { randomised group, and likely that important prognostic factors e.g. place of } \\
\text { intubation, surgery, may have been different in each group }\end{array}$ \\
\hline
\end{tabular}


Hanifi 2017

\section{Study characteristics}

Study design: 2-arm parallel-group RCT
Location: Iran
Number of centres: 1
Study period: Oct 2013 to March 2014
Funding source: Zanjan University of Medical Sciences

Participants

Setting: ICU

Inclusion criteria: The patient should undergo mechanical ventilation for at least 12 hours, being in the age range of 18 to 70 years, no history of pneumonia and aspiration during the hospitalisation, or chemotherapy, and no maxillofacial fractures, scalds, pregnancy, anaemia, alcohol intoxication, or a recent myocardial infarction

Exclusion criteria: Separation from the mechanical ventilation before the end of the study period, vomiting during the use of gastrointestinal tract, death, or being dissuaded from continuing in any part of the study either by the patients' guardians or the doctors... If the patient was diagnosed with pneumonia based on the clinical pulmonary infection score (CPIS) during the first 12 hours, they were not included in the study.

Number randomised: 80 (gp A: 40; gp B: 40)

Number evaluated: 74 (gp A: 39; gp B: 35)

Baseline characteristics:

-Gp A: Age: $14.42 \pm 1.39 \star$; M/F: 25/14; APACHE II score: not reported

-Gp B: Age: $44.61 \pm 1.78^{\star}$; M/F: 25/10; APACHE II score: not reported

\section{Comparison: $0.05 \mathrm{ppm}$ ozonated water versus $0.2 \% \mathrm{CHX}$}

Gp A (ozonated water): Both of these mouthwashes were applied identically 3 times a day. Before the intervention, patients' mouth and trachea received standard suctioning. The swab impregnated with either of the mouthwashes was rubbed rotationally on the upper gums from the right to the left side of the mouth. It was, then, changed and rubbed rotationally on the lower gums from left to right. Two other swabs impregnated with the mouthwash were used to cleanse the upper and lower teeth. After using the swabs and having prepared by the suction, the cuff pressure of the ET tube was increased to $35 \mathrm{mmHg}$ via a manometer specifically used to measure the ET tube cuff pressure. Then, approximately $15 \mathrm{~mL}$ of the mouthwash was inserted into the patient's mouth and 30 seconds later the suctioning process was conducted. Immediately after the intervention, the cuff pressure was reduced to 15 to 20 $\mathrm{mmHg}$. This intervention occurred over a 4-day period.

Gp B (CHX): same as gp A, different mouthwash

Outcomes 1. VAP incidence

Notes

Sample size calculation: to determine the sample size, a pilot study was conducted. By considering $\alpha=$ $0.01, ß=0.1, P 1=0.13$ and $P 2=0.5$, the sample size of each group was estimated as 40 .

Other information of note: none

\section{Risk of bias}

Bias Authors' judgement Support for judgement


Hanifi 2017 (Continued)

Random sequence genera- Low risk "a range of numbers was randomly selected by the table of random numbers". tion (selection bias)

\begin{tabular}{lll}
\hline $\begin{array}{l}\text { Allocation concealment } \\
\text { (selection bias) }\end{array}$ & Unclear risk & Not described \\
\hline $\begin{array}{l}\text { Blinding of participants } \\
\text { and personnel (perfor- } \\
\text { mance bias) }\end{array}$ & High risk & $\begin{array}{l}\text { Double-blind means subjects and outcome assessor; blinding of the caregivers } \\
\text { not described and not possible. Difference between intervention and control } \\
\text { means caregivers would be aware of who was in each group. }\end{array}$ \\
\hline
\end{tabular}

$\begin{array}{ll}\text { Blinding of outcome as- } & \text { Low risk } \\ \text { sessment (detection bias) } & \text { server blind to the intervention method". }\end{array}$

All outcomes

\begin{tabular}{|c|c|c|}
\hline $\begin{array}{l}\text { Incomplete outcome data } \\
\text { (attrition bias) } \\
\text { All outcomes }\end{array}$ & Unclear risk & $\begin{array}{l}\text { Although the attrition rate ( } 7.5 \%) \text { was relatively low, the number of dropouts } \\
\text { was unbalanced between groups, and the reason for each dropout was not } \\
\text { clearly reported. }\end{array}$ \\
\hline
\end{tabular}

All outcomes clearly reported.

\begin{tabular}{lll}
\hline $\begin{array}{l}\text { Selective reporting (re- } \\
\text { porting bias) }\end{array}$ & Low risk & Planned outcomes reported \\
\hline Other bias & Low risk & No other sources of bias identified \\
\hline
\end{tabular}

\section{Hu 2009}

\section{Study characteristics}

\begin{tabular}{ll}
\hline Methods & Study design: RCT \\
Location: Beijing, China \\
Number of centres: 1 \\
Study period: Not stated \\
Funding source: No external funding \\
Setting: ICU in second affiliated hospital of PLA General Hospital \\
Inclusion criteria: Patients in ICU receiving mechanical ventilation \\
Exclusion criteria: Unclear \\
Number randomised: 47 \\
Number evaluated: Unclear \\
Baseline characteristics: Not reported for each randomised group in total \\
Those with $48 / 72$ hour data: \\
- Experimental group: $\mathrm{n}=25, \mathrm{M} / \mathrm{F} 16 / 9$, age range 19 - 68 \\
- Control group: $\mathrm{n}=22, \mathrm{M} / \mathrm{F} 13 / 9$, age range 22 - 60
\end{tabular}

Interventions Comparison: Saline swab + rinse versus saline swab


Hu 2009 (Continued)

Experimental group: Lips, teeth, tongue and palate were swabbed with a saline saturated cotton ball and the oral cavity was rinsed with saline twice daily.

Control group: Lips, teeth, tongue and palate were swabbed with saline saturated cotton ball twice daily.

\begin{tabular}{ll}
\hline Outcomes & VAP, mortality, days on ventilator, days in hospital, halitosis, ulceration \\
\hline Notes & $\begin{array}{l}\text { Information translated from Chinese paper by Shi Zongdao and colleagues. Unable to confirm outcome } \\
\text { data with trial authors }\end{array}$
\end{tabular}

\title{
Risk of bias
}

\begin{tabular}{|c|c|c|}
\hline Bias & Authors' judgement & Support for judgement \\
\hline $\begin{array}{l}\text { Random sequence genera- } \\
\text { tion (selection bias) }\end{array}$ & Low risk & $\begin{array}{l}\text { Email from author "the sequence was generated by using a random number } \\
\text { table". }\end{array}$ \\
\hline $\begin{array}{l}\text { Allocation concealment } \\
\text { (selection bias) }\end{array}$ & Low risk & $\begin{array}{l}\text { Email from author "allocation was concealed using opaque envelopes num- } \\
\text { bered with inclusion sequence". }\end{array}$ \\
\hline $\begin{array}{l}\text { Blinding of participants } \\
\text { and personnel (perfor- } \\
\text { mance bias) } \\
\text { All outcomes }\end{array}$ & High risk & Participants and caregivers were not blinded to interventions received. \\
\hline $\begin{array}{l}\text { Blinding of outcome as- } \\
\text { sessment (detection bias) } \\
\text { All outcomes }\end{array}$ & Low risk & $\begin{array}{l}\text { Email from author "the outcome assessors were a group of nurses not involvec } \\
\text { with the interventions". Probably blinded to allocated treatment group. }\end{array}$ \\
\hline $\begin{array}{l}\text { Incomplete outcome data } \\
\text { (attrition bias) } \\
\text { All outcomes }\end{array}$ & High risk & $\begin{array}{l}\text { The number of participants included in the outcome assessments at each time } \\
\text { point was unclear. VAP reported as percentages only }\end{array}$ \\
\hline $\begin{array}{l}\text { Selective reporting (re- } \\
\text { porting bias) }\end{array}$ & High risk & All planned outcomes reported but as percentages only \\
\hline Other bias & Low risk & No other sources of bias identified \\
\hline
\end{tabular}

Irani 2019

\section{Study characteristics}

Methods

\author{
Study design: 2-arm parallel-group RCT \\ Location: Iran \\ Number of centres: One \\ Study period: 2018 \\ Funding source: No funding was received for this study.
}

$\begin{array}{ll}\text { Participants } & \text { Setting: ICU } \\ & \text { Inclusion criteria: Anaesthetised patients aged } 18-65 \text { years, insertion of endotracheal tube on admis- } \\ & \text { sion to ICU and its maintenance during the study, lack of "immunoi", hepatitis, or HIV infection, scor- } \\ \text { ing below } 11 \text { based on Beck oral assessment scale, no history of herbal allergy, no hospitalisation prior }\end{array}$


Irani 2019 (Continued)

to admission to ICU, no history/symptom of gastric content aspiration, no coagulation disorders, no removable denture, at least 24 hours past the admission to ICU, no pregnancy, no chronic pulmonary disease (including chronic obstructive pulmonary disease, lung cancer, and chest trauma), scoring below 5 based on the modified clinical pulmonary infection score at the onset of the study

Exclusion criteria: Patient's death, patient's transfer to other departments before the end of the study, any visible oral injury and bleeding caused by endotracheal intubation or oropharyngeal airway insertion after the start of the study, removal of endotracheal tube for any reason, endotracheal re-intubation or tracheostomy at the time of the study, diagnosis of aspiration symptoms after the start of the study as documented in the patient's admission records, restriction in oral care practices and thus risk of aspiration, developing pneumonia 48 hours after starting the study as diagnosed by the physician, withdrawal of mechanical ventilation before 96 hours, and requiring cardiopulmonary resuscitation

Number randomised: 70 (group A: 35; group B: 35)

Number evaluated: 70 (group A: 35; group B: 35)

Baseline characteristics:

- Group A (Miswak): Age: 33.65 (13.51); M/F: 29/6; Glasgow Coma Scale (GCS): 5.8 (1.24)

- Group B (Chlorhexidine): Age: 34.83 (13.95); M/F: 26/9; GCS: 5.7 (1.36)

Interventions

Comparison: Miswak versus Chlorhexidine

Miswak: For five consecutive days, oral care was provided twice a day (every 12 hours) using miswak in the intervention group and $0.2 \%$ chlorhexidine mouthwash in the control group...After that, miswak was wetted using cool water, which had been boiled for 15 minutes; it was used to gently brush back and forth all interior, exterior, and masticatory surfaces of the teeth.

Chlorhexidine: Oral care procedure was similar to the intervention group except that, instead of miswak, a cotton swab dipped in $0.2 \%$ chlorhexidine was administered.

\begin{tabular}{ll}
\hline Outcomes & 1. Incidence of VAP \\
\hline Notes & Sample size calculation: Using the following formula and the incidence rate of VAP reported by Yao \\
& 2011, the sample size was estimated at 16 for each group within the confidence interval of $95 \%$ and sta- \\
tistical power of $95 \%$. In order to ensure sample size adequacy and to take account of possible attrition, & 35 patients were allocated to each group (total = 70). \\
& Other information of note: None
\end{tabular}

\section{Risk of bias}

\begin{tabular}{|c|c|c|}
\hline Bias & Authors' judgement & Support for judgement \\
\hline $\begin{array}{l}\text { Random sequence genera- } \\
\text { tion (selection bias) }\end{array}$ & Low risk & $\begin{array}{l}\text { "...randomly divided into the intervention and control groups through coin } \\
\text { flipping (heads = intervention group, tails = control group)" }\end{array}$ \\
\hline $\begin{array}{l}\text { Allocation concealment } \\
\text { (selection bias) }\end{array}$ & Unclear risk & Not described \\
\hline $\begin{array}{l}\text { Blinding of participants } \\
\text { and personnel (perfor- } \\
\text { mance bias) } \\
\text { All outcomes }\end{array}$ & High risk & This was single-blinded; only the outcome assessor was blinded. \\
\hline $\begin{array}{l}\text { Blinding of outcome as- } \\
\text { sessment (detection bias) } \\
\text { All outcomes }\end{array}$ & Low risk & $\begin{array}{l}\text { "To meet the blinding criterion, patients and the physician responsible for } \\
\text { pneumonia diagnosis were not aware of the distribution of the two study } \\
\text { groups." }\end{array}$ \\
\hline
\end{tabular}


Irani 2019 (Continued)

Incomplete outcome data Low risk Comment: The study flow diagram was not provided. Insufficient information (attrition bias) to permit judgement

All outcomes

\begin{tabular}{|c|c|}
\hline $\begin{array}{l}\text { Selective reporting (re- } \\
\text { porting bias) }\end{array}$ & High risk \\
\hline
\end{tabular}

Other bias Low risk No other sources of bias identified

Khaky 2018

\title{
Study characteristics
}

Methods

\author{
Study design: Two-arm parallel-group RCT \\ Location: Iran \\ Number of centres: one \\ Study period: November 2016 to May 2017 \\ Funding source: Not mentioned
}

\section{Participants}

\author{
Setting: ICU \\ Exclusion criteria: none \\ Number randomised: 80 (gp A: 40; gp B: 40) \\ Number evaluated: 75 (gp A: 37; gp B: 38) \\ Baseline characteristics:
}

Inclusion criteria: age between 18 to 70 years old, lack of clear trauma to the jaw and face that prevents oral care, having tracheal tube, locating the patient under mechanical ventilation, lack of pneumonia or respiratory infections at the beginning of entry to the hospital (MCPIS $<7$ ) up to 48 hours after intubation and there was no ban in respect of using Nanosil or Chlorhexidine such as allergy.

-Gp A: (Age: $41.6 \pm$ 15.9; M/F: 29/11; APACHE II score: not reported)

-Gp B: (Age: $44.1 \pm 16.5$; M/F: 27/13; APACHE II score: not reported)

\section{Interventions Comparison: Nanosil versus $2 \%$ Chlorhexidine}

Gp A (Nanosil): Patients in the case group received oral care with same method except that Nanosil was used instead of chlorhexidine. The intervention continued for five days or until obtaining the exit criteria.

Gp B (Chlorhexidine): Patients in the control group received standard treatment. For these patients, oral care was done by $15 \mathrm{~mL}$ of a $2 \%$ chlorhexidine solution, 3 times per day for five days that involved brushing the teeth, suctioning oral secretions, and rubbing the oropharyngeal mucosa.
Outcomes
1. VAP incidence (five days after initiation of intubation)
2. Mortality (five days after initiation of intubation)
3. MCPIS
4. SOFA 
Khaky 2018 (Continued)

5. GCS

Notes Sample size calculation: Not reported

Other information of note: None

\section{Risk of bias}

\begin{tabular}{|c|c|c|}
\hline Bias & Authors' judgement & Support for judgement \\
\hline $\begin{array}{l}\text { Random sequence genera- } \\
\text { tion (selection bias) }\end{array}$ & Unclear risk & Not described \\
\hline $\begin{array}{l}\text { Allocation concealment } \\
\text { (selection bias) }\end{array}$ & Unclear risk & Not described \\
\hline $\begin{array}{l}\text { Blinding of participants } \\
\text { and personnel (perfor- } \\
\text { mance bias) } \\
\text { All outcomes }\end{array}$ & High risk & $\begin{array}{l}\text { Blinding not described and not possible. Difference between intervention and } \\
\text { control meant caregivers would have been aware of who was in each group. }\end{array}$ \\
\hline $\begin{array}{l}\text { Blinding of outcome as- } \\
\text { sessment (detection bias) } \\
\text { All outcomes }\end{array}$ & Unclear risk & Not described \\
\hline $\begin{array}{l}\text { Incomplete outcome data } \\
\text { (attrition bias) } \\
\text { All outcomes }\end{array}$ & Unclear risk & $\begin{array}{l}\text { "During the study, } 3 \text { patients in the case group and } 2 \text { patients in the control } \\
\text { group were excluded." } \\
\text { Reasons for exclusion were not provided. }\end{array}$ \\
\hline $\begin{array}{l}\text { Selective reporting (re- } \\
\text { porting bias) }\end{array}$ & High risk & Mortality-related data were not reported. \\
\hline Other bias & Low risk & No other sources of bias identified \\
\hline
\end{tabular}

Koeman 2006

\section{Study characteristics}

$\begin{array}{ll}\text { Methods } & \text { Study design: multicentre randomised double-blind placebo-controlled trial with } 3 \text { parallel groups } \\ \text { Location: } 2 \text { university hospitals and } 3 \text { general hospitals in the Netherlands } \\ \text { Number of centres: } 5 \text { hospitals ( } 2 \text { surgical and } 5 \text { mixed ICUs) } \\ \text { Study period: February } 2001 \text { to March } 2003 \\ \text { Funding source: ZONMw Netherlands Organization for Health Research and Development (project } \\ \text { number 2200.0046) } \\ \text { Inclusion criteria: consecutive adult patients (> 18 years of age) needing mechanical ventilation for at } \\ \text { least } 48 \text { hours were included within } 24 \text { hours after intubation and start of mechanical ventilation. } \\ \text { Exclusion criteria: immunocompromised status pre-admission, pregnancy, physical condition not al- } \\ \text { lowing oral application of study medication } \\ \text { Age group: not stated } \\ \text { Number randomised: } 385\end{array}$


Koeman 2006 (Continued)

Number evaluated: 379

Group A: Chlorhexidine group: $\mathrm{n}=127$; mean age: $60.9 \pm 15.3$; M/F: 71/57; APACHE II: $22.2 \pm 7.02$

Group B: Chlorhexidine/COL group: $\mathrm{n}=128$; mean age: $62.4 \pm 19.1$; M/F: 66/61; APACHE II: $23.7 \pm 7.38$

Group C: Control group: $\mathrm{n}=130$; mean age: $62.1 \pm 15.9$; M/F: 93/37; APACHE II: $21.8 \pm 7.43$

\section{Interventions Comparison: Chlorhexidine (in petroleum jelly) versus petroleum jelly alone}

Group A: Chlorhexidine group $(n=127)$ : oral decontamination with chlorhexidine $(2 \%)$ in vaseline petroleum jelly

Group B: Chlorhexidine/COL group $(n=128)$ : oral decontamination with chlorhexidine plus colistin antibiotic chlorhexidine/colistin ( $\mathrm{CHX} / \mathrm{COL} 2 \% / 2 \%)$ in vaseline petroleum jelly

Group C: Control $(n=130)$ : oral decontamination with vaseline petroleum jelly

Trial medication was administered 4 times daily, after removing remnants of the previous dose with a gauze moistened with saline. Approximately $2 \mathrm{~cm}$ of paste, approximately $0.5 \mathrm{~g}$, was put on a gloved fingertip and administered to each side of the buccal cavity.

\section{Outcomes}

The following outcome variables were reported for each group.

1. Incidence of VAP

2. Incidence of early onset VAP

3. Days ventilated (mean $\pm S D)$

4. ICU stay (mean $\pm S D)$

5. Days in hospital after ICU discharge (mean \pm SD)

6. Changes of endotracheal colonisation through cultures in 3 time windows after ventilation, 1 to 3 days, 5 to 8 days and 9 to 12 days, respectively

Notes Sample size calculation: reported in paper together with planned sequential analysis

Only group $\mathrm{A}$ and group $\mathrm{C}$ included in this review

Email sent to author 26 August 2016 requesting mortality data but failed due to invalid email address

\section{Risk of bias}

\begin{tabular}{lll}
\hline Bias & Authors' judgement & Support for judgement \\
\hline $\begin{array}{l}\text { Random sequence genera- } \\
\text { tion (selection bias) }\end{array}$ & Low risk & $\begin{array}{l}\text { "...randomly assigned to one of three study groups by computerised randomi- } \\
\text { sation schedule. Randomization was stratified by hospital". }\end{array}$ \\
\hline $\begin{array}{l}\text { Allocation concealment } \\
\text { (selection bias) }\end{array}$ & Low risk & $\begin{array}{l}\text { The interventions were produced by an independent unit and we considered } \\
\text { allocation was concealed from the research team. }\end{array}$ \\
\hline $\begin{array}{l}\text { Blinding of participants } \\
\begin{array}{l}\text { and personnel (perfor- } \\
\text { mance bias) }\end{array}\end{array}$ & Low risk & Double-blind, placebo-controlled \\
$\begin{array}{l}\text { All outcomes } \\
\begin{array}{l}\text { Blinding of outcome as- } \\
\text { sessment (detection bias) } \\
\text { All outcomes }\end{array}\end{array}$ & Low risk & Double-blind, placebo-controlled \\
\hline
\end{tabular}


Koeman 2006 (Continued)

Incomplete outcome data Low risk The study was discontinued in 6 participants: 5 participants withdrew consent, (attrition bias) 1 due to adverse event. Intention-to-treat analysis included all participants for All outcomes primary outcome.

Selective reporting (re- Low risk All planned outcomes reported
porting bias)

Other bias Low risk Unlikely

Kusahara 2012a

\section{Study characteristics}

Methods

Study design: double-blind placebo-controlled RCT

Location: Sao Paulo, Brazil

Number of centres: 1, tertiary care hospital affiliated with Federal University of Sao Paulo, Brazil

Study period: 36 months, dates not stated

Funding source: grant from Fundacao de Amparo a Pesquisa do Estado de Sao Paulo (04-13361-2)

\section{Participants}

\section{Setting: PICU}

Inclusion criteria: Children admitted to PICU likely to require ventilation within 24 hours of admission

Exclusion criteria: Newborn, confirmed diagnosis of pneumonia at admission, known hypersensitivity to chlorhexidine, tracheostomy, duration of ventilation $<48$ hours, intubated for $>24$ hours prior to PICU admission

Number randomised: 96 (46/50)

Number evaluated: 96 , at day $2: 44 / 45$, at day $4: 23 / 23$

Baseline characteristics:

- Intervention group: Age: $12 \pm 49.75$ months; M/F: 28/18

- Control group: Age: $34.5 \pm 58.8$ months; M/F: $32 / 18$

\section{Toothbrushing $+0.12 \%$ chlorhexidine gel versus toothbrushing + placebo}

Experimental group: Oral care with toothbrushing and oral gel containing chlorhexidine twice daily (08:00 \& 20:00 hours). Mouth was divided into 4 quadrants and each brushed in a defined pattern. With child in lateral position, gel was applied directly to toothbrush, and all tooth surfaces (vestibular, lingual, occlusal and incisal) were cleaned and ventral surface of tongue was brushed posterior to anterior. Each quadrant was rinsed with water and excess fluid and debris were removed with continuous suction. Finally, oral foam applicator was immersed in the gel and applied all over the gingival surfaces of the participant.

Control group: Oral care with toothbrushing and placebo oral gel twice daily. With child in lateral position, gel was applied directly to toothbrush, and all tooth surfaces (vestibular, lingual, occlusal and incisal) were cleaned and ventral surface of tongue was brushed posterior to anterior. Each quadrant was rinsed with water and excess fluid and debris were removed with continual suction. Finally, oral foam applicator was immersed in the gel and applied all over the gingival surfaces of the participant.

$\begin{array}{ll}\text { Outcomes } & \text { 1. Incidence of VAP } \\ \text { 2. Duration of ventilation in PICU }\end{array}$

Oral hygiene care for critically ill patients to prevent ventilator-associated pneumonia (Review) 
Kusahara 2012a (Continued)
3. Length of stay in PICU
4. Hospital mortality
5. Tracheal colonisation with Gram +ve \& -ve organisms

Sample size calculation: reported that this was not done "due to the absence of previous research on
this population"
Email correspondence with Prof Pedreira confirmed that Pedreira 2009 and Kusahara 2012a both refer
to the same study (NCT $01083407 \&$ NCT0410682 at ClinicalTrials.gov)

\title{
Risk of bias
}

\begin{tabular}{|c|c|c|}
\hline Bias & Authors' judgement & Support for judgement \\
\hline $\begin{array}{l}\text { Random sequence genera- } \\
\text { tion (selection bias) }\end{array}$ & Low risk & $\begin{array}{l}\text { "..randomised into two groups using a balanced randomisation table generat- } \\
\text { ed by True Epistat Program" }\end{array}$ \\
\hline $\begin{array}{l}\text { Allocation concealment } \\
\text { (selection bias) }\end{array}$ & Low risk & $\begin{array}{l}\text { Both chlorhexidine and identical placebo gels were supplied by pharmacy in } \\
\text { identical containers and only the pharmacist was aware of the gel type for } \\
\text { each participant. }\end{array}$ \\
\hline $\begin{array}{l}\text { Blinding of participants } \\
\text { and personnel (perfor- } \\
\text { mance bias) } \\
\text { All outcomes }\end{array}$ & Low risk & $\begin{array}{l}\text { Double-blind. Identical placebo used so that neither participants nor clinical } \\
\text { staff were aware of allocated treatment }\end{array}$ \\
\hline $\begin{array}{l}\text { Blinding of outcome as- } \\
\text { sessment (detection bias) } \\
\text { All outcomes }\end{array}$ & Low risk & $\begin{array}{l}\text { Double-blind. Only the pharmacist was aware of the gel type for each partici- } \\
\text { pant. }\end{array}$ \\
\hline $\begin{array}{l}\text { Incomplete outcome data } \\
\text { (attrition bias) } \\
\text { All outcomes }\end{array}$ & Low risk & All randomised participants included in the outcome evaluation \\
\hline $\begin{array}{l}\text { Selective reporting (re- } \\
\text { porting bias) }\end{array}$ & Low risk & One primary and 4 secondary outcomes reported in full \\
\hline Other bias & Unclear risk & $\begin{array}{l}\text { Statistically significant difference in mean age of children in each group. This } \\
\text { may have introduced a bias. }\end{array}$ \\
\hline
\end{tabular}

Long 2012

\section{Study characteristics}

Methods

\author{
Study design: single-centre RCT with 2 parallel groups \\ Location: China \\ Number of centres: 1 ICU in the university hospital \\ Study period: February 2010 to March 2012 \\ Funding source: programme for Masters degree
}

\section{Participants}

Inclusion criteria: patients admitted to ICU, with oral intubation, receiving mechanical ventilation $\geq 48$ hours, age $\geq 18$ years, patients or their relatives agreed to participate in the study 
Long 2012 (Continued)

Exclusion criteria: intubated in emergency e.g. after cardiac arrest, operations upon the oral cavity, trauma of the respiratory tract, with severe bleeding or coagulation disorders

Number randomised: 70

Number evaluated: 61 (the other 9 were death or ventilation $<48$ hours)

- Intervention group: mean age: $60.06 \pm 10.71$ years, M/F 20/11, APACHE $17.94 \pm 1.24$

- Control group: mean age: $63.67 \pm 10.02$ years, M/F 18/12, APACHE $18.23 \pm 0.57$

Interventions

\section{Comparison: povidone iodine + toothbrushing vs povidone iodine alone}

Experimental group $(n=31)$ : modified oral nursing method: swab with $0.1 \%$ povidone iodine immediately before intubation, then toothbrushing and rinsing with $0.1 \%$ povidone iodine, 3 times a day

Control group $(n=30)$ : usual oral nursing method: swab with cotton balls soaked with $0.1 \%$ povidone iodine

\begin{tabular}{|c|c|c|}
\hline \multirow[t]{4}{*}{ Outcomes } & \multicolumn{2}{|c|}{3 outcome variables were available: } \\
\hline & \multicolumn{2}{|l|}{ 1. Incidence of VAP } \\
\hline & \multicolumn{2}{|l|}{ 2. Mortality } \\
\hline & \multicolumn{2}{|l|}{ 3. Ventilation days } \\
\hline Notes & \multicolumn{2}{|c|}{$\begin{array}{l}\text { Microbial examinations for the aspirate secretions obtained from inferior respiratory tract every day af- } \\
\text { ter intubation were referred for diagnosis of VAP. }\end{array}$} \\
\hline \multicolumn{3}{|l|}{ Risk of bias } \\
\hline Bias & Authors' judgement & Support for judgement \\
\hline $\begin{array}{l}\text { Random sequence genera- } \\
\text { tion (selection bias) }\end{array}$ & Unclear risk & $\begin{array}{l}\text { "...patients were randomly assigned into } 2 \text { groups, observing group and con- } \\
\text { trol group with } 35 \text { cases in each group". }\end{array}$ \\
\hline $\begin{array}{l}\text { Allocation concealment } \\
\text { (selection bias) }\end{array}$ & Unclear risk & Not specified \\
\hline $\begin{array}{l}\text { Blinding of participants } \\
\text { and personnel (perfor- } \\
\text { mance bias) } \\
\text { All outcomes }\end{array}$ & High risk & $\begin{array}{l}\text { Blinding not described and not possible for the caregivers who would be } \\
\text { aware of who was in each group }\end{array}$ \\
\hline $\begin{array}{l}\text { Blinding of outcome as- } \\
\text { sessment (detection bias) } \\
\text { All outcomes }\end{array}$ & Unclear risk & Not specified \\
\hline $\begin{array}{l}\text { Incomplete outcome data } \\
\text { (attrition bias) } \\
\text { All outcomes }\end{array}$ & Low risk & $\begin{array}{l}9 \text { randomised participants were excluded from analysis; numbers and reasons } \\
\text { similar for each group }\end{array}$ \\
\hline $\begin{array}{l}\text { Selective reporting (re- } \\
\text { porting bias) }\end{array}$ & Low risk & Planned outcomes reported \\
\hline Other bias & Unclear risk & $\begin{array}{l}\text { Results of microbial examination of the aspirate secretions from the inferior } \\
\text { respiratory tract as tool of VAP diagnosis may not be enough. }\end{array}$ \\
\hline
\end{tabular}


Lorente 2012

\section{Study characteristics}

\begin{tabular}{ll}
\hline Methods & Study design: Parallel-group RCT \\
Location: Tenerife, Spain \\
Number of centres: 1 \\
Study period: August 2010 to August 2011 \\
Funding source: Hospital funding \\
Setting: medical/surgical ICU \\
Inclusion criteria: consecutive patients undergoing invasive mechanical ventilation for at least 24 hours \\
Exclusion criteria: edentulous, aged < 18 years, pregnant, HIV positive, white blood cells < 1000 cells/ \\
mm 3 , solid or haematological tumour, immunosuppressive therapy, mechanical ventilation duration < \\
24 hours \\
Number randomised: 436 (217/219) \\
Number evaluated: 436 \\
Baseline characteristics: \\
- Intervention group: age: $61.0 \pm 15.6$ years; M/F: $146 / 71$ \\
- Control group: age: $60.4 \pm 16.6$ years; M/F: $145 / 74$ \\
\hline
\end{tabular}

Interventions

\section{Toothbrushing $+\mathbf{0 . 1 2} \%$ chlorhexidine gel vs chlorhexidine alone}

Experimental group $(n=217)$ : oral cleansing performed with $0.12 \%$ chlorhexidine-impregnated gauze, and oral cavity injection, followed by manual brushing of the teeth with a brush impregnated with $0.12 \%$ chlorhexidine (tooth by tooth on the anterior and posterior surfaces, the gum line and the tongue for a period of 90 seconds)

Control group $(n=219)$ : oral cleansing performed with $0.12 \%$ chlorhexidine-impregnated gauze, and oral cavity injection only

In both groups, nurse performed oral care every 8 hours. First endotracheal cuff pressure was tested, oropharyngeal secretions were aspirated, then chlorhexidine-impregnated gauze was used to cleanse the teeth, tongue and mucosal surfaces, followed by injection of $10 \mathrm{~mL} 0.12 \%$ of chlorhexidine digluconate into oral cavity, and finally after 30 seconds the OParea was suctioned.

\begin{tabular}{|c|c|}
\hline \multirow[t]{5}{*}{ Outcomes } & 1. Incidence of VAP \\
\hline & 2. Duration of ventilation \\
\hline & 3. ICU mortality \\
\hline & 4. Tracheal colonisation with gram +ve \& -ve organisms \\
\hline & 5. Antibiotic exposure \\
\hline
\end{tabular}
a error of $5 \%$, to show a reduction in VAP from $15 \%$ to $7.5 \%$

\section{Risk of bias}

Bias Authors' judgement Support for judgement


Lorente 2012 (Continued)
Random sequence genera- Low risk
"...a list of random numbers generated with Excel software (Microsoft, Seattle, tion (selection bias) WA)"

Allocation concealment $\quad$ Unclear risk No information about allocation concealment
(selection bias)

\begin{tabular}{|c|c|c|}
\hline $\begin{array}{l}\text { Blinding of participants } \\
\text { and personnel (perfor- } \\
\text { mance bias) } \\
\text { All outcomes }\end{array}$ & High risk & Not possible \\
\hline
\end{tabular}

\begin{tabular}{|c|c|c|}
\hline $\begin{array}{l}\text { Blinding of outcome as- } \\
\text { sessment (detection bias) } \\
\text { All outcomes }\end{array}$ & Low risk & $\begin{array}{l}\text { "The diagnosis of VAP was made by an expert panel, blinded to group assign- } \\
\text { ment". }\end{array}$ \\
\hline $\begin{array}{l}\text { Incomplete outcome data } \\
\text { (attrition bias) } \\
\text { All outcomes }\end{array}$ & Low risk & All randomised participants are included in the outcome evaluations. \\
\hline $\begin{array}{l}\text { Selective reporting (re- } \\
\text { porting bias) }\end{array}$ & Low risk & Planned outcomes reported in full \\
\hline Other bias & Low risk & No other sources of bias identified \\
\hline
\end{tabular}

\section{Meidani 2018}

\section{Study characteristics}

\begin{tabular}{|c|c|}
\hline \multirow[t]{5}{*}{ Methods } & Study design: 3-arm parallel-group RCT \\
\hline & Location: Iran \\
\hline & Number of centres: 1 \\
\hline & Study period: 2011 to 2012 \\
\hline & $\begin{array}{l}\text { Funding source: fully sponsored by Research Council of Isfahan University of Medical Sciences, Isfahan, } \\
\text { Iran }\end{array}$ \\
\hline \multirow[t]{9}{*}{ Participants } & Setting: ICU \\
\hline & $\begin{array}{l}\text { Inclusion criteria: ICU-admitted patients on ventilator for more than } 48 \text { hours, age over } 18 \text { years, no } \\
\text { fever at the time of entering the ICU, no pneumonia, no allergy to the drugs used }\end{array}$ \\
\hline & $\begin{array}{l}\text { Exclusion criteria: in the case of patients who died or were released from hospital before the due date } \\
\text { or patients with the appearance of drug complications were excluded from the study. They were also } \\
\text { excluded if they had pneumonia before } 48 \mathrm{~h} \text { of hospitalisation or ventilation. }\end{array}$ \\
\hline & Number randomised: 150 (gp A: 50; gp B: 50; gp C: 50) \\
\hline & Number evaluated: 150 (gp A: 50; gp B: 50; gp C: 50) \\
\hline & Baseline characteristics: \\
\hline & -Gp A: (Age: $50.6 \pm$ 19.1; M/F: 37/13; APACHE II score: not reported) \\
\hline & -Gp B: (Age: $49.8 \pm 22.7 ;$ M/F: 37/13; APACHE II score: not reported) \\
\hline & -Gp C: (Age: $51.7 \pm 18.9 ;$ M/F: 33/17; APACHE II score: not reported) \\
\hline
\end{tabular}


Meidani 2018 (Continued)

Interventions

\section{Comparison: $0.2 \% \mathrm{CHX}$ versus $0.01 \%$ potassium permanganate versus control}

Gp A ( $\mathrm{CHX}$ ), B (potassium permanganate) and C (control): mouth and pharynx washing of selected patients was done by the trained nurses, three times a day, each time for 5 minutes, for 1 week by tongue depresson and sterile gas with $10 \mathrm{cc}$ solution

1. Incidence of VAP

2. Mortality
Sample size calculation: not mentioned

Other information of note: none

\section{Risk of bias}

\begin{tabular}{|c|c|c|}
\hline Bias & Authors' judgement & Support for judgement \\
\hline $\begin{array}{l}\text { Random sequence genera- } \\
\text { tion (selection bias) }\end{array}$ & Unclear risk & No details of method of sequence generation provided in report \\
\hline $\begin{array}{l}\text { Allocation concealment } \\
\text { (selection bias) }\end{array}$ & Unclear risk & Not described \\
\hline $\begin{array}{l}\text { Blinding of participants } \\
\text { and personnel (perfor- } \\
\text { mance bias) } \\
\text { All outcomes }\end{array}$ & High risk & $\begin{array}{l}\text { Blinding not described and not possible. Difference between intervention and } \\
\text { control meant caregivers would be aware of who was in each group. }\end{array}$ \\
\hline $\begin{array}{l}\text { Blinding of outcome as- } \\
\text { sessment (detection bias) } \\
\text { All outcomes }\end{array}$ & Unclear risk & Not described \\
\hline $\begin{array}{l}\text { Incomplete outcome data } \\
\text { (attrition bias) } \\
\text { All outcomes }\end{array}$ & Unclear risk & $\begin{array}{l}\text { "In case of patient's death or release from hospital before due date or appear- } \\
\text { ance of drug complications, they were excluded from the study. They were al- } \\
\text { so excluded if they had pneumonia before } 48 \text { h of hospitalization or ventila- } \\
\text { tion." }\end{array}$ \\
\hline $\begin{array}{l}\text { Selective reporting (re- } \\
\text { porting bias) }\end{array}$ & Unclear risk & Insufficient information \\
\hline Other bias & Unclear risk & $\begin{array}{l}\text { Insufficient information in the trial report to produce confidence in the } \\
\text { methodology of this trial }\end{array}$ \\
\hline
\end{tabular}

Meinberg 2012

\section{Study characteristics}

\begin{tabular}{ll}
\hline Methods & Study design: parallel-group RCT \\
Location: Brazil \\
Number of centres: 1 \\
Study period: July 2007 to December 2009 \\
Funding source: not stated \\
\hline
\end{tabular}


Meinberg 2012 (Continued)
Participants
Setting: surgical ICU
Inclusion criteria: > 18 years, receiving mechanical ventilation within 24 hours of admission, expected to require ventilation for $>72$ hours
Exclusion criteria: aspiration pneumonia, tracheostomy, pregnancy and immunosuppression
Number randomised: 52 (28/24)
Number evaluated: 52 (28/24)
Baseline characteristics:
- Intervention group: age: $40.1 \pm 14.6$ years; APACHE II $17.9 \pm 4.5$
- Control group: age: $41.0 \pm 19.0$ years; APACHE II $16.7 \pm 6.8$

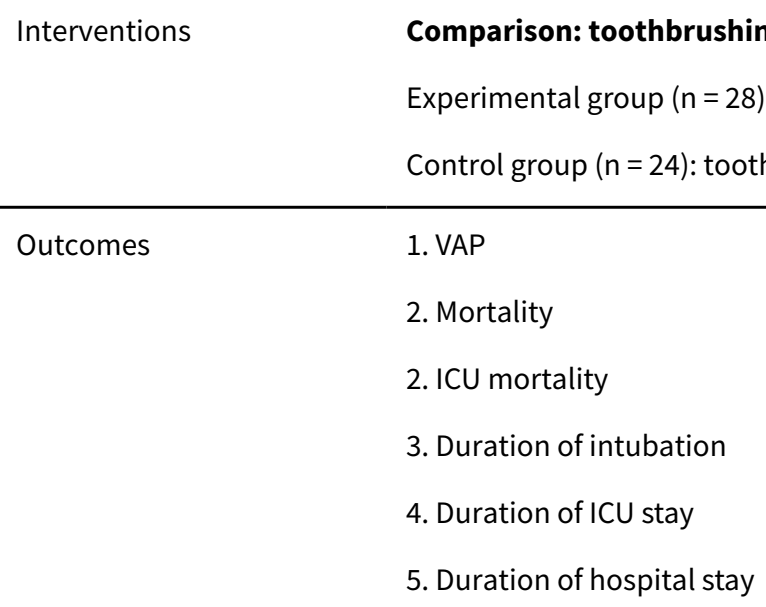

Notes

Errors in numbers reported for duration of intubation in Table 2

\section{Risk of bias}

\begin{tabular}{|c|c|c|}
\hline Bias & Authors' judgement & Support for judgement \\
\hline $\begin{array}{l}\text { Random sequence genera- } \\
\text { tion (selection bias) }\end{array}$ & Unclear risk & This was undertaken by the pharmacist. \\
\hline $\begin{array}{l}\text { Allocation concealment } \\
\text { (selection bias) }\end{array}$ & Low risk & $\begin{array}{l}\text { "only the pharmacist responsible for preparing the solutions and for the ran- } \\
\text { domisation process knew the contents of the distributed gel tubes". }\end{array}$ \\
\hline $\begin{array}{l}\text { Blinding of participants } \\
\text { and personnel (perfor- } \\
\text { mance bias) } \\
\text { All outcomes }\end{array}$ & Low risk & $\begin{array}{l}\text { "only the pharmacist responsible for preparing the solutions and for the ran- } \\
\text { domisation process knew the contents of the distributed gel tubes", } \\
\text { "placebo group (gel with same colour and consistency)" }\end{array}$ \\
\hline $\begin{array}{l}\text { Blinding of outcome as- } \\
\text { sessment (detection bias) } \\
\text { All outcomes }\end{array}$ & Low risk & $\begin{array}{l}\text { "only the pharmacist responsible for preparing the solutions and for the ran- } \\
\text { domisation process knew the contents of the distributed gel tubes". }\end{array}$ \\
\hline $\begin{array}{l}\text { Incomplete outcome data } \\
\text { (attrition bias) } \\
\text { All outcomes }\end{array}$ & Low risk & No dropouts \\
\hline
\end{tabular}


Meinberg 2012 (Continued)

Selective reporting (re- High risk Adverse events not reported. Data not fully reported. Data errors porting bias)

Other bias

High risk

Study terminated due to 'futility'. Reason for termination unclear

Mo 2016

\section{Study characteristics}

\begin{tabular}{|c|c|c|}
\hline \multirow[t]{5}{*}{ Methods } & \multicolumn{2}{|c|}{ Study design: 2-arm parallel-group RCT } \\
\hline & \multicolumn{2}{|l|}{ Location: China } \\
\hline & \multicolumn{2}{|l|}{ Number of centres: 1} \\
\hline & \multicolumn{2}{|c|}{ Study period: December 2012 to May 2015} \\
\hline & \multicolumn{2}{|c|}{ Funding source: not reported } \\
\hline \multirow[t]{8}{*}{ Participants } & \multicolumn{2}{|c|}{ Setting: Department of Cardio-Thoracic Surgery } \\
\hline & \multicolumn{2}{|c|}{ Inclusion criteria: mechanical ventilation $>48$ hours } \\
\hline & \multicolumn{2}{|c|}{ Exclusion criteria: patients with pulmonary infections or oral diseases } \\
\hline & \multicolumn{2}{|c|}{ Number randomised: 210 (gp A: 105; gp B: 105) } \\
\hline & \multicolumn{2}{|c|}{ Number evaluated: 210 (gp A: 105; gp B: 105) } \\
\hline & \multicolumn{2}{|c|}{ Baseline characteristics: } \\
\hline & \multicolumn{2}{|c|}{ - Gp A: Age: 59.14 (12.06); M/F: 60/45 } \\
\hline & \multicolumn{2}{|c|}{ - Gp B: Age: 56.71 (10.53); M/F: 68/37 } \\
\hline \multirow[t]{3}{*}{ Interventions } & \multicolumn{2}{|c|}{ Comparison: saline rinse vs saline swab (usual care) } \\
\hline & \multicolumn{2}{|c|}{ Gp A: rinse with saline for 10 minutes each time, 4 times per day } \\
\hline & \multicolumn{2}{|c|}{ Gp B: swab with saline 4 times per day } \\
\hline \multirow[t]{2}{*}{ Outcomes } & \multicolumn{2}{|l|}{ 1. Incidence of VAP } \\
\hline & \multicolumn{2}{|l|}{ 2. Mortality } \\
\hline Notes & \multicolumn{2}{|c|}{ Sample size calculation: Not reported } \\
\hline \multicolumn{3}{|l|}{ Risk of bias } \\
\hline Bias & Authors' judgement & Support for judgement \\
\hline $\begin{array}{l}\text { Random sequence genera- } \\
\text { tion (selection bias) }\end{array}$ & Low risk & $\begin{array}{l}\text { Quote: "randomised patients to the experimental and control group using a } \\
\text { random number table" }\end{array}$ \\
\hline $\begin{array}{l}\text { Allocation concealment } \\
\text { (selection bias) }\end{array}$ & Unclear risk & Not reported \\
\hline
\end{tabular}


Mo 2016 (Continued)

Blinding of participants High risk Blinding not described and not possible and personnel (perfor-

mance bias)

All outcomes

\begin{tabular}{lll}
\hline Blinding of outcome as- & Unclear risk & Assessor blinding not described \\
sessment (detection bias) &
\end{tabular}

All outcomes

Incomplete outcome data Low risk

All randomised participants included in analysis

(attrition bias)

All outcomes

\begin{tabular}{lll}
\hline $\begin{array}{l}\text { Selective reporting (re- } \\
\text { porting bias) }\end{array}$ & Low risk & Planned outcomes reported \\
\hline Other bias & Low risk & No other sources of bias identified \\
\hline
\end{tabular}

Nobahar 2016

\section{Study characteristics}

\begin{tabular}{|c|c|}
\hline \multirow[t]{5}{*}{ Methods } & Study design: 2-arm parallel-group RCT \\
\hline & Location: Iran \\
\hline & Number of centres: 1 \\
\hline & Study period: May 232013 to December 232012 \\
\hline & $\begin{array}{l}\text { Funding source: Research and Technology Deputy of Semnan University of Medical Sciences (Grant no. } \\
\text { 514) }\end{array}$ \\
\hline \multirow[t]{8}{*}{ Participants } & Setting: ICU \\
\hline & $\begin{array}{l}\text { Inclusion criteria: being over the age of } 18 \text {, having been under mechanical ventilation for over } 48 \text { hours, } \\
\text { having had no more than one intubation attempt, no facial or oral trauma, no contraindications to nei- } \\
\text { ther mouthwash use nor to } 30^{\circ} \text { bedhead elevation, no history of HP allergies, and no evidence suggest- } \\
\text { ing VAP or aspiration }\end{array}$ \\
\hline & $\begin{array}{l}\text { Exclusion criteria: having had pneumonia prior to the beginning of the study and in the first } 48 \text { hours of } \\
\text { mechanical ventilation, transfer from other departments and the elapse of } 24 \text { hours since the insertion } \\
\text { of the tracheal tube, the removal of the tracheal tube for any reason during the } 5 \text { days the study was } \\
\text { being conducted, and the patient's death or transfer from the internal unit to the surgery ICU and vice } \\
\text { versa at any time during the } 5 \text { days of the study }\end{array}$ \\
\hline & Number randomised: 68 (HP group: 34; control group: 34) \\
\hline & Number evaluated: 68 (HP group: 34; control group: 34 ) \\
\hline & Baseline characteristics: \\
\hline & - HP group: (age: $66 \pm 15.5 ;$ M/F: 17/17; APACHE II score: not reported) \\
\hline & - Control group: (age: $63.4 \pm 20.5 ; \mathrm{M} / \mathrm{F}: 18 / 16 ;$ APACHE II score: not reported) \\
\hline
\end{tabular}

Interventions

Comparison: $3 \%$ hydrogen peroxide (HP) versus $0.9 \%$ normal saline (NS) 
HP: after wearing sterile gloves, the patient's oral mucosal membrane, tongue and gingiva were washed using 4-6 cotton swabs (depending on the patient's oral health) soaked in $15 \mathrm{cc}$ of $3 \% \mathrm{HP}$. Any excess discharges were collected through suction pumps under similarly equal conditions. The application of these mouthwash formulas continued for five days.

Control: after wearing sterile gloves, the patient's oral mucosal membrane, tongue and gingiva were washed using 4-6 cotton swabs (depending on the patient's oral health) soaked in $15 \mathrm{cc}$ of $0.9 \%$ NS. Any excess discharges were collected through suction pumps under similarly equal conditions. The application of these mouthwash formulas continued for five days.

Conditions of using the mouthwash were similar in both groups, and after washing their hands, the bedhead was elevated $30^{\circ}$ in order to prevent aspiration of secretions. Before the application of mouthwash and after elevating the bedhead, the tracheal tube and mouth secretions were suctioned out using a green nelaton catheter size 14 . The suction nozzle was replaced after each application of the mouthwash. This procedure was repeated twice every day at 8 a.m. and 4 p.m.

Outcomes Incidence of VAP

\section{Notes}

\section{Risk of bias}

\begin{tabular}{|c|c|c|}
\hline Bias & Authors' judgement & Support for judgement \\
\hline $\begin{array}{l}\text { Random sequence genera- } \\
\text { tion (selection bias) }\end{array}$ & Low risk & $\begin{array}{l}\text { "Patients were randomly divided into two groups by the use of a coin toss, } \\
\text { where heads were assigned to the intervention and tails to the control group". }\end{array}$ \\
\hline $\begin{array}{l}\text { Allocation concealment } \\
\text { (selection bias) }\end{array}$ & Unclear risk & Not described \\
\hline $\begin{array}{l}\text { Blinding of participants } \\
\text { and personnel (perfor- } \\
\text { mance bias) } \\
\text { All outcomes }\end{array}$ & Unclear risk & $\begin{array}{l}\text { Impossible to blind health providers due to the obvious difference between } \\
\text { hydrogen peroxide and normal saline }\end{array}$ \\
\hline $\begin{array}{l}\text { Blinding of outcome as- } \\
\text { sessment (detection bias) } \\
\text { All outcomes }\end{array}$ & Unclear risk & Not described \\
\hline $\begin{array}{l}\text { Incomplete outcome data } \\
\text { (attrition bias) } \\
\text { All outcomes }\end{array}$ & Low risk & No dropouts \\
\hline $\begin{array}{l}\text { Selective reporting (re- } \\
\text { porting bias) }\end{array}$ & High risk & $\begin{array}{l}\text { Planned baseline information (e.g. occupation, the department referring the } \\
\text { patient to the ICU, duration of hospital stay) and results regarding adverse ef- } \\
\text { fects were not reported. }\end{array}$ \\
\hline Other bias & Low risk & No other sources of bias identified \\
\hline
\end{tabular}

Ozcaka 2012

\section{Study characteristics}

\begin{tabular}{ll}
\hline Methods & Study design: double-blind placebo-controlled RCT \\
& Location: Izmir, Turkey
\end{tabular}


Ozcaka 2012 (Continued)

\section{Number of centres: 1}

Study period: November 2007 to November 2009

Funding source: "The study was funded solely by the institutions of the authors".

Setting: respiratory ICU
Inclusion criteria: patients aged 18 or over, admitted to respiratory ICU expecting to require ventilation
for $>48$ hours
Exclusion criteria: witnessed episode of aspiration, confirmed diagnosis of post-obstructive pneumo-
nia, known hypersensitivity to chlorhexidine, diagnosed thrombocytopenia, pregnancy, oral mucositis,
readmission to same ICU, expected survival < 1 week, edentulism
Number randomised: 66
Number evaluated: 61
Baseline characteristics:
- Intervention group: age: $60.5 \pm 14.7$ years
- Control group: age: $56.0 \pm 18.2$ years

Interventions Comparison: chlorhexidine solution vs saline

Experimental group $(n=32)$ : oral mucosa was swabbed with $0.2 \%$ chlorhexidine on sponge pellets, 4 times daily. Excess rinse was suctioned from patient's mouth after 1 minute.

Control group ( $n=34)$ : oral mucosa was swabbed with saline on sponge pellets, 4 times daily. Excess rinse was suctioned from patient's mouth after 1 minute.

Deep suctioning was performed in both groups every 6 hours and following position changes to remove pooled secretions from around the cuff of the endotracheal tube.

\begin{tabular}{|c|c|c|}
\hline \multirow[t]{5}{*}{ Outcomes } & \multicolumn{2}{|l|}{ 1. Incidence of VAP } \\
\hline & \multicolumn{2}{|l|}{ 2. Mortality } \\
\hline & \multicolumn{2}{|c|}{ 3. Duration of ventilation in ICU } \\
\hline & \multicolumn{2}{|l|}{ 4. Length of stay in ICU } \\
\hline & \multicolumn{2}{|c|}{ 5. Presence of potential respiratory pathogens in minibronchoalveolar lavage } \\
\hline \multirow[t]{2}{*}{ Notes } & \multicolumn{2}{|c|}{$\begin{array}{l}\text { Sample size calculation: estimated that } 28 \text { participants would be required in each group to give } 81 \% \\
\text { power with a of } 5 \% \text {, to show a reduction in VAP from } 70 \% \text { to } 30 \%\end{array}$} \\
\hline & \multicolumn{2}{|c|}{ Email sent 22 January 2013 and reply received 29 January 2013} \\
\hline \multicolumn{3}{|l|}{ Risk of bias } \\
\hline Bias & Authors' judgement & Support for judgement \\
\hline $\begin{array}{l}\text { Random sequence genera- } \\
\text { tion (selection bias) }\end{array}$ & Unclear risk & $\begin{array}{l}\text { "The randomisation prepared a set of subject identification (SID) numbers } \\
\text { which had assigned treatment". Description unclear }\end{array}$ \\
\hline $\begin{array}{l}\text { Allocation concealment } \\
\text { (selection bias) }\end{array}$ & Unclear risk & "Study nurse obtained the SID number when the patient was enrolled". \\
\hline
\end{tabular}


Ozcaka 2012 (Continued)

Blinding of participants Low risk "Assignment of treatment was blinded to patients and to all investigators, inand personnel (perforcluding periodontist,... respiratory ICU physicians and outcome statisticians". mance bias)

All outcomes

\section{Blinding of outcome as- Low risk} sessment (detection bias) All outcomes

\begin{abstract}
"Assignment of treatment was blinded to patients and to all investigators, including periodontist,.... respiratory ICU physicians and outcome statisticians".
\end{abstract}

\section{Incomplete outcome data Low risk (attrition bias)}

All outcomes

Alective reporting (re-

Selective reporting (re- Low risk Planned outcomes reported
porting bias)

66 participants randomised, 1 secondary exclusion from each group, and 2 and 1 early deaths in chlorhexidine and control groups, respectively. Unlikely to have introduced a bias

Other bias Low risk No other sources of bias identified

Panchabhai 2009

\section{Study characteristics}

\begin{tabular}{ll}
\hline Methods & Study design: open-label RCT \\
Location: Mumbai, India \\
Number of centres: 1 \\
Study period: 8 months - dates not stated \\
Funding source: not stated \\
Setting: ICU (mixed medical and surgical), tertiary care hospital \\
Inclusion criteria: all patients admitted to ICU during study period who signed consent \\
Exclusion criteria: pregnant women, those with pneumonia at baseline, those for whom oral care was \\
contraindicated, those with allergy to chlorhexidine \\
Number randomised: 512 \\
Number evaluated: 471 (only $88 / 83=171$ on mechanical ventilation) \\
Baseline characteristics (given for 471 who completed the trial only): \\
- Intervention group: age: $35.2 \pm 15.9 ;$ M/F: $136 / 88 ;$ APACHE II score: $12 \pm(9-17)$ \\
- Control group: age: $36.9 \pm 16.2 ;$ M/F: $171 / 76$; APACHE II score: $14 \pm$ (9 - 19) \\
\hline
\end{tabular}

Interventions

\section{Comparison: chlorhexidine vs potassium permanganate}

Experimental group $(n=250)$ : oral and pharyngeal suction of pooled secretions followed by swabbing of the oral cavity, teeth, palate, buccal spaces, posterior pharyngeal wall, and hypopharynx with normal saline. Then oropharyngeal cleansing, following the same procedure, twice daily with $0.2 \%$ chlorhexidine solution

Control group ( $n=262$ ): oral and pharyngeal suction of pooled secretions followed by swabbing of the oral cavity, teeth, palate, buccal spaces, posterior pharyngeal wall, and hypopharynx with normal saline. Then oropharyngeal cleansing twice daily, following the same procedure, with $0.01 \%$ potassium permanganate solution 
Panchabhai 2009 (Continued)

Non-intubated participants, rinsed with water, then rinsed and gargled with $10 \mathrm{~mL}$ of study solution. No eating/drinking for 1 hour post-intervention

\begin{tabular}{ll}
\hline Outcomes & 1. Incidence of nosocomial pneumonia \\
2. Day of development of pneumonia \\
3. Mortality (hospital) \\
4. Duration of ICU stay \\
Notes \\
$\begin{array}{l}\text { Sample size calculation: "This study had a statistical power of } 75 \% \text { to detect a } 50 \% \text { reduction in the in- } \\
\text { dence of pneumonia in the control group was } 16 \%, 506 \text { subjects were required". }\end{array}$ \\
Email sent to author 14 November 2012
\end{tabular}

\title{
Risk of bias
}

\begin{tabular}{|c|c|c|}
\hline Bias & Authors' judgement & Support for judgement \\
\hline $\begin{array}{l}\text { Random sequence genera- } \\
\text { tion (selection bias) }\end{array}$ & Unclear risk & $\begin{array}{l}\text { "..randomly assigned to treatment .... by concealed simple random sampling" } \\
\text { No details of sequence generation provided }\end{array}$ \\
\hline $\begin{array}{l}\text { Allocation concealment } \\
\text { (selection bias) }\end{array}$ & Unclear risk & $\begin{array}{l}\text { "..concealed simple randomisation" } \\
\text { Unclear whether allocation was concealed from researchers }\end{array}$ \\
\hline $\begin{array}{l}\text { Blinding of participants } \\
\text { and personnel (perfor- } \\
\text { mance bias) } \\
\text { All outcomes }\end{array}$ & High risk & Open-label RCT \\
\hline $\begin{array}{l}\text { Blinding of outcome as- } \\
\text { sessment (detection bias) } \\
\text { All outcomes }\end{array}$ & Low risk & $\begin{array}{l}\text { Open-label RCT but "two independent, blinded reviewers made the diagnosis } \\
\text { of nosocomial pneumonia". }\end{array}$ \\
\hline $\begin{array}{l}\text { Incomplete outcome data } \\
\text { (attrition bias) } \\
\text { All outcomes }\end{array}$ & Unclear risk & $\begin{array}{l}26 / 250(10 \%) \text { and } 15 / 262(5.7 \%) \text { were excluded from the analysis in the } \\
\text { chlorhexidine and control groups, respectively. Reasons given were ICU stay } \\
<48 \text { hours, } 14 / 250 \text { versus } 6 / 262 \text {, and protocol violation } 12 / 250 \text { and } 9 / 262 \text {, re- } \\
\text { spectively. }\end{array}$ \\
\hline $\begin{array}{l}\text { Selective reporting (re- } \\
\text { porting bias) }\end{array}$ & Low risk & All planned outcomes reported in full \\
\hline Other bias & Unclear risk & Baseline parameters only reported for those who completed the study \\
\hline
\end{tabular}

Pobo 2009

\section{Study characteristics}

Methods

\author{
Study design: prospective, single-blind, randomised trial with parallel groups \\ Location: Spain \\ Number of centres: 1 ICU at a hospital \\ Study period: not stated
}


Pobo 2009 (Continued)

Funding source: supported by Fondo de Investigaciones Sanitarias (FISS 06/060), Centro de Investigación Biomédica en Red Enfermedades Respiratorias (06/06/36), and the Agency for the Administration of University and Research Grants (2005/SGR/920)

Participants

Inclusion criteria: intubated adults without evidence of pulmonary infection, expected to remain ventilated for $>48$ hours. Randomised within 12 hours of intubation

Exclusion criteria: edentulous, suspicion of pneumonia at time of intubation or evidence of massive aspiration during intubation, tracheostomy (or expected within 48 hours), recent enrolment in other trials, pregnancy, and chlorhexidine allergy

Age group: adults

Intervention group: $\mathrm{n}=74$; age: $55.3 \pm 17.9$; M/F: 49/25; mean APACHE II score: $18.8 \pm 7.1$

Control group: $\mathrm{n}=73$; age: $52.6 \pm 17.2$; M/F: 46/27; mean APACHE II score: $18.7 \pm 7.3$

Number randomised: 147 (74 in toothbrush group and 73 in standard care group)

Number evaluated: 147

Interventions

Comparison: powered toothbrush + standard oral care vs standard oral care alone

Group 1 ( $n=74)$ : standard oral care plus toothbrush group: besides the standard oral care, toothbrushing was performed tooth by tooth, on anterior and posterior surfaces, and along the gumline, the tongue was also brushed. A powered toothbrush was used (Braun Oral B AdvancePower 450 TX, Braun $\mathrm{GmbH})$. This procedure was repeated once every 8 hours

Group 2 ( $n=73$ ): standard oral care: maintaining head elevation at $30^{\circ}$. After aspiration of oropharyngeal secretions and adjustment of endotracheal cuff pressure, a gauze containing $20 \mathrm{~mL}$ of $0.12 \%$ chlorhexidine digluconate was applied to all the oral surfaces including tongue and mucosal surface, and $10 \mathrm{~mL}$ of $0.12 \%$ chlorhexidine digluconate was injected into oral cavity, being aspirated after 30 seconds, repeated every 8 hours

The following outcome variables were reported for each group:
1. Incidence of VAP
2. Incidence of suspected VAP per 1000 days of mechanical ventilation
3. Mean days of mechanical ventilation (mean \pm SD)
4. ICU length of stay (mean \pm SD)
5. Mortality

Notes

In the review, the standard oral care group was viewed as the intervention with chlorhexidine and the other group was viewed as the control with toothbrushing

Sample size calculation: estimated that 200 participants would be required in each group to show a $50 \%$ reduction in VAP with $80 \%$ power and a error of $5 \%$. After 147 of planned 400 participants were randomised, the study was stopped by the steering committee due to no difference in VAP between the groups.

NCT 00842478 at ClinicalTrials.gov

\section{Risk of bias}

\begin{tabular}{lll}
\hline Bias & Authors' judgement & Support for judgement \\
\hline $\begin{array}{l}\text { Random sequence genera- } \\
\text { tion (selection bias) }\end{array}$ & Low risk & $\begin{array}{l}\text { Randomisation by means of a computer-generated list, stratified for antibiotic } \\
\text { use at admission }\end{array}$ \\
\hline
\end{tabular}


Pobo 2009 (Continued)

$\begin{array}{ll}\text { Allocation concealment } \quad \text { Low risk } & \text { The list was concealed in opaque sealed envelopes opened by the nurse within } \\ \text { (selection bias) } & 12 \text { hours of intubation. }\end{array}$

Blinding of participants High risk
and personnel (perfor-

High risk 12 hours of intubation.
Blinding not possible. Participants unlikely to be aware of treatment, but caregivers were aware

All outcomes

$\begin{array}{ll}\text { Blinding of outcome as- } & \text { Low risk } \quad \text { Investigators and attending physicians were blinded to assigned groups. } \\ \text { sessment (detection bias) }\end{array}$

sessment (detection bias)

All outcomes

Incomplete outcome data Low risk No withdrawals. All randomised participants included in the analysis
(attrition bias)

All outcomes

Selective reporting (re- Low risk $\quad$ Expected outcomes reported, including adverse events

porting bias)

Other bias High risk

Study stopped early after recruitment of 147 of planned 400 participants because no differences between groups were found and revised estimates indicated that 1500 participants would need to be recruited to show a difference. Numbers not feasible in this centre

\section{Study characteristics}

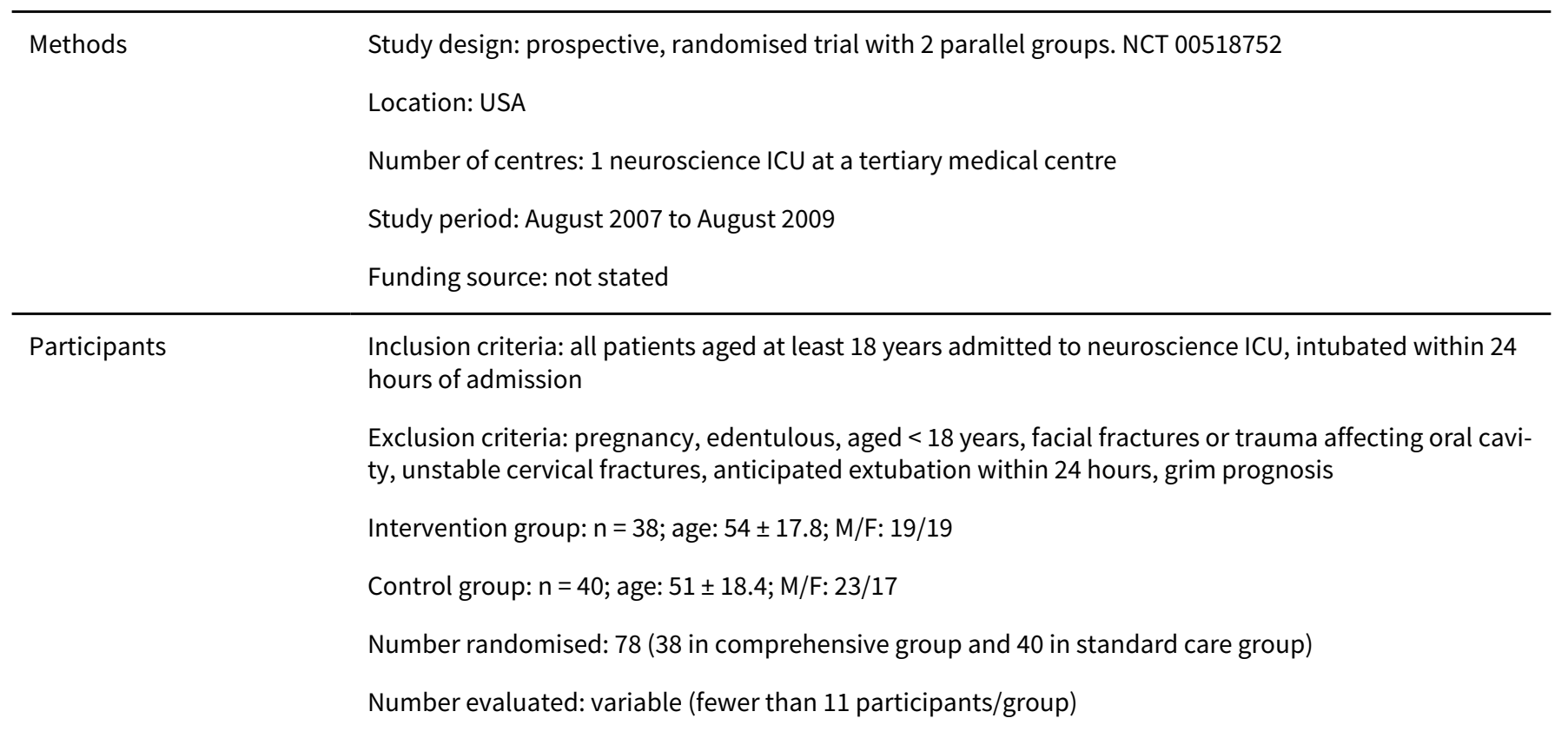

Interventions

\section{Comparison: powered toothbrush + comprehensive oral care vs manual toothbrush + standard oral care}

Group 1 ( $n=38)$ : tongue scraping using a low-profile tongue scraper with posterior to anterior sweeping motion across the dorsal surface of the tongue, then toothbrushing with Oral $B$ vitality powered toothbrush + Biotene (non-foaming) toothpaste for 2 minutes. Then a liberal application of Oral Balance gel. Care performed twice daily 
Prendergast 2012 (Continued)

Group $2(n=40)$ : standard oral care: using manual paediatric toothbrush, toothpaste with $1000 \mathrm{ppm}$ fluoride with SLS and water-based inert lubricant ("KY jelly"). Care performed twice daily

\begin{tabular}{|c|c|c|}
\hline \multirow[t]{5}{*}{ Outcomes } & \multicolumn{2}{|c|}{ The following outcome variables were reported for each group: } \\
\hline & \multicolumn{2}{|c|}{ 1. Oral and sputum cultures every 48 hours } \\
\hline & \multicolumn{2}{|c|}{ 2. Incidence of suspected VAP (day 2-6) } \\
\hline & \multicolumn{2}{|c|}{ 3. ICU length of stay (mean \pm SD) } \\
\hline & \multicolumn{2}{|l|}{ 4. Mortality } \\
\hline \multirow[t]{2}{*}{ Notes } & \multicolumn{2}{|c|}{ Sample size calculation: not reported } \\
\hline & \multicolumn{2}{|c|}{ NCT 00518752 at ClinicalTrials.gov } \\
\hline \multicolumn{3}{|l|}{ Risk of bias } \\
\hline Bias & Authors' judgement & Support for judgement \\
\hline $\begin{array}{l}\text { Random sequence genera- } \\
\text { tion (selection bias) }\end{array}$ & Low risk & $\begin{array}{l}\text { "..randomized ... using a computer generated list maintained in a separate } \\
\text { locked cabinet" }\end{array}$ \\
\hline $\begin{array}{l}\text { Allocation concealment } \\
\text { (selection bias) }\end{array}$ & Low risk & $\begin{array}{l}\text { "..list was maintained in a separate locked cabinet from enrolment forms to } \\
\text { prevent manipulation of eligibility judgements". }\end{array}$ \\
\hline $\begin{array}{l}\text { Blinding of participants } \\
\text { and personnel (perfor- } \\
\text { mance bias) } \\
\text { All outcomes }\end{array}$ & High risk & Not possible \\
\hline $\begin{array}{l}\text { Blinding of outcome as- } \\
\text { sessment (detection bias) } \\
\text { All outcomes }\end{array}$ & Low risk & $\begin{array}{l}\text { Diagnosis of VAP by examination of chest radiographs, by physicians blinded } \\
\text { to allocated treatment (information in Prendergast dissertation) }\end{array}$ \\
\hline $\begin{array}{l}\text { Incomplete outcome data } \\
\text { (attrition bias) } \\
\text { All outcomes }\end{array}$ & High risk & $\begin{array}{l}\text { Unclear how many were assessed at each time point but paper stated that } \\
\text { "less than } 11 \text { patients in each group at each time point" }\end{array}$ \\
\hline $\begin{array}{l}\text { Selective reporting (re- } \\
\text { porting bias) }\end{array}$ & Low risk & All planned outcomes reported \\
\hline Other bias & Low risk & No other sources of bias identified \\
\hline
\end{tabular}

\section{Roca Biosca 2011}

\section{Study characteristics}

\begin{tabular}{ll}
\hline Methods & Study design: Single-blind RCT \\
Location: Tarragona, Spain \\
Number of centres: 1 \\
Study period: June 2006 to May 2009 \\
Funding source: Grant from Health Investigation Fund (FISS 06/060) \\
\hline
\end{tabular}


Roca Biosca 2011 (Continued)
Participants
Setting: ICU (14-bed)
Inclusion criteria: adults aged $>18$ years, requiring mechanical ventilation for at least 48 hours, no pneumonia at baseline, at least 2 premolars and 1 incisor, consenting to take part
Exclusion criteria: edentulous, suspected pneumonia $<18$ years, requiring $<48$ hours mechanical venti- lation, tracheotomy, moribund (death expected within 72 hours) allergic to chlorhexidine
Number randomised: 147
Number evaluated: not stated
Baseline characteristics: report stated that there were no differences in gender, age, diagnosis, APACHE scores between the groups at baseline. No supporting data reported

Interventions

\section{Comparison: powered toothbrush + standard oral care vs standard oral care alone}

Experimental group: Standard oral hygiene protocol + powered toothbrush. Participant was elevated to $35^{\circ}$, oropharyngeal secretions were aspirated, intubation cuff pressure checked, then teeth, tongue and oral cavity cleaned with swab soaked in $10 \mathrm{~mL} 0.12 \%$ chlorhexidine digluconate. Solution left for 30 seconds then excess was aspirated. All tooth surfaces then brushed using a powered toothbrush

Control group: Standard oral hygiene protocol alone as described for treatment group

\begin{tabular}{l} 
Outcomes \\
$\begin{array}{l}\text { 1. Plaque index (Silness 1964) days } 1,5 \text { and } 10 \\
\text { 2. Plaque cultures } \\
\text { 3. VAP } \\
\text { 4. Halitosis }\end{array}$ \\
\hline
\end{tabular}

Notes

Sample size calculation: not reported

Translated from Portuguese by Luisa Fernandez-Mauleffinch

Email to authors sent 14 November 2012

\section{Risk of bias}

\begin{tabular}{|c|c|c|}
\hline Bias & Authors' judgement & Support for judgement \\
\hline $\begin{array}{l}\text { Random sequence genera- } \\
\text { tion (selection bias) }\end{array}$ & Unclear risk & $\begin{array}{l}\text { "Group assignment was done randomly by sealed envelope". } \\
\text { Method of sequence generation not described }\end{array}$ \\
\hline $\begin{array}{l}\text { Allocation concealment } \\
\text { (selection bias) }\end{array}$ & Low risk & "Group assignment was done randomly by sealed envelope". \\
\hline $\begin{array}{l}\text { Blinding of participants } \\
\text { and personnel (perfor- } \\
\text { mance bias) } \\
\text { All outcomes }\end{array}$ & High risk & Not possible to blind participants or personnel \\
\hline $\begin{array}{l}\text { Blinding of outcome as- } \\
\text { sessment (detection bias) } \\
\text { All outcomes }\end{array}$ & Unclear risk & Study described as single blind but unclear who was blinded \\
\hline $\begin{array}{l}\text { Incomplete outcome data } \\
\text { (attrition bias) } \\
\text { All outcomes }\end{array}$ & High risk & $\begin{array}{l}\text { Numbers of participants included in outcome of plaque index were } 74 \text { and } 73 \\
\text { at day } 0,60 \text { and } 57 \text { at day 5, and } 29 \text { and } 32 \text { at day } 10 \text { for toothbrush and control } \\
\text { groups respectively. Reasons for missing outcome data are extubation, need }\end{array}$ \\
\hline
\end{tabular}

Oral hygiene care for critically ill patients to prevent ventilator-associated pneumonia (Review) 
Roca Biosca 2011 (Continued)

for tracheotomy, VAP, death or intubation for total of 28 days. No information as to numbers missing by group for each reason

\begin{tabular}{lll}
\hline $\begin{array}{l}\text { Selective reporting (re- } \\
\text { porting bias) }\end{array}$ & High risk & $\begin{array}{l}\text { Planned outcomes of plaque index and microbiological culture reported, but } \\
\text { data for VAP and halitosis in each group not reported }\end{array}$ \\
\hline Other bias & Unclear risk & Insufficient information in trial report to be clear about potential for other bias \\
\hline
\end{tabular}

Scannapieco 2009

\section{Study characteristics}

Study design: A randomised, double-blind, placebo-controlled clinical trial
Location: USA
Number of centres: 1 18-bed trauma ICU
Study period: March 2004 until November 2007
Funding source: USPH grant R01DE-14685 from the National Institute of Dental and Craniofacial Re-
search

Participants

Inclusion criteria: Those admitted to the ICU who were expected to be intubated and mechanically ventilated within 48 hours of admission

Exclusion criteria: A witnessed aspiration suspected with chemical pneumonitis; a confirmed diagnosis of post-obstructive pneumonia e.g. advanced lung cancer; a known hypersensitivity to chlorhexidine; absence of consent; a diagnosed thrombocytopenia (platelet count $<40$ and/or a INR $>2$, or other coagulopathy); a do-not-intubate order; children < 18 years; pregnant women; legal incarceration; transfer from another ICU; oral mucositis; immunosuppression either HIV- or drug-induced e.g. organ transplant patients or those on long-term steroid therapy; and readmission to the ICU

Number randomised: 175

Number evaluated: 146

Intervention group (chlorhexidine 1): $\mathrm{n}=47$; mean age: $44.8 \pm 19.9$; M/F: 43/15; mean APACHE II score: $18.5 \pm 4.1$

Intervention group (chlorhexidine 2): $\mathrm{n}=50$; mean age: $47.6 \pm 19.1$; M/F: 44/14; mean APACHE II score: $19.7 \pm 6.1$

Control group: $\mathrm{n}=49$; mean age: $50.0 \pm 22.5 ; \mathrm{M} / \mathrm{F}: 36 / 23$; mean APACHE II score: $19.1 \pm 6.1$

Interventions

\section{Comparison: chlorhexidine twice per day + toothbrush vs chlorhexidine once per day + tooth- brush vs placebo + toothbrush}

Intervention group: chlorhexidine $(0.12 \% \mathrm{CHX}$ gluconate) was applied using a rinse-saturated oral foam applicator (Sage Products, Cary, IL, USA) once a day (placebo at other time).

Intervention group: chlorhexidine $(0.12 \% \mathrm{CHX}$ gluconate) was applied using a rinse-saturated oral foam applicator (Sage Products, Cary, IL, USA) twice a day (in the morning at about 8 a.m. and in the evening at about 8 p.m.).

Control group: placebo was applied using a rinse-saturated oral foam applicator twice per day.

All groups had routine oral care using a suction toothbrush (Sage Products, Cary, IL, USA) twice a day and as needed to brush teeth and the surface of the tongue or approximately 1-2 minutes, and applying suction at completion and as needed during the brushing. 
Scannapieco 2009 (Continued)

Outcomes

1. Incidence of VAP (diagnosed as the presence of more than $10^{4} \mathrm{CFU}$ of pathogen/ml of bqBAL fluid)

2. Death

3. Days ventilated

4. Days in hospital

5. Antibiotic use

Notes

Sample size calculation: estimated that 53 participants per arm would give $90 \%$ power to detect a 505 decrease in colonisation. For outcomes 2-5, the P values were for 3-group comparisons.

NCT00123123 at ClinicalTrials.gov

\section{Risk of bias}

\begin{tabular}{lll}
\hline Bias & Authors' judgement & Support for judgement \\
\hline $\begin{array}{l}\text { Random sequence genera- } \\
\text { tion (selection bias) }\end{array}$ & Low risk & $\begin{array}{l}\text { A web-based enrolment system which allocated randomised participant iden- } \\
\text { tification numbers }\end{array}$ \\
\hline $\begin{array}{l}\text { Allocation concealment } \\
\text { (selection bias) }\end{array}$ & Low risk & $\begin{array}{l}\text { The oral topical treatment for each box was formulated and prepared by the } \\
\text { hospital pharmacy. Sealed envelopes containing a random number were gen- } \\
\text { erated in blocks of } 6 \text { to provide concealment of participant assignment from } \\
\text { the investigators. }\end{array}$
\end{tabular}

Blinding of participants Low risk "Assignment of treatment was blinded to patients and all investigators includand personnel (perfor- $\quad$ ing outcome assessors, statisticians and care providers".

mance bias)

All outcomes

\begin{tabular}{|c|c|c|}
\hline $\begin{array}{l}\text { Blinding of outcome as- } \\
\text { sessment (detection bias) }\end{array}$ & Low risk & $\begin{array}{l}\text { "Assignment of treatment was blinded to patients and all investigators includ- } \\
\text { ing outcome assessors, statisticians and care providers". }\end{array}$ \\
\hline
\end{tabular}

All outcomes

Incomplete outcome data High risk

(attrition bias)

All outcomes
175 participants were randomised, microbiological baseline data were available for 146 participants, 115 had full data at 48 hours. > 20\% dropouts in all groups. ITT analysis used for 175 participants but unclear what imputation was used to account for losses

Planned microbiological outcomes were reported only in graphs with no data presented.

\begin{tabular}{|c|c|c|}
\hline $\begin{array}{l}\text { Selective reporting (re- } \\
\text { porting bias) }\end{array}$ & Unclear risk & $\begin{array}{l}\text { Planned microbiological outcomes were reported only in graphs with no data } \\
\text { presented. }\end{array}$ \\
\hline
\end{tabular}

\begin{tabular}{|c|c|c|}
\hline Other bias & High risk & $\begin{array}{l}\text { Problems with data analysis due to unclear denominator and imputations. } \\
\text { Pre-study antibiotic exposure higher in control group }\end{array}$ \\
\hline
\end{tabular}

\section{Seguin 2006}

\section{Study characteristics}

$\begin{array}{ll}\text { Methods } & \text { Study design: } 3 \text {-arm parallel RCT } \\ \text { Location: Rennes, France } \\ \text { Number of centres: } 1 \\ \text { Study period: August } 2001 \text { to January } 2003\end{array}$


Seguin 2006 (Continued)

Funding source: not stated

Setting: surgical ICU
Inclusion criteria: adults (> 18 years) with clos
mechanical ventilation for at least 2 days
Exclusion criteria: admitted > 12 hours after in
spinal injuries, known history of reaction to iodir
sion or need for curative antibiotics
Number randomised: 110 (38/36/36)
Number evaluated: 98 (36/31/31)
Baseline characteristics:
- lodine group: age: $38 \pm 17$ years; M/F: $28 / 10$
- Saline group: age: $38 \pm 16$ years; M/F: $24 / 12$
- Control group: age: $41 \pm 18$ years; M/F: $23 / 13$

\section{Comparison: povidone iodine versus saline versus usual care (no rinse)}

lodine group $(\mathrm{n}=38)$ : nasopharynx and oropharynx rinsed 4-hourly with $20 \mathrm{~mL}$ of $10 \%$ povidone iodine aqueous solution (Betadine oral rinse solution) reconstituted in a $60 \mathrm{~mL}$ solution with sterile water, followed by aspiration of oropharyngeal secretions

Saline group ( $n=36$ ): nasopharynx and oropharynx rinsed 4-hourly with $60 \mathrm{~mL}$ saline, followed by aspiration of oropharyngeal secretions

Control group $(n=36)$ : standard regimen without any instillation but with aspiration of oropharyngeal secretions

For all participants, the suction catheters were inserted as distally as possible. Procedures were reported on patient charts.

\begin{tabular}{|c|c|}
\hline \multirow[t]{4}{*}{ Outcomes } & 1. Incidence of VAP - early and late onset \\
\hline & 2. Duration of ventilation in surgical ICU \\
\hline & 3. Length of stay in surgical ICU \\
\hline & 4. Surgical ICU mortality \\
\hline
\end{tabular}

Notes

Sample size calculation: estimated that 30 participants in each group would provide $80 \%$ power with $a$ error $=5 \%$ to detect a reduction in VAP from $50 \%$ to $20 \%$

\section{Risk of bias}

\begin{tabular}{lll}
\hline Bias & Authors' judgement & Support for judgement \\
\hline $\begin{array}{l}\text { Random sequence genera- } \\
\text { tion (selection bias) }\end{array}$ & Low risk & $\begin{array}{l}\text { "Patients were randomly assigned to received one of three regimens according } \\
\text { to computer-generated random number codes kept in sealed envelopes". }\end{array}$ \\
\hline $\begin{array}{l}\text { Allocation concealment } \\
\text { (selection bias) }\end{array}$ & Low risk & $\begin{array}{l}\text { "Patients were randomly assigned to received one of three regimens according } \\
\text { to computer-generated random number codes kept in sealed envelopes". }\end{array}$ \\
\hline $\begin{array}{l}\text { Blinding of participants } \\
\begin{array}{l}\text { and personnel (perfor- } \\
\text { mance bias) }\end{array}\end{array}$ & High risk & Not possible \\
\end{tabular}


Seguin 2006 (Continued)

All outcomes

\begin{tabular}{lll}
\hline $\begin{array}{l}\text { Blinding of outcome as- } \\
\text { sessment (detection bias) } \\
\text { All outcomes }\end{array}$ & Unclear risk & Unclear information about blinding of outcome assessors \\
\hline $\begin{array}{l}\text { Incomplete outcome data } \\
\text { (attrition bias) }\end{array}$ & Low risk & $\begin{array}{l}12 \text { randomised participants }(11 \%) \text { excluded from analysis. } 6 \text { participants } \\
(1 / 3 / 2 \text { in each group) were withdrawn because unexpected recovery meant } \\
\text { All outcomes }\end{array}$ \\
& $\begin{array}{l}\text { that they were not on mechanical ventilation for } 48 \text { hours and a further } 6 \text { par- } \\
\text { ticipants }(1 / 2 / 3) \text { died. Unlikely to have introduced a bias }\end{array}$
\end{tabular}

Selective reporting (re- Low risk Planned outcomes reported in full

porting bias)

Other bias Low risk No other sources of bias identified

Seguin 2014

\section{Study characteristics}

\begin{tabular}{|c|c|}
\hline \multirow[t]{5}{*}{ Methods } & Study design: 2-arm parallel-group RCT \\
\hline & Location: France \\
\hline & Number of centres: 6 \\
\hline & Study period: May 2008 to May 2011 \\
\hline & Funding source: French Ministry of Health \\
\hline \multirow[t]{9}{*}{ Participants } & Setting: ICU \\
\hline & $\begin{array}{l}\text { Inclusion criteria: > } 18 \text { years, closed traumatic brain injury (Glasgow Coma Score } \leq 8 \text { ), expected me- } \\
\text { chanical ventilation } \geq 48 \text { hours. Protocol amended to include patients with cerebral haemorrhage }\end{array}$ \\
\hline & $\begin{array}{l}\text { Exclusion criteria: patients in whom oral care procedure could not be performed within } 12 \text { hours after } \\
\text { intubation, or had tetraplegia, facial trauma, pulmonary contusion involving > } 1 \text { lobe, aspiration pneu- } \\
\text { monia, current curative antimicrobial therapy, known allergy to povidone-iodine, pregnancy. }\end{array}$ \\
\hline & Number randomised: 179 (povidone-iodine: 91; control: 88) \\
\hline & Number evaluated: 150 (povidone-iodine: 78; control: 72) \\
\hline & Baseline characteristics: \\
\hline & - Povidone iodine*: age: 48 (19); M/F: 60/25; SAPS II score: 47 (11) \\
\hline & - Control*: age: 48 (18); M/F: 64/18; SAPS II score: 46 (12) \\
\hline & ${ }^{*}$ data presented on participants analysed \\
\hline
\end{tabular}

Interventions

\section{Comparison: povidone-iodine vs placebo}

Povidone iodine: betadine $10 \%$ oral antiseptic solution portioned in identical vials containing $125 \mathrm{~mL}$ of product. Participants received nasopharynx and oropharynx rinsing with $20 \mathrm{~mL}$ of povidone iodine (10\%) using a $60 \mathrm{~mL}$ syringe (final concentration 3.3\%). The solution was progressively injected in the buccal and pharyngeal cavities and regularly suctioned during 2 minutes, every 4 hours. The protocol was continued until extubation or until day 30 .

Placebo: used as above 
Seguin 2014 (Continued)
Outcomes
1. Incidence of VAP
2. VAP as time to first occurrence
3. Incidence of early ( $<7$ days) and late ( $\geq 7$ days) VAP
4. Incidence density of VAP per 1000 ventilator days
5. ICU and 90-day mortality
6. Duration of ICU and hospital stay
7. Number of ventilation-free days
8. Oropharayngeal and tracheal colonisation by potentially pathogenic microorganisms
9. Incidence of ventilator-associated tracheobronchitis
10. Incidence of acute respiratory distress syndrome
11. Events of other nosocomial infections
12. Systemic antibiotic use
13. Adverse effects: agitation/hypertension, epistaxis, oxygen desaturation, aspiration, others

Notes Sample size calculation: reported for VAP

\section{Risk of bias}

Bias Authors' judgement Support for judgement

Random sequence genera- Low risk tion (selection bias)
"Randomization was centralized and performed by the pharmacy of the coordinating centre, stratified by centre and by type of patients (trauma or cerebral haemorrhage), and equilibrated by blocks of 4 ".

Probably done well using computer-generated random numbers

\begin{tabular}{ll}
\hline $\begin{array}{l}\text { Allocation concealment } \\
\text { (selection bias) }\end{array}$ & "Row risk \\
& $\begin{array}{l}\text { dinating centre, stratified by centre and by type of patients (trauma or cere- } \\
\text { bral haemorrhage), and equilibrated by blocks of 4". }\end{array}$ \\
\hline
\end{tabular}

\begin{tabular}{ll}
\hline $\begin{array}{l}\text { Blinding of participants } \\
\text { and personnel (perfor- }\end{array}$ & Low risk \\
mance bias) & $\begin{array}{l}\text { "The placebo was identical to povidone-iodine in terms of colour, small and } \\
\text { texture. Both povidone-iodine and placebo were portioned in identical vials". }\end{array}$
\end{tabular}

All outcomes

\begin{tabular}{|c|c|c|}
\hline $\begin{array}{l}\text { Blinding of outcome as- } \\
\text { sessment (detection bias) } \\
\text { All outcomes }\end{array}$ & Low risk & $\begin{array}{l}\text { "An independent diagnosis validation committee...blindly classified each pa- } \\
\text { tient as positive or negative for VAP." }\end{array}$ \\
\hline
\end{tabular}

\begin{tabular}{lll}
\hline $\begin{array}{l}\text { Incomplete outcome data } \\
\text { (attrition bias) } \\
\text { All outcomes }\end{array}$ & Low risk & $\begin{array}{l}16 \% \text { attrition rate for VAP incidence, but the numbers and reasons for lost to } \\
\text { follow-up were similar in each group. }\end{array}$ \\
\hline $\begin{array}{l}\text { Selective reporting (re- } \\
\text { porting bias) }\end{array}$ & Low risk & Planned outcomes reported \\
\hline Other bias & Low risk & No other sources of bias identified \\
\hline
\end{tabular}




\section{Study characteristics}

\begin{tabular}{|c|c|}
\hline \multirow[t]{5}{*}{ Methods } & Study design: 2-arm parallel-group RCT \\
\hline & Location: USA \\
\hline & Number of centres: 1 \\
\hline & Study period: June 2010 to January 2012 \\
\hline & $\begin{array}{l}\text { Funding source: Forsyth Medical Center Sara Lee for Women's Health and WFSM Department of Paedi- } \\
\text { atric Research Funds }\end{array}$ \\
\hline \multirow[t]{8}{*}{ Participants } & Setting: neonatal ICU \\
\hline & $\begin{array}{l}\text { Inclusion criteria: extremely low birth weight, gestational age } \leq 28 \text { weeks, receipt of mechanical venti- } \\
\text { lation of at least } 3 \text { days in the first week of life and in the interval between days } 7 \text { and } 10 \text { of life; a parent } \\
\text { provided written informed consent }\end{array}$ \\
\hline & $\begin{array}{l}\text { Exclusion criteria: chromosomal or major congenital anomaly, the attending physician did not intend } \\
\text { to provide full medical support }\end{array}$ \\
\hline & Number randomised: 41 (biotene: 20; control: 21 ) \\
\hline & Number evaluated: 41 (biotene: 20 ; control: 21 ) \\
\hline & Baseline characteristics: \\
\hline & - Biotene: (median gestational age: 24 weeks (24-25); M/F: 7/13) \\
\hline & - Control: (median gestational age: 25 weeks (24-25); M/F: 11/10) \\
\hline
\end{tabular}

Interventions

\section{Comparison: biotene vs control}

Biotene: timed oral care performed using sterile foam-tip swabs with OralBalance Gel from $2 \mathrm{~mL}$ single use twist-tip vials, and involved hygiene of buccal mucosa, tongue and areas around endotracheal tube, every 4 hours from enrolment to final extubation.

Control: timed oral care performed using sterile foam tip swabs with sterile water from $2 \mathrm{~mL}$ single use twist-tip vials, and involved hygiene of buccal mucosa, tongue and areas around endotracheal tube, every 4 hours from enrolment to final extubation.

All infants received VAP bundling, consisting of good hand hygiene and use of gloves when handling respiratory secretions, head of bed elevation, avoidance of routine use of saline with tracheal suctioning process, and weekly change of ventilator circuits.

Outcomes Incidence of VAP
2. Number of VAP per 1000 ventilator days
3. Mortality
4. Length of hospital stay
5. Duration of mechanical ventilation
6. Micro-organism colonisation in tracheal aspirate
7. Adverse effects


Stefanescu 2013 (Continued)

Risk of bias

\begin{tabular}{|c|c|c|}
\hline Bias & Authors' judgement & Support for judgement \\
\hline $\begin{array}{l}\text { Random sequence genera- } \\
\text { tion (selection bias) }\end{array}$ & Low risk & $\begin{array}{l}\text { "We used blocked randomisation with varying block size". } \\
\text { Probably done using computer-generated random numbers }\end{array}$ \\
\hline $\begin{array}{l}\text { Allocation concealment } \\
\text { (selection bias) }\end{array}$ & Low risk & $\begin{array}{l}\text { "Group assignments were provided in sealed envelopes which were kept se- } \\
\text { cure by the investigational pharmacist, who was responsible for identifying } \\
\text { the group to which each randomised patient was allocated". }\end{array}$ \\
\hline $\begin{array}{l}\text { Blinding of participants } \\
\text { and personnel (perfor- } \\
\text { mance bias) } \\
\text { All outcomes }\end{array}$ & High risk & $\begin{array}{l}\text { "the primary limitation to our study was that we did not blind the staff to the } \\
\text { intervention". }\end{array}$ \\
\hline $\begin{array}{l}\text { Blinding of outcome as- } \\
\text { sessment (detection bias) } \\
\text { All outcomes }\end{array}$ & Unclear risk & $\begin{array}{l}\text { "All radiographs where VAP was suspected were reviewed with the paediatric } \\
\text { radiologists who were blinded to individual study assignment". } \\
\text { Potential for bias in deciding whether VAP was suspected }\end{array}$ \\
\hline $\begin{array}{l}\text { Incomplete outcome data } \\
\text { (attrition bias) } \\
\text { All outcomes }\end{array}$ & Low risk & No dropouts \\
\hline $\begin{array}{l}\text { Selective reporting (re- } \\
\text { porting bias) }\end{array}$ & Low risk & Planned outcomes reported \\
\hline Other bias & Unclear risk & $\begin{array}{l}\text { More infants in the control group received a complete course of antenatal } \\
\text { steroids compared to infants in the biotene group }(P=0.045) \text {. A complete } \\
\text { course of antenatal steroids improves neonatal lung maturity and function } \\
\text { and may reduce the risk of VAP (Roberts } 2017) \text {. This imbalance is likely to lead } \\
\text { to an underestimate of the benefit of the active treatment. }\end{array}$ \\
\hline
\end{tabular}

Tang 2013

\section{Study characteristics}

\begin{tabular}{ll}
\hline Methods & Study design: RCT \\
& Location: adult ICU (China) \\
& Number of centres: 1 \\
& Study period: 14 months (dates not given) \\
& Funding source: unclear \\
\hline Participants & Setting: adult ICU \\
& Inclusion criteria: all patients admitted to the ICU with receipt of mechanical ventilation of at least 48 \\
& Exclusion criteria: unclear \\
& Number randomised: 60 (gp A: $30 ; g p$ B: 30$)$ \\
& Number evaluated: 60 (gp A: $30 ; g p$ B: 30$)$ \\
\hline
\end{tabular}


Tang 2013 (Continued)

Baseline characteristics: age: 56 (13.22); M/F: 38/22

"Age and sex comparable between groups"

Interventions Comparison: saline rinse vs saline swab

Gp A: rinse oral cavity with saline

Gp B: saline swab with saline cotton ball

\begin{tabular}{ll}
\hline Outcomes & 1. VAP \\
2. Mortality \\
3. Duration of ventilation
\end{tabular}

\begin{tabular}{|c|c|c|}
\hline Notes & \multicolumn{2}{|c|}{ Sample size calculation: not reported } \\
\hline \multicolumn{3}{|l|}{ Risk of bias } \\
\hline Bias & Authors' judgement & Support for judgement \\
\hline $\begin{array}{l}\text { Random sequence genera- } \\
\text { tion (selection bias) }\end{array}$ & Unclear risk & No details provided \\
\hline $\begin{array}{l}\text { Allocation concealment } \\
\text { (selection bias) }\end{array}$ & Unclear risk & No details provided \\
\hline $\begin{array}{l}\text { Blinding of participants } \\
\text { and personnel (perfor- } \\
\text { mance bias) } \\
\text { All outcomes }\end{array}$ & High risk & Blinding not mentioned and not possible \\
\hline $\begin{array}{l}\text { Blinding of outcome as- } \\
\text { sessment (detection bias) } \\
\text { All outcomes }\end{array}$ & Unclear risk & Assessor blinding not mentioned \\
\hline $\begin{array}{l}\text { Incomplete outcome data } \\
\text { (attrition bias) } \\
\text { All outcomes }\end{array}$ & Low risk & All randomised participants included in analysis \\
\hline $\begin{array}{l}\text { Selective reporting (re- } \\
\text { porting bias) }\end{array}$ & Low risk & Planned outcomes reported \\
\hline Other bias & Unclear risk & $\begin{array}{l}\text { The authors did not give a detailed description about the intervention meth- } \\
\text { ods and frequency of oral care in each group. }\end{array}$ \\
\hline
\end{tabular}

Tantipong 2008

\title{
Study characteristics
}

Methods

\author{
Study design: single-centre RCT with 2 parallel groups \\ Location: Thailand \\ Number of centres: 1 tertiary care university hospital \\ Study period: January 2006 through March 2007
}


Tantipong 2008 (Continued)

Funding source: Thailand Research Fund and Faculty of Medicine Siriraj Hospital

\section{Participants}

Inclusion criteria: eligible patients were adults aged $\geqq 18$ years who were hospitalised in intensive care units ( 36 beds) or general medical wards ( 240 beds) at Siriraj Hospital and who received mechanical ventilation.

Exclusion criteria: patients who had pneumonia at enrolment or who had a chlorhexidine allergy

Number randomised: 207

Number evaluated: 207 (110 participants received mechanical ventilation for $>48$ hours)

- Experimental group: $\mathrm{n}=102$; age: $56.5 \pm 20.1$; M/F: 50/52; mean APACHE II score: $16.7 \pm 7.9$

- Control group: $\mathrm{n}=105$; age: $60.3 \pm 19.1$; M/F: 51/54; mean APACHE II score: $18.2 \pm 8.1$

Participants' demographic characteristics between groups did not differ significantly.

\section{Comparison: toothbrush + chlorhexidine vs toothbrush + placebo}

Experimental group $(n=102)$ : received oral care 4 times a day with brushing the teeth, suctioning any oral secretions, and rubbing the oropharyngeal mucosa with $15 \mathrm{~mL}$ of a $2 \%$ chlorhexidine solution, until their endotracheal tubes were removed.

Control group $(n=105)$ : same oral care procedure with normal saline solution
1. Incidence of VAP

2. Number of cases of VAP per 1000 ventilator days

3. Incidence of VAP for participants who received mechanical ventilation for $>2$ days

4. Overall mortality

5. Mean days of mechanical ventilation (mean \pm SD)

6. Rate of irritation of oral mucosa

Sample size calculation: estimated that 108 participants required in each group to give $80 \%$ power to detect a $50 \%$ decrease in VAP with 5\% Type 1 error

\section{Risk of bias}

\begin{tabular}{lll}
\hline Bias & Authors' judgement & Support for judgement \\
\hline $\begin{array}{l}\text { Random sequence genera- } \\
\text { tion (selection bias) }\end{array}$ & Low risk & $\begin{array}{l}\text { "...randomized...by stratified randomization according to sex and hospital lo- } \\
\text { cation of eligible patient" }\end{array}$ \\
\hline $\begin{array}{l}\text { Allocation concealment } \\
\text { (selection bias) }\end{array}$ & Unclear risk & Not mentioned and probably not done \\
\hline $\begin{array}{l}\text { Blinding of participants } \\
\text { and personnel (perfor- } \\
\text { mance bias) } \\
\text { All outcomes }\end{array}$ & High risk & $\begin{array}{l}\text { Not blinded as chlorhexidine solution had different odour and taste from } \\
\text { saline }\end{array}$ \\
\hline $\begin{array}{l}\text { Blinding of outcome as- } \\
\text { sessment (detection bias) } \\
\text { All outcomes }\end{array}$ & Low risk & $\begin{array}{l}\text { The assessors who determined whether a participant developed pneumonia } \\
\text { were unaware of the participant's study group assignment. }\end{array}$ \\
\hline $\begin{array}{l}\text { Incomplete outcome data } \\
\text { (attrition bias) }\end{array}$ & Unclear risk & $\begin{array}{l}\text { All randomised participants included in outcome evaluation but only 53\% of } \\
\text { participants on ventilators for }>2 \text { days and therefore at risk of VAP }\end{array}$ \\
\hline
\end{tabular}


Tantipong 2008 (Continued)

All outcomes

\begin{tabular}{|c|c|c|}
\hline $\begin{array}{l}\text { Selective reporting (re- } \\
\text { porting bias) }\end{array}$ & Unclear risk & $\begin{array}{l}\text { Planned outcome VAP but not all participants at risk and information unclear. } \\
\text { Mortality reported }\end{array}$ \\
\hline
\end{tabular}

Other bias Unclear risk Only $60 \%$ of study participants received ventilation in ICU and only $53 \%$ of participants received mechanical ventilation for $>48$ hours. Likely that nursing care protocols were different in general medical wards compared to ICUs

Tuon 2017

\section{Study characteristics}

\begin{tabular}{|c|c|}
\hline \multirow[t]{5}{*}{ Methods } & Study design: 2-arm parallel group RCT \\
\hline & Location: Brazil \\
\hline & Number of centres: 1 \\
\hline & Study period: June 2014 to March 2015 \\
\hline & Funding source: no funding \\
\hline \multirow[t]{8}{*}{ Participants } & Setting: ICU \\
\hline & $\begin{array}{l}\text { Inclusion criteria: hospital admission followed by MV; age }>=18 \text { years, patients identified as having a } \\
\text { high probability of MV for }>48 \mathrm{~h} \text { and permanent teeth (anterior and posterior) }\end{array}$ \\
\hline & $\begin{array}{l}\text { Exclusion criteria: failure to provide written informed consent, hospitalisation }>24 \mathrm{~h} \text {, recent use of an- } \\
\text { tibiotics }(<1 \text { week), recent admission to another hospital or emergency room, suspected infection in } \\
\text { the upper or lower respiratory tract, fewer than four culture samples }\end{array}$ \\
\hline & Number randomised: 16 (intervention group: 8; control group: 8) \\
\hline & Number evaluated: 16 (intervention group: 8; control group: 8) \\
\hline & Baseline characteristics: \\
\hline & - Intervention group: age: 53.1; M/F: 5/3; APACHE II score: not reported) \\
\hline & - Control group: age: 42.8; M/F: 4/4; APACHE II score: not reported) \\
\hline
\end{tabular}

\section{Comparison: $2 \% \mathrm{CHX}$ vs placebo $(0.9 \%$ normal saline)}

$\mathrm{CHX}$ : patients received oral washing with $15 \mathrm{~mL}$ of $2 \% \mathrm{CHX}$ digluconate by a trained nursery team. The $\mathrm{CHX}$ solution was gently brushed into the gum, oral mucosa and tongue two times daily until ICU discharge.

Placebo: patients underwent mouthwashing with a $0.9 \% \mathrm{NaCl}$ solution

\begin{tabular}{ll}
\hline Outcomes & 1. Incidence of VAP \\
& 2. Microbiological profiles \\
\hline Notes & Sample size calculation: not mentioned \\
& Other information of note: none
\end{tabular}

\section{Risk of bias}


Tuon 2017 (Continued)

\begin{tabular}{lll} 
Bias & Authors' judgement & Support for judgement \\
\hline $\begin{array}{l}\text { Random sequence genera- } \\
\text { tion (selection bias) }\end{array}$ & Unclear risk & Not described \\
\hline $\begin{array}{l}\text { Allocation concealment } \\
\text { (selection bias) }\end{array}$ & Unclear risk & Not described \\
\hline
\end{tabular}

\begin{tabular}{|c|c|c|}
\hline $\begin{array}{l}\text { Blinding of participants } \\
\text { and personnel (perfor- } \\
\text { mance bias) } \\
\text { All outcomes }\end{array}$ & Unclear risk & $\begin{array}{l}\text { Blinding not described and not possible. Difference between intervention and } \\
\text { control meant caregivers would be aware of who was in each group. }\end{array}$ \\
\hline
\end{tabular}

\begin{tabular}{lll}
\hline $\begin{array}{l}\text { Blinding of outcome as- } \\
\text { sessment (detection bias) } \\
\text { All outcomes }\end{array}$ & Unclear risk & Not described \\
\hline $\begin{array}{l}\text { Incomplete outcome data } \\
\text { (attrition bias) } \\
\text { All outcomes }\end{array}$ & Low risk & All randomised participants included in outcome evaluation \\
\hline $\begin{array}{l}\text { Selective reporting (re- } \\
\text { porting bias) }\end{array}$ & Low risk & All planned outcomes reported \\
\hline Other bias & Low risk & No other sources of bias identified \\
\hline
\end{tabular}

\section{Study characteristics}

\begin{tabular}{ll}
\hline Methods & Study design: parallel-group RCT \\
Location: Nanjing, China \\
Number of centres: 1 \\
Study period: December 2004 to June 2006 \\
Funding source: no external funding \\
\hline Setting: ICU in drum tower hospital of Nanjing University \\
Inclusion criteria: critically ill adult patients in ICU receiving mechanical ventilation \\
Exclusion criteria: patients with severe oral diseases, mechanical ventilation for $>24$ hours prior to \\
Study entry, those who refused oral care protocol \\
Number randomised: 164 \\
Number evaluated: 164 \\
Baseline characteristics: not reported for each randomised group
\end{tabular}

Interventions

\section{Comparison: saline swab vs saline rinse versus both}

Experimental group A $(n=58)$ : rinsing the oropharyngeal cavity with saline for 5 -10 seconds, followed by suction aspiration, repeated 5-10 times twice daily for 7 days

Experimental group $B(n=62)$ : both wipe and rinse as above, twice daily for 7 days 
Xu 2007 (Continued)

Control group $(n=44)$ : usual care - wiping the oropharyngeal cavity with saline-soaked cotton ball twice daily for 7 days

\begin{tabular}{|c|c|c|}
\hline Outcomes & \multicolumn{2}{|c|}{ VAP, stomatitis, fungal infection } \\
\hline Notes & \multicolumn{2}{|c|}{$\begin{array}{l}\text { Diagnosis of VAP was according to Chinese Society of Respiratory Diseases criteria. } \\
\text { Information translated from Chinese paper by Shi Zongdao and colleagues }\end{array}$} \\
\hline \multicolumn{3}{|l|}{ Risk of bias } \\
\hline Bias & Authors' judgement & Support for judgement \\
\hline $\begin{array}{l}\text { Random sequence genera- } \\
\text { tion (selection bias) }\end{array}$ & Unclear risk & "randomly allocated" but no details of sequence generation described \\
\hline $\begin{array}{l}\text { Allocation concealment } \\
\text { (selection bias) }\end{array}$ & Unclear risk & Not described \\
\hline $\begin{array}{l}\text { Blinding of participants } \\
\text { and personnel (perfor- } \\
\text { mance bias) } \\
\text { All outcomes }\end{array}$ & High risk & Not possible \\
\hline $\begin{array}{l}\text { Blinding of outcome as- } \\
\text { sessment (detection bias) } \\
\text { All outcomes }\end{array}$ & Unclear risk & Not described \\
\hline $\begin{array}{l}\text { Incomplete outcome data } \\
\text { (attrition bias) } \\
\text { All outcomes }\end{array}$ & Low risk & All randomised participants included in outcome evaluation \\
\hline $\begin{array}{l}\text { Selective reporting (re- } \\
\text { porting bias) }\end{array}$ & Low risk & Planned outcomes reported \\
\hline Other bias & Low risk & No other sources of bias identified \\
\hline
\end{tabular}

Xu 2008

\section{Study characteristics}

\begin{tabular}{ll}
\hline Methods & Study design: parallel-group RCT \\
Location: Shandong, China \\
Number of centres: 1 \\
Study period: not stated \\
Funding source: no external funding \\
\hline Setting: ICU of the second hospital of Shandong University \\
Inclusion criteria: adults entering ICU receiving mechanical ventilation expected to last $>48$ hours \\
Exclusion criteria: patients with pulmonary infections \\
Number randomised: 116
\end{tabular}


Xu 2008 (Continued)

Number evaluated: 116

Baseline characteristics: not reported for each randomised group

Interventions Comparison: saline rinse vs saline swab

Experimental group $(n=64)$ : rinse of the oropharyngeal cavity with saline for $5-10$ seconds, followed by suction aspiration and repeated 5-10 times, twice daily

Control group ( $n=52)$ : standard oral care comprising scrubbing with a cotton ball soaked in saline, twice daily

\begin{tabular}{ll}
\hline Outcomes & VAP, duration of ventilation (days) \\
\hline Notes & Diagnosis of VAP was according to Chinese Society of Respiratory Diseases criteria. \\
& Information translated from Chinese paper by Shi Zongdao and colleagues \\
\hline
\end{tabular}

\section{Risk of bias}

\begin{tabular}{|c|c|c|}
\hline Bias & Authors' judgement & Support for judgement \\
\hline $\begin{array}{l}\text { Random sequence genera- } \\
\text { tion (selection bias) }\end{array}$ & Unclear risk & "randomly allocated". Method of sequence generation not described \\
\hline $\begin{array}{l}\text { Allocation concealment } \\
\text { (selection bias) }\end{array}$ & Unclear risk & Not mentioned \\
\hline $\begin{array}{l}\text { Blinding of participants } \\
\text { and personnel (perfor- } \\
\text { mance bias) } \\
\text { All outcomes }\end{array}$ & High risk & Not possible \\
\hline $\begin{array}{l}\text { Blinding of outcome as- } \\
\text { sessment (detection bias) } \\
\text { All outcomes }\end{array}$ & Unclear risk & Not mentioned \\
\hline $\begin{array}{l}\text { Incomplete outcome data } \\
\text { (attrition bias) } \\
\text { All outcomes }\end{array}$ & Low risk & All randomised participants included in the outcome evaluation \\
\hline $\begin{array}{l}\text { Selective reporting (re- } \\
\text { porting bias) }\end{array}$ & Low risk & Both outcomes listed in Methods were reported in the Results section. \\
\hline Other bias & Low risk & No other sources of bias identified \\
\hline
\end{tabular}

Yao 2011

\section{Study characteristics}

Study design: single-blind pilot RCT (NCT00604916)
Location: Taiwan
Number of centres: 1
Study period: March to November 2007


Yao 2011 (Continued)

Funding source: grants from Taiwan National Science Council and Career Development grant from National Health Research Institutes

Setting: surgical ICU
Inclusion criteria: intubated and ventilated postoperative patients expected to be in ICU $>48$ hours and
expected to require mechanical ventilation for 48 to 72 hours with nasal or endotracheal intubation
Exclusion criteria: pneumonia at baseline
Number randomised: 53
Number evaluated: 53 (VAP), 50 at day 3-4, 42 at day $7-8$
Baseline characteristics:
- Intervention group: age: $60.7 \pm 16.0 ;$ M/F: $17 / 11 ;$ APACHE II score: $19.6 \pm 5.2$
- Control group: age: $60.5 \pm 16.5 ;$ M/F: $17 / 8$; APACHE II SCore: $19.4 \pm 4.4$

Interventions

Comparison: oral care + toothbrushing twice a day vs usual oral care

Experimental group: standardised oral care protocol twice daily for 15-20 minutes for 7 days from trained intervention nurse. Bed elevated $30^{\circ}$ to $45^{\circ}$, hypopharyngeal suctioning, mouth moistened with 5-10 mL purified water, buccal surfaces of teeth cleaned with powered toothbrush and lingual tooth surfaces and tongue, gums and mucosa massaged with soft paediatric toothbrush. Oral cavity then cleaned with toothette swab connected to a suction tube and rinsed with $50 \mathrm{~mL}$ water + hypopharyngeal suctioning

Control group: received oral care protocol, twice daily for 10-15 minutes provided by same trained intervention nurse. Participants elevated, hypopharyngeal suctioning, lips moistened with toothette swab and water, then further hypopharyngeal suctioning

1. Oral Assessment Guide (OAG) score
$\begin{aligned} & \text { 2. Plaque score (Turesky-Gilmore-Glickman modification of Quigley-Hein plaque index with disclosing } \\ & \text { dye. Recorded } 1 \text { tooth from each quadrant (prioritising premolars and incisors) scores summed) }\end{aligned}$
3. Duration of ventilation
4. Length of ICU stay
5. Incidence of VAP (defined as CPIS >6)
4. Mortality (ICU)

Notes Sample size calculation: pilot study

NCT 00604916 at ClinicalTrials.gov

Email sent to author 14 November 2012. Reply received 12 December 2012

\section{Risk of bias}

\begin{tabular}{lll}
\hline Bias & Authors' judgement & Support for judgement \\
\hline $\begin{array}{l}\text { Random sequence genera- } \\
\text { tion (selection bias) }\end{array}$ & Low risk & "...randomized using a computer generated randomization table" \\
\hline $\begin{array}{l}\text { Allocation concealment } \\
\text { (selection bias) }\end{array}$ & Unclear risk & Not mentioned in trial report \\
& $\begin{array}{l}\text { Unclear whether allocation was concealed from researchers prior to assign- } \\
\text { ment }\end{array}$ \\
\hline \hline
\end{tabular}




\section{Yao 2011 (Continued)}

Blinding of participants and personnel (perfor-

High risk mance bias)

All outcomes
Experimental group received toothbrushing (both powered and manual) and control group did not, so blinding of participants and personnel not possible

$\begin{array}{ll}\text { Blinding of outcome as- } & \text { Low risk }\end{array}$ Outcomes assessed blinded to allocated treatment

All outcomes

\begin{tabular}{lll}
\hline $\begin{array}{l}\text { Incomplete outcome data } \\
\text { (attrition bias) } \\
\text { All outcomes }\end{array}$ & Low risk & $\begin{array}{l}\text { VAP outcome assessed in all randomised participants. For oral health and } \\
\text { plaque outcomes, 8/28 (experimental) and } 7 / 25 \text { (control) participants lost } \\
\text { (transferred to ward) and } 2 / 28 \text { participants in experimental group died }\end{array}$ \\
\hline $\begin{array}{l}\text { Selective reporting (re- } \\
\text { porting bias) }\end{array}$ & Low risk & $\begin{array}{l}\text { Planned outcomes reported, but denominators unclear for VAP and mortality. } \\
\text { However, this information was supplied by email from the authors. }\end{array}$ \\
\hline Other bias & Unclear risk & $\begin{array}{l}3 / 28(11 \%) \text { and } 1 / 25 \text { (4\%) participants in experimental and control groups } \\
\text { were edentulous. Unclear how the intervention and outcomes were applied in } \\
\text { these participants }\end{array}$ \\
\hline
\end{tabular}

\section{Zhao 2012}

\section{Study characteristics}

\begin{tabular}{ll}
\hline Methods & Study design: single-centre RCT with 2 parallel groups \\
& Location: China \\
& Number of centres: 1 surgical ICU in city hospital \\
& Study period: May 2010 to April 2011 \\
& Funding source: not stated \\
\hline Inclusion criteria: admission into the ICU, orally intubated, receiving mechanical ventilation \\
Exclusion criteria: not specified \\
Number randomised: 324 (162 per group) \\
Number evaluated: 324 \\
Age group: mean $66.25 \pm 15.28$ \\
Baseline characteristics were comparable.
\end{tabular}

Interventions

\section{Comparison: Yikou (triclosan) rinse vs saline}

Experimental group: oral cavity swab with $15 \mathrm{~mL}$ of Yikou gargle (triclosan was main ingredient), 4 times a day

Control group: oral cavity swab with normal saline, 4 times a day

Secretions were aspirated using suction once daily and sent to lab for culture.
Outcomes
1. Incidence of VAP in $<4$ days of ventilation and within 4 to 10 days of ventilation
2. Mechanical ventilation days
3. ICU stay days 
Zhao 2012 (Continued)

4. Culture of the samples taking from oropharyngeal cavity and inferior respiratory tract (Table 3, detection rates of microbial pathogens before and after oral nursing care were listed)

Notes

Diagnosis of VAP was mainly determined by microbial examination of the aspirate secretions from the inferior respiratory tract, which was performed every day.

\section{Risk of bias}

\begin{tabular}{lll}
\hline Bias & Authors' judgement & Support for judgement \\
\hline $\begin{array}{l}\text { Random sequence genera- } \\
\text { tion (selection bias) }\end{array}$ & Unclear risk & "randomly divided into 2 groups" \\
\hline $\begin{array}{l}\text { Allocation concealment } \\
\text { (selection bias) }\end{array}$ & Unclear risk & Not specified \\
\hline $\begin{array}{l}\text { Blinding of participants } \\
\begin{array}{l}\text { and personnel (perfor- } \\
\text { mance bias) }\end{array}\end{array}$ & Unclear risk & $\begin{array}{l}\text { Blinding not described and unclear whether Yikou and saline had the same ap- } \\
\text { All outcomes }\end{array}$ \\
\hline
\end{tabular}

\begin{tabular}{ll}
\hline Blinding of outcome as- & Unclear risk
\end{tabular}

\begin{tabular}{lll}
\hline $\begin{array}{l}\text { Incomplete outcome data } \\
\text { (attrition bias) } \\
\text { All outcomes }\end{array}$ & Low risk & The main results were all reported. \\
\hline $\begin{array}{l}\text { Selective reporting (re- } \\
\text { porting bias) }\end{array}$ & Low risk & The results were fully reported. \\
\hline Other bias & Unclear risk & $\begin{array}{l}\text { Only the results of microbial examination of the aspirate secretions from the } \\
\text { inferior respiratory tract as tool of VAP diagnosis was mentioned and its diag- } \\
\text { nostic efficacy may not be enough. }\end{array}$ \\
\hline
\end{tabular}

AIDS = acquired immunodeficiency syndrome

APACHE II = Acute Physiology and Chronic Health Evaluation II

$\mathrm{CAO}=$ caries/absent/occluded

$\mathrm{CDC}=$ Centers for Disease Control

$\mathrm{CHX}=$ chlorhexidine

$\mathrm{COL}=$ colistin

CPIS = Clinical Pulmonary Infection Score

DMFT $=$ decayed $/$ missing/filled teeth

$\mathrm{ED}=$ emergency department

$\mathrm{ET}=$ endotracheal tube

$\mathrm{GCS}=$ Glasgow coma scale

gp = group

HIV = human immunodeficiency viruses

$\mathrm{HP}=$ hydrogen peroxide

ICU = intensive care unit

INR = international normalised ratio

IQRs = interquartile ranges

ITT = intention-to-treat

MCPIS = modified clinical pulmonary infection score

$\mathrm{M} / \mathrm{F}=$ male/female

$\mathrm{MV}=$ mechanical ventilation

$\mathrm{NaCl}=$ sodium chloride

$\mathrm{NS}=$ normal saline

Oral hygiene care for critically ill patients to prevent ventilator-associated pneumonia (Review) 
OAG = oral assessment guide

$\mathrm{PICU}=$ paediatric intensive care unit

ppm $=$ parts per million

$\mathrm{RCT}=$ randomised controlled trial

$\mathrm{RTI}=$ respiratory tract infection

SAPS = Simplified Acute Physiologic Score

$\mathrm{SD}=$ standard deviation

SID = subject identification

SLS = sodium lauryl sulfate

SOFA = sequential organ failure assessment

TRISS = Trauma Injury Severity Score

$\mathrm{UTI}=$ urinary tract infection

VAP $=$ ventilator-associated pneumonia

vs $=$ versus

Characteristics of excluded studies [ordered by study ID]

\begin{tabular}{ll}
\hline Study & Reason for exclusion \\
\hline Abusibeih 2010 & Quasi-randomised trial \\
\hline Anon 2012 & Abstract only; insufficient information to assess \\
\hline Atashi 2018 & A complex bundle versus a simpler bundle, which is outside the scope of this review \\
\hline Baradari 2012 & Not aimed to assess VAP incidence or mortality \\
\hline Bellissimo-Rodrigues 2014 & Intervention was dental care, not dental hygiene care \\
\hline Bordenave 2011 & $\begin{array}{l}\text { Identified from ClinicalTrials.gov website as ongoing study, but email from contact author on } 8 \text { No- } \\
\text { vember 2012 confirmed that this study did not proceed due to lack of funding }\end{array}$ \\
\hline Buckley 2013 & Not RCT \\
\hline Chao 2009 & Not RCT \\
\hline Chen 2008 & CHX versus saline: the intervention group received "routine oral care" but the control group did not \\
\hline Da Collina 2017 & $\begin{array}{l}\text { Published protocol identified, but email from contact author on 18 March 2020 confirmed that this } \\
\text { trial was not performed due to the withdrawal of the dentist (PhD student) who would carry out the } \\
\text { treatment of patients }\end{array}$ \\
\hline
\end{tabular}

\begin{tabular}{ll}
\hline Dale 2019 & Protocol for a trial on a bundle including suctioning \\
\hline Darnell 2015 & Not RCT \\
\hline DeRiso 1996 & Unclear if all those who developed VAP had been on mechanical ventilation for at least 48 hours \\
\hline Epstein 1994 & The participants involved in the study were not critically ill \\
\hline Fan 2012 & $\begin{array}{l}\text { The ingredients of the mouthwash used in the trial were not reported, so we could not judge } \\
\text { whether it contained antibiotics or not }\end{array}$ \\
\hline Fan 2015 & The CHX solution used in interventions contained antibiotics \\
\hline Ferozali 2007 & The target population was long-term care residents, not critically ill people in hospitals \\
\hline Fourrier 2000 & Unclear if all those who developed VAP had been on mechanical ventilation for at least 48 hours \\
\hline \hline
\end{tabular}




\begin{tabular}{|c|c|}
\hline Study & Reason for exclusion \\
\hline Fourrier 2005 & $\begin{array}{l}\text { Unclear if all those who developed VAP had been on mechanical ventilation for at least } 48 \text { hours; } \\
\text { some of the participants had pneumonia at baseline }\end{array}$ \\
\hline Genuit 2001 & Not RCT \\
\hline Grap 2004 & Not aiming to assess VAP incidence or mortality \\
\hline Gu 2013 & Not RCT \\
\hline Guo 2007 & $\mathrm{RCT}$, but patients had lung trauma (injury before receiving the oral nursing intervention) \\
\hline Guo 2017 & Participants had pneumonia at baseline \\
\hline Haghighi 2017 & $\begin{array}{l}\text { The interventions being tested in the experimental group included adjustment of the endotracheal } \\
\text { tube cuff pressure, mouth and throat deep suctioning, and lip moistening in addition to oral hy- } \\
\text { giene care, which were outside the scope of the review }\end{array}$ \\
\hline Houston 2002 & $\begin{array}{l}\text { Likely that fewer than } 10 \% \text { of study participants had mechanical ventilation for a minimum of } 48 \\
\text { hours }\end{array}$ \\
\hline Jacomo 2011 & Unclear how many participants have been on mechanical ventilation for at least 48 hours \\
\hline Jafari 2007 & Abstract only; insufficient information to assess \\
\hline Kusahara 2012b & Not aiming to assess VAP incidence or mortality \\
\hline Labeau 2013 & Not RCT \\
\hline Lai 1997 & RCT of critically ill people, unclear how many were on mechanical ventilation; outcome candidiasis \\
\hline Li 2011 & Participants allocated to groups by alternation (quasi-RCT) \\
\hline Li 2012 & $\begin{array}{l}\text { The mouthwash (Kouitai) used in the trial contained both chlorhexidine and metronidazole, and } \\
\text { the latter is an antibiotic }\end{array}$ \\
\hline Liang 2007 & The participants involved in the study did not use mechanical ventilation \\
\hline Liao 2015 & Not RCT \\
\hline Liwu 1990 & Clinical controlled trial, not an RCT \\
\hline MacNaughton 2004 & Abstract only; insufficient information to assess \\
\hline Maury 2015 & Not RCT \\
\hline McCartt 2010 & Not aiming to assess VAP incidence or mortality \\
\hline McCoy 2012 & Not RCT \\
\hline Munro 2009 & Some of the participants had pneumonia at baseline \\
\hline Munro 2015 & Intervention was preintubation oral hygiene care \\
\hline Nasiriani 2016 & $\begin{array}{l}\text { Randomisation compromised as the authors replaced } 22 \text { dropouts with new participants (selection } \\
\text { method unknown) }\end{array}$ \\
\hline
\end{tabular}




\begin{tabular}{ll}
\hline Study & Reason for exclusion \\
\hline NCT01657396 & $\begin{array}{l}\text { Identified from ClinicalTrials.gov website, but email from contact author on } 9 \text { March } 2020 \text { con- } \\
\text { firmed that this trial was a pilot trial to test whether a larger trial was feasible and hence patient } \\
\text { outcomes were not the primary measures }\end{array}$
\end{tabular}

\begin{tabular}{ll}
\hline Needleman 2011 & Not aiming to assess VAP incidence or mortality \\
\hline Ogata 2004 & $\begin{array}{l}\text { The target population was patients about to receive orotracheal intubation - they were not on me- } \\
\text { chanical ventilation. Study about gargling with povidone iodine before oral intubation to reduce } \\
\text { the transport of bacteria into the trachea, not oral care intervention in critically ill patients to re- } \\
\text { duce VAP }\end{array}$ \\
\hline
\end{tabular}

\begin{tabular}{ll}
\hline Pawlak 2005 & Not RCT \\
\hline Pelucchi 2013 & Systematic review not RCT \\
\hline Pivkina 2014 & Abstract only; insufficient information to assess \\
\hline Sands 2015 & Not RCT \\
\hline Santos 2008 & $\begin{array}{l}\text { Email reply from Dr Santos stated that "The nurse put the first admission on biotene and the sec- } \\
\text { ond admission on cetylpyridium, the third admission on biotene and so on." Alternation as an allo- } \\
\text { cation method is not random and therefore this study was excluded }\end{array}$ \\
\hline Sebastian 2012 & Most of the children admitted to ICU had pneumonia at baseline \\
\hline Segers 2006 & The participants involved in the study did not use mechanical ventilation \\
\hline Seo 2011 & Not RCT \\
\hline Swartz 2015 & Not RCT \\
\hline Tattevin 2015 & Not RCT \\
\hline
\end{tabular}

Tian 2017 Authors did not report either the ingredients or product name of the 'biological enzyme disinfec-
tant' used, therefore we could not judge whether it contained antibiotics; contact information of
the authors was not provided

\begin{tabular}{ll}
\hline Tsai 2017 & Abstract only; insufficient information to assess; email address unavailable \\
\hline Ueda 2004 & The target population was people in nursing homes, not critically ill people in hospitals \\
\hline Wang 2006 & Quasi-RCT \\
\hline Wang 2012 & $\begin{array}{l}\text { The interventions being tested in the experimental group included elevation of the head of the bed, } \\
\text { closed endotracheal suctioning in addition to oral nursing care, which was outside the scope of the } \\
\text { review }\end{array}$ \\
\hline Wang 2016 & CHX solution contained antibiotics \\
\hline Yin 2004 & RCT aiming to improve oral cleanliness. Unlikely that participants received mechanical ventilation \\
\hline Yun 2011 & Not RCT \\
\hline Zouka 2010 & $\begin{array}{l}\text { Abstract only; insufficient information to include in review. Emailed contact author } 6 \text { November } \\
\text { 2012 without response }\end{array}$ \\
\hline
\end{tabular}


$\mathrm{CHX}=$ chlorhexidine

$\mathrm{ICU}=$ intensive care unit

$\mathrm{RCT}=$ randomised controlled trial

$\mathrm{VAP}=$ ventilator-associated pneumonia

\section{Characteristics of studies awaiting classification [ordered by study ID]}

Chacko 2017

\begin{tabular}{ll}
\hline Methods & RCT \\
\hline Participants & $\begin{array}{l}\text { Patients ventilated through an orotracheal tube, and recruited within } 4 \text { to } 6 \text { hours of intubation; } \\
\text { aged } 16 \text { years and older, receiving VAP bundle care }\end{array}$ \\
\hline Interventions & CHX + toothbrushing (and suction) versus CHX alone \\
\hline Outcomes & VAP, use of antibiotics, ventilator days, length of ICU stay \\
\hline Notes & Emailed study investigator on 16 March 2020 for length of follow-up/time point of VAP diagnosis \\
\hline
\end{tabular}

\section{Hashemi 2018}

\begin{tabular}{ll}
\hline Methods & RCT \\
\hline Participants & Patients admitted to ICU \\
\hline Interventions & Chlorhexidine mouthwash versus stop-snoring mouthwash \\
\hline Outcomes & Incidence of VAP \\
\hline Notes & Full texts in Persian. Sent to translators on 31 March 2020 for assistance \\
\hline
\end{tabular}

Hashemi 2019

\begin{tabular}{ll}
\hline Methods & RCT \\
\hline Participants & Patients admitted to ICU \\
\hline Interventions & Chlorhexidine mouthwash versus herbal cinnamol mouthwash \\
\hline Outcomes & Incidence of VAP \\
\hline Notes & Full texts in Persian. Sent to translators on 31 March 2020 for assistance \\
\hline
\end{tabular}

\section{IRCT20110427006318N12}

\begin{tabular}{ll}
\hline Methods & RCT \\
\hline Participants & $\begin{array}{l}\text { Patients } 18 \text { to } 75 \text { years old under mechanical ventilation for more than } 48 \text { hours, Glasgow Coma } \\
\text { scale between } 6 \text { and } 11, \text { feeding with gastric tube, no contraindications to oral care, propolis insen- } \\
\text { sitivity }\end{array}$ \\
\hline
\end{tabular}


IRCT20110427006318N12 (Continued)

\begin{tabular}{ll} 
Interventions & Propolis versus $\mathrm{CHX}$ \\
\hline Outcomes & VAP \\
\hline Notes & Emailed study investigator on 16 March 2020 to confirm whether published in full
\end{tabular}

\begin{tabular}{ll}
\hline Methods & RCT \\
\hline Participants & $\begin{array}{l}\text { Age between } 18 \text { to } 65 \text { years, having oral endotracheal tube, no pneumonia or immunosuppres- } \\
\text { sive diseases before the start of the study according to judgement of a physician, be permitted to } \\
\text { perform oral care for patients according to doctor, not having dentures, no history of allergy to } \\
\text { chlorhexidine, the absence of wound, infection and oral trauma, without underlying lung problems }\end{array}$ \\
\hline Interventions & CHX + brushing versus CHX \\
\hline Outcomes & Oral health; pneumonia \\
\hline Notes & Emailed study investigator on 16 March 2020 to confirm whether study published in full \\
\hline
\end{tabular}

\section{IRCT201512115363N8}

\begin{tabular}{ll}
\hline Methods & RCT \\
\hline Participants & $\begin{array}{l}\text { Age between } 20 \text { to } 50 \text { years; admission less than } 24 \text { hours in ICU; intubated patient; satisfaction of } \\
\text { patients and patients' families; the absence of pneumonia }\end{array}$ \\
\hline Interventions & Rose extract + CHX versus CHX \\
\hline Outcomes & Mortality, VAP, connection to ventilator days, length of intensive care unit stay \\
\hline Notes & Emailed study investigator on 16 March 2020 to ask whether study published in full \\
\hline
\end{tabular}

\begin{tabular}{ll}
\hline Methods & RCT \\
\hline Participants & $\begin{array}{l}18 \text { to } 65 \text { years old, having endotracheal tube through the mouth; admitted to ICU less than } 12 \\
\text { hours; having natural teeth; no history of antibiotic use within preceding two weeks; not pregnant; } \\
\text { no history of allergy to herbal compounds; no HIV; no use of steroid drugs; no injury in or around } \\
\text { the mouth; no pneumonia; no leukopenia and neutropenia and serum albumin }<2 / 5 \mathrm{mg} / \mathrm{dL}\end{array}$ \\
\hline Interventions & Aloe vera versus saline \\
\hline Outcomes & Pneumonia, dental plaque index \\
\hline Notes & Emailed study investigator on 16 March 2020 to ask whether study published in full
\end{tabular}


IRCT2017022032676N1

\begin{tabular}{ll}
\hline Methods & RCT \\
\hline Participants & Age between 18 and 65, intubated, under mechanical ventilation in 48 hours after admission \\
\hline Interventions & Persica versus CHX \\
\hline Outcomes & Pneumonia, complication, ICU mortality, intubation duration \\
\hline Notes & Emailed study investigator on 16 March 2020 to confirm whether published in full \\
\hline
\end{tabular}

\section{IRCT2017050727819N4}

\begin{tabular}{ll}
\hline Methods & RCT \\
\hline Participants & $\begin{array}{l}\text { Oral intubation, } 30 \text { to } 50 \text { years old, lack of pulmonary infection, lack of sensitivity to herbal combi- } \\
\text { nation, no history of immunosuppressive drugs, no history of diabetes, level of consciousness } 3 \text { to } \\
8, \text { no wound in the mouth }\end{array}$ \\
\end{tabular}

\begin{tabular}{ll}
\hline Interventions & Orthodentol versus CHX \\
\hline Outcomes & Pneumonia \\
\hline Notes & Emailed study investigator on 16 March 2020 to confirm study whether published in full \\
\hline
\end{tabular}

\section{IRCT20171225038053N1}

\begin{tabular}{ll}
\hline Methods & RCT \\
\hline Participants & $\begin{array}{l}\text { Fewer than } 48 \text { hours passed since the patient was admitted to the intensive care unit, lack of spe- } \\
\text { cific lesion of mouth and around it by using the Beck criterion }\end{array}$ \\
\hline Interventions & CHX versus CHX + hydrogen peroxide \\
\hline Outcomes & Incidence of VAP \\
\hline Notes & Emailed study investigator on 16 March 2020 to confirm whether study published in full \\
\hline
\end{tabular}

\begin{tabular}{ll}
\hline Methods & RCT \\
\hline Participants & $\begin{array}{l}\text { Patients with age of } 2 \text { months to } 14 \text { years who need mechanical ventilation for at least 48 hours ad- } \\
\text { mission in paediatric ICU }\end{array}$ \\
\hline Interventions & CHX versus dine mouthwash (Dineh Iran) \\
\hline Outcomes & Incidence of VAP \\
\hline Notes & Emailed study investigator on 16 March 2020 to confirm whether study published in full \\
\hline
\end{tabular}




\begin{tabular}{ll}
\hline Methods & RCT \\
\hline Participants & $\begin{array}{l}\text { Patient required to have an endotracheal tube, no mucosal inflammation or severe trauma to the } \\
\text { mouth, no chronic disease and immune deficiency, has teeth, does not have re-intubation, on the } \\
\text { first day of patient intubation }\end{array}$ \\
\hline Interventions & CHX versus CHX + toothbrushing \\
\hline Outcomes & Clinical pneumonia infection score, oral health score \\
\hline Notes & Emailed study investigator on 16 March 2020 to confirm whether study published in full \\
\hline
\end{tabular}

Jamshidi 2016

\begin{tabular}{ll}
\hline Methods & RCT \\
\hline Participants & $\begin{array}{l}\text { Patients admitted to ICUs of Ayatollah Mousavi Hospital of Zanjan that received intubation within } \\
24 \text { hours }\end{array}$ \\
\hline Interventions & CHX oral swab versus toothbrushing vs toothbrushing + CHX oral swab \\
\hline Outcomes & Incidence of VAP \\
\hline Notes & Full texts in Persian. Sent to translators on 31 March 2020 for assistance \\
\hline
\end{tabular}

Mehrabadi 2015

\begin{tabular}{ll}
\hline Methods & RCT \\
\hline Participants & Intubated patients in ICUs of educational hospitals in Arak in 2014 \\
\hline Interventions & Echinacea versus normal saline \\
\hline Outcomes & Incidence of VAP \\
\hline Notes & Full texts in Persian. Sent to translators on 31 March 2020 for assistance \\
\hline
\end{tabular}

$\mathrm{CHX}=$ chlorhexidine;

HIV = human immunodeficiency viruses;

ICU = intensive care unit;

$\mathrm{OA}=$ oral assessment;

$\mathrm{RCT}=$ randomised controlled trial;

$\mathrm{VAP}=$ ventilator-associated pneumonia;

vs $=$ versus

Characteristics of ongoing studies [ordered by study ID]

RBR-7p6568 
RBR-7p6568 (Continued)

\begin{tabular}{ll} 
Methods & RCT \\
\hline Participants & $\begin{array}{l}\text { Patients admitted to the intensive care unit of the Clinical Hospital of the Federal University of } \\
\text { Uberlandia from } 2019 \text { to } 2020 ; \text { dependent on mechanical ventilation for more than 48 hours; re- } \\
\text { gardless of gender; over } 18 \text { years old; head trauma victim }\end{array}$ \\
\hline Interventions & CHX versus cetylpyridinium versus water \\
\hline Outcomes & $\begin{array}{l}\text { Mortality; ventilator-associated pneumonia; adverse events; days of extubation time, length of stay } \\
\text { in the intensive care unit and length of hospital stay }\end{array}$ \\
\hline Starting date & May 2019 \\
\hline Contact information & drapaulacunhavieira@gmail.com \\
\hline Notes & Emailed study investigator 16 March 2020 to confirm whether published in full. Reply received 21 \\
& March 2020 - ongoing trial
\end{tabular}

\section{TCTR20190530003}

\begin{tabular}{ll}
\hline Study name & $\begin{array}{l}\text { Efficacy of moraceae with chlorhexidine mouthwash on microbial flora of critically ill intubated pa- } \\
\text { tients }\end{array}$ \\
\hline Methods & RCT \\
\hline Participants & $\begin{array}{l}\text { Adults (age more than } 18 \text { years); admitted in the medical intensive care unit within } 24 \text { hours; hav- } \\
\text { tion for moraceae or chlorhexidine mouthwash }\end{array}$ \\
\hline Interventions & CHX + moraceae versus CHX \\
\hline Outcomes & Oral microbial flora; adverse events; oral health; ventilator-associated pneumonia \\
\hline Starting date & May 2019 \\
\hline Contact information & vveerapong@gmail.com \\
\hline Notes & $\begin{array}{l}\text { Emailed study investigator } 8 \text { March } 2020 \text { to confirm whether published in full. Reply received } 8 \\
\text { March } 2020 \text { - ongoing trial }\end{array}$ \\
\hline
\end{tabular}

$\mathrm{CHX}=$ chlorhexidine;

$\mathrm{ICU}=$ intensive care unit;

$\mathrm{OA}=$ oral assessment;

$\mathrm{RCT}=$ randomised controlled trial;

$\mathrm{VAP}=$ ventilator-associated pneumonia

\section{DATA AND ANALYSES}


Comparison 1. Chlorhexidine versus placebo/usual care

\begin{tabular}{|c|c|c|c|c|}
\hline Outcome or subgroup title & $\begin{array}{l}\text { No. of } \\
\text { studies }\end{array}$ & $\begin{array}{l}\text { No. of } \\
\text { partici- } \\
\text { pants }\end{array}$ & Statistical method & Effect size \\
\hline 1.1 Incidence of VAP & 13 & 1206 & Risk Ratio (M-H, Random, 95\% Cl) & $0.67[0.47,0.97]$ \\
\hline $\begin{array}{l}\text { 1.1.1 Chlorhexidine solution versus placebo (no } \\
\text { toothbrushing in either group) }\end{array}$ & 6 & 429 & Risk Ratio (M-H, Random, 95\% CI) & $0.57[0.33,1.00]$ \\
\hline $\begin{array}{l}\text { 1.1.2 Chlorhexidine gel versus placebo (no } \\
\text { toothbrushing in either group) }\end{array}$ & 2 & 297 & Risk Ratio (M-H, Random, 95\% CI) & $0.53[0.29,0.97]$ \\
\hline $\begin{array}{l}\text { 1.1.3 Chlorhexidine solution versus placebo } \\
\text { (toothbrushing both groups) }\end{array}$ & 3 & 332 & Risk Ratio (M-H, Random, 95\% Cl) & $0.74[0.29,1.89]$ \\
\hline $\begin{array}{l}\text { 1.1.4 Chlorhexidine gel versus placebo (tooth- } \\
\text { brushing both groups) }\end{array}$ & 2 & 148 & Risk Ratio (M-H, Random, 95\% Cl) & $1.22[0.83,1.79]$ \\
\hline 1.2 Mortality & 9 & 944 & Risk Ratio (M-H, Random, 95\% CI) & $1.02[0.84,1.23]$ \\
\hline $\begin{array}{l}\text { 1.2.1 Chlorhexidine solution versus placebo (no } \\
\text { toothbrushing in either group) }\end{array}$ & 4 & 374 & Risk Ratio (M-H, Random, 95\% CI) & $1.03[0.80,1.33]$ \\
\hline $\begin{array}{l}\text { 1.2.2 Chlorhexidine gel versus placebo (no } \\
\text { toothbrushing in either group) }\end{array}$ & 1 & 40 & Risk Ratio (M-H, Random, 95\% Cl) & Not estimable \\
\hline $\begin{array}{l}\text { 1.2.3 Chlorhexidine solution versus placebo } \\
\text { (toothbrushing both groups) }\end{array}$ & 2 & 382 & Risk Ratio (M-H, Random, 95\% Cl) & $1.00[0.72,1.40]$ \\
\hline $\begin{array}{l}\text { 1.2.4 Chlorhexidine gel versus placebo (tooth- } \\
\text { brushing both groups) }\end{array}$ & 2 & 148 & Risk Ratio (M-H, Random, 95\% Cl) & $1.00[0.59,1.68]$ \\
\hline 1.3 Duration of ventilation (days) & 4 & 594 & $\begin{array}{l}\text { Mean Difference (IV, Random, 95\% } \\
\mathrm{Cl})\end{array}$ & $\begin{array}{l}-1.10[-3.20 \\
1.00]\end{array}$ \\
\hline $\begin{array}{l}\text { 1.3.1 Chlorhexidine solution versus placebo (no } \\
\text { toothbrushing in either group) }\end{array}$ & 3 & 263 & $\begin{array}{l}\text { Mean Difference (IV, Random, 95\% } \\
\mathrm{Cl} \text { ) }\end{array}$ & $\begin{array}{l}-2.63[-3.35 \\
-1.90]\end{array}$ \\
\hline $\begin{array}{l}\text { 1.3.2 Chlorhexidine gel versus placebo (no } \\
\text { toothbrushing in either group) }\end{array}$ & 1 & 257 & $\begin{array}{l}\text { Mean Difference (IV, Random, 95\% } \\
\mathrm{Cl})\end{array}$ & $\begin{array}{l}2.21[-0.30 \\
4.72]\end{array}$ \\
\hline $\begin{array}{l}\text { 1.3.3 Chlorhexidine solution versus placebo } \\
\text { (toothbrushing both groups) }\end{array}$ & 1 & 74 & $\begin{array}{l}\text { Mean Difference (IV, Random, 95\% } \\
\mathrm{CI})\end{array}$ & $\begin{array}{l}-1.30[-4.20 \\
1.60]\end{array}$ \\
\hline 1.4 Duration of ICU stay (days) & 5 & 627 & $\begin{array}{l}\text { Mean Difference (IV, Random, 95\% } \\
\mathrm{CI})\end{array}$ & $\begin{array}{l}-0.89[-3.59 \\
1.82]\end{array}$ \\
\hline $\begin{array}{l}\text { 1.4.1 Chlorhexidine solution versus placebo (no } \\
\text { toothbrushing in either group) }\end{array}$ & 3 & 274 & $\begin{array}{l}\text { Mean Difference (IV, Random, 95\% } \\
\mathrm{CI})\end{array}$ & $\begin{array}{l}-2.92[-4.18 \\
-1.66]\end{array}$ \\
\hline $\begin{array}{l}\text { 1.4.2 Chlorhexidine gel versus placebo (no } \\
\text { toothbrushing in either group) }\end{array}$ & 1 & 257 & $\begin{array}{l}\text { Mean Difference (IV, Random, 95\% } \\
\mathrm{Cl})\end{array}$ & $\begin{array}{l}1.32[-2.43 \\
5.07]\end{array}$ \\
\hline $\begin{array}{l}1.4 .3 \text { Chlorhexidine gel versus placebo (tooth- } \\
\text { brushing both groups) }\end{array}$ & 1 & 96 & $\begin{array}{l}\text { Mean Difference (IV, Random, 95\% } \\
\mathrm{Cl} \text { ) }\end{array}$ & $\begin{array}{l}5.00[-2.20 \\
12.20]\end{array}$ \\
\hline
\end{tabular}




\begin{tabular}{|c|c|c|c|c|}
\hline Outcome or subgroup title & $\begin{array}{l}\text { No. of } \\
\text { studies }\end{array}$ & $\begin{array}{l}\text { No. of } \\
\text { partici- } \\
\text { pants }\end{array}$ & Statistical method & Effect size \\
\hline $\begin{array}{l}\text { 1.5 Duration of systemic antibiotic therapy } \\
\text { (days) }\end{array}$ & 1 & 146 & Mean Difference (IV, Fixed, 95\% Cl) & $\begin{array}{l}0.65[-0.58 \\
1.88]\end{array}$ \\
\hline $\begin{array}{l}\text { 1.5.1 Chlorhexidine solution versus placebo } \\
\text { (toothbrushing both groups) }\end{array}$ & 1 & 146 & Mean Difference (IV, Fixed, 95\% Cl) & $\begin{array}{l}0.65[-0.58 \\
1.88]\end{array}$ \\
\hline $\begin{array}{l}\text { 1.6 Number of participants treated with sys- } \\
\text { temic antibiotics }\end{array}$ & 1 & & Risk Ratio (M-H, Fixed, 95\% Cl) & Subtotals only \\
\hline $\begin{array}{l}\text { 1.6.1 Chlorhexidine solution versus placebo (no } \\
\text { toothbrushing in either group) }\end{array}$ & 1 & 16 & Risk Ratio (M-H, Fixed, 95\% Cl) & $0.86[0.53,1.38]$ \\
\hline 1.7 Plaque index & 2 & & $\begin{array}{l}\text { Std. Mean Difference (IV, Fixed, } \\
95 \% \mathrm{Cl})\end{array}$ & $\begin{array}{l}\text { Totals not se- } \\
\text { lected }\end{array}$ \\
\hline $\begin{array}{l}\text { 1.7.1 Chlorhexidine solution versus placebo (no } \\
\text { toothbrushing in either group) }\end{array}$ & 2 & & $\begin{array}{l}\text { Std. Mean Difference (IV, Fixed, } \\
95 \% \mathrm{CI} \text { ) }\end{array}$ & $\begin{array}{l}\text { Totals not se- } \\
\text { lected }\end{array}$ \\
\hline 1.8 Adverse effects & 1 & & Risk Ratio (M-H, Fixed, 95\% Cl) & Subtotals only \\
\hline 1.8.1 Reversible mild irritation of oral mucosa & 1 & 207 & Risk Ratio (M-H, Fixed, 95\% Cl) & $\begin{array}{l}10.29[1.34 \\
78.97]\end{array}$ \\
\hline
\end{tabular}


Analysis 1.1. Comparison 1: Chlorhexidine versus placebo/usual care, Outcome 1: Incidence of VAP

\begin{tabular}{cccccccc} 
& \multicolumn{2}{c}{ Chlorhexidine } & Placebo/Usual care & & \multicolumn{2}{c}{ Risk Ratio } & Risk Ratio \\
Study or Subgroup & Events & Total & Events & Total & Weight & M-H, Random, 95\% CI & M-H, Random, 95\% CI
\end{tabular}

1.1.1 Chlorhexidine solution versus placebo (no toothbrushing in either group) $\begin{array}{llllll}\text { Fu } 2019 & 7 & 40 & 37 & 40 & 9.0 \%\end{array}$

Meidani 2018

Grap 2011 (1)

Ozcaka 2012

Bellissimo-Rodrigues 2009

Tuon 2017

Subtotal $(95 \%$ CI)

Total events:

$6 \quad 50$

15

Heterogeneity: $\mathrm{Tau}^{2}=0.33 ; \mathrm{Chi}^{2}=17.96, \mathrm{df}=5(\mathrm{P}=0.003) ; \mathrm{I}^{2}=72 \%$

Test for overall effect: $\mathrm{Z}=1.97(\mathrm{P}=0.05)$

1.1.2 Chlorhexidine gel versus placebo (no toothbrushing in either group)

$\begin{array}{lrrrrrr}\text { Cabov } 2010 & 1 & 17 & 6 & 23 & 2.6 \% & 0.23[0.03,1.70] \\ \text { Koeman } 2006 & 13 & 127 & 23 & 130 & 9.4 \% & 0.58[0.31,1.09] \\ \text { Subtotal (95\% CI) } & & \mathbf{1 4 4} & & \mathbf{1 5 3} & \mathbf{1 2 . 0 \%} & \mathbf{0 . 5 3}[\mathbf{0 . 2 9}, \mathbf{0 . 9 7}]\end{array}$

Total events: $14 \quad 29$

Heterogeneity: $\mathrm{Tau}^{2}=0.00 ; \mathrm{Chi}^{2}=0.77, \mathrm{df}=1(\mathrm{P}=0.38) ; \mathrm{I}^{2}=0 \%$

Test for overall effect: $\mathrm{Z}=2.04(\mathrm{P}=0.04)$

1.1.3 Chlorhexidine solution versus placebo (toothbrushing both groups)

Tantipong 2008

Scannapieco 2009 (2)

Berry 2011 (3)

Subtotal (95\% CI)

$\begin{array}{rrrr}58 & 10 & 52 & 6.6 \% \\ 97 & 12 & 49 & 8.9 \% \\ 33 & 1 & 43 & 2.4 \% \\ \mathbf{1 8 8} & & \mathbf{1 4 4} & \mathbf{1 7 . 8 \%}\end{array}$

Total events:

Heterogeneity: $\mathrm{Tau}^{2}=0.36 ; \mathrm{Chi}^{2}=4.30, \mathrm{df}=2(\mathrm{P}=0.12) ; \mathrm{I}^{2}=53 \%$

Test for overall effect: $\mathrm{Z}=0.64(\mathrm{P}=0.53)$

1.1.4 Chlorhexidine gel versus placebo (toothbrushing both groups)

$\begin{array}{lllllll}\text { Kusahara 2012a (4) } & 15 & 46 & 16 & 50 & 9.8 \% & 1.02[0.57,1.82] \\ \text { Meinberg 2012 } & 18 & 28 & 11 & 24 & 10.4 \% & 1.40[0.84,2.35] \\ \text { Subtotal (95\% CI) } & & \mathbf{7 4} & & \mathbf{7 4} & \mathbf{2 0 . 2 \%} & \mathbf{1 . 2 2}[\mathbf{0 . 8 3}, \mathbf{1 . 7 9}]\end{array}$

Total events: 33

Heterogeneity: $\mathrm{Tau}^{2}=0.00 ; \mathrm{Chi}^{2}=0.67, \mathrm{df}=1(\mathrm{P}=0.41) ; \mathrm{I}^{2}=0 \%$

Test for overall effect: $\mathrm{Z}=1.00(\mathrm{P}=0.32)$

Total $(95 \%$ CI $)$

618

Total events:

122

18

Heterogeneity: $\mathrm{Tau}^{2}=0.26 ; \mathrm{Chi}^{2}=35.29, \mathrm{df}=12(\mathrm{P}=0.0004) ; \mathrm{I}^{2}=66 \%$

Test for overall effect: $\mathrm{Z}=2.14(\mathrm{P}=0.03)$

Test for subgroup differences: $\mathrm{Chi}^{2}=7.69, \mathrm{df}=3(\mathrm{P}=0.05), \mathrm{I}^{2}=61.0 \%$

$588 \quad 100.0 \%$

Footnotes

(1) Single CHX rinse, no placebo

(2) 47 patients treated $1 x /$ day \& $502 x /$ day

(3) Some randomised participants were ineligible

(4) Children
$0.40[0.17,0.95]$

$1.01[0.56,1.83]$

$2.00[0.50,8.00]$

$0.57[0.33,1.00]$ 
Analysis 1.2. Comparison 1: Chlorhexidine versus placebo/usual care, Outcome 2: Mortality

\begin{tabular}{|c|c|c|c|c|c|c|}
\hline \multirow[b]{2}{*}{ Study or Subgroup } & \multicolumn{2}{|c|}{ Chlorhexidine } & Placebo/usual care & \multicolumn{2}{|r|}{ Risk Ratio } & Risk Ratio \\
\hline & Events & Total & Events & Weight & M-H, Random, 95\% CI & M-H, Random, $95 \% \mathrm{Cl}$ \\
\hline
\end{tabular}

1.2.1 Chlorhexidine solution versus placebo (no toothbrushing in either group)

$\begin{array}{llllll}\text { Bellissimo-Rodrigues } 2009 & 34 & 64 & 32 & 69 & 30.1 \%\end{array}$

$\begin{array}{llllll}\text { Ozcaka } 2012 & 17 & 29 & 19 & 32 & 20.1 \%\end{array}$

$\begin{array}{llllll}\text { Meidani } 2018 & 4 & 50 & 5 & 50 & 2.2 \%\end{array}$

$\begin{array}{llllll}\text { Fu } 2019 & 3 & 40 & 7 & 40 & 2.2 \%\end{array}$

$\begin{array}{llll}\text { Subtotal }(95 \% \text { CI }) & 183 & 191 & 54.6 \%\end{array}$

Total events: $\quad 58 \quad 63$

Heterogeneity: $\mathrm{Tau}^{2}=0.00 ; \mathrm{Chi}^{2}=2.46, \mathrm{df}=3(\mathrm{P}=0.48) ; \mathrm{I}^{2}=0 \%$

Test for overall effect: $\mathrm{Z}=0.21(\mathrm{P}=0.83)$

1.2.2 Chlorhexidine gel versus placebo (no toothbrushing in either group)

$\begin{array}{lllll}\text { Cabov } 2010 & 0 & 17 & 0\end{array}$

Subtotal (95\% CI)

Total events:

0

Not estimable

Heterogeneity: Not applicable

Test for overall effect: Not applicable

1.2.3 Chlorhexidine solution versus placebo (toothbrushing both groups)

$\begin{array}{lllrrr}\text { Tantipong 2008 } & 36 & 102 & 37 & 105 & 25.9 \% \\ \text { Scannapieco 2009 } & 16 & 116 & 8 & 59 & 5.7 \% \\ \text { Subtotal (95\% CI) } & & \mathbf{2 1 8} & & \mathbf{1 6 4} & \mathbf{3 1 . 6 \%} \\ \text { Total events: } & 52 & & 45 & & \end{array}$

Heterogeneity: $\mathrm{Tau}^{2}=0.00 ; \mathrm{Chi}^{2}=0.00, \mathrm{df}=1(\mathrm{P}=0.97) ; \mathrm{I}^{2}=0 \%$

Test for overall effect: $\mathrm{Z}=0.03(\mathrm{P}=0.98)$

1.2.4 Chlorhexidine gel versus placebo (toothbrushing both groups)

$\begin{array}{lrrrrrr}\text { Kusahara 2012a (1) } & 8 & 46 & 12 & 50 & 5.5 \% & 0.72[0.33,1.61] \\ \text { Meinberg 2012 } & 13 & 28 & 9 & 24 & 8.3 \% & 1.24[0.65,2.38] \\ \text { Subtotal (95\% CI) } & & \mathbf{7 4} & & \mathbf{7 4} & \mathbf{1 3 . 8 \%} & \mathbf{1 . 0 0}[\mathbf{0 . 5 9}, \mathbf{1 . 6 8}]\end{array}$

Total events: $\quad 21 \quad 21$

Heterogeneity: $\mathrm{Tau}^{2}=0.01 ; \mathrm{Chi}^{2}=1.06, \mathrm{df}=1(\mathrm{P}=0.30) ; \mathrm{I}^{2}=6 \%$

Test for overall effect: $\mathrm{Z}=0.01(\mathrm{P}=0.99)$

Total $(\mathbf{9 5 \%}$ CI)
$\begin{aligned} & \text { Total events: } \\ & \text { Heterogeneity: } \mathrm{Tau}^{2}=0.00 \cdot \mathrm{Chi}^{2}=3.50, \mathrm{df}=7(\mathrm{P}=0.84) ; \mathrm{I}^{2}=0 \%\end{aligned}$

Heterogeneity: $\mathrm{Tau}^{2}=0.00 ; \mathrm{Chi}^{2}=3.50, \mathrm{df}=7(\mathrm{P}=0.84) ; \mathrm{I}^{2}=0 \%$

Test for overall effect: $\mathrm{Z}=0.17(\mathrm{P}=0.86)$

Test for subgroup differences: $\mathrm{Chi}^{2}=0.02, \mathrm{df}=2(\mathrm{P}=0.99), \mathrm{I}^{2}=0 \%$

$1.00[0.69,1.45]$

$1.02[0.46,2.24]$

$1.00[0.72,1.40]$

Footnotes

(1) Children

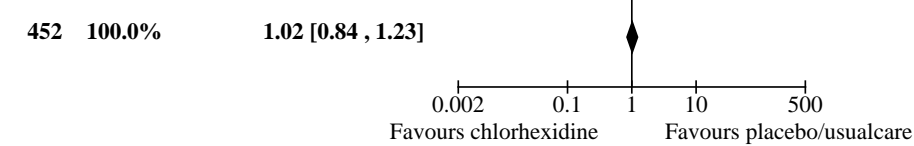


Analysis 1.3. Comparison 1: Chlorhexidine versus placebo/usual care, Outcome 3: Duration of ventilation (days)

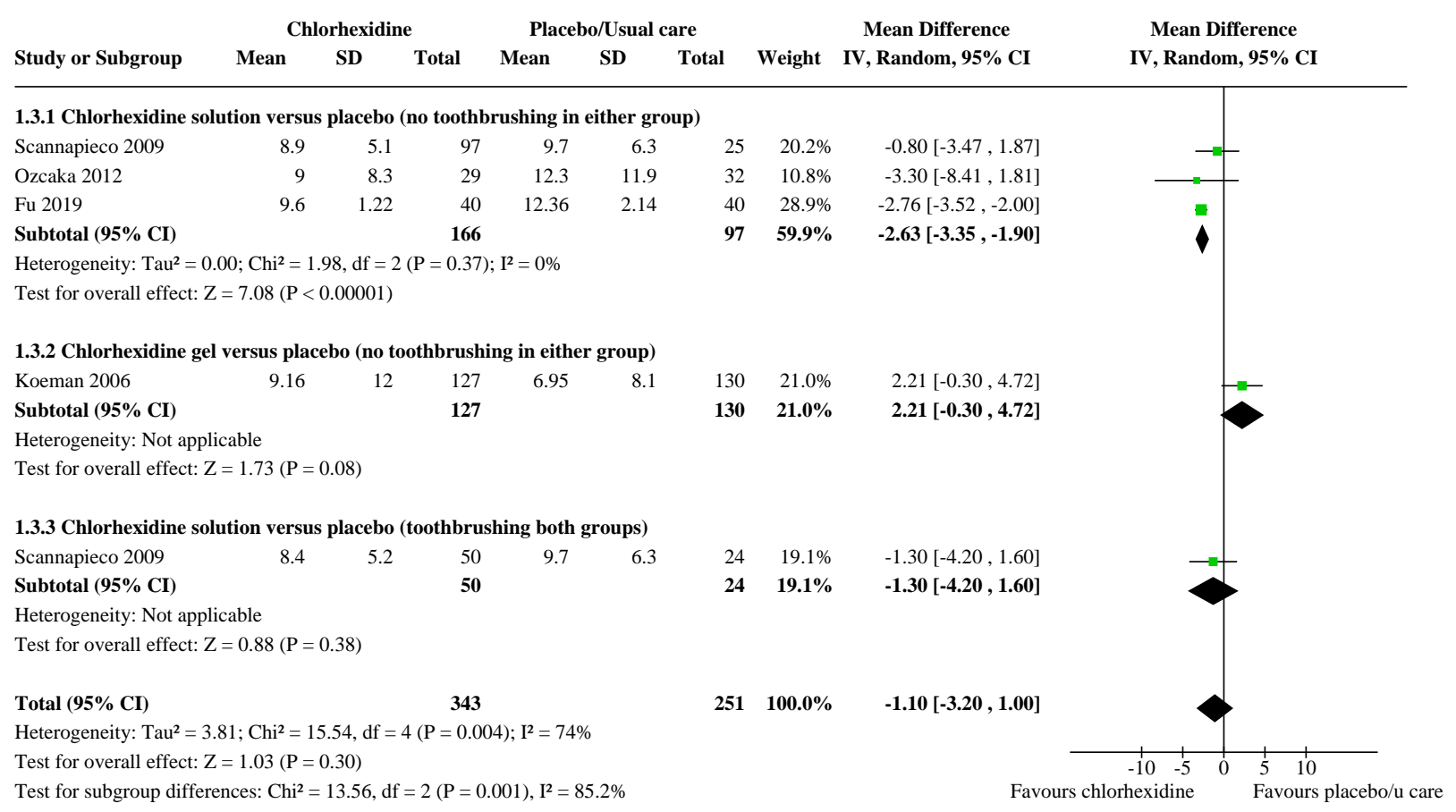

Analysis 1.4. Comparison 1: Chlorhexidine versus placebo/usual care, Outcome 4: Duration of ICU stay (days)

\begin{tabular}{|c|c|c|c|c|c|c|c|c|c|}
\hline \multirow[b]{2}{*}{ Study or Subgroup } & \multicolumn{3}{|c|}{ Chlorhexidine } & \multicolumn{3}{|c|}{ Placebo/Usual care } & \multirow[b]{2}{*}{ Weight } & \multirow{2}{*}{$\begin{array}{c}\text { Mean Difference } \\
\text { IV, Random, 95\% CI }\end{array}$} & \multirow{2}{*}{$\begin{array}{c}\text { Mean Difference } \\
\text { IV, Random, 95\% CI }\end{array}$} \\
\hline & Mean & SD & Total & Mean & SD & Total & & & \\
\hline \multicolumn{10}{|c|}{ 1.4.1 Chlorhexidine solution versus placebo (no toothbrushing in either group) } \\
\hline Bellissimo-Rodrigues 2009 & 9.7 & 9.4 & 64 & 10.4 & 9.4 & 69 & $23.2 \%$ & $-0.70[-3.90,2.50]$ & \\
\hline Ozcaka 2012 & 12.2 & 11.3 & 29 & 15.4 & 13.5 & 32 & $12.2 \%$ & $-3.20[-9.43,3.03]$ & 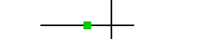 \\
\hline Fu 2019 & 6.5 & 0.69 & 40 & 9.76 & 1.03 & 40 & $34.0 \%$ & $-3.26[-3.64,-2.88]$ & - \\
\hline Subtotal $(95 \%$ CI $)$ & & & 133 & & & 141 & $69.4 \%$ & $-2.92[-4.18,-1.66]$ & 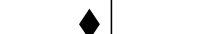 \\
\hline \multicolumn{10}{|c|}{ Heterogeneity: $\mathrm{Tau}^{2}=0.46 ; \mathrm{Chi}^{2}=2.43, \mathrm{df}=2(\mathrm{P}=0.30) ; \mathrm{I}^{2}=18 \%$} \\
\hline \multicolumn{10}{|c|}{ Test for overall effect: $\mathrm{Z}=4.56(\mathrm{P}<0.00001)$} \\
\hline \multicolumn{10}{|c|}{ 1.4.2 Chlorhexidine gel versus placebo (no toothbrushing in either group) } \\
\hline Koeman 2006 & 13.77 & 17.4 & 127 & 12.45 & 12.9 & 130 & $20.6 \%$ & $1.32[-2.43,5.07]$ & \\
\hline Subtotal $(95 \%$ CI $)$ & & & 127 & & & 130 & $20.6 \%$ & $1.32[-2.43,5.07]$ & \\
\hline \multicolumn{10}{|l|}{ Heterogeneity: Not applicable } \\
\hline \multicolumn{10}{|c|}{ Test for overall effect: $Z=0.69(P=0.49)$} \\
\hline \multicolumn{10}{|c|}{ 1.4.3 Chlorhexidine gel versus placebo (toothbrushing both groups) } \\
\hline Kusahara 2012a & 15.8 & 23.6 & 46 & 10.8 & 8.32 & 50 & $10.0 \%$ & $5.00[-2.20,12.20]$ & \\
\hline Subtotal (95\% CI) & & & 46 & & & 50 & $10.0 \%$ & $5.00[-2.20,12.20]$ & \\
\hline \multicolumn{10}{|l|}{ Heterogeneity: Not applicable } \\
\hline \multicolumn{10}{|c|}{ Test for overall effect: $\mathrm{Z}=1.36(\mathrm{P}=0.17)$} \\
\hline Total $(95 \%$ CI $)$ & & & 306 & & & 321 & $100.0 \%$ & $-0.89[-3.59,1.82]$ & \\
\hline \multicolumn{10}{|c|}{ Heterogeneity: $\mathrm{Tau}^{2}=5.56 ; \mathrm{Chi}^{2}=12.95, \mathrm{df}=4(\mathrm{P}=0.01) ; \mathrm{I}^{2}=69 \%$} \\
\hline Test for overall effect: $Z=0$ & $\mathrm{P}=0.52)$ & & & & & & & $-\frac{1}{-20}$ & -10 \\
\hline
\end{tabular}




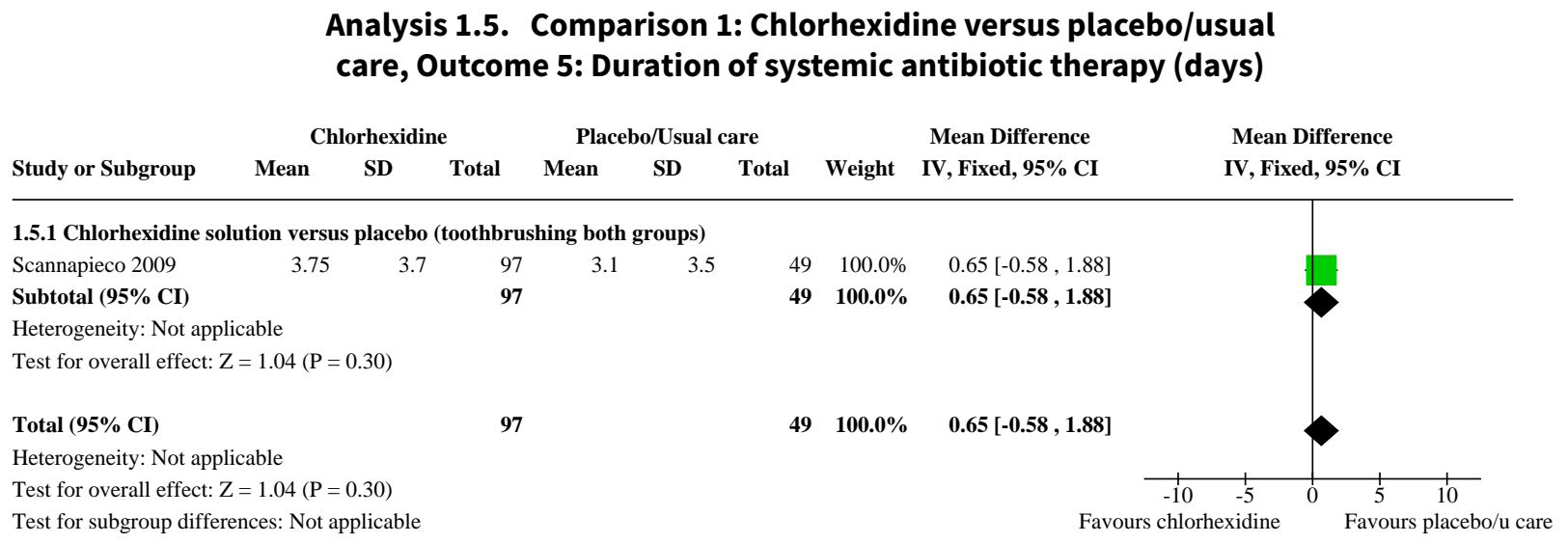

Analysis 1.6. Comparison 1: Chlorhexidine versus placebo/usual care, Outcome 6: Number of participants treated with systemic antibiotics

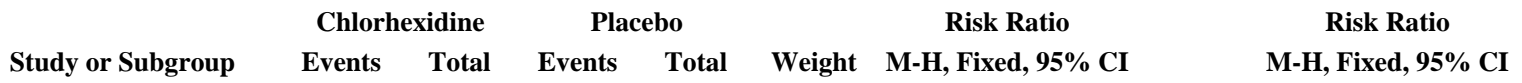

1.6.1 Chlorhexidine solution versus placebo (no toothbrushing in either group)

$\begin{array}{lllllll}\text { Tuon } 2017 & 6 & 8 & 7 & 8 & 100.0 \% & 0.86[0.53,1.38] \\ \text { Subtotal }(\mathbf{9 5 \%} \text { CI) } & & \mathbf{8} & & \mathbf{8} & \mathbf{1 0 0 . 0 \%} & \mathbf{0 . 8 6}[\mathbf{0 . 5 3}, \mathbf{1 . 3 8}] \\ \text { Total events: } & 6 & & 7 & & & \end{array}$

Heterogeneity: Not applicable

Test for overall effect: $\mathrm{Z}=0.63(\mathrm{P}=0.53)$

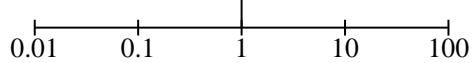

Favours chlorhexidine Favours placebo

\section{Analysis 1.7. Comparison 1: Chlorhexidine versus placebo/usual care, Outcome 7: Plaque index}

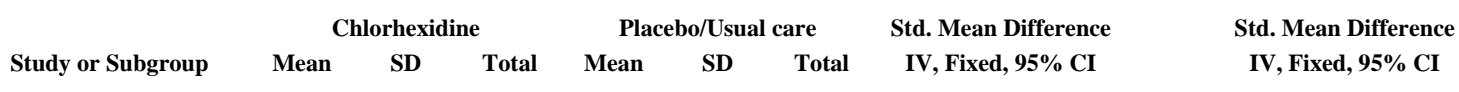

1.7.1 Chlorhexidine solution versus placebo (no toothbrushing in either group)

$\begin{array}{lrlllrrrr}\text { Fu 2019 (1) } & 0.75 & 0.13 & 40 & 1.66 & 0.2 & 40 & -5.34[-6.30,-4.39] & -1- \\ \text { Ozcaka 2012(2) } & 86.6 & 21.6 & 29 & 84.7 & 19.3 & 32 & 0.09[-0.41,0.59] & -1\end{array}$

Footnotes

(1) A four-point ordinal scale ( 0 to 3 ), with ' 0 ' representing no plaque and ' 3 ' being the most severe category

(2) The proportion $(\%)$ of participants presented with dental plaque 
Analysis 1.8. Comparison 1: Chlorhexidine versus placebo/usual care, Outcome 8: Adverse effects

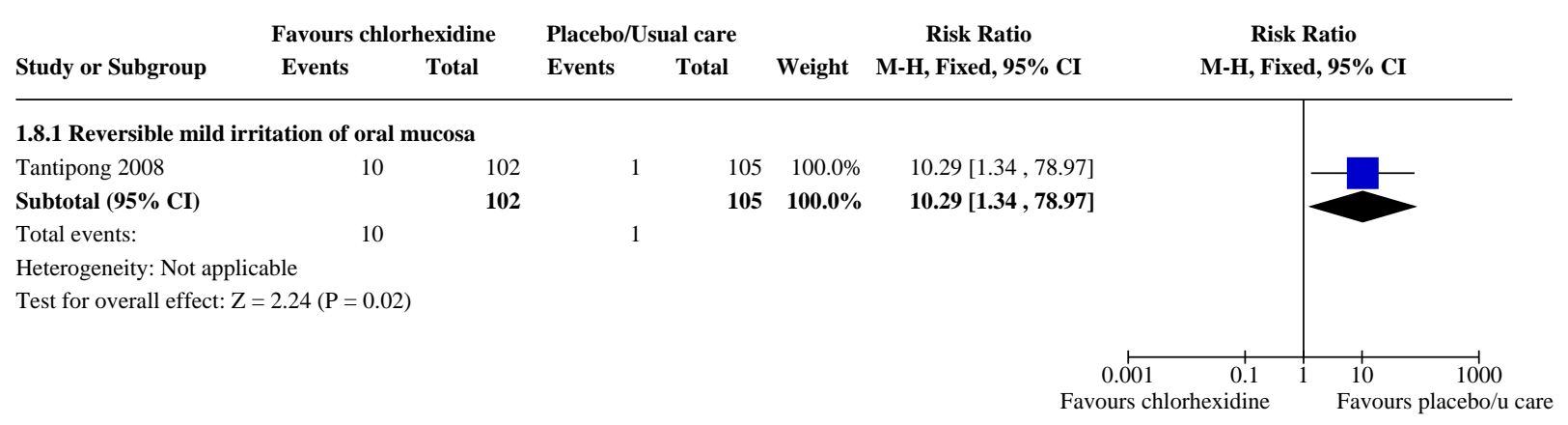

Comparison 2. Chlorhexidine versus other oral care agents

\begin{tabular}{|c|c|c|c|c|}
\hline Outcome or subgroup title & $\begin{array}{l}\text { No. of } \\
\text { studies }\end{array}$ & $\begin{array}{l}\text { No. of } \\
\text { partici- } \\
\text { pants }\end{array}$ & Statistical method & Effect size \\
\hline 2.1 Incidence of VAP & 6 & & Risk Ratio (M-H, Fixed, 95\% Cl) & Subtotals only \\
\hline $\begin{array}{l}\text { 2.1.1 Chlorhexidine versus potassium } \\
\text { permanganate }\end{array}$ & 2 & 271 & Risk Ratio (M-H, Fixed, 95\% Cl) & $0.87[0.50,1.52]$ \\
\hline $\begin{array}{l}\text { 2.1.2 Chlorhexidine versus ozonated } \\
\text { water }\end{array}$ & 1 & 74 & Risk Ratio (M-H, Fixed, 95\% Cl) & $2.60[1.12,6.03]$ \\
\hline 2.1.3 Chlorhexidine versus Nanosil & 1 & 75 & Risk Ratio (M-H, Fixed, 95\% Cl) & $8.76[1.17,65.78]$ \\
\hline $\begin{array}{l}\text { 2.1.4 Chlorhexidine versus hydrogen } \\
\text { peroxide }\end{array}$ & 1 & 70 & Risk Ratio (M-H, Fixed, 95\% Cl) & $0.29[0.06,1.28]$ \\
\hline 2.1.5 Chlorhexidine versus miswak & 1 & 70 & Risk Ratio (M-H, Fixed, 95\% Cl) & $13.00[0.76,222.31]$ \\
\hline 2.2 Mortality & 3 & & Risk Ratio (M-H, Fixed, 95\% Cl) & Subtotals only \\
\hline $\begin{array}{l}\text { 2.2.1 Chlorhexidine versus potassium } \\
\text { permanganate }\end{array}$ & 2 & 271 & Risk Ratio (M-H, Fixed, 95\% Cl) & $1.11[0.89,1.38]$ \\
\hline 2.2.2 Chlorhexidine versus Nanosil & 1 & 75 & Risk Ratio (M-H, Fixed, 95\% Cl) & $4.87[0.24,98.18]$ \\
\hline $\begin{array}{l}2.3 \text { Number of participants treated } \\
\text { with systemic antibiotics }\end{array}$ & 1 & & Risk Ratio (M-H, Fixed, 95\% Cl) & Totals not selected \\
\hline 2.3.1 Chlorhexidine versus miswak & 1 & & Risk Ratio (M-H, Fixed, 95\% Cl) & Totals not selected \\
\hline
\end{tabular}


Analysis 2.1. Comparison 2: Chlorhexidine versus other oral care agents, Outcome 1: Incidence of VAP

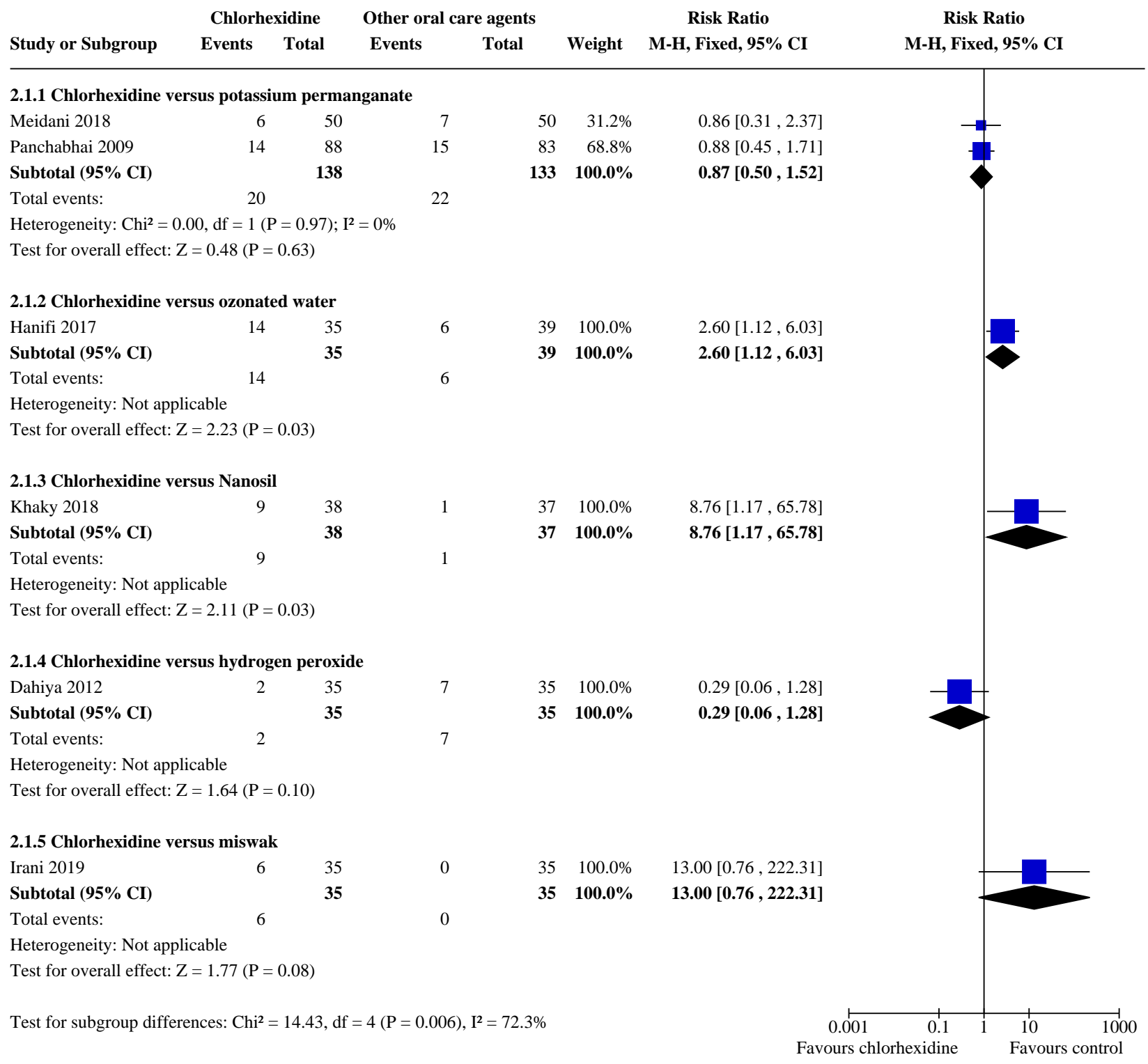


Analysis 2.2. Comparison 2: Chlorhexidine versus other oral care agents, Outcome 2: Mortality

\begin{tabular}{|c|c|c|c|c|c|c|c|}
\hline \multirow[b]{2}{*}{ Study or Subgroup } & \multicolumn{2}{|c|}{ Chlorhexidine } & \multicolumn{2}{|c|}{ Other oral agents } & \multirow[b]{2}{*}{ Weight } & Risk Ratio & \multirow{2}{*}{$\begin{array}{c}\text { Risk Ratio } \\
\text { M-H, Fixed, 95\% CI }\end{array}$} \\
\hline & Events & Total & Events & Total & & M-H, Fixed, 95\% CI & \\
\hline \multicolumn{8}{|c|}{ 2.2.1 Chlorhexidine versus potassium permanganate } \\
\hline Meidani 2018 & 4 & 50 & 7 & 50 & $11.8 \%$ & $0.57[0.18,1.83]$ & $\longrightarrow$ \\
\hline Panchabhai 2009 & 64 & 88 & 51 & 83 & $88.2 \%$ & $1.18[0.96,1.46]$ & \\
\hline Subtotal (95\% CI) & & 138 & & 133 & $100.0 \%$ & $1.11[0.89,1.38]$ & \\
\hline Total events: & 68 & & 58 & & & & \\
\hline \multicolumn{8}{|c|}{ Heterogeneity: $\mathrm{Chi}^{2}=1.59, \mathrm{df}=1(\mathrm{P}=0.21) ; \mathrm{I}^{2}=37 \%$} \\
\hline \multicolumn{8}{|c|}{ Test for overall effect: $\mathrm{Z}=0.95(\mathrm{P}=0.34)$} \\
\hline \multicolumn{8}{|c|}{ 2.2.2 Chlorhexidine versus Nanosil } \\
\hline Khaky 2018 & 2 & 38 & 0 & 37 & $100.0 \%$ & $4.87[0.24,98.18]$ & 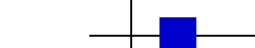 \\
\hline Subtotal (95\% CI) & & 38 & & 37 & $100.0 \%$ & $4.87[0.24,98.18]$ & \\
\hline Total events: & 2 & & 0 & & & & \\
\hline \multicolumn{8}{|c|}{ Heterogeneity: Not applicable } \\
\hline \multicolumn{8}{|c|}{ Test for overall effect: $\mathrm{Z}=1.03(\mathrm{P}=0.30)$} \\
\hline & & & & & & Favc & $\begin{array}{ccc}1 & 1 \\
0.1 & 1 & 10 \\
\text { hexidine } & & \text { Favour }\end{array}$ \\
\hline
\end{tabular}

\section{Analysis 2.3. Comparison 2: Chlorhexidine versus other oral care agents, Outcome 3: Number of participants treated with systemic antibiotics}

\begin{tabular}{|c|c|c|c|c|c|c|}
\hline & Chlor & xidine & Col & & Risk Ratio & Risk Ratio \\
\hline tudy or Subg & Events & Total & Events & Total & M-H, Fixed, 95\% CI & M-H, Fixed, 95\% CI \\
\hline
\end{tabular}

\subsubsection{Chlorhexidine versus miswak}

$\begin{array}{llllll}\text { Irani } 2019 & 29 & 35 & 28 & 35 & 1.04[0.83,1.30]\end{array}$

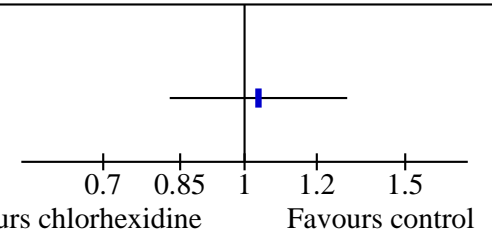

Comparison 3. Toothbrushing versus no toothbrushing

\begin{tabular}{lllll}
\hline Outcome or subgroup title & $\begin{array}{l}\text { No. of } \\
\text { studies }\end{array}$ & $\begin{array}{l}\text { No. of } \\
\text { partici- } \\
\text { pants }\end{array}$ & Statistical method & Effect size \\
\hline 3.1 Incidence of VAP & 5 & 910 & Risk Ratio (M-H, Random, 95\% Cl) & $0.61[0.41,0.91]$ \\
\hline $\begin{array}{l}3.1 .1 \text { Powered toothbrush + usual } \\
\text { care }( \pm \text { CHX) versus usual care } \pm \mathrm{CHX})\end{array}$ & 2 & 200 & Risk Ratio (M-H, Random, 95\% Cl) & $0.49[0.16,1.53]$ \\
\hline $\begin{array}{l}3.1 .2 \text { Toothbrush + CHX versus CHX } \\
\text { alone }\end{array}$ & 2 & 649 & Risk Ratio (M-H, Random, 95\% Cl) & $0.74[0.50,1.09]$ \\
\hline $\begin{array}{l}3.1 .3 \text { Toothbrush + povidone iodine } \\
\text { versus povidone iodine alone }\end{array}$ & 1 & 61 & Risk Ratio (M-H, Random, 95\% Cl) & $0.35[0.13,0.98]$ \\
\hline \begin{tabular}{l}
3.2 Mortality \\
\hline
\end{tabular} & 5 & 910 & Risk Ratio (M-H, Random, 95\% Cl) & $0.84[0.67,1.05]$ \\
\hline
\end{tabular}




\begin{tabular}{|c|c|c|c|c|}
\hline Outcome or subgroup title & $\begin{array}{l}\text { No. of } \\
\text { studies }\end{array}$ & $\begin{array}{l}\text { No. of } \\
\text { partici- } \\
\text { pants }\end{array}$ & Statistical method & Effect size \\
\hline $\begin{array}{l}\text { 3.2.1 Powered toothbrush + usual } \\
\text { care versus usual care }\end{array}$ & 2 & 200 & Risk Ratio (M-H, Random, 95\% Cl) & $1.31[0.17,9.91]$ \\
\hline $\begin{array}{l}\text { 3.2.2 Toothbrush }+\mathrm{CHX} \text { versus } \mathrm{CHX} \\
\text { alone }\end{array}$ & 2 & 649 & Risk Ratio (M-H, Random, 95\% Cl) & $0.87[0.68,1.12]$ \\
\hline $\begin{array}{l}\text { 3.2.3 Toothbrush + povidone iodine } \\
\text { versus povidone iodine alone }\end{array}$ & 1 & 61 & Risk Ratio (M-H, Random, 95\% Cl) & $0.58[0.15,2.22]$ \\
\hline 3.3 Duration of ventilation (days) & 4 & & Mean Difference (IV, Fixed, 95\% CI) & Subtotals only \\
\hline $\begin{array}{l}\text { 3.3.1 Toothbrush }+\mathrm{CHX} \text { versus } \mathrm{CHX} \\
\text { alone }\end{array}$ & 3 & 749 & Mean Difference (IV, Fixed, 95\% CI) & $-1.46[-2.69,-0.23]$ \\
\hline $\begin{array}{l}\text { 3.3.2 Toothbrush + povidone iodine } \\
\text { versus povidone iodine alone }\end{array}$ & 1 & 61 & Mean Difference (IV, Fixed, 95\% CI) & $0.13[-0.78,1.04]$ \\
\hline 3.4 Duration of ICU stay (days) & 3 & & Mean Difference (IV, Fixed, 95\% CI) & Subtotals only \\
\hline $\begin{array}{l}\text { 3.4.1 Toothbrush }+\mathrm{CHX} \text { versus } \mathrm{CHX} \\
\text { alone }\end{array}$ & 3 & 749 & Mean Difference (IV, Fixed, 95\% CI) & $-1.89[-3.52,-0.27]$ \\
\hline 3.5 Plaque score & 1 & & Std. Mean Difference (IV, Fixed, 95\% CI) & Subtotals only \\
\hline $\begin{array}{l}\text { 3.5.1 Powered toothbrush versus usu- } \\
\text { al care }\end{array}$ & 1 & 49 & Std. Mean Difference (IV, Fixed, 95\% CI) & $-1.22[-1.83,-0.60]$ \\
\hline
\end{tabular}


Analysis 3.1. Comparison 3: Toothbrushing versus no toothbrushing, Outcome 1: Incidence of VAP

\begin{tabular}{cccccccc} 
& \multicolumn{2}{c}{ Toothbrushing } & \multicolumn{2}{c}{ No toothbrushing } & \multicolumn{2}{c}{ Risk Ratio } & \multicolumn{2}{c}{ Risk Ratio } \\
Study or Subgroup & Events & Total & Events & Total & Weight & M-H, Random, 95\% CI & M-H, Random, 95\% CI
\end{tabular}

3.1.1 Powered toothbrush + usual care $( \pm \mathrm{CHX})$ versus usual care $( \pm \mathrm{CHX})$

$\begin{array}{llllll}\text { Pobo } 2009(1) & 15 & 74 & 18 & 73 & 23.5 \%\end{array}$

$\begin{array}{llllll}\text { Yao } 2011(2) & 4 & 28 & 14 & 25 & 12.7 \%\end{array}$

Subtotal $(95 \%$ CI)

$102 \quad 98 \quad 36.2 \%$

Total events:

19

32

Heterogeneity: $\mathrm{Tau}^{2}=0.52 ; \mathrm{Chi}^{2}=4.05, \mathrm{df}=1(\mathrm{P}=0.04) ; \mathrm{I}^{2}=75 \%$

Test for overall effect: $\mathrm{Z}=1.23(\mathrm{P}=0.22)$

3.1.2 Toothbrush + CHX versus CHX alone

$\begin{array}{lcccccc}\text { Lorente } 2012 & 21 & 217 & 24 & 219 & 25.7 \% & 0.88[0.51,1.54] \\ \text { De Lacerda } 2017 & 17 & 105 & 28 & 108 & 26.4 \% & 0.62[0.36,1.07] \\ \text { Subtotal (95\% CI) } & & \mathbf{3 2 2} & & \mathbf{3 2 7} & \mathbf{5 2 . 1 \%} & \mathbf{0 . 7 4}[\mathbf{0 . 5 0}, \mathbf{1 . 0 9}] \\ \text { Total events: } & 38 & & 52 & & & \end{array}$

$\begin{array}{lcc}\text { Total events: } & 38 & 52 \\ \text { Heterogeneity: } \mathrm{Tau}^{2}=0.00 & \mathrm{Chi}^{2}=0.77, \mathrm{df}=1(\mathrm{P}=0.38) ; \mathrm{I}^{2}=0 \%\end{array}$

Test for overall effect: $\mathrm{Z}=1.53(\mathrm{P}=0.13)$

3.1.3 Toothbrush + povidone iodine versus povidone iodine alone

$\begin{array}{lcccccc}\text { Long } 2012 & 4 & 31 & 11 & 30 & 11.6 \% & 0.35[0.13,0.98] \\ \text { Subtotal }(\mathbf{9 5 \%} \text { CI) } & & \mathbf{3 1} & & \mathbf{3 0} & \mathbf{1 1 . 6 \%} & \mathbf{0 . 3 5}[\mathbf{0 . 1 3}, \mathbf{0 . 9 8}] \\ \text { Total events: } & 4 & & 11 & & & \end{array}$

$0.82[0.45,1.50]$

$0.26[0.10,0.67]$

$0.49[0.16,1.53]$

Heterogeneity: Not applicable

Test for overall effect: $\mathrm{Z}=1.99(\mathrm{P}=0.05)$

$\begin{array}{lllll}\text { Total }(95 \% \text { CI }) & 455 & 455 & 100.0 \% & 0.61[0.41,0.91]\end{array}$

Total events:

61

95

Heterogeneity: $\mathrm{Tau}^{2}=0.08 ; \mathrm{Chi}^{2}=6.71, \mathrm{df}=4(\mathrm{P}=0.15) ; \mathrm{I}^{2}=40 \%$

Test for overall effect: $\mathrm{Z}=2.44(\mathrm{P}=0.01)$

Test for subgroup differences: $\mathrm{Chi}^{2}=2.03, \mathrm{df}=2(\mathrm{P}=0.36), \mathrm{I}^{2}=1.5 \%$

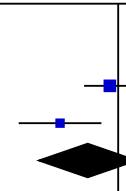

Footnotes

(1) CHX in both groups

(2) No CHX in either group 
Analysis 3.2. Comparison 3: Toothbrushing versus no toothbrushing, Outcome 2: Mortality

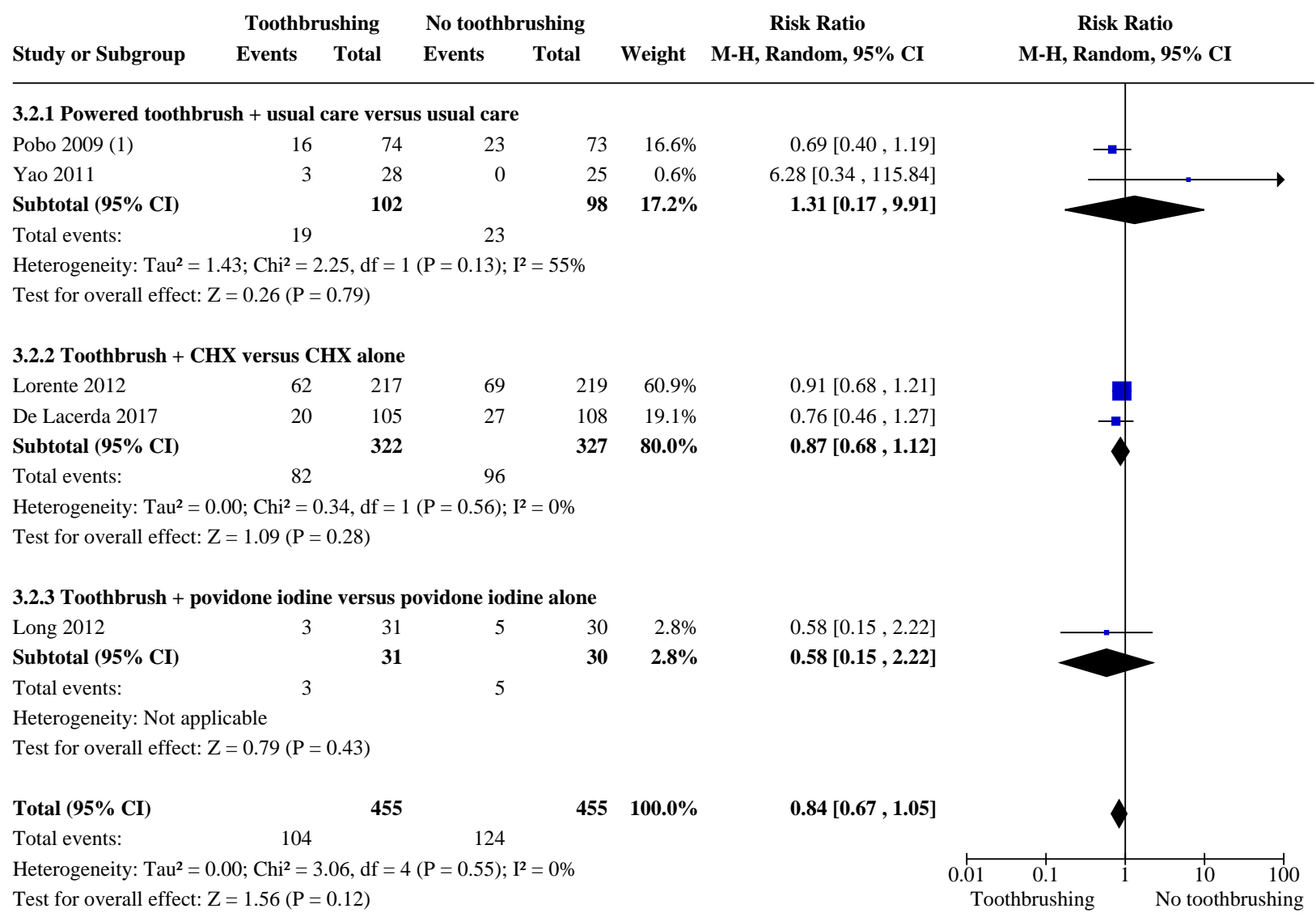

Footnotes

(1) CHX in both groups

Analysis 3.3. Comparison 3: Toothbrushing versus no toothbrushing, Outcome 3: Duration of ventilation (days)

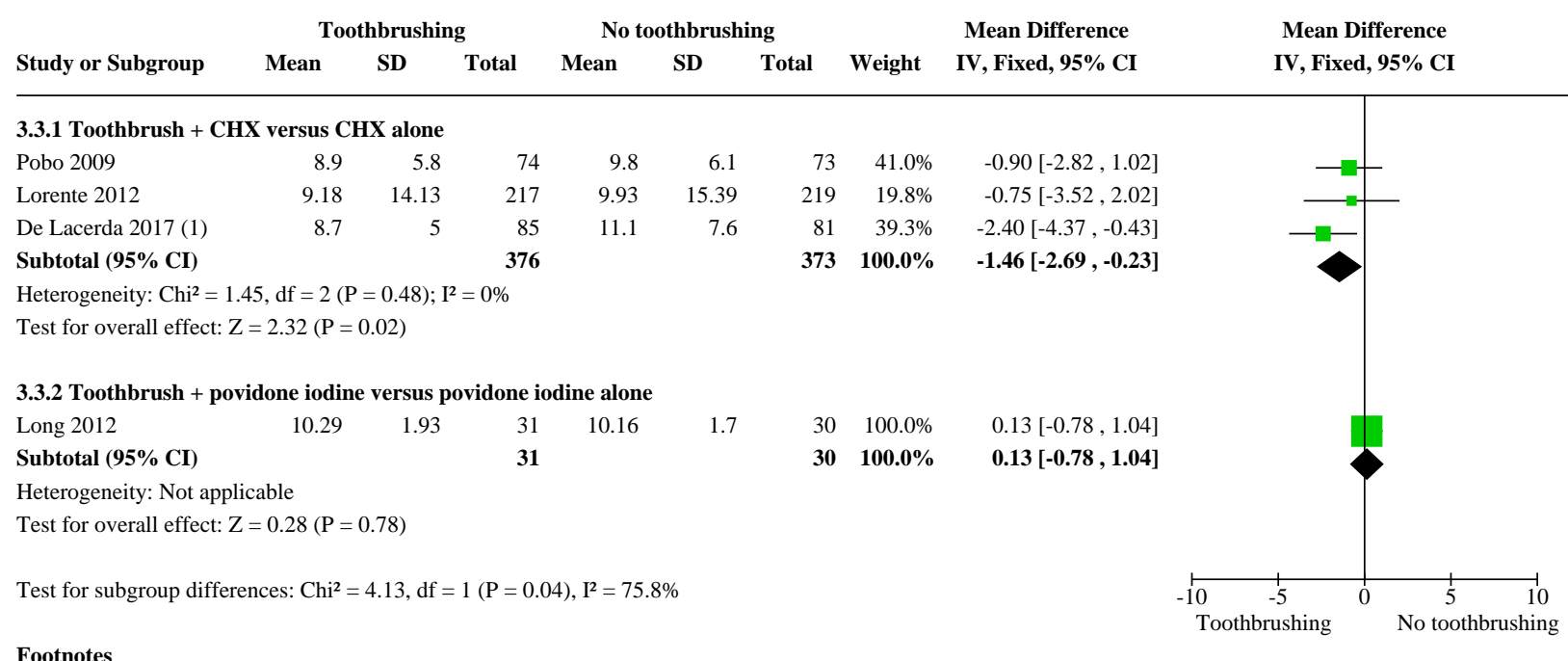

(1) Among patients who were discharged from the ICU 
Analysis 3.4. Comparison 3: Toothbrushing versus no toothbrushing, Outcome 4: Duration of ICU stay (days)

\begin{tabular}{|c|c|c|c|c|c|c|c|c|c|c|}
\hline \multirow[b]{2}{*}{ Study or Subgroup } & \multicolumn{3}{|c|}{ Toothbrushing } & \multicolumn{3}{|c|}{ No toothbrushing } & \multirow[b]{2}{*}{ Weight } & \multirow{2}{*}{$\begin{array}{c}\text { Mean Difference } \\
\text { IV, Fixed, 95\% CI }\end{array}$} & \multirow{2}{*}{\multicolumn{2}{|c|}{$\begin{array}{l}\text { Mean Difference } \\
\text { IV, Fixed, 95\% CI }\end{array}$}} \\
\hline & Mean & SD & Total & Mean & SD & Total & & & & \\
\hline \multicolumn{11}{|c|}{ 3.4.1 Toothbrush + CHX versus CHX alone } \\
\hline Pobo 2009 & 12.9 & 8.7 & 74 & 15.5 & 9.6 & 73 & $30.0 \%$ & $-2.60[-5.56,0.36]$ & & \\
\hline Lorente 2012 & 12.07 & 15.55 & 217 & 13.04 & 17.27 & 219 & $27.7 \%$ & $-0.97[-4.05,2.11]$ & & \\
\hline De Lacerda 2017 (1) & 11.9 & 7.77 & 85 & 13.9 & 8.6 & 81 & $42.3 \%$ & $-2.00[-4.50,0.50]$ & & \\
\hline Subtotal $(95 \%$ CI $)$ & & & 376 & & & 373 & $100.0 \%$ & $-1.89[-3.52,-0.27]$ & & \\
\hline \multicolumn{11}{|c|}{ Heterogeneity: $\mathrm{Chi}^{2}=0.57, \mathrm{df}=2(\mathrm{P}=0.75) ; \mathrm{I}^{2}=0 \%$} \\
\hline \multicolumn{11}{|c|}{ Test for overall effect: $\mathrm{Z}=2.29(\mathrm{P}=0.02)$} \\
\hline & & & & & & & & -10 & -5 & 5 \\
\hline \multicolumn{9}{|l|}{ Footnotes } & rushing & No too \\
\hline
\end{tabular}

(1) Among patients who were discharged from the ICU

\section{Analysis 3.5. Comparison 3: Toothbrushing versus no toothbrushing, Outcome 5: Plaque score}

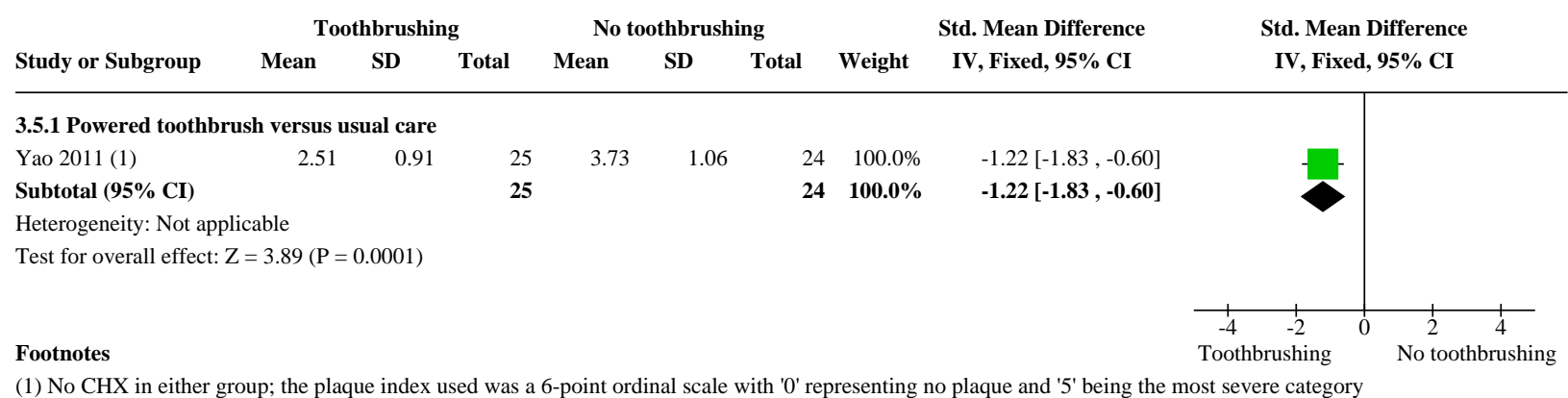

\section{Comparison 4. Powered toothbrush versus manual toothbrush}

\begin{tabular}{|c|c|c|c|c|}
\hline Outcome or subgroup title & $\begin{array}{l}\text { No. of } \\
\text { studies }\end{array}$ & $\begin{array}{l}\text { No. of } \\
\text { partici- } \\
\text { pants }\end{array}$ & Statistical method & Effect size \\
\hline 4.1 Incidence of VAP & 1 & & Risk Ratio (M-H, Fixed, 95\% Cl) & Subtotals only \\
\hline $\begin{array}{l}\text { 4.1.1 Powered toothbrush }+ \text { comp oral care ver- } \\
\text { sus manual toothbrush }+ \text { std oral care }\end{array}$ & 1 & 78 & Risk Ratio (M-H, Fixed, 95\% Cl) & $0.84[0.37,1.91]$ \\
\hline 4.2 Mortality & 1 & & Risk Ratio (M-H, Fixed, 95\% Cl) & Subtotals only \\
\hline $\begin{array}{l}\text { 4.2.1 Powered toothbrush }+ \text { comp oral care ver- } \\
\text { sus manual toothbrush }+ \text { std oral care }\end{array}$ & 1 & 78 & Risk Ratio (M-H, Fixed, 95\% Cl) & $1.05[0.16,7.10]$ \\
\hline 4.3 Duration of ventilation (days) & 1 & & Mean Difference (IV, Fixed, 95\% CI) & Subtotals only \\
\hline $\begin{array}{l}\text { 4.3.1 Powered toothbrush + comp oral care ver- } \\
\text { sus manual toothbrush }+ \text { std oral care }\end{array}$ & 1 & 78 & Mean Difference (IV, Fixed, 95\% CI) & $\begin{array}{l}0.00[-1.78 \\
1.78]\end{array}$ \\
\hline 4.4 Duration of ICU stay (days) & 1 & & Mean Difference (IV, Fixed, 95\% CI) & Subtotals only \\
\hline $\begin{array}{l}\text { 4.4.1 Powered toothbrush }+ \text { comp oral care ver- } \\
\text { sus manual toothbrush }+ \text { std oral care }\end{array}$ & 1 & 78 & Mean Difference (IV, Fixed, 95\% CI) & $\begin{array}{l}-2.00[-5.93 \\
1.93]\end{array}$ \\
\hline
\end{tabular}


Analysis 4.1. Comparison 4: Powered toothbrush versus manual toothbrush, Outcome 1: Incidence of VAP

\begin{tabular}{llllllll} 
& \multicolumn{2}{c}{ Powered toothbrush } & \multicolumn{2}{c}{ Manual toothbrush } & & & \multicolumn{2}{c}{ Risk Ratio } & Risk Ratio \\
Study or Subgroup & Events & Total & Events & Total & Weight & M-H, Fixed, 95\% CI & M-H, Fixed, 95\% CI
\end{tabular}

4.1.1 Powered toothbrush + comp oral care versus manual toothbrush + std oral care

Prendergast 2012

Subtotal (95\% CI)

$8 \quad 38$

38

10

$40 \quad 100.0 \%$

$0.84[0.37,1.91]$

Total events:

8

10

$40 \quad 100.0 \%$

$0.84[0.37,1.91]$

Heterogeneity: Not applicable

Test for overall effect: $\mathrm{Z}=0.41(\mathrm{P}=0.68)$

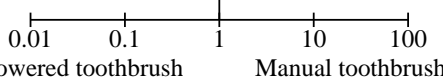

Analysis 4.2. Comparison 4: Powered toothbrush versus manual toothbrush, Outcome 2: Mortality

\begin{tabular}{llllllll} 
& \multicolumn{2}{c}{ Powered toothbrush } & Manual toothbrush & & \multicolumn{2}{c}{ Risk Ratio } & Risk Ratio \\
Study or Subgroup & Events & Total & Events & Total & Weight & M-H, Fixed, 95\% CI & M-H, Fixed, 95\% CI
\end{tabular}

4.2.1 Powered toothbrush + comp oral care versus manual toothbrush + std oral care

Prendergast 2012

Subtotal (95\% CI)

238

38

$40 \quad 100.0 \%$

$1.05[0.16,7.10]$

Total events:

2

$40 \quad \mathbf{1 0 0 . 0 \%}$

$1.05[0.16,7.10]$

Heterogeneity: Not applicable

Test for overall effect: $\mathrm{Z}=0.05(\mathrm{P}=0.96)$

Powered toothbrush Manual toothbrush

Analysis 4.3. Comparison 4: Powered toothbrush versus manual toothbrush, Outcome 3: Duration of ventilation (days)

\begin{tabular}{|c|c|c|c|c|c|c|c|c|c|}
\hline & Pov & d too & ush & $\mathrm{Ma}$ & t toot & & & Mean Difference & Mean Difference \\
\hline Study or Subgroup & Mean & SD & Total & Mean & SD & Total & Weight & IV, Fixed, 95\% CI & IV, Fixed, 95\% CI \\
\hline
\end{tabular}

4.3.1 Powered toothbrush + comp oral care versus manual toothbrush + std oral care

$\begin{array}{llllllllll}\text { Prendergast } 2012 & 8 & 4 & 38 & 8 & 4 & 40 & 100.0 \% & 0.00[-1.78,1.78]\end{array}$

Subtotal $(95 \%$ CI)

$40 \quad 100.0 \%$

$0.00[-1.78,1.78]$

Heterogeneity: Not applicable

Test for overall effect: $\mathrm{Z}=0.00(\mathrm{P}=1.00)$

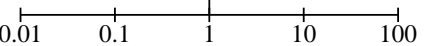

Powered toothbrush Manual toothbrush 
Analysis 4.4. Comparison 4: Powered toothbrush versus manual toothbrush, Outcome 4: Duration of ICU stay (days)

\begin{tabular}{|c|c|c|c|c|c|c|c|c|c|}
\hline \multirow{2}{*}{ Study or Subgroup } & \multicolumn{3}{|c|}{ Powered toothbrush } & \multicolumn{3}{|c|}{ Manual toothbrush } & \multicolumn{2}{|r|}{ Mean Difference } & Mean Difference \\
\hline & Mean & SD & Total & Mean & SD & Total & Weight & IV, Fixed, 95\% CI & IV, Fixed, $95 \%$ CI \\
\hline
\end{tabular}

4.4.1 Powered toothbrush + comp oral care versus manual toothbrush + std oral care

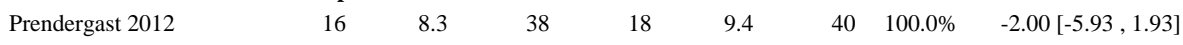

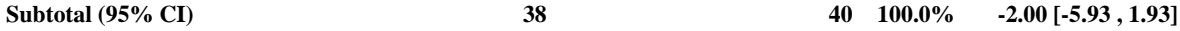

Heterogeneity: Not applicable

Test for overall effect: $\mathrm{Z}=1.00(\mathrm{P}=0.32)$

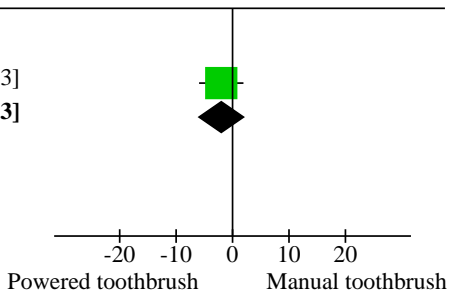

\section{Comparison 5. Other oral care agents}

\begin{tabular}{|c|c|c|c|c|}
\hline Outcome or subgroup title & $\begin{array}{l}\text { No. of } \\
\text { studies }\end{array}$ & $\begin{array}{l}\text { No. of } \\
\text { partici- } \\
\text { pants }\end{array}$ & Statistical method & Effect size \\
\hline 5.1 Incidence of VAP & 15 & & Risk Ratio (M-H, Fixed, 95\% Cl) & Subtotals only \\
\hline $\begin{array}{l}\text { 5.1.1 Povidone iodine versus } \\
\text { saline/placebo }\end{array}$ & 3 & 356 & Risk Ratio (M-H, Fixed, 95\% Cl) & $0.69[0.50,0.95]$ \\
\hline $\begin{array}{l}\text { 5.1.2 Povidone iodine versus usual } \\
\text { care }\end{array}$ & 1 & 67 & Risk Ratio (M-H, Fixed, 95\% Cl) & $0.20[0.06,0.63]$ \\
\hline $\begin{array}{l}\text { 5.1.3 Saline rinse versus saline } \\
\text { swab }\end{array}$ & 4 & 488 & Risk Ratio (M-H, Fixed, 95\% Cl) & $0.47[0.37,0.62]$ \\
\hline 5.1.4 Saline rinse versus usual care & 2 & 324 & Risk Ratio (M-H, Fixed, 95\% Cl) & $0.60[0.39,0.91]$ \\
\hline $\begin{array}{l}\text { 5.1.5 Saline rinse + swab versus } \\
\text { saline swab (usual care) }\end{array}$ & 2 & 153 & Risk Ratio (M-H, Fixed, 95\% Cl) & $0.41[0.23,0.72]$ \\
\hline $\begin{array}{l}\text { 5.1.6 Bicarbonate rinse versus wa- } \\
\text { ter }\end{array}$ & 2 & 347 & Risk Ratio (M-H, Fixed, 95\% Cl) & $1.57[0.62,3.99]$ \\
\hline 5.1.7 Triclosan rinse versus saline & 1 & 324 & Risk Ratio (M-H, Fixed, 95\% Cl) & $0.89[0.71,1.12]$ \\
\hline $\begin{array}{l}\text { 5.1.8 Furacilin versus povidone io- } \\
\text { dine }\end{array}$ & 1 & 136 & Risk Ratio (M-H, Fixed, 95\% Cl) & $0.49[0.23,1.04]$ \\
\hline 5.1.9 Furacilin versus saline & 1 & 133 & Risk Ratio (M-H, Fixed, 95\% Cl) & $0.29[0.14,0.58]$ \\
\hline 5.1.10 Listerine versus water & 1 & 265 & Risk Ratio (M-H, Fixed, 95\% Cl) & $1.09[0.36,3.28]$ \\
\hline 5.1.11 Listerine versus bicarbonate & 1 & 260 & Risk Ratio (M-H, Fixed, 95\% Cl) & $1.05[0.35,3.16]$ \\
\hline 5.1.12 Biotene versus control & 1 & 41 & Risk Ratio (M-H, Fixed, 95\% Cl) & $0.63[0.28,1.41]$ \\
\hline $\begin{array}{l}\text { 5.1.13 Hydrogen peroxide versus } \\
\text { normal saline }\end{array}$ & 1 & 68 & Risk Ratio (M-H, Fixed, 95\% Cl) & $0.38[0.15,0.96]$ \\
\hline $\begin{array}{l}\text { 5.1.14 Potassium permanganate } \\
\text { versus placebo }\end{array}$ & 1 & 100 & Risk Ratio (M-H, Fixed, 95\% Cl) & $0.47[0.21,1.05]$ \\
\hline
\end{tabular}




\begin{tabular}{|c|c|c|c|c|}
\hline Outcome or subgroup title & $\begin{array}{l}\text { No. of } \\
\text { studies }\end{array}$ & $\begin{array}{l}\text { No. of } \\
\text { partici- } \\
\text { pants }\end{array}$ & Statistical method & Effect size \\
\hline 5.2 Mortality & 8 & & Risk Ratio (M-H, Fixed, 95\% Cl) & Subtotals only \\
\hline $\begin{array}{l}\text { 5.2.1 Povidone iodine versus } \\
\text { saline/placebo }\end{array}$ & 2 & 217 & Risk Ratio (M-H, Fixed, 95\% Cl) & $1.00[0.66,1.50]$ \\
\hline $\begin{array}{l}\text { 5.2.2 Povidone iodine versus usual } \\
\text { care }\end{array}$ & 1 & 67 & Risk Ratio (M-H, Fixed, 95\% Cl) & $0.86[0.31,2.40]$ \\
\hline $\begin{array}{l}\text { 5.2.3 Saline rinse versus saline } \\
\text { swab }\end{array}$ & 2 & 270 & Risk Ratio (M-H, Fixed, 95\% Cl) & $0.29[0.12,0.69]$ \\
\hline $\begin{array}{l}\text { 5.2.4 Saline rinse + swab versus } \\
\text { saline swab (usual care) }\end{array}$ & 1 & 47 & Risk Ratio (M-H, Fixed, 95\% Cl) & $0.38[0.11,1.28]$ \\
\hline 5.2.5 Saline rinse versus usual care & 2 & 324 & Risk Ratio (M-H, Fixed, 95\% Cl) & $1.10[0.87,1.39]$ \\
\hline 5.2.6 Biotene versus control & 1 & 41 & Risk Ratio (M-H, Fixed, 95\% Cl) & $0.70[0.13,3.76]$ \\
\hline $\begin{array}{l}\text { 5.2.7 Potassium permanganate } \\
\text { versus placebo }\end{array}$ & 1 & 100 & Risk Ratio (M-H, Fixed, 95\% Cl) & $1.40[0.48,4.12]$ \\
\hline 5.3 Duration of ventilation (days) & 6 & & Mean Difference (IV, Fixed, 95\% CI) & Subtotals only \\
\hline 5.3.1 Povidone iodine versus saline & 1 & 67 & Mean Difference (IV, Fixed, 95\% CI) & $-1.00[-4.36,2.36]$ \\
\hline $\begin{array}{l}\text { 5.3.2 Povidone iodine versus usual } \\
\text { care }\end{array}$ & 1 & 67 & Mean Difference (IV, Fixed, 95\% CI) & $-3.00[-7.67,1.67]$ \\
\hline 5.3.3 Saline rinse versus usual care & 2 & 324 & Mean Difference (IV, Fixed, 95\% CI) & $-0.40[-2.55,1.75]$ \\
\hline $\begin{array}{l}\text { 5.3.4 Saline rinse + swab versus } \\
\text { saline swab }\end{array}$ & 1 & 47 & Mean Difference (IV, Fixed, 95\% CI) & $-3.91[-5.85,-1.97]$ \\
\hline $\begin{array}{l}\text { 5.3.5 Saline rinse versus saline } \\
\text { swab }\end{array}$ & 2 & 176 & Mean Difference (IV, Fixed, 95\% CI) & $-6.83[-8.94,-4.72]$ \\
\hline 5.3.6 Triclosan rinse versus saline & 1 & 324 & Mean Difference (IV, Fixed, 95\% CI) & $-5.24[-5.64,-4.84]$ \\
\hline 5.4 Duration of ICU stay (days) & 4 & & Mean Difference (IV, Fixed, 95\% CI) & Subtotals only \\
\hline $\begin{array}{l}\text { 5.4.1 Povidone iodine versus } \\
\text { saline/placebo }\end{array}$ & 2 & 217 & Mean Difference (IV, Fixed, 95\% CI) & $-0.35[-3.90,3.21]$ \\
\hline $\begin{array}{l}\text { 5.4.2 Povidone iodine versus usual } \\
\text { care }\end{array}$ & 1 & 67 & Mean Difference (IV, Fixed, 95\% CI) & $-4.00[-10.99,2.99]$ \\
\hline 5.4.3 Saline rinse versus usual care & 2 & 324 & Mean Difference (IV, Fixed, 95\% CI) & $-1.17[-3.95,1.60]$ \\
\hline 5.4.4 Triclosan rinse versus saline & 1 & 324 & Mean Difference (IV, Fixed, 95\% CI) & $-4.97[-5.55,-4.39]$ \\
\hline $\begin{array}{l}5.5 \text { Number of participants treated } \\
\text { with systemic antibiotics }\end{array}$ & 1 & 167 & Risk Ratio (M-H, Fixed, 95\% Cl) & $0.83[0.66,1.05]$ \\
\hline
\end{tabular}




\begin{tabular}{|c|c|c|c|c|}
\hline Outcome or subgroup title & $\begin{array}{l}\text { No. of } \\
\text { studies }\end{array}$ & $\begin{array}{l}\text { No. of } \\
\text { partici- } \\
\text { pants }\end{array}$ & Statistical method & Effect size \\
\hline $\begin{array}{l}\text { 5.5.1 Povidone iodine versus } \\
\text { saline/placebo }\end{array}$ & 1 & 167 & Risk Ratio (M-H, Fixed, 95\% Cl) & $0.83[0.66,1.05]$ \\
\hline 5.6 Adverse effects & 1 & & Risk Ratio (M-H, Fixed, 95\% Cl) & Subtotals only \\
\hline $\begin{array}{l}\text { 5.6.1 Acute respiratory distress } \\
\text { syndrome }\end{array}$ & 1 & 156 & Risk Ratio (M-H, Fixed, 95\% Cl) & $11.00[0.62,195.61]$ \\
\hline $\begin{array}{l}\text { 5.6.2 Agitation and/or hyperten- } \\
\text { sion }\end{array}$ & 1 & 167 & Risk Ratio (M-H, Fixed, 95\% Cl) & $0.48[0.12,1.86]$ \\
\hline 5.6.3 Epistaxis & 1 & 167 & Risk Ratio (M-H, Fixed, 95\% Cl) & $0.14[0.01,2.63]$ \\
\hline 5.6.4 Oxygen desaturation & 1 & 167 & Risk Ratio (M-H, Fixed, 95\% Cl) & $0.96[0.06,15.17]$ \\
\hline 5.6.5 Aspiration & 1 & 167 & Risk Ratio (M-H, Fixed, 95\% Cl) & $2.90[0.12,70.07]$ \\
\hline
\end{tabular}


Analysis 5.1. Comparison 5: Other oral care agents, Outcome 1: Incidence of VAP

\begin{tabular}{lrrrrrr} 
& \multicolumn{2}{c}{ Experimental } & \multicolumn{2}{c}{ Control } & \multicolumn{1}{c}{ Risk Ratio } \\
Study or Subgroup & Events & Total & Events & Total & Weight & M-H, Fixed, 95\% CI \\
\hline 5.1.1 Povidone iodine versus saline/placebo & & & & & \\
Seguin 2006 & 3 & 36 & 12 & 31 & $20.4 \%$ & $0.22[0.07,0.69]$ \\
Feng 2012 (1) & 18 & 71 & 29 & 68 & $46.8 \%$ & $0.59[0.37,0.97]$ \\
Seguin 2014 & 24 & 78 & 20 & 72 & $32.8 \%$ & $1.11[0.67,1.83]$ \\
Subtotal (95\% CI) & & $\mathbf{1 8 5}$ & & $\mathbf{1 7 1}$ & $\mathbf{1 0 0 . 0 \%}$ & $\mathbf{0 . 6 9}[\mathbf{0 . 5 0}, \mathbf{0 . 9 5}]$
\end{tabular}

Total events: $\quad 45 \quad 61$

Heterogeneity: $\mathrm{Chi}^{2}=7.64, \mathrm{df}=2(\mathrm{P}=0.02) ; \mathrm{I}^{2}=74 \%$

Test for overall effect: $\mathrm{Z}=2.27(\mathrm{P}=0.02)$

5.1.2 Povidone iodine versus usual care

$\begin{array}{lllllll}\text { Seguin } 2006 & 3 & 36 & 13 & 31 & 100.0 \% & 0.20[0.06,0.63] \\ \text { Subtotal }(\mathbf{9 5 \%} \text { CI) } & & \mathbf{3 6} & & \mathbf{3 1} & \mathbf{1 0 0 . 0 \%} & \mathbf{0 . 2 0}[\mathbf{0 . 0 6}, \mathbf{0 . 6 3}] \\ \text { Total events: } & 3 & & 13 & & & \end{array}$

Heterogeneity: Not applicable

Test for overall effect: $\mathrm{Z}=2.73(\mathrm{P}=0.006)$

5.1.3 Saline rinse versus saline swab

$\begin{array}{lrrrrrr}\text { Xu 2007 } & 11 & 58 & 16 & 44 & 15.3 \% & 0.52[0.27,1.01] \\ \text { Xu 2008 } & 30 & 64 & 26 & 52 & 24.1 \% & 0.94[0.64,1.37] \\ \text { Tang 2013 } & 5 & 30 & 25 & 30 & 21.0 \% & 0.20[0.09,0.45] \\ \text { Mo 2016 } & 15 & 105 & 47 & 105 & 39.5 \% & 0.32[0.19,0.53] \\ \text { Subtotal (95\% CI) } & & \mathbf{2 5 7} & & \mathbf{2 3 1} & \mathbf{1 0 0 . 0 \%} & \mathbf{0 . 4 7}[\mathbf{0 . 3 7}, \mathbf{0 . 6 2}] \\ \text { Total events: } & 61 & & 114 & & & \end{array}$

Heterogeneity: $\mathrm{Chi}^{2}=19.23, \mathrm{df}=3(\mathrm{P}=0.0002) ; \mathrm{I}^{2}=84 \%$

Test for overall effect: $\mathrm{Z}=5.61(\mathrm{P}<0.00001)$

5.1.4 Saline rinse versus usual care

$\begin{array}{lrrrrrr}\text { Seguin 2006 } & 12 & 31 & 13 & 31 & 29.7 \% & 0.92[0.50,1.69] \\ \text { Caruso 2009 } & 14 & 130 & 31 & 132 & 70.3 \% & 0.46[0.26,0.82] \\ \text { Subtotal (95\% CI) } & & \mathbf{1 6 1} & & \mathbf{1 6 3} & \mathbf{1 0 0 . 0 \%} & \mathbf{0 . 6 0}[\mathbf{0 . 3 9 ,}, \mathbf{0 . 9 1}]\end{array}$

Total events: $26 \quad 44$

Heterogeneity: $\mathrm{Chi}^{2}=2.77, \mathrm{df}=1(\mathrm{P}=0.10) ; \mathrm{I}^{2}=64 \%$

Test for overall effect: $\mathrm{Z}=2.39(\mathrm{P}=0.02)$

5.1.5 Saline rinse + swab versus saline swab (usual care)

$\begin{array}{lrrrrrr}\text { Xu } 2007 & 10 & 62 & 16 & 44 & 63.8 \% & 0.44[0.22,0.88] \\ \text { Hu } 2009 & 4 & 25 & 10 & 22 & 36.2 \% & 0.35[0.13,0.96] \\ \text { Subtotal (95\% CI) } & & \mathbf{8 7} & & \mathbf{6 6} & \mathbf{1 0 0 . 0 \%} & \mathbf{0 . 4 1}[\mathbf{0 . 2 3}, \mathbf{0 . 7 2}]\end{array}$

Total events: $14 \quad 26$

Heterogeneity: $\mathrm{Chi}^{2}=0.14, \mathrm{df}=1(\mathrm{P}=0.71) ; \mathrm{I}^{2}=0 \%$

Test for overall effect: $\mathrm{Z}=3.07(\mathrm{P}=0.002)$

5.1.6 Bicarbonate rinse versus water

$\begin{array}{lrrrrrr}\text { Berry 2011 (2) } & 4 & 33 & 1 & 43 & 12.9 \% & 5.21[0.61,44.47] \\ \text { Berry 2013 (2) } & 6 & 133 & 6 & 138 & 87.1 \% & 1.04[0.34,3.14] \\ \text { Subtotal (95\% CI) } & & \mathbf{1 6 6} & & \mathbf{1 8 1} & \mathbf{1 0 0 . 0 \%} & \mathbf{1 . 5 7}[\mathbf{0 . 6 2}, \mathbf{3 . 9 9}]\end{array}$

Total events: $\quad 10 \quad 7$

Heterogeneity: $\mathrm{Chi}^{2}=1.74, \mathrm{df}=1(\mathrm{P}=0.19) ; \mathrm{I}^{2}=43 \%$

Test for overall effect: $\mathrm{Z}=0.96(\mathrm{P}=0.34)$

5.1.7 Triclosan rinse versus saline 
Analysis 5.1. (Continued)

5.1.7 Triclosan rinse versus saline

Zhao 2012

$73 \quad 162$

Subtotal (95\% CI) $\quad 162$

Total events: $\quad 73$

Heterogeneity: Not applicable

Test for overall effect: $\mathrm{Z}=1.00(\mathrm{P}=0.32)$

5.1.8 Furacilin versus povidone iodine

$\begin{array}{ll}\text { Feng } 2012(1) & 8 \\ \text { Subtotal (95\% CI) }\end{array}$

Total events: $\quad 8$

Heterogeneity: Not applicable

Test for overall effect: $\mathrm{Z}=1.86(\mathrm{P}=0.06)$

5.1.9 Furacilin versus saline

$\begin{array}{llll}\text { Feng } 2012(1) & 8 & 65 & 29 \\ \text { Subtotal (95\% CI) } & & \mathbf{6 5} & \\ \text { Total events: } & 8 & & 29 \\ \text { Heterogeneity: Not applicable } & & \end{array}$

$\begin{array}{lll}68 & 100.0 \% & 0.29[0.14,0.58]\end{array}$

$68100.0 \% \quad 0.29[0.14,0.58]$

Heterogeneity: Not applicable

Test for overall effect: $\mathrm{Z}=3.45(\mathrm{P}=0.0006)$

5.1.10 Listerine versus water

Subtotal (95\% CI)

Total events:

Heterogeneity: Not applicable

Test for overall effect: $\mathrm{Z}=0.15(\mathrm{P}=0.88)$

5.1.11 Listerine versus bicarbonate

Berry 2013 (2) 6

Subtotal (95\% CI)

Heterogeneity: Not applicable

Test for overall effect: $Z=0.08(P=0.93)$

\subsubsection{Biotene versus control}

Stefanescu 2013

$6-20$

Subtotal $(95 \%$ CI $)$

Heterogeneity: Not applicable

Test for overall effect: $\mathrm{Z}=1.12(\mathrm{P}=0.26)$

5.1.13 Hydrogen peroxide versus normal saline

$\begin{array}{lllllll}\text { Nobahar } 2016 & 5 & 34 & 13 & 34 & 100.0 \% & 0.38[0.15,0.96] \\ \text { Subtotal (95\% CI) } & & \mathbf{3 4} & & \mathbf{3 4} & \mathbf{1 0 0 . 0 \%} & \mathbf{0 . 3 8}[\mathbf{0 . 1 5}, \mathbf{0 . 9 6}] \\ \text { Total events: } & 5 & & 13 & & & \end{array}$

Heterogeneity: Not applicable

Test for overall effect: $\mathrm{Z}=2.05(\mathrm{P}=0.04)$

5.1.14 Potassium permanganate versus placebo

$\begin{array}{lcccccc}\text { Meidani } 2018 & 7 & 50 & 15 & 50 & 100.0 \% & 0.47[0.21,1.05] \\ \text { Subtotal (95\% CI) } & & \mathbf{5 0} & & \mathbf{5 0} & \mathbf{1 0 0 . 0 \%} & \mathbf{0 . 4 7}[\mathbf{0 . 2 1}, \mathbf{1 . 0 5}] \\ \text { Total events: } & 7 & & 15 & & & \end{array}$

Heterogeneity: Not applicable 
Analysis 5.1. (Continued)

Total events: 7

Heterogeneity: Not applicable

Test for overall effect: $\mathrm{Z}=1.85(\mathrm{P}=0.06)$

Test for subgroup differences: $\mathrm{Chi}^{2}=31.97, \mathrm{df}=13(\mathrm{P}=0.002), \mathrm{I}^{2}=59.3 \%$

\section{Footnotes}

(1) Toothbrushing in both groups

(2) Some randomised participants were ineligible

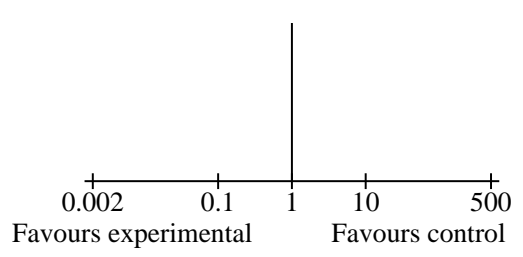


Analysis 5.2. Comparison 5: Other oral care agents, Outcome 2: Mortality

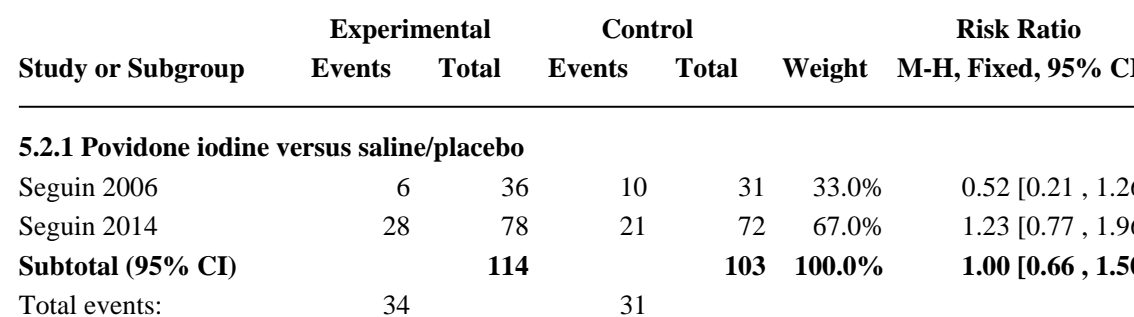

Heterogeneity: $\mathrm{Chi}^{2}=2.88, \mathrm{df}=1(\mathrm{P}=0.09) ; \mathrm{I}^{2}=65 \%$

Test for overall effect: $\mathrm{Z}=0.02(\mathrm{P}=0.98)$

5.2.2 Povidone iodine versus usual care

$\begin{array}{lllllll}\text { Seguin } 2006 & 6 & 36 & 6 & 31 & 100.0 \% & 0.86[0.31,2.40] \\ \text { Subtotal }(\mathbf{9 5 \%} \text { CI) } & & \mathbf{3 6} & & \mathbf{3 1} & \mathbf{1 0 0 . 0 \%} & \mathbf{0 . 8 6}[\mathbf{0 . 3 1}, \mathbf{2 . 4 0}] \\ \text { Total events: } & 6 & & 6 & & & \end{array}$

Heterogeneity: Not applicable

Test for overall effect: $\mathrm{Z}=0.29(\mathrm{P}=0.77)$

5.2.3 Saline rinse versus saline swab

$\begin{array}{lrrrrrr}\text { Tang } 2013 & 1 & 30 & 7 & 30 & 33.3 \% & 0.14[0.02,1.09] \\ \text { Mo } 2016 & 5 & 105 & 14 & 105 & 66.7 \% & 0.36[0.13,0.96] \\ \text { Subtotal }(\mathbf{9 5 \%} \text { CI) } & & \mathbf{1 3 5} & & \mathbf{1 3 5} & \mathbf{1 0 0 . 0 \%} & \mathbf{0 . 2 9}[\mathbf{0 . 1 2 , \boldsymbol { 0 . 6 9 }}] \\ \text { Total events: } & 6 & & 21 & & & \end{array}$

Heterogeneity: $\mathrm{Chi}^{2}=0.64, \mathrm{df}=1(\mathrm{P}=0.42) ; \mathrm{I}^{2}=0 \%$

Test for overall effect: $\mathrm{Z}=2.80(\mathrm{P}=0.005)$

5.2.4 Saline rinse + swab versus saline swab (usual care)

$\begin{array}{lllllll}\text { Hu } 2009 & 3 & 25 & 7 & 22 & 100.0 \% & 0.38[0.11,1.28] \\ \text { Subtotal (95\% CI) } & & \mathbf{2 5} & & \mathbf{2 2} & \mathbf{1 0 0 . 0 \%} & \mathbf{0 . 3 8}[\mathbf{0 . 1 1}, \mathbf{1 . 2 8}] \\ \text { Total events: } & 3 & & 7 & & & \end{array}$

Heterogeneity: Not applicable

Test for overall effect: $\mathrm{Z}=1.56(\mathrm{P}=0.12)$

5.2.5 Saline rinse versus usual care

$\begin{array}{lrrrrrr}\text { Seguin 2006 } & 10 & 31 & 6 & 31 & 8.5 \% & 1.67[0.69,4.02] \\ \text { Caruso 2009 } & 67 & 130 & 65 & 132 & 91.5 \% & 1.05[0.82,1.33] \\ \text { Subtotal }(\mathbf{9 5 \%} \text { CI) } & & \mathbf{1 6 1} & & \mathbf{1 6 3} & \mathbf{1 0 0 . 0 \%} & \mathbf{1 . 1 0}[\mathbf{0 . 8 7}, \mathbf{1 . 3 9}] \\ \text { Total events: } & 77 & & 71 & & & \end{array}$

Heterogeneity: $\mathrm{Chi}^{2}=1.02, \mathrm{df}=1(\mathrm{P}=0.31) ; \mathrm{I}^{2}=2 \%$

Test for overall effect: $\mathrm{Z}=0.80(\mathrm{P}=0.43)$

\subsubsection{Biotene versus control}

20

Subtotal (95\% CI)

Heterogeneity: Not applicable

Test for overall effect: $\mathrm{Z}=0.42(\mathrm{P}=0.68)$

5.2.7 Potassium permanganate versus placebo

$\begin{array}{lcccccc}\text { Meidani } 2018 & 7 & 50 & 5 & 50 & 100.0 \% & 1.40[0.48,4.12] \\ \text { Subtotal }(\mathbf{9 5 \%} \text { CI) } & & \mathbf{5 0} & & \mathbf{5 0} & \mathbf{1 0 0 . 0 \%} & \mathbf{1 . 4 0}[\mathbf{0 . 4 8 , 4 . 1 2}] \\ \text { Total events: } & 7 & & 5 & & & \end{array}$

Heterogeneity: Not applicable

Test for overall effect: $\mathrm{Z}=0.61(\mathrm{P}=0.54)$ 
Analysis 5.2. (Continued)

neterogeneity: ivot appinade

Test for overall effect: $\mathrm{Z}=0.61(\mathrm{P}=0.54)$

Test for subgroup differences: $\mathrm{Chi}^{2}=11.50, \mathrm{df}=6(\mathrm{P}=0.07), \mathrm{I}^{2}=47.8 \%$

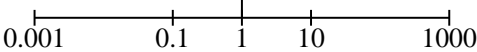

Favours experimental Favours control

\section{Analysis 5.3. Comparison 5: Other oral care agents, Outcome 3: Duration of ventilation (days)}

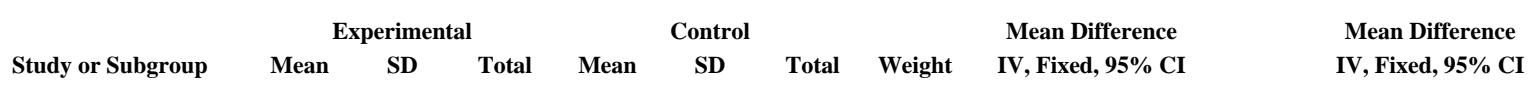

5.3.1 Povidone iodine versus saline

Seguin 2006

Subtotal $(95 \%$ CI $)$

Heterogeneity: Not applicable

Test for overall effect: $\mathrm{Z}=0.58(\mathrm{P}=0.56)$

5.3.2 Povidone iodine versus usual care

$\begin{array}{lllllllll}\text { Seguin } 2006 & 9 & 8 & 36 & 12 & 11 & 31 & 100.0 \% & -3.00[-7.67,1.67] \\ \text { Subtotal }(\mathbf{9 5 \%} \text { CI) } & & & \mathbf{3 6} & & & \mathbf{3 1} & \mathbf{1 0 0 . 0 \%} & \mathbf{- 3 . 0 0}[-\mathbf{7 . 6 7}, \mathbf{1 . 6 7}]\end{array}$

Heterogeneity: Not applicable

Test for overall effect: $\mathrm{Z}=1.26(\mathrm{P}=0.21)$

5.3.3 Saline rinse versus usual care

\begin{tabular}{|c|c|c|c|c|c|c|c|c|}
\hline Seguin 2006 & 10 & 6 & 31 & 12 & 11 & 31 & $23.8 \%$ & $-2.00[-6.41,2.41]$ \\
\hline Caruso 2009 & 11.2 & 11.2 & 130 & 11.1 & 9 & 132 & $76.2 \%$ & $0.10[-2.36,2.56]$ \\
\hline
\end{tabular}

Subtotal (95\% CI) 16

Heterogeneity: $\mathrm{Chi}^{2}=0.66, \mathrm{df}=1(\mathrm{P}=0.42) ; \mathrm{I}^{2}=0 \%$

$163100.0 \%$

$-0.40[-2.55,1$

Test for overall effect: $\mathrm{Z}=0.36(\mathrm{P}=0.72)$

5.3.4 Saline rinse + swab versus saline swab

Hu $2009 \quad 12.45 \quad 1.17$

Subtotal $(95 \%$ CI)

$\begin{array}{ll}12.45 \quad 1.17 & 25\end{array}$

Heterogeneity: Not applicable

Test for overall effect: $\mathrm{Z}=3.94(\mathrm{P}<0.0001)$

5.3.5 Saline rinse versus saline swab

$\begin{array}{lrrrrrrrr}\text { Xu } 2008 & 22.5 & 11.1 & 64 & 33.3 & 15.8 & 52 & 17.3 \% & -10.80[-15.88,-5.72] \\ \text { Tang 2013 } & 7 & 3.6 & 30 & 13 & 5.4 & 30 & 82.7 \% & -6.00[-8.32,-3.68] \\ \text { Subtotal (95\% CI) } & & & \mathbf{9 4} & & & \mathbf{8 2} & \mathbf{1 0 0 . 0 \%} & \mathbf{- 6 . 8 3}[-\mathbf{8 . 9 4}, \mathbf{- 4 . 7 2}]\end{array}$

Heterogeneity: $\mathrm{Chi}^{2}=2.83, \mathrm{df}=1(\mathrm{P}=0.09) ; \mathrm{I}^{2}=65 \%$

Test for overall effect: $\mathrm{Z}=6.34(\mathrm{P}<0.00001)$

5.3.6 Triclosan rinse versus saline

Subtotal $(95 \%$ CI)

$8.96 \quad 1.09$

Heterogeneity: Not applicable

Test for overall effect: $\mathrm{Z}=25.57(\mathrm{P}<0.00001)$
$-1.00[-4.36,2.36]$

$-1.00[-4.36,2.36]$ 
Analysis 5.4. Comparison 5: Other oral care agents, Outcome 4: Duration of ICU stay (days)

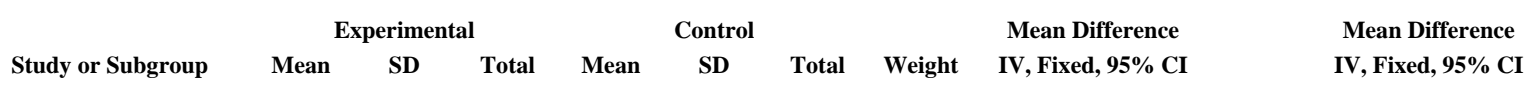

5.4.1 Povidone iodine versus saline/placebo

Seguin $2006 \quad 15 \quad 14$

Seguin $2014 \quad 15 \quad 13$

36

14

12

$31 \quad 32.6 \%$

IV, Fixed, 95\% CI

Subtotal (95\% CI) 78
114

16

14

$\begin{array}{rr}72 & 67.4 \% \\ 103 & \mathbf{1 0 0 . 0 \%}\end{array}$

$1.00[-5.23,7.23]$

Heterogeneity: $\mathrm{Chi}^{2}=0.27, \mathrm{df}=1(\mathrm{P}=0.61) ; \mathrm{I}^{2}=0 \%$

Test for overall effect: $\mathrm{Z}=0.19(\mathrm{P}=0.85)$

5.4.2 Povidone iodine versus usual care

$\begin{array}{lllllllll}\text { Seguin } 2006 & 15 & 14 & 36 & 19 & 15 & 31 & 100.0 \% & -4.00[-10.99,2.99] \\ \text { Subtotal (95\% CI) } & & & \mathbf{3 6} & & & \mathbf{3 1} & \mathbf{1 0 0 . 0 \%} & \mathbf{- 4 . 0 0}[-\mathbf{1 0 . 9 9}, \mathbf{2 . 9 9}]\end{array}$

Heterogeneity: Not applicable

Test for overall effect: $\mathrm{Z}=1.12(\mathrm{P}=0.26)$

5.4.3 Saline rinse versus usual care

$\begin{array}{lrrrrrrrr}\text { Seguin 2006 } & 14 & 12 & 31 & 19 & 15 & 31 & 16.8 \% & -5.00[-11.76,1.76] \\ \text { Caruso 2009 } & 17.2 & 12.3 & 130 & 17.6 & 12.8 & 132 & 83.2 \% & -0.40[-3.44,2.64] \\ \text { Subtotal (95\% CI) } & & & \mathbf{1 6 1} & & & \mathbf{1 6 3} & \mathbf{1 0 0 . 0 \%} & \mathbf{- 1 . 1 7}[-\mathbf{3 . 9 5}, \mathbf{1 . 6 0}]\end{array}$

Heterogeneity: $\mathrm{Chi}^{2}=1.48, \mathrm{df}=1(\mathrm{P}=0.22) ; \mathrm{I}^{2}=32 \%$

Test for overall effect: $\mathrm{Z}=0.83(\mathrm{P}=0.41)$

5.4.4 Triclosan rinse versus saline

$\begin{array}{lllllllll}\text { Zhao } 2012 & 10.65 & 2.21 & 162 & 15.62 & 3.06 & 162 & 100.0 \% & -4.97[-5.55,-4.39]\end{array}$

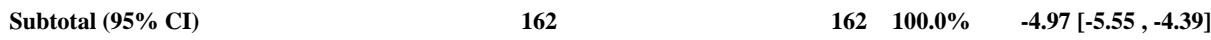

Heterogeneity: Not applicable

Test for overall effect: $Z=16.76(P<0.00001)$

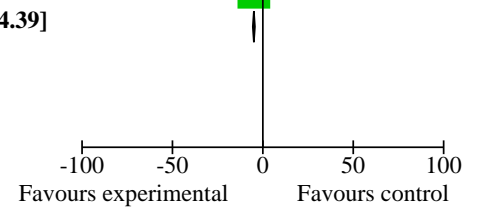

\section{Analysis 5.5. Comparison 5: Other oral care agents, Outcome 5: Number of participants treated with systemic antibiotics}

\begin{tabular}{lccccccc} 
& \multicolumn{2}{c}{ Povidone iodine } & \multicolumn{2}{c}{ Placebo } & \multicolumn{2}{c}{ Risk Ratio } & \multicolumn{2}{c}{ Risk Ratio } \\
Study or Subgroup & Events & Total & Events & Total & Weight & M-H, Fixed, 95\% CI & M-H, Fixed, 95\% CI
\end{tabular}

5.5.1 Povidone iodine versus saline/placebo

$\begin{array}{lcccccc}\text { Seguin } 2014 & 49 & 85 & 57 & 82 & 100.0 \% & 0.83[0.66,1.05] \\ \text { Subtotal }(\mathbf{9 5 \%} \mathbf{C I}) & & \mathbf{8 5} & & \mathbf{8 2} & \mathbf{1 0 0 . 0 \%} & \mathbf{0 . 8 3}[\mathbf{0 . 6 6 , \mathbf { 1 . 0 5 }}] \\ \text { Total events: } & 49 & & 57 & & & \end{array}$

Heterogeneity: Not applicable

Test for overall effect: $\mathrm{Z}=1.58(\mathrm{P}=0.11)$

Total (95\% CI)

85

$82 \quad 100.0 \%$

$0.83[0.66,1.05]$

Total events:

49

57

Heterogeneity: Not applicable

Test for overall effect: $\mathrm{Z}=1.58(\mathrm{P}=0.11)$

Test for subgroup differences: Not applicable

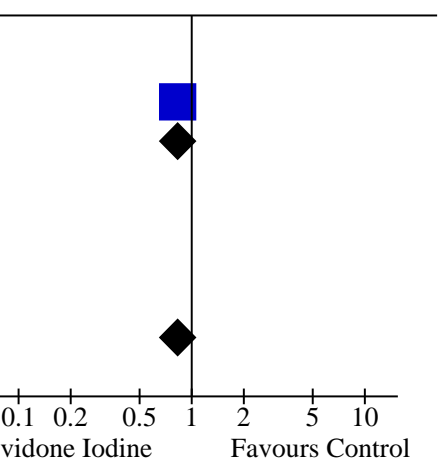


Analysis 5.6. Comparison 5: Other oral care agents, Outcome 6: Adverse effects

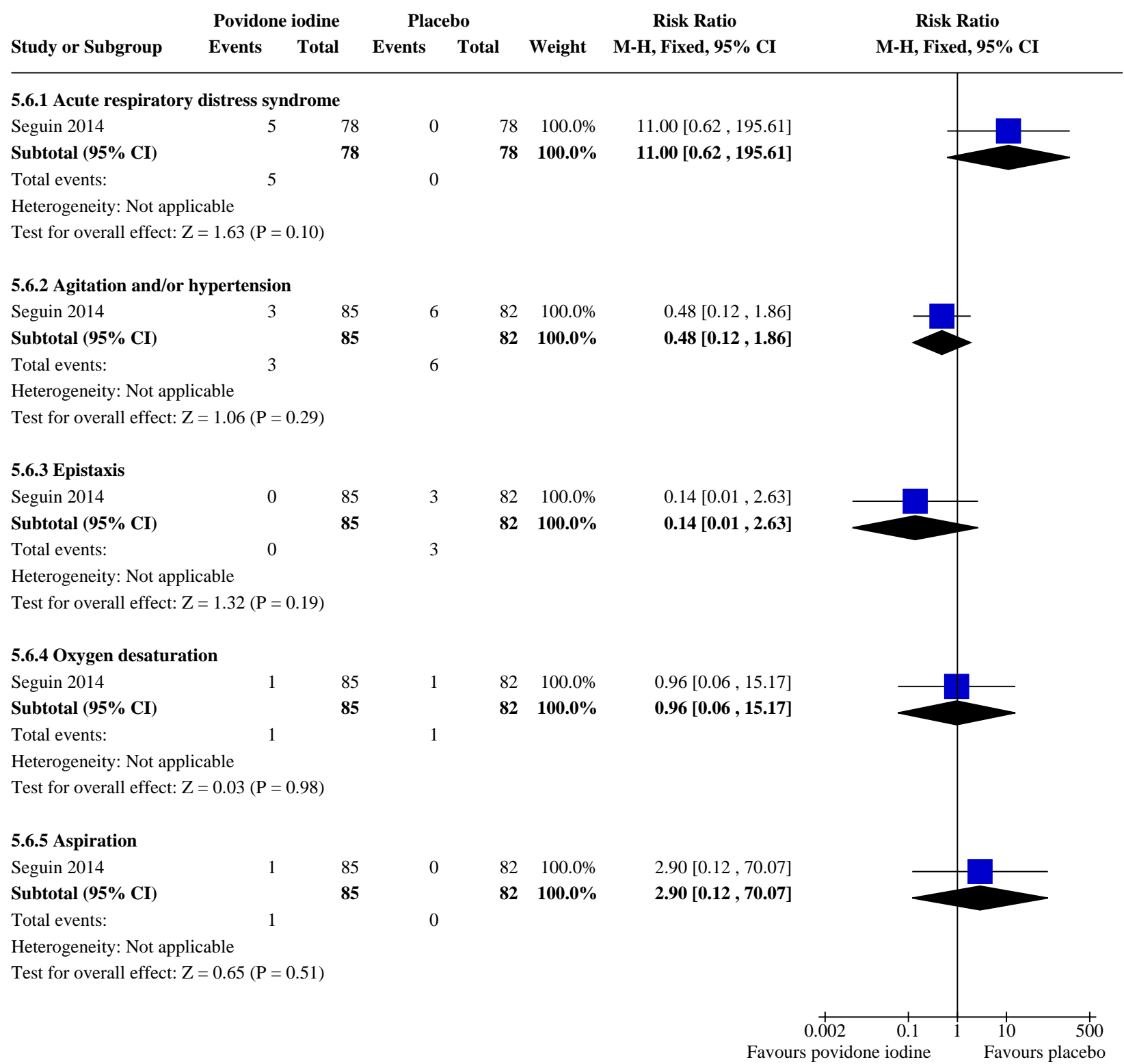

\section{ADDITIONAL TABLES}

Table 1. Other outcome data from included studies

\begin{tabular}{|c|c|c|c|c|}
\hline Comparison & $\begin{array}{l}\text { Number of partici- } \\
\text { pants }\end{array}$ & Outcome & Data & $\begin{array}{l}\text { Effect es- } \\
\text { timate } \\
(95 \% \mathrm{Cl})\end{array}$ \\
\hline $\begin{array}{l}\text { CHX versus sodium bi- } \\
\text { carbonate versus wa- } \\
\text { ter (Berry 2011) }\end{array}$ & $\begin{array}{l}\text { CHX group: } 33 \text {; } \\
\text { sodium bicarbon- } \\
\text { ate group: } 33 \text {; water } \\
\text { group: } 43\end{array}$ & $\begin{array}{l}\text { Adverse } \\
\text { events }\end{array}$ & $\begin{array}{l}\text { No adverse events were reported associated with inter- } \\
\text { ventions }\end{array}$ & \\
\hline
\end{tabular}




\section{Table 1. Other outcome data from included studies (Continued)}

\begin{tabular}{|c|c|c|c|c|}
\hline \multirow{4}{*}{$\begin{array}{l}\text { Listerine versus sodi- } \\
\text { um bicarbonate ver- } \\
\text { sus sterile water } \\
\text { (Berry 2013) }\end{array}$} & \multirow{4}{*}{$\begin{array}{l}\text { Listerine group: } \\
\text { 127; sodium bicar- } \\
\text { bonate group: } 133 ; \\
\text { sterile water group: } \\
138\end{array}$} & $\begin{array}{l}\text { Duration of } \\
\text { mechanical } \\
\text { ventilation }\end{array}$ & \multicolumn{2}{|l|}{$\begin{array}{l}\text { No significant difference between groups in median } \\
\text { ventilation hours ( } 81 \text { hours, SD 1058) }\end{array}$} \\
\hline & & $\begin{array}{l}\text { Duration of } \\
\text { ICU stay }\end{array}$ & $\begin{array}{l}\text { No significant difference between groups in median } \\
\text { length of ICU stay ( } 5 \text { days, SD 29) }\end{array}$ & \\
\hline & & $\begin{array}{l}\text { Systemic } \\
\text { antibiotic } \\
\text { use }\end{array}$ & No significant difference between groups $(P=0.21)$ & \\
\hline & & $\begin{array}{l}\text { Adverse } \\
\text { events }\end{array}$ & $\begin{array}{l}\text { No adverse events were reported associated with inter- } \\
\text { ventions }\end{array}$ & \\
\hline \multirow{3}{*}{$\begin{array}{l}\mathrm{CHX}+\text { toothbrushing } \\
\text { versus control (Bopp } \\
\text { 2006) }\end{array}$} & \multirow{3}{*}{$\begin{array}{l}\mathrm{CHX}+\text { toothbrush- } \\
\text { ing group: } 2 \text {; con- } \\
\text { trol group: } 3\end{array}$} & $\begin{array}{l}\text { Incidence } \\
\text { of VAP }\end{array}$ & $\begin{array}{l}0 \text { cases in } \mathrm{CHX}+\text { toothbrushing group and } 1 \text { case in } \\
\text { control group }\end{array}$ & \\
\hline & & $\begin{array}{l}\text { Duration of } \\
\text { ventilation }\end{array}$ & $\begin{array}{l}\text { Mean } 5.5 \text { days (SD 0.39) in toothbrushing group and } \\
\text { mean } 5 \text { days (SD 0.81) in control group }\end{array}$ & \\
\hline & & $\begin{array}{l}\text { Duration of } \\
\text { ICU stay }\end{array}$ & $\begin{array}{l}\text { Mean } 18 \text { days (SD 1.67) in toothbrushing group and } \\
\text { mean } 10.3 \text { days (SD 2.70) in control group }\end{array}$ & \\
\hline $\begin{array}{l}\text { Toothbrush }+\mathrm{CHX} \text { ver- } \\
\text { sus CHX alone (De Lac- } \\
\text { erda 2017) }\end{array}$ & $\begin{array}{l}\text { Toothbrush }+\mathrm{CHX} \\
\text { group: } 105 ; \mathrm{CHX} \\
\text { group: } 108\end{array}$ & $\begin{array}{l}\text { Adverse } \\
\text { events }\end{array}$ & $\begin{array}{l}\text { No adverse events were reported associated with inter- } \\
\text { ventions }\end{array}$ & \\
\hline $\begin{array}{l}\text { Nasosil versus } \mathrm{CHX} \\
\text { (Khaky 2018) }\end{array}$ & $\begin{array}{l}\text { Nasosil group: } 37 \\
\text { CHX group: } 38\end{array}$ & Mortality & $\begin{array}{l}\text { The Mann-Whitney test showed that there was no sig- } \\
\text { nificant difference between the two groups in the mor- } \\
\text { tality rate on the first and fifth day of study }(P>0.05)\end{array}$ & \\
\hline $\begin{array}{l}\text { CHX versus placebo } \\
\text { (Koeman 2006) }\end{array}$ & $\begin{array}{l}\text { CHX group: } 127 ; \\
\text { placebo group: } 130\end{array}$ & Mortality & $\mathrm{HR}$ & $\begin{array}{l}\text { HR } 1.12 \\
(95 \% \mathrm{Cl} \\
0.72 \text { to } \\
1.17)\end{array}$ \\
\hline
\end{tabular}

\begin{tabular}{|c|c|c|c|}
\hline \multirow[t]{2}{*}{$\begin{array}{l}\text { CHX versus placebo } \\
\text { (Meinberg 2012) }\end{array}$} & \multirow[t]{2}{*}{$\begin{array}{l}\text { CHX group: } 28 ; \\
\text { placebo group: } 24\end{array}$} & $\begin{array}{l}\text { Duration of } \\
\text { mechanical } \\
\text { ventilation }\end{array}$ & $\begin{array}{l}\text { Median days in } \mathrm{CHX} \text { group } 8.5 \text { (interquartile range, } 7.3 \\
\text { to } 14.7) \text { and median days in placebo group } 6 \text { ( } 4 \text { to } 12.7 \text { ) } \\
(\mathrm{P}=0.17)\end{array}$ \\
\hline & & $\begin{array}{l}\text { Duration of } \\
\text { ICU stay }\end{array}$ & $\begin{array}{l}\text { Median days in } \mathrm{CHX} \text { group } 12 \text { (interquartile range, } 9 \text { to } \\
\text { 29) and median days in placebo group } 11 \text { (5 to } 16)(\mathrm{P}= \\
0.36 \text { ) }\end{array}$ \\
\hline $\begin{array}{l}\text { Powered toothbrush + } \\
\text { standard oral care ver- } \\
\text { sus standard oral care } \\
\text { alone (Pobo 2009) }\end{array}$ & $\begin{array}{l}\text { Toothbrush group: } \\
74 \text {; control group: } \\
73\end{array}$ & $\begin{array}{l}\text { Adverse } \\
\text { events }\end{array}$ & $\begin{array}{l}\text { No adverse events were reported associated with inter- } \\
\text { ventions }\end{array}$ \\
\hline \multirow[t]{2}{*}{$\begin{array}{l}\text { Powered toothbrush }+ \\
\mathrm{CHX} \text { versus } \mathrm{CHX} \text { alone } \\
\text { (Roca Biosca 2011) }\end{array}$} & \multirow[t]{2}{*}{$\begin{array}{l}\text { Powered tooth- } \\
\text { brush group: } 29 \\
\text { CHX alone group: } \\
32\end{array}$} & $\begin{array}{l}\text { Plaque in- } \\
\text { dex }\end{array}$ & $\begin{array}{l}\text { Mean in toothbrush group } 1.68 \text { and mean in control } \\
\text { group 1.91; } \\
\text { no estimates of variance but reported that } P=0.7 \text { (no } \\
\text { difference) }\end{array}$ \\
\hline & & $\begin{array}{l}\text { Incidence } \\
\text { of VAP }\end{array}$ & OR $0.78(95 \% \mathrm{Cl} 0.36$ to $1.68, \mathrm{P}=0.56)$ \\
\hline
\end{tabular}


Table 1. Other outcome data from included studies (Continued)

\begin{tabular}{|c|c|c|c|}
\hline $\begin{array}{l}\text { CHX (once daily or } \\
\text { twice daily) versus } \\
\text { placebo (Scannapieco } \\
\text { 2009) }\end{array}$ & $\begin{array}{l}\text { CHX 1x/day group: } \\
\text { 47; CHX 2x/day } \\
\text { group: 50; placebo } \\
\text { group: } 49\end{array}$ & $\begin{array}{l}\text { Plaque in- } \\
\text { dex }\end{array}$ & $\begin{array}{l}\text { No difference between the } 3 \text { groups (data presented } \\
\text { graphically) }\end{array}$ \\
\hline \multirow[t]{2}{*}{$\begin{array}{l}\text { Biotene OralBalance } \\
\text { versus control (Ste- } \\
\text { fanescu 2013) }\end{array}$} & $\begin{array}{l}\text { Biotene OralBal- } \\
\text { ance group: } 20 ; \\
\text { control group: } 21\end{array}$ & $\begin{array}{l}\text { Duration of } \\
\text { mechanical } \\
\text { ventilation }\end{array}$ & No difference between groups $(P=0.77)$ \\
\hline & & $\begin{array}{l}\text { Adverse } \\
\text { events }\end{array}$ & $\begin{array}{l}\text { No significant difference between groups with respect } \\
\text { to adverse events in buccal mucosa }\end{array}$ \\
\hline
\end{tabular}

$\mathrm{CHX}=$ chlorhexidine;

$\mathrm{Cl}=$ confidence interval;

CPIS = Clinical Pulmonary Infection Score;

$\mathrm{HR}=$ hazard ratio;

$\mathrm{ICU}=$ intensive care unit;

$\mathrm{OR}=$ odds ratio;

$\mathrm{P}=$ probability;

$\mathrm{SD}=$ standard deviation;

$\mathrm{VAP}=$ ventilator-associated pneumonia

\section{APPEN DICES}

\section{Appendix 1. Cochrane Oral Health's Trials Register search strategy}

Cochrane Oral Health's Trials Register is available via the Cochrane Register of Studies. For information on how the register is compiled, see https://oralhealth.cochrane.org/trials.

\#1 ((critical* AND ill*):ti,ab) AND (INREGISTER)

\#2 ((depend ${ }^{\star}$ and patient*):ti,ab) AND (INREGISTER)

\#3 (("critical care" or " intensive care" or ICU or CCU):ti,ab) AND (INREGISTER)

\#4 ((intubat* ${ }^{\star}$ or ventilat*):ti,ab) AND (INREGISTER)

\#5 ((\#1 or \#2 or \#3 or \#4)) AND (INREGISTER)

\#6 ((pneumonia or "nosocomial infect*" or VAP):ti,ab) AND (INREGISTER)

\#7 (\#5 and \#6) AND (INREGISTER)

\section{Appendix 2. Cochrane Central Register of Controlled Trials (CENTRAL) search strategy}

\#1 MeSH descriptor Critical illness this term only

\#2 (critical ${ }^{*}$ in All Text near/6 ill* in All Text) $^{*}$

\#3 (depend ${ }^{\star}$ in All Text near/6 patient* in All Text)

\#4 MeSH descriptor Critical care this term only

\#5 (intensive-care in All Text or "intensive care" in All Text or critical-care in All Text or "critical care" in All Text)

\#6 ICU in Title, Abstract or Keywords

\#7 ((intubat* in All Text near/5 patient* in All Text) or (ventilat* in All Text near/5 patient ${ }^{\star}$ in All Text))

\#8 (\#1 or \#2 or \#3 or \#4 or \#5 or \#6 or \#7)

\#9 (VAP in Title, Abstract or Keywords or VAP in Title, Abstract or Keywords)

\#10 "nosocomial infection*" in Title, Abstract or Keywords

\#11 MeSH descriptor Pneumonia, Ventilator-Associated this term only

$\# 12$ pneumonia in All Text

\#13 (\#9 or \#10 or \#11 or \#12)

\#14 MeSH descriptor Oral health this term only

\#15 MeSH descriptor Oral hygiene explode all trees

\#16 MeSH descriptor Dentifrices explode all trees

\#17 MeSH descriptor Mouthwashes explode all trees

\#18 MeSH descriptor Periodontal diseases explode all trees

\#19 periodont* in All Text 
\#20 ("oral care" in All Text or "oral health" in All Text or oral-health in All Text or "mouth care" in All Text or "oral hygien*" in All Text or oral-hygien* in All Text or "dental hygien*" in All Text or decontaminat* in All Text)

\#21 (mouthwash* in All Text or mouth-wash* in All Text or mouth-rins* in All Text or mouthrins* in All Text or "oral rins ${ }^{\star} "$ in All Text or oralrins* in All Text or "artificial saliva" in All Text or "saliva substitut " in All Text or ( (denture* in All Text near/6 clean* in All Text) or toothpaste*

in All Text) or dentifrice* in All Text)

\#22 (\#14 or \#15 or \#16 or \#17 or \#18 or \#19 or \#20 or \#21)

\#23 (\#8 and \#13)

\#24 (\#22 and \#23)

\section{Appendix 3. MEDLINE Ovid search strategy}

1. CRITICAL ILLNESS/

2. (critical\$ adj5 ill\$).mp.

3. (depend\$ adj5 patient\$).mp.

4. INTENSIVE CARE/

5. ("intensive care" or intensive-care or "critical care" or critical-care).mp.

6. ICU.mp. or CCU.ti,ab.

7. ((intubat\$ or ventilat\$) adj5 patient\$).mp.

8. or/1-7

9. PNEUMONIA, VENTILATOR-ASSOCIATED/

10. pneumonia.ti,ab.

11. VAP.ti,ab.

12. "nosocomial infection".mp.

13. or/9-12

14. exp ORAL HYGIENE/

15. exp DENTIFRICES/

16. MOUTHWASHES/

17. ANTI-INFECTIVE AGENTS, LOCAL/

18. Cetylpyridinium/

19. Chlorhexidine/

20. Povidone-lodine/

21. ("oral care" or "mouth care" or "oral hygien\$" or oral-hygien\$ or "dental hygien\$").ti,ab.

22. (mouthwash\$ or mouth-wash\$ or mouth-rins\$ or mouthrins\$ or "oral rins\$" or oral-rins\$ or toothpaste\$ or dentifrice\$ or toothbrush\$ or chlorhexidine\$ or betadine\$ or triclosan\$ or cepacol or Corsodyl or Peridex or Hibident or Prexidine or Parodex or Chlorexil or Peridont or Eludril or Perioxidin or Chlorohex or Savacol or Periogard or Chlorhexamed or Nolvasan or Sebidin or Tubulicid or hibitane).mp.

23. (antiseptic\$ or antiinfect\$ or "local microbicide\$" or "topical microbicide\$").mp.

24. or/14-23

25.8 and 13 and 24

\section{Appendix 4. Embase Ovid search strategy}

1. CRITICAL ILLNESS/

2. (critical\$ adj5 ill\$).mp.

3. (depend\$ adj5 patient\$).mp.

4. INTENSIVE CARE/

5. ("intensive care" or intensive-care or "critical care" or critical-care).mp.

6. (ICU or CCU).ti,ab.

7. ((intubat\$ or ventilat\$) adj5 patient\$).mp.

8. or/1-7

9. PNEUMONIA, VENTILATOR-ASSOCIATED/

10. pneumonia.ti,ab.

11. VAP.ti,ab.

12. "nosocomial infection".mp.

13. or/9-12

14. exp ORAL HYGIENE/

15. exp DENTIFRICES/

16. MOUTHWASHES/

17. ANTI-INFECTIVE AGENTS, LOCAL/

18. Cetylpyridinium/

19. Chlorhexidine/

20. Povidone-lodine/

21. ("oral care" or "mouth care" or "oral hygien\$" or oral-hygien\$ or "dental hygien\$").ti,ab. 
22. (mouthwash\$ or mouth-wash\$ or mouth-rins\$ or mouthrins\$ or "oral rins\$" or oral-rins\$ or toothpaste\$ or dentifrice\$ or toothbrush\$ or chlorhexidine\$ or betadine\$ or triclosan\$ or cepacol or Corsodyl or Peridex or Hibident or Prexidine or Parodex or Chlorexil or Peridont or Eludril or Perioxidin or Chlorohex or Savacol or Periogard or Chlorhexamed or Nolvasan or Sebidin or Tubulicid or hibitane).mp.

23. (antiseptic\$ or antiinfect\$ or "local microbicide\$" or "topical microbicide\$").mp.

24. or/14-23

25.8 and 13 and 24

This subject search was linked to the Cochrane search filter for identifying randomised trials in Embase (2016 version) as referenced in Lefebvre 2019.

1. Randomized controlled trial/

2. Controlled clinical study/

3. random $\$ . t i, a b$.

4. randomization/

5. intermethod comparison/

6. placebo.ti,ab.

7. (compare or compared or comparison).ti.

8. ((evaluated or evaluate or evaluating or assessed or assess) and (compare or compared or comparing or comparison)).ab.

9. (open adj label).ti,ab.

10. ((double or single or doubly or singly) adj (blind or blinded or blindly)).ti,ab.

11. double blind procedure/

12. parallel group $\$ 1 . t i, a b$.

13. (crossover or cross over).ti,ab.

14. ((assign\$ or match or matched or allocation) adj5 (alternate or group $\$ 1$ or intervention $\$ 1$ or patient $\$ 1$ or subject $\$ 1$ or participant

\$1)).ti,ab.

15. (assigned or allocated).ti,ab.

16. (controlled adj7 (study or design or trial)).ti,ab.

17. (volunteer or volunteers).ti,ab.

18. human experiment/

19. trial.ti.

20. or/1-19

21. random\$ adj sampl\$ adj7 ("cross section\$" or questionnaire\$1 or survey\$ or database $\$ 1)$ ).ti,ab. not (comparative study/ or controlled study/ or randomi?ed controlled.ti,ab. or randomly assigned.ti,ab.)

22. Cross-sectional study/not (randomized controlled trial/ or controlled clinical study/ or controlled study/ or randomi?ed controlled.ti,ab. or control group $\$ 1 . t i, a b$.

23. (((case adj control\$) and random\$) not randomi?ed controlled).ti,ab.

24. (Systematic review not (trial or study)).ti.

25. (nonrandom\$ not random\$).ti,ab.

26. "Random field\$".ti,ab.

27. (random cluster adj3 sampl\$̧).ti,ab.

28. (review.ab. and review.pt.) not trial.ti.

29. "we searched".ab. and (review.ti. or review.pt.)

30. "update review".ab.

31. (databases adj4 searched).ab.

32. (rat or rats or mouse or mice or swine or porcine or murine or sheep or lambs or pigs or piglets or rabbit or rabbits or cat or cats or dog or dogs or cattle or bovine or monkey or monkeys or trout or marmoset $\$ 1) . t i$. and animal experiment/

33. Animal experiment/ not (human experiment/ or human/)

34. or/21-33

35. 20 not 34

\section{Appendix 5. CINAHL EBSCO search strategy}

\section{S25 S14 and S24}

S24 S15 or S16 or S17 or S18 or S19 or S20 or S21 or S22 or S23

S23 (antiseptic* or antiinfect* or "local microbicide*" or "topical microbicide*")

S22 (mouthwash* or mouth-wash* or mouth-rins or mouthrins $^{\star}$ or "oral rins " $^{*}$ or oral-rins ${ }^{\star}$ or toothpaste* or dentifrice or toothbrush $^{\star}$ or chlorhexidine $e^{\star}$ or betadine* or triclosan* or cepacol or Corsodyl or Peridex or Hibident or Prexidine or Parodex or Chlorexil or Peridont or Eludril or Perioxidin or Chlorohex or Savacol or Periogard or Chlorhexamed or Nolvasan or Sebidin or Tubulicid or hibitane)

S21 ("oral care" or "mouth care" or "oral hygien*" or oral-hygien* or "dental hygien*")

S20 (MH Povidone-lodine)

S19 (MH Chlorhexidine)

S18 (MH "Antiinfective Agents, Local")

S17 MH MOUTHWASHES

Oral hygiene care for critically ill patients to prevent ventilator-associated pneumonia (Review) 
S16 (MH "DENTIFRICES+")

S15 (MH "Oral Hygiene+")

S14 S8 AND S13

S13 S9 or S10 or S11 or S12

S12 TI pneumonia or AB pneumonia

S11 MH PNEUMONIA, VENTILATOR-ASSOCIATED

S10 TI "nosocomial infection" and AB "nosocomial infection"

S9 TIVAP or AB VAP

$\mathrm{S} 8 \mathrm{~S} 1$ or $\mathrm{S} 2$ or $\mathrm{S} 3$ or $\mathrm{S} 4$ or $\mathrm{S} 5$ or $\mathrm{S} 6$ or $\mathrm{S} 7$

S7 ((intubat ${ }^{\star}$ N5 patient $\left.{ }^{\star}\right)$ or (ventilat ${ }^{\star}$ N5 patient $\left.{ }^{\star}\right)$ )

S6 TIICU or AB ICU or TI CCU or AB CCU

S5 (intensive-care or "intensive care" or critical-care or "critical care")

S4 MH CRITICAL CARE

S3 (depend* N6 patient*)

S2 (critical $^{*} \mathrm{~N} 6$ ill $\left.^{*}\right)$

S1 MH CRITICAL ILLNESS

\section{Appendix 6. LILACS BIREME Virtual Health Library search strategy}

(Mh Critical illness or "Enfermedad Crítica" or "Estado Terminal" or "critical illness\$" or Mh Intensive care or "Cuidados Intensivos" or "Terapia Intensiva" or "critical care" or "intensive care" or "ICU" or "CCU" or intubate\$ or ventilate\$) [Words] and (Mh Pneumonia, Ventilator-Associated or "Neumonia Asociada al Ventilador" or "Pneumonia Associada à Ventilação Mecânica" or (ventilator AND pneumonia)) [Words] and (Mh Oral hygiene or "oral hygiene" or "Higiene Bucal" or "oral care" or "mouth care" or mouthwash\$ or mouthrins \$ or toothpaste\$ or dentifrice\$ or chlorhexidine or betadine or triclosan or Clorhexidina or Clorexidina or "Antisépticos Bucales" or "Antissépticos Bucais" or "Cepillado Dental" or "Escovação Dentária" or antiseptic\$ or antiinfective\$)

\section{Appendix 7. VIP search strategy}

$(R=$ 口腔 AND R=肺炎 AND R=随机) limited to (核心期刊 AND Time=2012-2016)

\section{Appendix 8. Search strategies used for previous versions of this review}

\section{Chinese Biomedical Literature Database search strategy}

\#1 缺省[智能]:危重-限定:1978-2012

\#2 缺省:ICU -限定:1978-2012

\#3 缺省:VAP -限定: 1978-2012

\#4 缺省:插管-限定:1978-2012

\#5 \#4 or \#3 or \#2 or \#1

\#6 缺省: 口腔护理

\#7 缺省[智能]: 口腔清洁

\#8 缺省:口腔卫生

\#9 缺省 [智能]:刷牙

\#10 \#9 or \#8 or \#7 or \#6

\#11 \#10 and \#5

\#12 缺省 [智能]: 随机

\#13 缺省: 随机对照

\#14 \#13 or \#12

\#15 \#14 and \#11

\section{China National Knowledge Infrastructure search strategy}

\#1 数据库：中国期刊全文数据库 检索条件 : ( (题名=VAP) 或者 (摘要=ICU) 或者 (题名=危重)) 并且(摘要=呼吸机相关性肺炎) 或者 (摘要=插管) (模糊匹配);2003-2012; 全部期刊; 时间排序; 单库检索 
\#2 数据库: 中国期刊全文数据库检索条件：(题名=口腔护理) 或者 (摘要=口腔去污染) 或者 (题名=口腔清洁) 或者 (摘要=刷牙) 或 者 (主题=口腔卫生) (模糊匹配); 时间排序; 单库检索(结果中检索)

\#3 数据库：中国期刊全文数据库 检索条件：(题名=随机对照) 或者 (摘要=随机) 或者 (题名=随机对照实验) 或者 (摘要=随机分配) 或者 (主题=随机隐藏) (模糊匹配); 时间排序; 单库检索(结果中检索)

\section{Wan Fang Database search strategy}

1. ((全部字段=(模糊匹配) "危重") ) ; 按相关度排序

2. ((全部字段=(模糊匹配) "ICU") ) ; 按相关度排序

3. ((全部字段=(模糊匹配) "VAP")) ; 按相关度排序

4. ((全部字段=(模糊匹配) "口腔" $)$ ) ; 按相关度排序

5. ((全部字段=(模糊匹配) "刷牙") ) ; 按相关度排序

6. ((全部字段=(模糊匹配) "去污染") ) ; 按相关度排序

7. ((全部字段=(模糊匹配) "洗必泰") ) ; 按相关度排序

8. ((全部字段=(模糊匹配) "口腔冲洗") ) ; 按相关度排序

9. ((全部字段=(模糊匹配) "危重" $)$ ) 或 ((全部字段=(模糊匹配) "ICU") ) 或 ((全部字段=(模糊匹配) "VAP") )

10. ( (全部字段=(模糊匹配) "口腔" $)$ ) 或 ((全部字段=(模糊匹配) "刷牙" $))$ 或 ((全部字段 =(模糊匹配) "去污染") ) 或 ((全部字段 $=($ 模糊匹配) $)$ "洗必泰" $)$ ) 或 ((全部字段 =(模糊匹配) "口腔冲洗" $)$ )

11. ( ( (全部字段=(模糊匹配) "口腔") ) 或 ((全部字段=(模糊匹配) "刷牙") ) 或 ((全部字段=(模糊匹配) "去污染") ) 或 ((全部字段 $=($ 模糊匹配) "洗必泰" $)$ ) 或 $(($ 全部字段 $=($ 模糊匹配 $)$ "口腔冲洗" $))$ 与 $(($ (全部字段 =(模糊匹配) "口腔" $))$ 或 $(($ 全部字段=(模糊匹 配) "刷牙") ) 或 ((全部字段=(模糊匹配) "去污染" ) ) 或 ((全部字段=(模糊匹配) "洗必泰" $)$ ) 或 ((全部字段 =(模糊匹配) "口腔冲 洗" $)$ ) 与 ((全部字段=(模糊匹配) "危重" $)$ ) 或 ((全部字段=(模糊匹配) "ICU") ) 或 ((全部字段=(模糊匹配) "VAP") ) )

\section{Appendix 9. US National Institutes of Health Ongoing Trials Register (ClinicalTrials.gov) search strategy}

ventilator and pneumonia and "oral hygiene"

\section{Appendix 10. World Health Organization International Clinical Trials Registry Platform search strategy}

ventilator and pneumonia and "oral hygiene"

\section{FEE D B A C K}

\section{Mortality data for chlorhexidine, November 2016}

\section{Summary}

Hua and colleagues examined the effect of chlorhexidine (CHX) on mortality (analysis 1.2) and found no benefit of CHX compared to placebo (risk ratio (RR) 1.09, 95\% confidence interval ( $\mathrm{Cl}$ ) 0.96 to 1.23 ). a Those results differ from those derived in a recent meta-analysis by our group (odds ratio (OR) $1.25,95 \% \mathrm{Cl} 1.05$ to 1.50).b The review authors specifically discussed this and suggested that this discrepancy could be accounted for by differences in review methodology.

We fully agree. We sought to explore the effect of $\mathrm{CHX}$ (and selective digestive or oropharygneal decontamination) on mortality in general adult intensive care units so we excluded studies on cardiac surgery patients and children. We did include a study by MacNaughton and colleagues that was published only as an abstractc. Hua and colleagues suggested that our inclusion of this abstract might contribute to the observed difference in the two pooled estimates. However, removal of this study from our meta-analysis led to a very similar result (OR $1.29,95 \% \mathrm{Cl} 1.07$ to 1.56 ).

When considering the studies included in both our reviews, there were three studies that both Hua and colleagues and we identified but handled differently. We wonder if this accounts for much of the observed discrepancy.

Berry and colleagues ${ }^{d}$ : the primary outcome of this study was bacterial growth at day 4 . Berry and colleagues accordingly excluded patients who had died within 96 hours from their analysis; this is shown in Figure 1 of their paper. Although Hua and colleagues state that they used intensive care unit (ICU) mortality when available, they appear to have used these 96-hour mortality data in their pooled estimates. Berry and colleagues did not publish ICU mortality data but we managed to obtain the data from them. 
Koeman et ale: the authors omitted mortality data from this moderately large (relevant arms consisting of 257 patients) and robust trial from their pooled estimates. We included these data. Of note, other meta-analyses on this subject that have examined mortality have included this study in their pooled estimates; Hua et al are unique in choosing to exclude it (references on request).

Munro and colleagues ${ }^{f}$ Hua and colleagues chose to use the "day 3 analysis sample" rather than obtaining intention-to-treat data. This means they have included only 192 patients out of an enrolled population of 547 (the largest randomised controlled trial on this subject published to date). In their paper, Munro and colleagues explained how this group came about: "Of the 547 enrolled patients, 249 were still endotracheally intubated on study day 3; of these, 209 patients had complete day 3 CPIS [Clinical Pulmonary Infection Score] data. Because of missing values on some of the components of the CPIS, only 192 patients had CPIS values on both days 1 and 3, and their data could be analyzed completely." Accordingly, 298 patients have been excluded either owing to extubation or death and 57 patients have been excluded owing to lack of data for a scoring system that is irrelevant to the outcome of death.

In summary, the authors have, in our view, three relevant omissions in their dataset. These might be for reasons such as being unable to contact authors, as indeed was the case for one of our included studiesg. Nevertheless, there has been substantial attrition of potentially available data in their pooled estimate and accordingly we question if they are correct in their claim that their result "reflects the current evidence base".

I do not have any affiliation with or involvement in any organisation with a financial interest in the subject matter of my comment.

References:

aHua F, Xie H, Worthington HV, Furness S, Zhang Q, Li C. Oral hygiene care for critically ill patients to prevent ventilator-associated pneumonia. Cochrane Database of Systematic Reviews 2016, Issue 10. Art. No.: CD008367. DOI: 10.1002/14651858.CD008367.pub3.

bPrice R, MacLennan G, Glen J. Selective digestive or oropharyngeal decontamination and topical oropharyngeal chlorhexidine for prevention of death in general intensive care: systematic review and network meta-analysis. BMJ 2014; 348 : g2197.

CMacNaughton PD, Bailey J, Donlin N, Branfield P, Williams A, Rowswell H. A randomised controlled trial assessing the efficacy of oral chlorhexidine in ventilated patients. Intensive Care Medicine 2004; 30: S12.

dBerry AM, Davidson PM, Masters J, Rolls K, Ollerton R. Effects of three approaches to standardized oral hygiene to reduce bacterial colonization and ventilator associated pneumonia in mechanically ventilated patients: A randomised control trial. International Journal of Nursing Studies 2011; 48: 681-8.

eKoeman M, Van der Ven AJ, Hak E, Joore HC, Kaasjager K, De Smet AM, et al. Oral decontamination with chlorhexidine reduces the incidence of ventilator-associated pneumonia. American Journal of Respiratory Critical Care Medicine 2006; 173: $1348-55$.

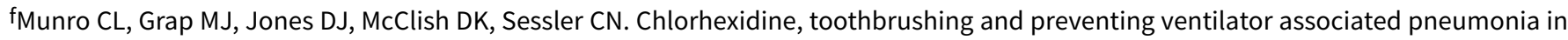
critically ill adults. American Journal of Critical Care 2009; 18: 428-38.

gPanchabhai TS, Dangayach NS, Krishnan A, Kothari VM, Karnad DR. Oropharyngeal cleansing with $0.2 \%$ chlorhexidine for prevention of nosocomial pneumonia in critically ill patients. Chest 2009; 135: 1150-6.

\section{Reply}

We thank Price and colleagues for their feedback on our reviewa. We know that the association between oral care using $\mathrm{CHX}$ and ICU mortality has been a hot topic in recent years, with lots of new discussions in the literature. b,c,d,

In the Discussion section of our review, we mentioned the Price 2014 reviewc and said, "Reasons for the discrepancy between this finding and ours mainly include differences in the review scope (e.g. whether focussed on adults, general intensive care only) and review methodology (e.g. inclusion of studies for which only abstracts are available)."

Firstly, in their review, Price and colleagues ${ }^{c}$ excluded trials carried out on cardiac surgery patients and children, while our review did not have such restrictions. Also, one of our main inclusion criteria for trials and participants was mechanical ventilation for a minimum of 48 hours, but Price and colleagues ${ }^{c}$ did not state such a requirement. Therefore, the questions that these two reviews tried to answer were essentially different. For instance, the DeRiso 1996 studye, which enrolled only cardiac surgery patients, was included in our review but not in Price 2014c. If Price 2014 was to include this study, the pooled OR would become 1.19 (95\% Cl 0.96 to 1.46$)$. Actually, other similar systematic reviews ${ }^{b}$, f have also included DeRiso 1996. In addition, according to a post hoc subgroup analysis, we found that the mortality results of the adult trials and the child trials included in our Analysis 1.2 were not significantly different $(P=0.14)$, indicating that analysing these two types of trials separately may not be necessary.

Secondly, there is potential risk in directly using unpublished trial data from previous systematic reviews. Such data may or may not be trustworthy. One perfect example here is that for the same MacNaughton 2004 studyg, an abstract that did not clearly report results for mortality, data used in Price 2014 (29/101 for treatment, 29/93 for control)c and Klompas 2014 (36/91 for treatment, 33/88 for control) ${ }^{\mathrm{b}}$ differed substantially. In terms of Koeman 2006, we noticed that both Price and colleagues $\mathrm{s}^{\mathrm{C}}$ and Klompas and colleagues ${ }^{\mathrm{b}}$ used data provided in a previous systematic review ${ }^{f}$, but without verifying the data by contacting original authors. As documented in our

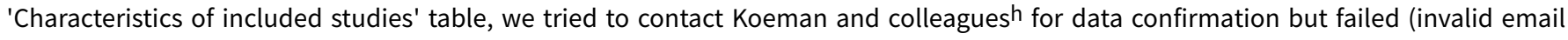
address). Plus, if we used the same Koeman data as in Price 2014', our pooled RR would remain similar (1.11, 95\% Cl 0.99 to 1.25). 
We noticed that for multiple studies, including Berry $2011^{i}$ and Munro 2009j, the data that we used for Analysis 1.2 were different from those used in the Price review [3]. As all of these data were extracted for the previously published version of our reviewk, we re-examined these data and agree that the inclusion of the 96-hour mortality data in Berry 2011 is inappropriate and we have therefore decided to exclude these data from our Analysis 1.2. After this revision, our pooled RR remains 1.09 ( $95 \% \mathrm{Cl} 0.96$ to 1.23$)$. As to other studies included in this analysis, no mistakes in the use of data were found so we do not plan to make other modifications.

As described in our Abstract and Methods section, the predetermined primary objective of our review was to assess the effects of oral hygiene care on the incidence of ventilator-associated pneumonia (VAP) in critically ill patients receiving mechanical ventilation in ICUs. The participants that we were interested in were those who received mechanical ventilation for at least 48 hours and therefore were at risk of developing VAP. Thus, our use of the Day 3 sample data in Munro 2009j was reasonable. The same reason (predetermined PICO) can also explain the differences between our review and Price 2014c for the data of Panchabhai 2009l, Cabov 2010m and Bellissimo-Rodrigues $2009 n$. Authors of the previous version of our reviewk obtained relevant data that met our criteria from the original authors of those studies.

Thank you for your interest in our work.

\section{References}

aHua F, Xie H, Worthington HV, Furness S, Zhang Q, Li C. Oral hygiene care for critically ill patients to prevent ventilator-associated pneumonia. Cochrane Database of Systematic Reviews 2016, Issue 10. Art. No.: CD008367. DOI: 10.1002/14651858.CD008367.pub3.

bKlompas M, Speck K, Howell MD, Greene LR, Berenholtz SM. Reappraisal of routine oral care with chlorhexidine gluconate for patients receiving mechanical ventilation: systematic review and meta-analysis. JAMA Internal Medicine 2014; 174: 751-61.

cPrice R, MacLennan G, Glen J, Su DC. Selective digestive or oropharyngeal decontamination and topical oropharyngeal chlorhexidine for prevention of death in general intensive care: systematic review and network meta-analysis. BMJ 2014; 348: g2197.

dKlompas M, Li LL, Kleinman K, Szumita PM, Massaro AF. Associations between ventilator bundle components and outcomes. JAMA Internal Medicine 2016; 176: 1277-83.

edeRiso AJ, 2nd, Ladowski JS, Dillon TA, Justice JW, Peterson AC. Chlorhexidine gluconate $0.12 \%$ oral rinse reduces the incidence of total nosocomial respiratory infection and nonprophylactic systemic antibiotic use in patients undergoing heart surgery. Chest 1996; 109: 1556-61.

fChan EY, Ruest A, Meade MO, Cook DJ. Oral decontamination for prevention of pneumonia in mechanically ventilated adults: systematic review and meta-analysis. BMJ 2007; 334: 889.

gMacNaughton P, Bailey J, Donlin N, Branfield P, Williams A, Rowswell H. A randomised controlled trial assessing the efficacy of oral chlorhexidine in ventilated patients. Intensive Care Medicine 204; 30: S12.

hKoeman M, Van der ven AJ, Hak E, Joore HC, Kaasjager K, et al. Oral decontamination with chlorhexidine reduces the incidence of ventilator-associated pneumonia. American Journal of Respiratory Critical Care Medicine 2006; 173: 1348-55.

iBerry AM, Davidson PM, Masters J, Rolls K, Ollerton R. Effects of three approaches to standardized oral hygiene to reduce bacterial colonization and ventilator associated pneumonia in mechanically ventilated patients: a randomised control trial. International Journal of Nursing Studies 2011; 48: 681-8.

jMunro CL, Grap MJ, Jones DJ, McClish DK, Sessler CN. Chlorhexidine, toothbrushing, and preventing ventilator-associated pneumonia in critically ill adults. American Journal of Critical Care 2009; 18: 428-37; quiz 438.

kShi Z, Xie H, Wang P, Zhang Q, Wu Y, Chen E, et al. Oral hygiene care for critically ill patients to prevent ventilator-associated pneumonia. Cochrane Database of Systematic Reviews 2013, Issue 8. Art. No.: CD008367 DOI: 10.1002/14651858.CD008367.pub2.

IPanchabhai TS, Dangayach NS, Krishnan A, Kothari VM, Karnad DR. Oropharyngeal cleansing With $0.2 \%$ chlorhexidine for prevention of nosocomial pneumonia in critically ill patients an open-label randomized trial with $0.01 \%$ potassium permanganate as control. Chest 2009 ; 135: 1150-6.

mCabov T, Macan D, Husedzinovic I, Skrlin-Subic J, Bosnjak D, Sestan-Crnek S, et al. The impact of oral health and $0.2 \%$ chlorhexidine oral gel on the prevalence of nosocomial infections in surgical intensive-care patients: a randomized placebo-controlled study. Wien Klin Wochenschr 2010; 122: 397-404.

nBellissimo-Rodrigues F, Bellissimo-Rodrigues WT, Viana JM, Teixeira CA, Nicolini E, Auxiliadora-Martins M, et al. Effectiveness of oral rinse with chlorhexidine in preventing nosocomial respiratory tract infections among intensive care unit patients. Infection Control \& Hospital Epidemiology 2009; 30: 952-8.

\section{Contributors}

Comment: Richard Price, Graeme MacLennan, John Glen and Brian H Cuthbertson on behalf of the SuDDICU collaboration (Selective Decontamination of the Digestive tract in critically ill patients treated in Intensive Care Unit).

Reply: Review authors Fang Hua, Susan Furness and Helen Worthington.

\section{WHAT'S NEW}




\begin{tabular}{ll}
\hline Date & Event \\
\hline 1 May 2020 & $\begin{array}{l}\text { New citation required and conclusions } \\
\text { have changed }\end{array}$
\end{tabular}

\section{Description}

In the previous version, we found no evidence of a benefit from toothbrushing patients in intensive care; however, in our updated review, we found low-certainty evidence that it may reduce the incidence of VAP and very low certainty evidence that it may reduce the length of ICU stay.

In this update, we found the number needed to treat for an additional beneficial outcome from $\mathrm{CHX}$ is probably 12 , whereas it was 17 in the previous version.
Inclusion criteria modified. New search run, which found 9 new studies for inclusion. Seven previously included studies now excluded. Added new comparison ( $\mathrm{CHX}$ versus other oral care agents) and reclassified included studies accordingly.

\section{H I S T O R Y}

Protocol first published: Issue 2, 2010

Review first published: Issue 8, 2013

\begin{tabular}{lll}
\hline Date & Event & Description \\
\hline 6 March 2017 & Feedback has been incorporated & $\begin{array}{l}\text { See Feedback section for comments regarding different interpre- } \\
\text { tations in other reviews of the effects of chlorhexidine on mortal- } \\
\text { ity in critically ill patients. }\end{array}$ \\
& &
\end{tabular}

6 March $2017 \quad$ Amended

Edits to Analysis 1.2 and 4.2.

In response to the feedback, review authors decided that mortality data derived from trial flow diagrams in Berry 2011 and Berry 2013 should not be used. This does not change the mortality results: chlorhexidine versus placebo, RR 1.09 ( $95 \% \mathrm{Cl} 0.96$ to 1.23 ).

Removal of Berry 2011 and 2013 mortality data also means no conclusions can be drawn about the effect on mortality of bicarbonate rinse versus water, Listerine versus water or Listerine versus bicarbonate (previous analyses 4.2.6, 4.2.7, 4.2.8).

20 July $2016 \quad \begin{aligned} & \text { New citation required but conclusions } \\ & \text { have not changed }\end{aligned}$

6 new studies included. 3 previously included studies now excluded. Some changes to Methods (see 'Differences between protocol and review' section).

\begin{tabular}{lll}
\hline 17 December 2015 & New search has been performed & Search updated. \\
\hline 27 November 2013 & Amended & Minor typographical error. \\
\hline
\end{tabular}

\section{CONTRIBUTIONS OFAUTHORS}

Conducting and writing the initial review: QZ, HW

Conducting and writing the 2016 update of this review: QZ, CL, HW, FH

Co-ordinating the update: $\mathrm{FH}$

Developing search strategy and undertaking searches for the update: $\mathrm{TZ}, \mathrm{XW}, \mathrm{CL}, \mathrm{FH}$

Screening search results for the update: $T Z, X W, Q Z, H W, F H$

Extracting data and assessing risk of bias for the update: $\mathrm{TZ}, \mathrm{XW}, \mathrm{FH}$ 
Analysing and interpreting data for the update: TZ, XW, HW, FH

Writing the review update: $\mathrm{TZ}, \mathrm{XW}, \mathrm{FH}$

Approving the final review update prior to submission: TZ, XW, QZ, CL, HW, FH

\section{DECLARATIONSOF INTEREST}

Tingting Zhao: none known

Xinyu Wu: none known

Qi Zhang: none known

Chunjie Li: none known

Helen V Worthington: none known. I am an Editor with Cochrane Oral Health.

Fang Hua: none known. I am an Editor with Cochrane Oral Health.

\section{SOURCES OF SUPPORT}

\section{Internal sources}

- School and Hospital of Stomatology, Wuhan University, China

- Division of Dentistry, School of Medical Sciences, Faculty of Biology, Medicine and Health, The University of Manchester, UK

- Manchester Academic Health Sciences Centre (MAHSC), UK

Cochrane Oral Health is supported by MAHSC and the NIHR Manchester Biomedical Research Centre

- West China College of Stomatology of Sichuan University and the Chinese Cochrane Center, China

The 2013 version of this review was supported by the West China College of Stomatology, Sichuan University academically and in manpower resource; statistical analysis was supported by the Chinese Cochrane Center

\section{External sources}

- Wuhan Young and Middle-aged Medical Talents Training Program (No. [2019]87), China

- Cochrane Oral Health Global Alliance, Other

The production of Cochrane Oral Health reviews has been supported financially by our Global Alliance since 2011 (oralhealth.cochrane.org/partnerships-alliances). Contributors over the past two years have been the American Association of Public Health Dentistry, USA; AS-Akademie, Germany; the British Association for the Study of Community Dentistry, UK; the British Society of Paediatric Dentistry, UK; the Canadian Dental Hygienists Association, Canada; the Centre for Dental Education and Research at All India Institute of Medical Sciences, India; the National Center for Dental Hygiene Research \& Practice, USA; New York University College of Dentistry, USA; NHS Education for Scotland, UK; and the Swiss Society for Endodontology, Switzerland.

- National Institute for Health Research (NIHR), UK

This project was supported by the NIHR, via Cochrane Infrastructure funding to Cochrane Oral Health. The views and opinions expressed therein are those of the authors and do not necessarily reflect those of the Evidence Synthesis Programme, the NIHR, the NHS or the Department of Health and Social Care.

- CMB funding SR0510, Project of Development of Systematic Review supported by Chinese Medical Board of New York, USA

\section{DIFFERENCES BETWEEN PROTOCOLAND REVIEW}

For this 2020 update:

- We added another comparison (Comparison 2: $\mathrm{CHX}$ versus other oral care agents) to better accommodate head-to-head trials, and reclassified the included studies accordingly.

- We added another subgroup analysis - intervention concentration.

- We excluded some trials that had been included in the original review, but on further investigation did not meet the inclusion criteria, in particular, the requirement to ensure participants did not have pneumonia at baseline and to consider only participants who had been on mechanical ventilation for at least 48 hours.

Changes to methodology between 2013 and 2016 versions:

- As the purpose of this systematic review is to determine the effects of oral hygiene care on the development of VAP in a group of very ill patients in intensive care, we excluded studies that reported only intermediate outcomes, such as microbial colonisation or CPIS scores, because the relationship between these outcomes and VAP or mortality is unclear. 
- We dropped the outcome 'microbial colonisation'. We excluded studies that only reported this outcome, and not VAP incidence or mortality, as an analysis of this outcome for the included studies would lead to selective reporting. Additionally, most traditional criteria for VAP diagnosis already incorporate results of microbial colonisation laboratory tests (Waters 2015).

- We undertook a subgroup analysis for a dose-response relationship for chlorhexidine, as research suggested a possible relationship between chlorhexidine dose and mortality/effectiveness in VAP reduction (Klompas 2014; Zhang 2013).

- We used the risk ratio (RR) rather than the odds ratio (OR) for the binary data, in line with current Cochrane Oral Health policy, as this made interpretation of the results easier.

- We only searched the VIP database for Chinese studies, because the previous search strategies are no longer valid.

- We added the outcomes reported in the 'Summary of findings tables' to the Methods section.

Differences between the protocol and the first version of the review (2013):

1) We clarified inclusion criteria.

- Participants in trials should not have a respiratory infection at baseline.

- The interventions must include an oral hygiene care component. We excluded trials where the intervention being evaluated was a type of suction system or variation of method, timing, or place where mechanical ventilation was introduced (e.g. emergency room or ICU).

- Minimum duration of mechanical ventilation of 48 hours, in order for the diagnosis of nosocomial pneumonia, either during the period of ventilation or within 48 hours of extubation, to be considered ventilator-associated pneumonia.

- Outcome of mortality defined as either all-cause ICU mortality or, where this was not available, all-cause 30-day mortality. We considered that the effect of the underlying condition(s) on mortality would be similar in each randomised treatment group during this period.

- In order to avoid duplication, we excluded trials where the intervention was selective decontamination of the digestive tract with antibiotics, as these interventions are included in another Cochrane Review (D'Amico 2009).

- Likewise, we excluded trials where the intervention was probiotics, as these interventions are included in another Cochrane Review (Hao 2015).

2) We updated the text in the Methods section of this review about the 'Risk of bias' assessment in line with the latest version of the Cochrane Handbook for Systematic Reviews of Interventions, and we added more details about the process followed.

\section{NOTES}

This is the second update of a review originally published in 2013 (Shi 2013) and first updated in 2016 (Hua 2016).

\section{INDEX TERMS}

\section{Medical Subject Headings (MeSH)}

Chlorhexidine [therapeutic use]; ${ }^{\star}$ Critical Illness; Intensive Care Units; Mouthwashes [therapeutic use]; Oral Hygiene [ ${ }^{\star}$ methods]; Pneumonia, Ventilator-Associated [ ${ }^{*}$ prevention \& control]; Randomized Controlled Trials as Topic; Respiration, Artificial [ ${ }^{\star}$ adverse effects]; Toothbrushing [instrumentation] [methods]

\section{MeSH check words}

Adult; Child; Humans 